\title{
A Systemic Functional Approach to Applied Linguistic
}

\section{Article Conclusions}

\author{
by
}

Viktoria Volkova

\begin{abstract}
A thesis submitted to
the Faculty of Graduate and Postdoctoral Affairs

in partial fulfillment of the requirements for the degree of

Master of Arts

in
\end{abstract}

Applied Linguistics and Discourse Studies

Carleton University

Ottawa, Ontario

(C) 2012

Viktoria Volkova 
Library and Archives

Canada

Published Heritage

Branch

395 Wellington Street

Ottawa ON K1A ON4

Canada
Bibliothèque et

Archives Canada

Direction du

Patrimoine de l'édition

395 , rue Wellington

Ottawa ON K1A ON4

Canada
Your file Votre référence

ISBN: 978-0-494-93617-7

Our file Notre référence

ISBN: $978-0-494-93617-7$
NOTICE:

The author has granted a nonexclusive license allowing Library and Archives Canada to reproduce, publish, archive, preserve, conserve, communicate to the public by telecommunication or on the Internet, loan, distrbute and sell theses worldwide, for commercial or noncommercial purposes, in microform, paper, electronic and/or any other formats.

The author retains copyright ownership and moral rights in this thesis. Neither the thesis nor substantial extracts from it may be printed or otherwise reproduced without the author's permission.
AVIS:

L'auteur a accordé une licence non exclusive permettant à la Bibliothèque et Archives Canada de reproduire, publier, archiver, sauvegarder, conserver, transmettre au public par télécommunication ou par l'Internet, prêter, distribuer et vendre des thèses partout dans le monde, à des fins commerciales ou autres, sur support microforme, papier, électronique et/ou autres formats.

L'auteur conserve la propriété du droit d'auteur et des droits moraux qui protege cette thèse. $\mathrm{Ni}$ la thèse ni des extraits substantiels de celle-ci ne doivent être imprimés ou autrement reproduits sans son autorisation.
In compliance with the Canadian Privacy Act some supporting forms may have been removed from this thesis.

While these forms may be included in the document page count, their removal does not represent any loss of content from the thesis.
Conformément à la loi canadienne sur la protection de la vie privée, quelques formulaires secondaires ont été enlevés de cette thèse.

Bien que ces formulaires aient inclus dans la pagination, il n'y aura aucun contenu manquant. 


\section{ACKNOWLEDGEMENT}

I owe an incredible debt of gratitude to my supervisor Dr. Lynne Young who not only introduced me to Systemic Functional Linguistics but encouraged my research projects throughout my graduate studies. Her close reading and valuable advice helped me to shape the ideas and observations into this thesis. I have never met such an inspiring thesis supervisor before. Every conversation with Dr. Young enriched me academically and gave me positive energy to take any sort of challenge with dignity and strength. I could not have done without her.

I would like to thank the faculty and staff in the School of Linguistics and Applied Language Studies at Carleton University for their dedication, knowledge, and support. I would also like to thank Dr. Betty Samraj (San Diego State University) and Dr. Graham Smart (Carleton University), the reviewers of this MA thesis, for their valuable opinions and time.

And, of course, I am very grateful to my mother Nina Volkova, my arduous supporter, for her faith and love that helped me to overcome the obstacles and pursue my professional and personal perfection. 


\begin{abstract}
This thesis studies and attempts to interpret the meanings of the ideational, interpersonal, and textual metafunctions in the discourse of applied linguistic article conclusions. The objective of this research is to apply an SFL model of three metafunctions to the analysis of the clauses and their constituents in order to track some common features in the structural and semantic frameworks of AL conclusions. I explored four research article conclusions from four different applied linguistic branches in order to determine the common lexico-grammatical and semantic features that result in producing the systemic constructs of the AL discourse. The SFL analysis shows that mental processes are prominent in the AL discourse and the declarative Mood is clearly preferred over interrogatives and imperatives. Temporal Finite Operators, terminological density and content-carrying Theme patterns are also prominent commonalities to be noticed. The mapping of the common features reported as the research results of my SFL metafunctional analyses may assist the present and future applied linguists in composing their RA conclusions and in focusing on their meanings within the clause structure and semantics. The systemic functional approach reveals the mysteries of language as a set of language users' choices and their conscious incentives to make the realizations of these choices function properly and efficiently in discourse. Thus the discourse becomes a successful social event that initiates the responsive reactions.
\end{abstract}




\section{TABLE OF CONTENTS}

Chapter One - Introduction ............................................................................................ 1

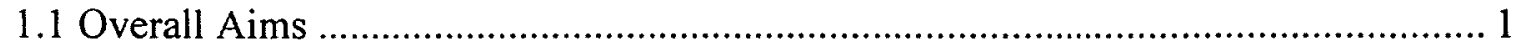

1.2 Social and Pedagogical Significance of Discourse Analysis ................................... 1

1.3 Research Motivation and Research Question......................................................... 2

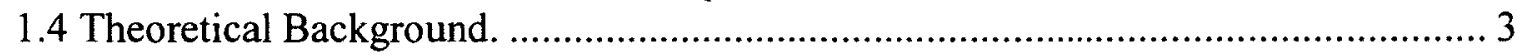

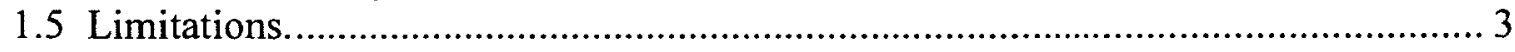

1.6 Organization of Chapters................................................................................. 4

Chapter Two - SFL Approach to Analysis of Academic Discourse................................ 6

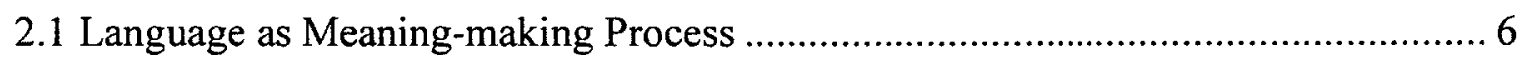

2.2 Meaning-making Processes in Academic Discourse .............................................. 7

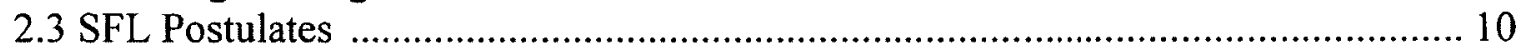

2.4 Systemic Functional Approach to Grammar and Semantics.................................. 12

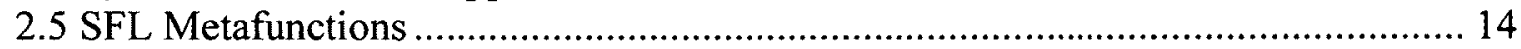

2.5.1 Ideational Metafunction: Clause as Representation ..................................... 15

2.5.2 Interpersonal Metafunction: Clause as Exchange ....................................... 19

2.5.1 Textual Metafunction: Clause as Message ……………................................... 21

2.6 SFL Experiences in Discourse Analysis................................................................ 22

2.7 SFL Diversification of Discourse Analysis of Academic Texts: Comparisons ....... 24

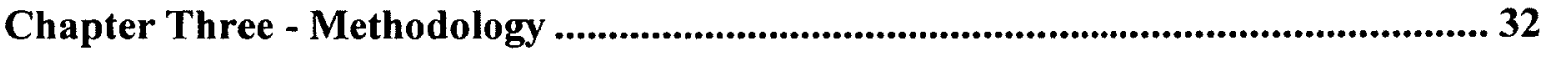

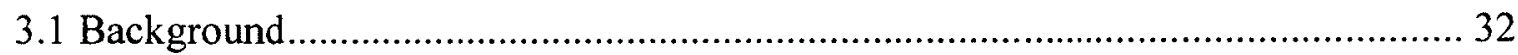

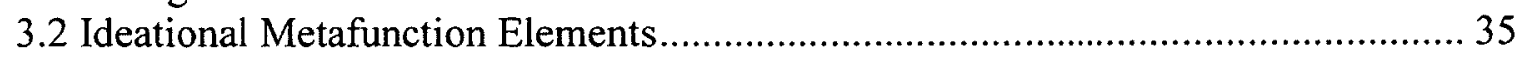

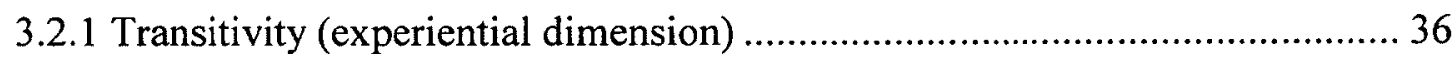

3.2.2 Taxis and Logico-semantic Clause Type (logical dimension) ....................... 40

3.3 Interpersonal Metafunction Elements.................................................................. 43

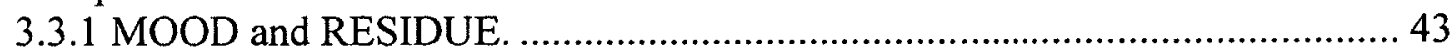

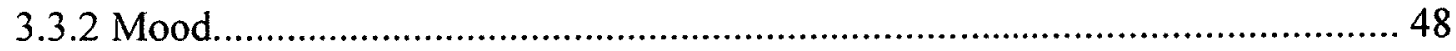

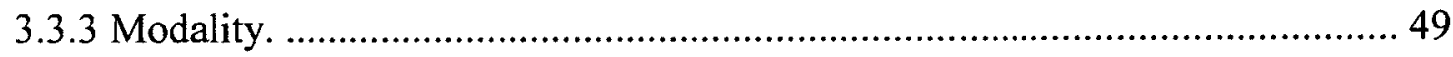

3.3.4 Attitudinal Items. ................................................................................. 51

3.4 Textual Metafunction Elements ......................................................................... 51

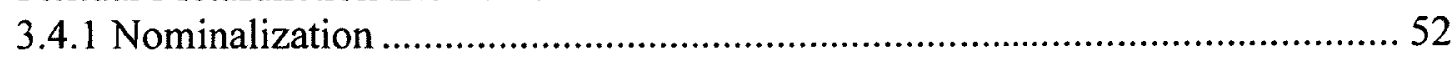

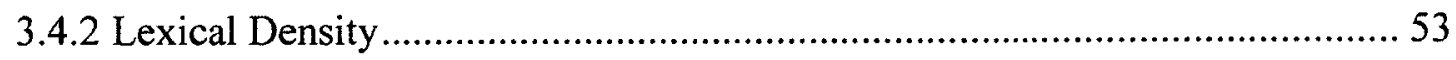

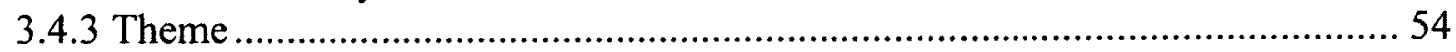

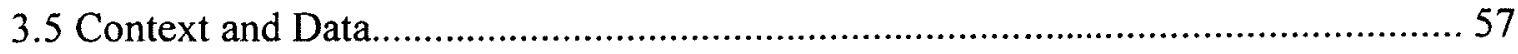

Chapter Four - SFL Analysis of Text 1 ...................................................................... 59

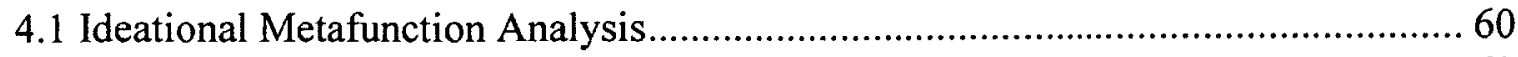

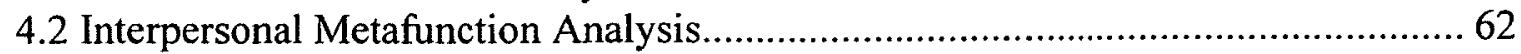

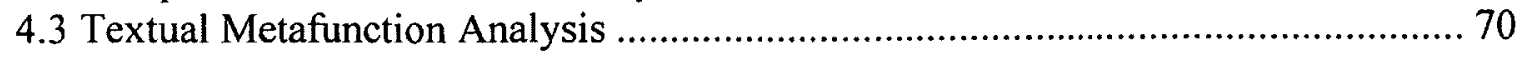


Chapter Five - SFL Analysis of Text 2 ............................................................................ 78

5.1 Ideational Metafunction Analysis..................................................................... 79

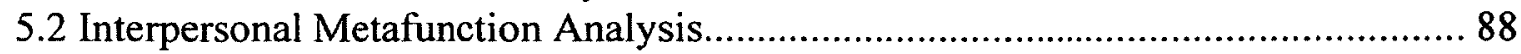

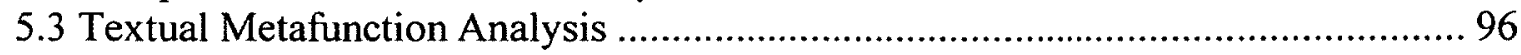

Chapter Six - SFL Analysis of Text 3 ...................................................................... 105

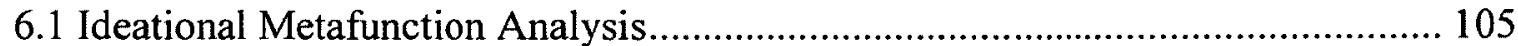

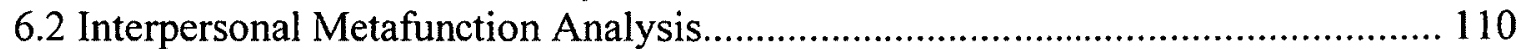

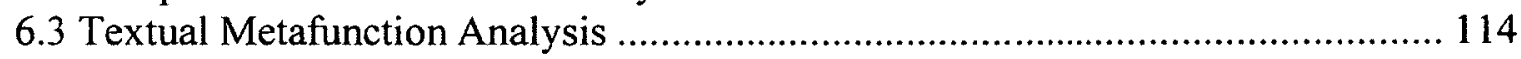

Chapter Seven - SFL Analysis of Text 4 ................................................................. 122

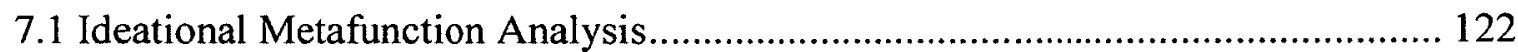

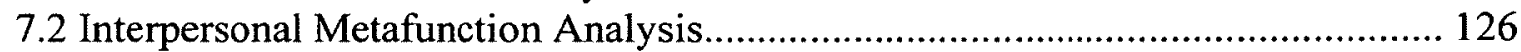

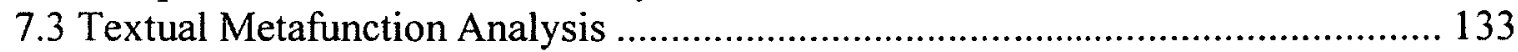

Chapter Eight - Discussion ................................................................................................... 138

Chapter Nine - Conclusion ......................................................................................... 164

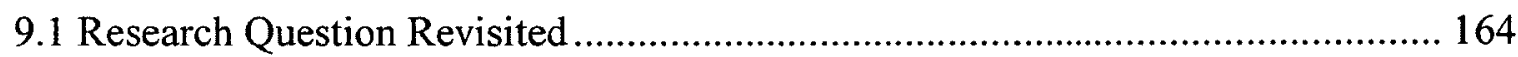

9.2 Implications of SFL Approach to Discourse ……............................................... 165

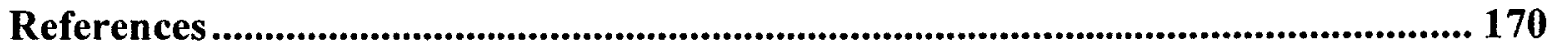

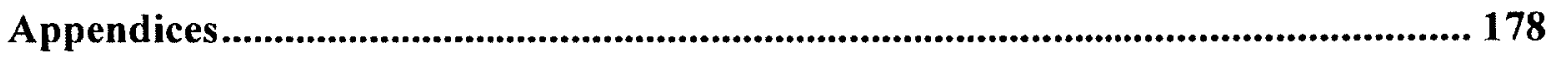


FIGURE 1. LANGUAGE MEANINGS IN RELATION TO CONTEXTUAL ASPECTS 11 FIGURE 2. LANGUAGE AS A THREE-STRATUM SYSTEM 13

FIGURE 3. CORRELATION OF METAFUNCTIONS AND BASES

FIGURE 4. CLAUSE AS INTERACTION (PYRAMID) 90

FIGURE 5. DIALOGUE OF THREE INTERACTANTS IN THE DISCOURSE OF TEXT 4

\section{LIST OF TABLES}

TABLE 1. METAFUNCTIONS IN TEXT

TABLE 2. LEXICOGRAMMAR RANK-FUNCTION MATRIX FOR ANALYSIS

TABLE 3. THE GRAMMAR OF EXPERIENCE 36

TABLE 4. TRANSITIVITY AS SYSTEM NETWORK

TABLE 5. TAXIS AND LOGICO-SEMANTIC RELATIONSHIPS $\quad 40$

TABLE 6. LOGICO-SEMANTIC TYPES (DETAILED) 42

TABLE 7. TYPES OF ADJUNCTS $\quad 47$

$\begin{array}{ll}\text { TABLE 8. MOOD } & 48\end{array}$

TABLE 9. MODALITY AS SYSTEM $\quad 50$

TABLE 10. LEXICAL DENSITY IN A SPECIFIC-NATURED DISCOURSE 53

TABLE 11. THEME IN CLAUSE $\quad 55$

TABLE 12. SPEECH FUNCTIONS $\quad 63$

TABLE 13. MOOD IN TEXT $1 \quad 66$

TABLE 14. THEME IN TEXT 1

TABLE 15. SPECIFIC LEXICAL DENSITY IN TEXT 1

TABLE 16. TAXIS AND LOGICO-SEMANTIC RELATIONSHIPS BETWEEN CLAUSES IN TEXT 284

TABLE 17. SPEECH ROLES AND COMMODITY EXCHANGED $\quad 89$

TABLE 18. COMMODITY EXCHANGED IN RA CONCLUSIONS 91

TABLE 19. FINITES IN TEXT 2

TABLE 20. SPECIFIC LEXICAL DENSITY IN TEXT 2 99

TABLE 21. SPECIFIC LEXICAL ZONES IN TEXT 2 99

TABLE 22. THEME IN TEXT 2 101

TABLE 23. PROCESSES IN TEXT $3 \quad 106$

TABLE 24. MOOD \& RESIDUE IN TEXT $3 \quad 111$

TABLE 25. COMPLIMENTS AND ADJUNCTS IN TEXT 3 112

TABLE 26. SPECIFIC LEXICAL DENSITY $\quad 117$

TABLE 27. THEME IN TEXT 3 119

TABLE 28. MOOD IN TEXT 4 127

TABLE 29. MOOD \& RESIDUE IN TEXT 4 127

TABLE 30. FINITES IN TEXT 4 129

TABLE 31. COMPLEMENTS AND ADJUNCTS IN TEXT 4 130

TABLE 32. SPECIFIC LEXICAL DENSITY IN TEXT 4 134

TABLE 33. THEME IN TEXT 4 136

TABLE 34. Processes IN AL ARTICLE CONCLUSIONS (OVERVIEW) 140

TABLE 35. CLAUSE SIMPLEXES AND COMPEXES (OVERVIEW) 143 
TABLE 36. TAXIS AND LOGICO-SEMANTIC TYPES OF RELATIONSHIPS BETWEEN CLAUSES (OVERVIEW)

TABLE 37. SUBJECTS (OVERVIEW)

TABLE 38. FINITE TYPES AND STRUCTURES (OVERVIEW)

TABLE 39. POLARITY (OVERVIEW)

TABLE 40. COMPLEMENTS AND ADJUNCTS (OVERVIEW)

TABLE 41. MODALITY (OVERVIEW)

TABLE 42. SPECIFIC LEXICAL DENSITY (OVERVIEW)

TABLE 43. THEME IN 4 AL ARTICLE CONCLUSIONS (OVERVIEW)

TABLE 44. SiNGLE AND MULTIPLE THEMES (OVERVIEW)

\section{LIST OF APPENDICES}

\section{APPENDiX 1 - APPlied Linguistic ARTICle ConClusions for ANALysis}

TEXT 1

TEXT 2

TEXT 3

TEXT 4

\section{APPENDIX 2 - SFL METAFUNCTIONAL ANALYSIS}

1.1 IDEATIONAL METAFUNCTION IN TEXT 1

PROCESS ANALYSIS

LOGICO-SEMANTIC TYPES OF CLAUSES

1.2 INTERPERSONAL METAFUNCTION IN TEXT 1

MOOD \& RESIDUE

1.3 TEXTUAL METAFUNCTION IN TEXT 1

THEME

192

COHESION

2.1 IDEATIONAL METAFUNCTION IN TEXT 2

PROCESS ANALYSIS

LOGICO-SEMANTIC TYPES OF CLAUSES

2.2 INTERPERSONAL METAFUNCTION IN TEXT 2

MOOD \& RESIDUE

2.3 TEXTUAL METAFUNCTION IN TEXT 2

SPECIFIC LEXICAL DENSITY

REFERENCE

THEME

3.1 IDEATIONAL METAFUNCTION IN TEXT 3

PROCESS ANALYSIS 
3.2 INTERPERSONAL METAFUNCTION IN TEXT 3 MOOD \& RESIDUE

3.3 TEXTUAL METAFUNCTION IN TEXT 3

SPECIFIC LEXICAL DENSITY

THEME

4.1 IDEATIONAL METAFUNCTION IN TEXT 4

PROCESS ANALYSIS

LOGICO-SEMANTIC TYPES OF CLAUSES

4.2 INTERPERSONAL METAFUNCTION IN TEXT 4 MOOD \& RESIDUE

4.3 TEXTUAL METAFUNCTION IN TEXT 4

THEME

REFERENCE CHAINS 


\section{Chapter One - Introduction}

\subsection{Overall Aims}

This thesis attempts to understand how discourse can be constructed in a specific field of applied linguistics (AL). I chose four conclusions from four applied linguistic articles to see how concepts are exchanged and organized. My first overall purpose led me to detailed analyses of the AL conclusions to see how the applied linguist realizes abstract research contexts through concrete language forms and functions to communicate his or her academic message to the reader of his article. My thesis will concentrate on three SFL metafunctions to trace the development of ideational, interpersonal, and textual implications in the AL discourse.

\subsection{Social and Pedagogical Significance of Discourse Analysis}

Discourse is not a mere articulation of ideas and attitudes. Every discourse is a social practice (Fairclough, 2004), i. e. ideas are packed in a message and sent to a partner in the dialogue. The AL discourse is a part of the academic space. It carries a specific-subject message and involves knowledgeable interaction participants. The conclusion in an $\mathrm{AL}$ article is a small part of the $\mathrm{AL}$ discourse that focuses on the meanings addressed to the $\mathrm{AL}$ community. This utterance may be accepted or tempered but it will never lose its status as a socially significant manifestation of specific domain of applied linguistics (knowledge, research, findings, etc.).

I need also to mention the pedagogical potential of my SFL analyses of $\mathrm{AL}$ article conclusions. The academic discourse is created to broaden existing knowledge. It is especially relevant to applied linguistics that studies theories in order to develop practical 
applications of theory into real-life language practices. Applied linguistics discourse can show how abstract meanings can be materialized through language to be received and turned into social practices. The social context cements the connections with other texts and identities in the discursive semantic space and, as a result, brings us our 'own knowledge, experiences, and points of view' (Young \& Fitzgerald, 2006). It is important to analyze the process of implanting meanings to see the commonalities of the conclusion discourse as signals of belonging to $\mathrm{AL}$ and its professional coding that make the text terminologically loaded but comprehensible and academically enriching.

\subsection{Research Motivation and Research Question}

I have a genuine interest in applied linguistics discourse because that is the area of my own professional and social existence. After studying applied linguistics for years, I feel that there is a gap in explaining what means should be used to produce meanings in the AL discourse (Swales, 1990, 2004). Researchers have already analyzed meanings themselves and generic moves in AL research articles (Swales \& Najjar, 1987; Yang \& Allison, 2003, 2004). My observations and findings aim at enriching the systemic functional perspective of the AL discourse and its interpretations. And my basic question was how to make explicit these very profound AL meanings in order to be recognized by colleagues and other readers. The SFL three-metafunction model, associated with Halliday and Matthiessen $(1999,2004)$ and developed by Gregory (1987), Fawcett (1987), Martin (1990, 2000),Ventola (1988, 1992), Fairclough (2004), Eggins (2004), Young \& Fitzgerald (2006), Christie (2004) and other scholars, became the key to open the semantico-structural doors of discourse meaning-making processes. The SFL approach presented me an opportunity to see how every language item is realized with 
implicit functions. To be able to interpret these functions means to get at the discourse mechanisms of efficiency and compact meaningfulness. And the SFL three-metafunction analyses became the tools to show that in concrete texts of $\mathrm{AL}$ article conclusions.

This thesis will provide analytical discussion of the ideational, interpersonal, and textual metafunctions in the four $\mathrm{AL}$ conclusions. The given discourses are examined to find common features between them and to showcase the existence of the specific nature of the discourse of $\mathrm{AL}$ conclusions. My research aims to answer the following research question:

- What elements of SFL tri-functional model are prominent in the framework of applied linguistic article conclusions?

\subsection{Theoretical Background}

SFL attempts to examine discourse through its metafunctions. In an effort to show how applied linguistics is a society-oriented study as "social behaviour" (Ventola, 1988, p. 75) that foregrounds the role of a language user, this paper insists on perceiving the meanings through their forms and functions that, in their turn, are created and controlled by the article author. SFL theory and the concept of three metafunctions becomes the universal arsenal of tools and methods to decipher the AL code in the framework of an AL conclusion.

\subsection{Limitations}

This research represents a detailed analysis of the three SFL metafunctions, realized at the level of the clause in $\mathrm{AL}$ article conclusions. It is beyond the scope of this thesis to 
analyze all the implications of the ideational, interpersonal, and textual metafunctions. It is an attempt to observe the language means by which clauses are designed to function productively in the framework of an $\mathrm{AL}$ conclusion. Further, it will focus discrepancies in different discourses belonging to one scientific community.

Critical discourse analysis, defined by Gee (1993) as high-order thinking (p. 333), can also be an asset to supplement SFL methodology to decode the ideological component and interaction of powers (stances) in the AL discourse.

\subsection{Organization of Chapters}

Chapter 2 explains the principal SFL postulates, its interpretation of texts and meaning-making processes in them and compares various linguistic approaches to academic discourse analysis. The section introduces SFL metafunctions that become the main tools for mining meanings in the discourse of $\mathrm{AL}$ article conclusions in this research.

Chapter 3 presents a methodological framework that helps to analyze four $\mathrm{AL}$ conclusions. The three metafunctions and their subcategories are explained in detail. The rationale of the data selection is given.

Chapters 4-7 consist of 12 analyses. Four texts of AL article conclusions are analyzed through three SFL metafunctions to clarify their conceptual, interactive and compositional frameworks. 
Chapter 8 offers a discussion of the results in terms of finding common features in the realization ideational, interpersonal and textual meanings via SFL metafunctional meanings.

The implications and perspectives of this study are summarized in Chapter 9 .

The Appendix offers a demonstration of how the SFL approach is applied to the text, namely $\mathrm{AL}$ article conclusions. 


\section{Chapter Two - SFL Approach to Analysis of Academic Discourse}

\subsection{Language as a Meaning-making Process}

Humans are given one capability that is more precious than any other talent being granted or gained. That is language, a complex system of making meanings and transmitting information. Storing our experiences as knowledge, language users encode and de-code these experiences. These processes of coding are interpretations. Therefore language is a profound network of human interpretations. Knowledge and meanings create a unique semantic system, where language "plays the central role not only storing and exchanging experience but also in construing it" (Halliday \& Matthiessen, 1999, p. 1) and serves as "a paradigmatic set of choices available in a certain environment" (Ventola, 1988 , p. 520).

To use language means to construct meanings on the base of experience, according to Halliday \& Matthiessen $(1999,2004)$, Martin $(1992,1993,2003)$ and other SFL researchers. Systemic functional linguists prove that "the language is not passively reflecting pre-existing conceptual structure; on the contrary, it is actively engaged in bringing such structures into being" (Kilpert, 2003, p. 166). As Martin (1993) clearly states, "the language does not simply correspond to, reflect or describe human experience; rather, it interprets it or construes it (p. 8).

Thus the language system incorporates knowledge and experience to construe the multi-dimensional discourse. The academic discourse is a particular semantic space where it is possible to observe how witnessing construes reality (Lewin, Fine, \& Young, 2001). 


\subsection{Meaning-making Processes in Academic Discourse}

The academic (scientific) discourse intrigues researchers as it is profound. Many linguists are interested in attempting to reveal its mysteries. This type of discourse is closely connected to a limited group of recipients, i.e. members of academic communities. Swales (1998) is one of those who contributed to a very important understanding of academic texts as discourses of a specific genre with a shared communicative purpose. Academic discourse is not only a genre, that is a type of register with some predictable moves and forms (Halliday, 1978 cited in Lewin, Fine, \& Young, 2001), but is a social context with the three layers, field, tenor, and mode. This three-tier register construction, defined by Halliday \& Hasan ( 1976) as "the set of meanings, the configuration of semantic patterns, that are typically drawn upon under the specified conditions, along with the words and structures that are used in the realization of meanings" (p. 23). Field connects the discourse with the social event, tenor makes prominent the relations between the sender and recipient, and, finally, mode is responsible for the way the information is sent via text.

The field, tenor, and mode act collectively as determinants of the text through their specification of the register; at the same time they are systemically associated with the linguistic system through the functional components of the semantics ((Halliday 1978 cited in Lewin, Fine, \& Young, 2001, p. 9).

As a result, context influences the academic discourse, an inseparable part of which are the academic journal articles, the following way:

1. Field accounts for the academically conventional way of exchanging concepts among scholars and communicating knowledge (Halliday 1978, Lewin, Fine, \& Young, 2001). It aims at "sharing one's discovery with peers, making one's claim 
to a new theory or discovery, or bidding for credit for testing a specific hypothesis or challenging an existing claim, providing background information for specialists, present and future" (Lewin, Fine, \& Young, 2001, p. 9-10).

2. Tenor is responsible for the relationships between the article author and his readers. The particularity of the research article is the fact that the author knows that the reader is from the same academic environment, sharing the same educational and professional backgrounds. In fact, this is the dialogue of peers. In the final sections of the article, such as Discussion or Conclusion, this balance of powers becomes evident in "avoiding explicit expressions of their [article authors'] opinion and submerging their presence" (Lewin, Fine, \& Young, 2001, p. 10).

3. Mode evokes choices between spoken or written discourse. The text represents itself as a report of objective scientific concepts with hypotheses and evidence provided. The discourse of an academic article has a specific characteristic of being didactic and scientifically convincing. The text is performative (the author performs an act with an utterance, for example, 'I argue', 'I promise', etc.) to establish " a claim to ownership of ideas; the text is a report of objective facts (the description of research acts) and an interpretation of those facts; the text can be understood as an independent unit but it must be related to past texts and have potential as a progenitor of new texts" (Lewin, Fine, \& Young, 2001, p. 10). In most cases, the language of the academic discourse is English (Swales, 1990).

Therefore, the AL articles should have some features in common though every text will clearly be unique in the realization of its meanings. "Membership of texts in the 
same genre is established not by a fixed set of obligatory features but by the fact that they select their structural elements from a common repertoire and these elements tend to form a highly probable pattern" (Martin, 1992; Ventola, 1987 cited in Lewin, Fine, \& Young, 2001, p. 21).

Evidently, there can be no one ideal way of composing an academic journal article and the conclusion in it. However, it is possible to observe the processes of making meanings in miscellaneous layers of the RA discourse (Halliday \& Matthiessen, 1999, 2004; Halliday \& Hasan, 1976; Ventola, 1988; Eggins, 2004). Following the comprehension of the academic (scientific) discourse by Lewin, Fine, \& Young (2001), to get deeper into the academic discursive meanings means to analyze the research article discourse (AL conclusions in my thesis):

a. To understand texts as "an outgrowth of social realities encompassing particular social norms and values" (p. 21)

b. To provide a method of analysis of the genre-determined patterns in order to find common productive models ( $\mathrm{SFL}$ is chosen to be the method for my thesis)

c. To identify the common rhetorical structures (i.e. elements directed by their communicative purposes) in organizing one section of the article (Conclusions will be the scope of this paper)

d. To accept the flexibility of the patterns with consideration of the authors' personalities and their specific-knowledge domains 
The SFL approach allows me to discuss how the language user interprets the discourse meanings at the level of representation, interaction, and composition in the $\mathrm{AL}$ discourse. As an applied linguist, I feel necessity to analyze how "the theory expands and enhances our view of language and how it reconnects language and society" (Kilpert, 2003, p. 159) in order to grasp the applicability aspect in applied linguistics.

\subsection{SFL Postulates}

The Systemic Functional Linguistics approach is the central linguistic theory that provides the tripartite metafunctional language model to be used in the analysis of four research article conclusions in applied linguistic. The 3-metafunctional language vision stems from Michael Halliday's works, starting from the 1960s. The theory connects language and context, accentuating their high degrees of interdependency and reciprocity.

Systemic Functional Linguistics analyzes how human language choices combine together as an entity in text and function in context to generate meanings. The functionality means the degree of efficiency with which the information is sent and the understanding is negotiated. In my opinion, the SFL approach is one of the keys to finding the golden mean between the text and context. The interaction between these two macro-elements in language results in communication, the essence of human life. The systemic functional method manages to de-compose the process of creating meanings within the visual graphics of words. It is amazing how it can provide the language analyst with tools and techniques of the "descriptive and interpretative framework for viewing language as a strategic, meaning-making resource" (Eggins, 2004, p. 2). 
Thus SFL foregrounds communication as the fundamental impetus and the result of human language activities. The three metafunctions with ideational, interpersonal and textual meanings affect all the strata of the socio-cognitive human expressions. The general tripartite model gets more detailed, if I connect the metafunctions with more explicit situational concepts of Field (contextual aspect of the interaction), Tenor (relations of powers), and Mode (language mode).

Figure 1.Language meanings in relation to situational concepts

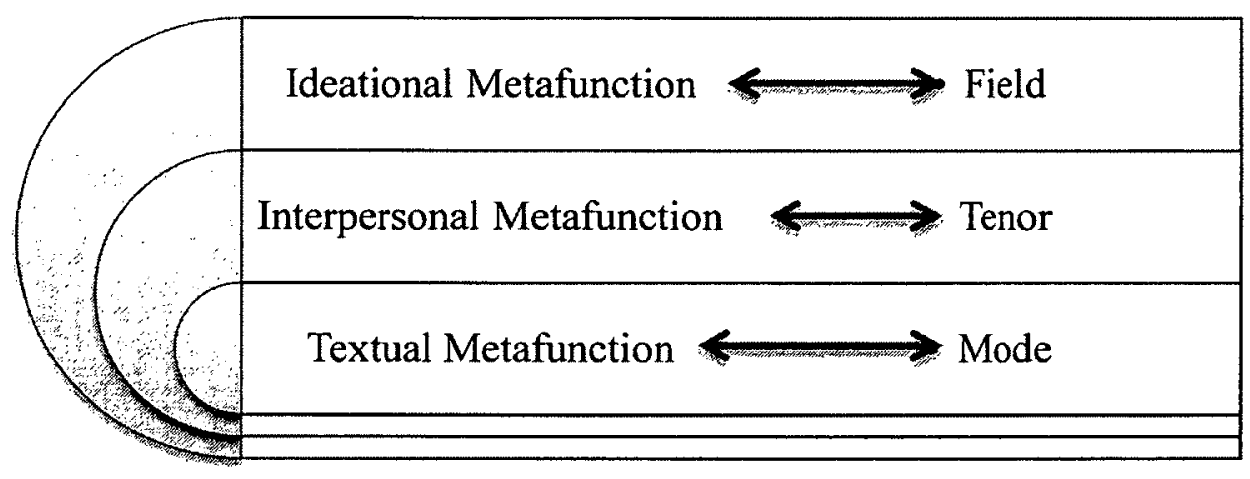

In realization, they combine the implicit and explicit meaning articulation to encode the message that is to be uncoiled by/in the dialogue between language users, their individualized interpretations and cultural contexts.

Identifying systems of lexical choice involves recognizing that words encode meaningful oppositions, and that the process of choosing a lexical item is a semiotic process.... The system, thus the conceptual world, according to culturally established conventions about dimensions of reality, are meaningful (Eggins, 2004, p. 16, p. 18).

To explain the importance of SFL language perspective, I would use a metaphor to compare linguistics with geometry. In geometry a problem can have several methods to achieve one and the same interpretations. In my opinion, the breakthrough of Halliday and his colleagues is innovative for his time and the method assists in text analysis, 
conclusions and interpretations. Using Halliday's metafunctions (as geometrical axioms), the analyst does not need to contradict already existing theories but finds a new trail instead of taking classical grammar paths. Instead of sparking controversies, systemic functional linguists insist on expanding and enhancing.

It [the process of denying your opponent's theory and setting up your theory as the right one] leaves little room for the second scholar to take a positive line - to suggest, perhaps, that s/he finds much (or at least some!) common ground with the first approach, and that $\mathrm{s} / \mathrm{he}$ might not have thought of the ideas being presented without the stimulus of the first scholar's work (Halliday \& Fawcett, 1987, p. 2).

Systemic functionalists add their insights to the global understanding of language. Halliday $(1973,1997)$, Halliday \& Matthiessen $(1999,2004)$, Halliday \& Hassan (1976, 1989), Halliday \& Fawcett (1987), Martin (1987, 1992, 1993, 200, 2003), Eggins (2004), Gregory (1987), Lewin, Fine \& Young (2001),Ventola (1988, 1992, 1997) and others open up a new SFL dimension for language studies. This paper presents the analysis based on the SFL fundamental theory of three metafunctions that create texts and contexts that result in a comprehensive notion of discourse. In terms of the systemic approach it can be summarized as, "Language is seen as the foundation of human experience, and meaning as the essential mode of higher-order human consciousness" (Halliday \& Matthiessen, 1999, p. 3). Thus language makes the streaming of knowledge visible and tangible. This paper aims at analyzing the metafunctional realizations in order to discover the grounds to support interpretations.

\subsection{Systemic Functional Approach to Grammar and Semantics}

Language as a system has its inner grammatical and semantic relationships. Systemic Functional Linguistics offers explanations to the interrelationships within language. Halliday and Matthiessen (1999) suggest that: 
A systemic grammar is one of the classes of functional grammars, which means (among other things) that it is semantically motivated, or 'natural'. In a systemic grammar every category [organizing theoretical concept] is based on meaning (p. 4)

They describe this as the process of discovering semantic potentials at the level of higher textual organization. Hence, the text is organized in the way to be unfolded and interpreted in terms of meaning, not knowledge. Halliday and Matthiessen (1999) draw a figure to reflect the collaboration of three language strata.

Figure 2. Language as a three-stratum system

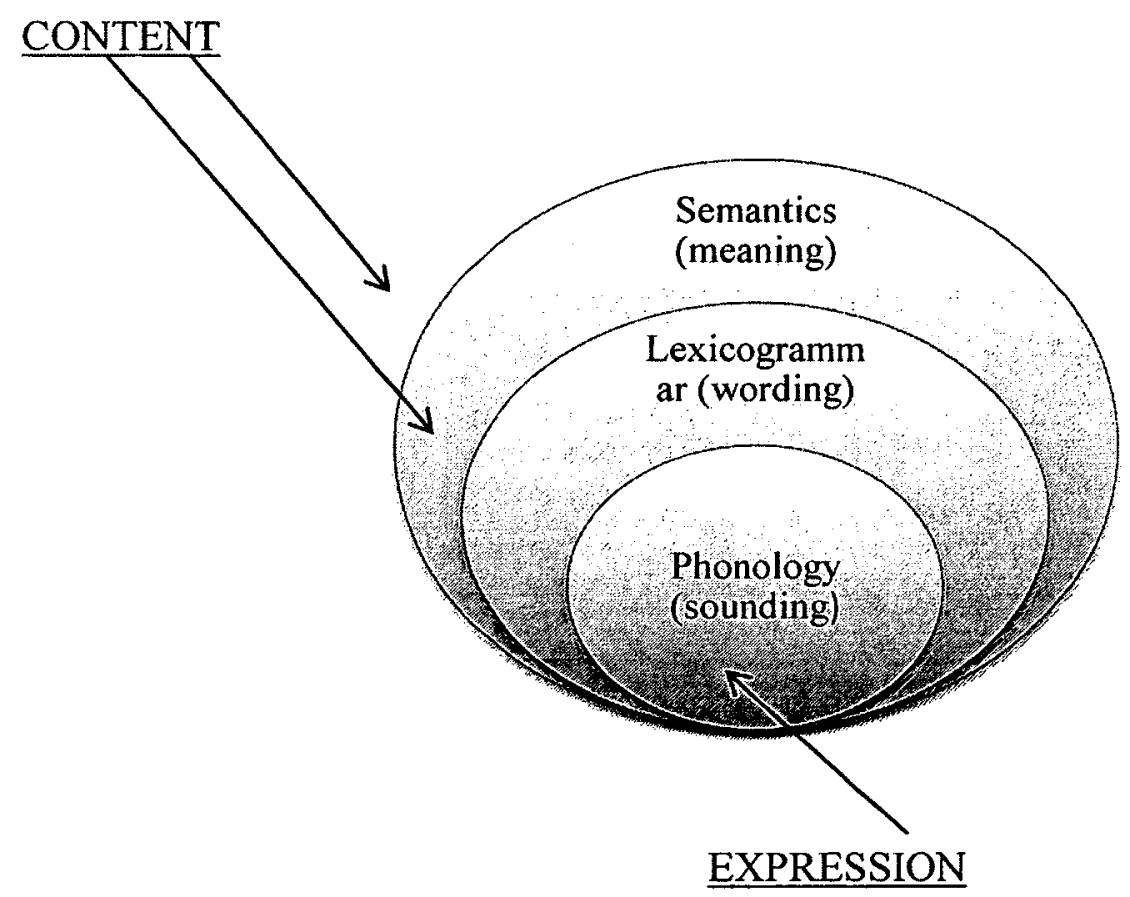

SFL discusses the closeness of grammatics and semantics and their collateral efforts to decipher the functions language performs. The term 'grammatics' is used by Halliday and Matthiessen (1999) to designate a theory of grammar, while the term 'grammar' is a theory of experience,

To show that a grammar is a theory of experience we use a functional, semantically motivated grammatics, since this allows us to seek explanations of the form of the grammar in terms of functions to which language is adapted (p. 6). 
In this way, the functional approach amplifies the field of formal grammar and redirects it into the semantic direction. This argument seems very significant for the linguistics of the $20^{\text {th }}$ and $21^{\text {st }}$ centuries. This viewpoint opens an entire dimension of language where meanings nest in contexts.

\subsection{SFL Metafunctions}

The content dimension is presented through the ideational, interpersonal, and textual meanings. The ideational metafunction is accountable for maintaining logical and experiential meanings. The interpersonal metafunction negotiates the speech roles and attitudes in texts. Finally, the textual metafunction arranges the order and structure of the discourse framework. Halliday and Matthiessen $(1999,2004)$ also talk about the ideation, interaction, and text bases. These domains are constituents which form a wholeness of language. The ideation base consists of "resources [which] construe our experience of the world that is around us and inside us" (Halliday \& Matthiessen, 1999, p. 11). Human experiences become meanings and acquire ranks. The units, appropriately, configure processes, participants and circumstances organize the text complex semantically. The interaction base is in charge of interaction. The dialogue is being carried out by the speaker / writer and listener / reader. They communicate reactions by igniting meanings. As SFL states, this base "includes both the semantic strategies speaker and listener deploy in dialogic exchanges and the social personae of the interactants" (Halliday \& Matthiessen, 1999, p. 12). And to complete the system, there is the text base. It is impossible to produce discourse without it. Through this base people receive generically appropriate and well-organized patterns of text, "for differentiating among the different

values and statuses of the components of the unfolding text, and for ongoingly expanding 
the text so as to create and maintain the semiotic flow" (Halliday \& Matthiessen, 1999, p. 12). In Figure 3 the metafunctions can be correlated with the bases into one common domain of meaning.

Figure 3. Correlation of metafunctions and bases (Halliday \& Matthiessen, 1999, p. 13)

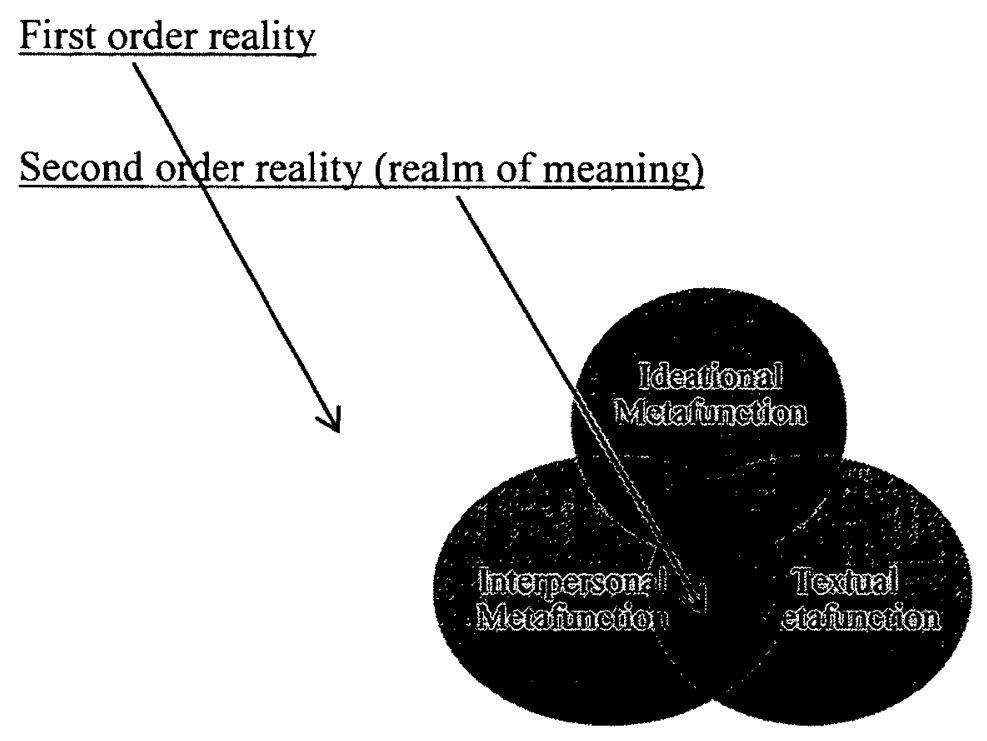

Grammatics in a human's mind takes on the form of the concrete text. This SFL position changes methods of the linguistic analysis completely. Scholars start to interpret contextual meanings, not only pure grammar formalities.

The pivotal model of the systemic functional linguistics (also called formal grammar) is the tripartite metafunction scale that creates meanings within the text, i.e. discourse.

\subsubsection{Ideational Metafunction: Clause as Representation}

Metafunction is the mode of making meaning in language whose "meaning potential has evolved around three motifs - the metafunctions of ideational, interpersonal 
and textual" (Halliday \& Matthiessen, 1999, p. 511). The ideational metafunction represents the dimension of human experiences. Halliday and Matthiessen (1999) explain it as "our interpretation of all that goes on around us, and also inside ourselves" (p. 511). There are two main parts that construe this metafunction. Firstly, the transitivity system showcases processes that happen in the discourse to reflect the experiential meanings. Secondly, the relationships between the processes in the clause (clause types) and connections between the clauses (clause simplexes and complexes) are to report about the logico-semantic meanings. Together these are the two criteria of constructing an efficient text to be perceived through grammar by human consciousness,

The grammar construes this experience of change in the form of a process configuration: the fundamental element of grammar is a clause, and the clause presents the parameters within which processes may unfold (Halliday \& Matthiessen, 199, p. 512).

The cornerstone phenomena in the world of human experiences are participants, processes, and circumstances. The entity of the discourse develops through the participants along with the processes. Meanwhile both categories are enhanced by the circumstances, such as location, time, manner, matter, etc. This mechanism of evolving a meaning reflects on the explicit field of lexicogrammar and implicit semantic layers. The ideational metafunction provide language realizations with semiotic prominence in the framework of discursive context. The language user is placed in a specific environment filled with cognitive constituents to be collected and interpreted in it. Halliday and Matthiessen (2004) call this environment 'a flexible semantic space' (p. 516). Interpreting the ideational meanings, it is possible to expand or reduce it to PPC (participants, processes, and circumstances). 
Nouns are expanded lexically as well as grammatically, so that, while entities (like processes) are located deictically relative to the 'here- $\&$-now', they are also (unlike processes) extensively classified and described (Halliday \& Matthiessen, 1999, p. 518).

Thus the universe of text is organized via process types and nominal taxonomies. They get support not only from the verbal groups but the secondary circumstantial element. This so-called 'third party' may represent "some qualification of the process in terms of its manner of occurrence (an adverbial group, in the case of English) or an entity that is involved in the process of but only indirectly (in English, a prepositional phrase, consisting of preposition plus nominal group)" (Halliday \& Matthiessen, 1999, p. 518). The small pieces combine into one complete mosaic to embody the context (situation).

The experiential constituents are connected and this logical connection makes the ideation level complete. Human experiences cannot be perceived separately. Conversely, they are tightly linked. So the structure and type of a clause is a speaking form behind which meanings lie. "In the logical world, the parts are not constituents of an organic configuration, like the process, participants and circumstances of the clause. They are elements standing to each other in a potentially iterative relationship; and each element represents an entire process" (Halliday \& Matthiessen, 1999, p. 520).

Two logical itineraries can be distinguished, that of expansion and that of projection. Expended processes engender further interpretations of the very first process. Expanding means elaborating (clause as addition), exemplifying (clause as clarification), and enhancing (clause as time, cause, condition, etc.). Projected processes get a level of semiotic enrichment through speaking (speech projection or locution in verbal processes) and thinking (idea projection in mental processes). As a result, "the grammar can project 
in this way, semiotic events, both those which are extremalized as sayings and those which are internalized as thoughts, are brought within the overall domain of the phenomena of experience" (Halliday \& Matthiessen, 1999, p. 521).

The network of logico-experiential relationships exists in language. But every language system creates a particular micro-scheme. English definitely possesses its own logical nexus (Halliday \& Matthiessen 1999, 2004) and consequential dependencies. The specific tendencies in choosing a structure and type for each clause are the scope of the ideational metafunction analysis. In the analysis of the ideational dimension, it is necessary to understand:

1) the implications of a separate process and the sequence of all processes in text as a conceptual message

2) the correlations between a process and its surroundings (participants and circumstances)

3) the links between the participant and circumstance elements around one given process

4) the connections between clauses as concentrations of meaningful realizations

Every language will disclose its inner systemic regulations in the process of interpretation. Moreover, every text in language will have a unique organization of circulating concepts and representations in the context. My research focuses on the conclusion section of the primary research article in applied linguistics to show the mechanism of communicating experiences. 


\subsubsection{Interpersonal Metafunction: Clause as Exchange}

The Interpersonal Metafunction reveals the attitudes and stances towards a discourse as a dialogue. The basis of human language activity is dual, giving (declarative Mood) or demanding (interrogative Mood). As Halliday and Matthiessen (2004) describe the process of exchange, giving means 'inviting to receive' and demanding means 'inviting to give'. Human beings exchange abstract (information) and concrete (goods and services) commodities through language.

The whole concept of exchanging information is difficult ... Goods and services are obvious enough... although I may use language as a means of getting what I want, the requirement itself is not a linguistic commodity - it is something that arises independently of language. Information, on the other hand, does not; it has no existence except in the form of language. In statements and questions, language itself is commodity that is being exchanged; and it is by no means simple ... the principle that language $s$ used for the purpose of exchange language (Halliday \& Matthiessen, 2004, p. 110).

This quote makes me think about the depth of language as interaction. If I look at such categories as Mood, MOOD \& RESIDUE, Modality, and Attitudinal items, the principle of exchange becomes more explicit. Thus the dialogue in discourse can be traced through discourse and its constituents. The grammar forms and structures are not only means towards stating and questioning. The interpretation of their functioning become 'the point of entry' (Halliday \& Matthiessen, 1999) to a great variety of functions. Starting with giving or demanding, the discourse gets ready to the exchange of the information through the Subject and Finite that are located in the MOOD pattern. The Finite is called that because it makes the proposition finite. That means it makes the preposition arguable (e.g. 'They saw me, didn't they?' where 'saw' is a combination of the Finite and Predicator and 'didn't' in the tag is the Finite with negative polarity). The 
Finite (Temporal or Modal) is an indispensable interpersonal component. Halliday and Matthiessen (2004) call this phenomenon an interpersonal deixis,

They [Finites] locate the exchange within the semantic space that is opened up between speaker and listener. With primary tense, the dimension is that of time: primary tense construes time interpersonally, as defined by what is 'present' to you and me at the time of saying. With modality the dimension is that of assessment: modality construes a region of uncertainty where I can express, or ask you to express, an assessment of validity of what is being said (p. 116).

Positive or negative Polarity is usually a part of the Finite. The specification of Polarity works in collaboration with the specification of temporal or modal reference to represent a speech event in the discourse (Halliday \& Matthiessen, 2004). Thus the discourse gets its verbal element, the central element of the clause system in the English language.

The pivotal Finite component is supported by the nominal groups that surround it. The main nominal group in the clause is the Subject. The Subject precedes the Finite in an English affirmative structure. When I say 'They saw me', the interaction happens with the help of the two components, the Subject 'they' and the Finite + Predicator 'saw'. Halliday and Matthiessen (2004) characterize the Subject as a 'responsible' element that makes the information valid. If the requirement of validity is met (the clause has the Subject), the dialogue gets its elaboration and unfolding in the discourse dimension. Overall, the MOOD element carries "the burden of the clause as an interactive event" (Halliday \& Matthiessen, 2004, p. 120).

The RESIDUE elements are the Predicator, Complement, and Adjunct. The Predicator endorses the Finite, concerning its time, aspect, process references, etc. The Compliment can be called the 'younger brother element' of the Subject. It is a nominal 
group with potentials of being 'the nub [the Subject] of the argument' (Halliday \& Matthiessen, 2004). The Adjunct represents circumstances around other clause interactive elements. Usually it is realized by an adverbial or prepositional group to underline the experiences being discussed. There are particularities within this class as not every Adjunct is always a part of the RESIDUE. There are Mood Adjuncts and Comments that can be found in the MOOD. The Conjunctive Adjuncts are neither in MOOD, nor in the RESIDUE. They perform their special functions of interpersonal and textual co-builders within the framework of the discourse dialogue. In my further chapters these cases will be discussed in more detail. Now to show how the clause is structured to function interpersonally, I will develop the typical scheme of a typical English clause:

Subject ${ }^{\wedge}$ Finite $\wedge^{\wedge}$ Predicator $\wedge^{\wedge}$ Compliment ${ }^{\wedge}$ Adjunct

Studying the interpersonal meanings in the clause is seeing how the dialogue is being created step by step by the author and hos reader in the discourse of an RA conclusion.

Tenor is realized through interpersonal meanings, which are in turn realized through the grammar of the clause as exchange. Our [SFL] analysis allows us to study how choices in Mood and Modality (as well as in ... Vocation and Attitude) are the realizations of tenor (Eggins, 2004, p. 187).

\subsubsection{Textual Metafunction: Clause as Message}

Each discourse, no matter how small it is, is organized in a meaningful way. The Given starts the clause and the New follows. Together, these parts combine in one textual entity to communicate a message to the reader / listener. The relationship between the Given Information and New Information is called the Theme-Rheme relationship. The Theme functions as the main clause construct that connects the previous information item 
with the successive one because it is the point of departure in every clause. Themes as a class organize the flow of the discourse and, most importantly, locate and orient it with its context (Halliday \& Matthiessen, 2004). The Theme can be expressed by a nominal, adverbial, or prepositional phrase. Being distinguished with an intonation, it is rather distinct in speaking but in the written text the Theme pattern is not obvious. However, when it is identified in the written discourse, the structure can immediately be seen as two balanced patterns, that is of Theme and of Rheme. In addition, Halliday and Matthiessen (2004) describe nominalization, lexical density, cohesion, and reference that make the organization well-organized and harmonious.

As a result, the textual metafunction exhibits the existence of interrelations between the discourse patterns as textual units placed in a meaningful order. In addition to the necessity of being tied together in a proper grammatical way, they contribute to the semantics of the discourse. The textual coherence and cohesion complete the semantic mission of the discourse, started with the representational (ideational) and communication (interpersonal) meanings. This third function is to 'enable' (Halliday \& Matthiessen, 1999, 2004; Eggins, 2004).

The essential contribution made by textual meaning is to actualize a range of different textual structures which operate at all levels of the text, and whose function is to enable the ideational and interpersonal meanings we have chosen to make to be realized in a cohesive text (Eggins, 2004, p. 326).

\subsection{SFL Experiences in Discourse Analysis}

Systemic Functional Linguistics has already been used by many researchers to analyze the discourse. The most detailed descriptions of SFL tri-functional model in revealing the discourse implications are given by Halliday and Matthiessen's works 
$(1999,2004)$. Gregory (1987) helps to understand the profound significance of SFL metafunctions in the discourse. One of the largest collections of analyses at the SFL metafunction level can be found in Eggins' (2004) Introduction to Systemic Functional Linguistics.

Researchers analyze the texts using Halliday and Matthiessen's SFL methods as an opportunity to get deeper into the forms and structures to decode the functions of the discourse. Halliday (1973) uses his SFL model to analyze W. Golding's The Inheritor. Jim Martin (2000) examines the ideational metafunction to reflect participants' modifications through processes in the discourse of Mrs. Piggott's Piggybook. Lewin, Fine, and Young (2001) analyze how lexical and grammatical choices function in the social science discourse. They prove that the explicit realizations are the tip of the semiotic iceberg in the discourse of the research article. The SFL approach is used by them as an analytical tool to show how the RA framework makes function of the implied knowledge and explicit lexico-grammar as a discursive entity. The SFL understanding of realizations of meanings in text assists (Ventola, 1988) in discussing the problems of L2 language users in speaking and writing in English. Iwasaki $(1995,1996)$ examines the processes and their ideational meanings in the discourse of war-time Japanese newspapers. She finds an interesting feature of the war-time Japanese discourse, i.e. a great number of pseudo-effective processes. The concentration of material processes with non-material Goals and Ranges to disguise the defeat of Japan at the end of WWII:

The soldier demonstrated the true mettle of Japanese fighting men. (They manifested spirit but not an action).

Ushuima units win supreme honour for gallant defense action in Okinawa. (The spiritual victory is accentuated not the actual battle result). 
To sum up, the SFL theory has contributed to the modern understanding of discourse. SFL helps to see how the discourse is being structured to function as representation, exchange, and textual message. This thesis aims at concentrating on the micro-structuring to observe how clause and its constituents produce meanings to cluster later in bigger generic patterns.

\subsection{Diversification of Discourse Analysis of Academic Texts: Comparisons}

This section presents a brief comparative study to discuss the foci of other linguistic analytical approaches of the RA framework. I will mention some works that concern separate RA sections and general academic discourse investigations and I will compare these studies with the SFL cognitive matrix to find the common points of support and the place for the systemic functional linguistics. The research article framework in reporting on scientific findings illustrates a study of discourse at various levels.

Academic discourse encompasses a wide range of specific academic genres, such as research articles, abstracts, conference papers, dissertations, etc. Different approaches to studying linguistic phenomena in academic genres allow the researchers to look at language from diverse points of view. This diversity leads to a more profound understanding of the language functioning in a particular academic environment.

Linguistic theories can only develop and enlarge their knowledge bases with practical observations of texts. In this section I will mention scholars who analyzed the RA discourse. In this thesis, as I have mentioned earlier, I will undertake an SFL analysis of the patterns that were not examined in the discourse analytical background as we shall 
see. Thus the systemic functional analyses will try to bridge the gap between SFL and other schools of linguistic insights into the realm of academic texts.

Such researchers as Swales (1998), Swales \& Najjar (1987), Hyland (2002, 2004, 2005, 2007, 2008), Samraj (2002), Atkinson (2003), Bunton (2005), Yang \& Allison $(2003,2004)$ have interpreted various constructs of research articles to reveal their generic features and semantic potentials. Therefore, before starting the SFL examination, I will mention those who contributed to the collective knowledge about academic texts from other linguistics' viewpoints.

Keeping in mind the representational potentials in academic texts, I begin with Swales who dedicates a lot time to academic discourse analysis at the conceptual level of 'move'. That correlates with Eggins' (2004) descriptions of phases in the dimension of ideational meanings. He describes macro-structural moves as meta-discourse descriptors that elaborate the genre framework of a research article, especially the section Introduction. He interprets the academic discursive steps in terms of the genre analysis. The introductory moves are summarized by Swales (1990, 2004; Bunton, 2005), as follows:

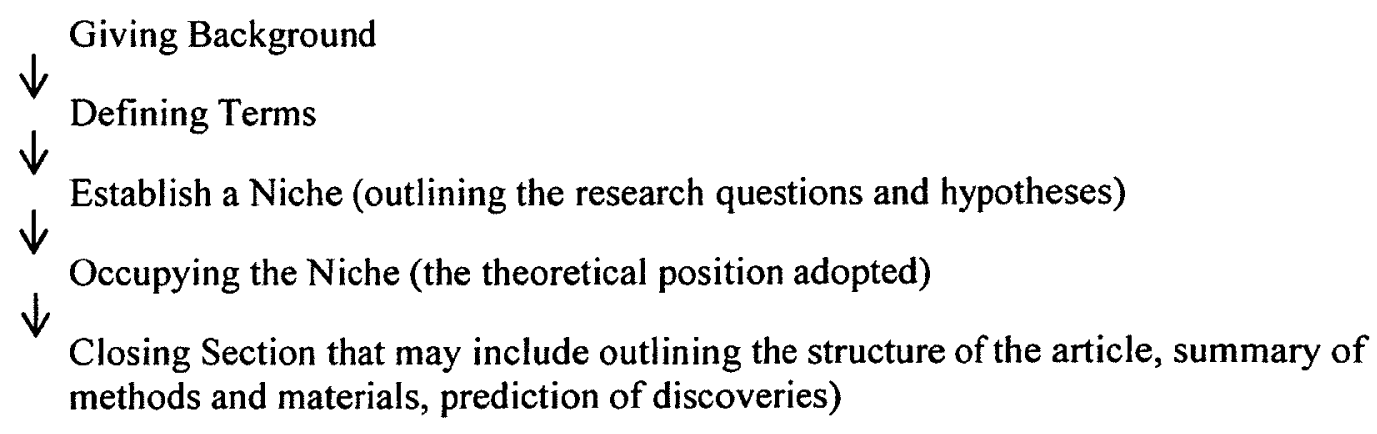

Swales scrutinizes the classical IMRD-nature (Introduction - Methodology Results - Discussion) RA discourse with his CARS (Create a Research Space) analytical 
techniques to detect the typical communicative steps and to find similarities in a given discipline. Swales shows the way of socialization and acculturation into a discourse community through composing congruent genre-based patterns:

The study of text in the academy is a cake that can, of course, be cut many ways. As we have seen, analysis could involve comparing national rhetorical traditions, or it could examine the history of a discipline (Swales, 1998, p. 111).

Through the genre analysis methodology, Swales shapes a comprehensive RA

framework in order "to provide a rhetorical map of a particular corpus of RAs that may then be aligned with disciplinarity proclivities" (Swales, 2004, p. 240):

1. Do Introductions

a) have a straight shot or a recycled character?

b) have a clear gap-indication?

c) announce their principle findings?

d) provide positive evaluations of the proposed research?

e) outline the article structure?

2. Do Methods (and Materials)

a) have a clipped or an elaborated character?

b) if the latter, are there many purposive or rationale statements?

3. Do Results

a) have evaluative or discussive elements?

b) if so, of what kind?

4. Do Discussions

a) have subsections?

b) open with the main findings or with a broader introduction?

c) include much self-advocacy?

d) close with implications and research recommendations?

Mapping of rhetorical moves is definitely of great importance. And it would seem that the SFL analysis may enrich the RA discourse research with mapping of prominent lexicogrammatical features. That can help discourse analysts not only to reach the meanings from the ideational, interpersonal and textual realizations in the form of lexicogrammar but to comprehend the holistic nature of the discourse. Combining the 
form and the meaning can lead to a more profound perception of the discourses of diverse disciplines

In terms of the conceptual and interactive planes, Hyland focuses on smaller patterns in academic discourse, namely contexts of citation, research-oriented lexical bundles, reporting verbs, appraisal structures, questioning and hedging. This research direction deals with identifying the discursive element functioning to express the author's concepts and stances as the indicators of the social nature of knowledge in the RA. Importantly, Hyland accentuates the significance of the written discourse in all the disciplines, noting that "writing is not just another aspect of what goes on in the disciplines; it is seen as producing them" (Hyland, 2000, p. 3). Hyland (2007) detects micro -elements of academic construing experiences, notably reformulation and exemplification ('in other words / especially / that is / specifically / namely, particularly' and others) in RAs in different disciplines, including AL. In addition, Hyland scrutinizes the role of interaction in the academic texts. The dialogical nature of the academic writing is implicit but undoubtedly powerful. It is "rhetorically and interactionally complex and represent[s] a carefully crafted accomplishment ... to offer an insightful perspective, drawing on considerable knowledge of the field, but at the same time respond to the complex demands of this delicate interactional situation" (Hyland, 2000, p. 43-44). According to Hyland, the interactive meanings maintain the dialogical nature of the academic discourse. His interactive position corresponds with the SFL understanding of the interpersonal metafunction that nurtures a dialogue in texts. Hyland claims the necessity to expand the examination area and goes beyond the ideational dimension: 
[Academic] writers are seen as doing more than producing texts that plausibly represent an external reality. They are also perceived as negotiating the status of their claims with their peers, presenting their work in ways that readers are likely to find both credible and persuasive (Hyland, 2002, p. 1).

He studies structures that establish the exchange in the discourse of RA and textbooks chapters. For example, he analyzes questions in academic texts as genre patterns in a specific discipline that is "claiming solidarity and acknowledging alternative views, but most importantly inviting readers to engage with the argument" (Hyland, 2002, p. 25). In SFL theory these relationships are discussed with the choices of the mood, speech roles distribution and processes of exchanging information, goods and commodities.

Talking about the balance between the authorial involvement and reader's engagement, Hyland (2008) discusses the voices (in such discourse components as hedges, attitude markers, self-mention, directives, the author's / reader's pronouns) that "represent relatively conventional way of making meaning and so elucidate a context for interpretations, showing how writers and readers make connections, through texts to their disciplinary cultures" (Hyland, 2008, p. 22).

Hyland's (2008) text-oriented lexical bundles might be useful when starting the examination of SFL textual metafunction analyses. He distinguishes several groups of them, namely transition, resultative, structuring and framing signals, to send a message as departure for academic argument. After conducting this research, he concedes:

More work with different disciplines, genres, and first language groups is likely to yield a fuller picture of community specific practices. ... These findings have clear implications for EAP practitioners. ... Numerous studies now show the extent to which language features are specific to particular disciplines, and that the best way to prepare students for their studies is not to search for universally appropriate 
teaching items, but to provide them with an understanding of the features of the discourse they will encounter in their particular courses (Hyland, 2008, p. 20).

Separate RA sections are also examined by language analysts. In particular, Swales (1998), Swales \& Najjar (1987), Swales \& Feak (2000), Samraj (2002), and Atkinson (2003) concentrate on the organizational structures of RA Introductions. For instance, Samraj mentions that the differences in the structural and textual organization of research article in various disciplines should be examined thoroughly, acknowledging "an important pedagogical implication of these differences [which] students should be aware [of]" (Samraj, 2002, p. 14).

Bunton (2005), Yang \& Allison $(2003,2004)$ carry out research in the area of RA Results and Conclusions. Bunton (2005) does a genre analysis of conclusions in the $\mathrm{PhD}$ dissertation by following the pattern of Swales' generic steps:

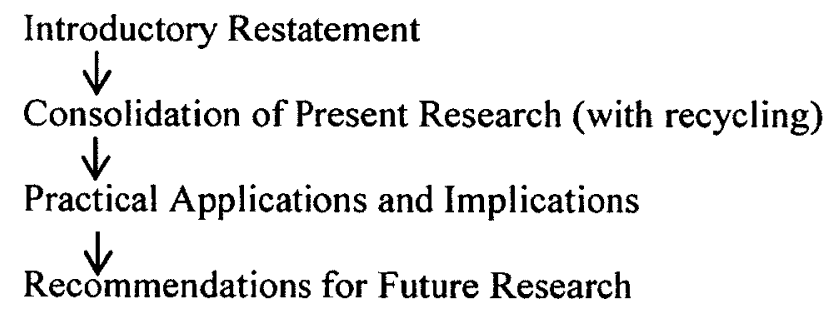

Bunton summarizes his observations about titling, size, references, and moves (introductory statement, consolidation of research space, recommendations, applications, implications, and concluding restatement). He compares numbers of the Discussion and Conclusion titling tendencies, finding the prominence of the title Discussion in concluding PhD chapters. In the end, Bunton draws the following conclusion:

Given the lack of differentiation of thesis- writing guide books between Discussions and Conclusions, the provision of research-based models could be of real value to $\mathrm{PhD}$ students and supervisors (Bunton, 2005, p. 17). 
As I have tried to suggest in this section, the research of RA framework is more diversified, and includes thesis-writing orientations. I would though like to support Bunton's standpoint about the necessity of further research. To be precise, further research from the perspective of various linguistic theories is necessary. Thus, my thesis is designed to add to the literature by expanding a study on the conclusion-writing in academic text with SFL analysis of my data to further show how language functions in $\mathrm{AL}$ article contexts.

Discourse analysis can tackle macro-structures or micro-elements. Each type of examination will complement the others to create an objective picture of deeper layers of meaning. As Yang and Allison (2004) state, there are three main approaches in in research genre features. These methodologies should be regarded as "complimentary, rather than competing approaches: ESP genre analysis, New Rhetoric studies, and ...Systemic Functional Linguistics" (Yang \& Allison, 2004, p. 265). I have focused on the third approach to contribute to understanding the RA framework as a multi-layered phenomenon analyzed from diverse aspects. The variety of findings from different researchers will help to get an objective spectrum of the discursive signals that enrich academic contexts with explicit articulations and meanings.

Therefore, SFL analysis becomes one of the pieces of the language kaleidoscope. The systemic functional approach deals with lexicogrammar forms that serve as a means to identify meanings and to trigger their interpretations. Distinguishing the most prominent elements at the level of lexical and grammatical realizations of clauses will help to reveal semantic and structural implications that have not received as much attention as the examination of macro-level discursive patterns. SFL teaches the 
researcher to attend to small discourse details that appear to be deliberate choices of the academic writer. Focusing on the micro level, it facilitates the evaluation of the larger macro level features. This way SFL analysis of the RA discourse may play the role of the bridge between the form and meaning in academic texts at different levels. 


\section{Chapter Three - Methodology}

My methodology centres around SFL tripartite metafunction model and its application in the analysis of four RA conclusions in applied linguistics. The threedimension model is described in the works of Halliday \& Matthiessen (1999), Halliday \& Matthiessen (2004), Eggins (2004) as we have seen. The Ideational, Interpersonal and Textual Metafunctions are observed in the texts to help us to understand how applied linguists create meanings and bond them together in an entity, i.e. the conclusion section of an article. In this chapter, I will distinguish the categories that can be traced in the discourse within each of the three metafunctions. Going through them, an SFL analyst sees the dimensions of experiences, interactions, and textual organizations in detail. Together, they forms a 'force' that moves the reader through the text, involving him into the process of knowledge and expertise exchange.

\subsection{Background}

Text is a complex network of explicitly grammatical and implicitly semantic elements which in combination create the author's message. It is a multi-faceted phenomenon (Halliday \& Hasan, 1976; Ventola, 1988, Halliday \& Matthiessen, 1999, 2004; Eggins 2004) that can be explored from different angles regarding the meaningmaking processes in it. Text is an object of analysis but it is its own instrument as well (Halliday \& Matthiessen, 2004). The texture of the text (Halliday \& Hasan, 1976; Hasan, 1985; Eggins 2004) is a specific feature that makes text to be opposed to non-texts.

Texture is the property that distinguishes texts from non-texts. Texture is what holds the clauses of a text together to give them an entity. [It] involves the interaction of two components: coherence, or the text's relationships to its extratextual context (the social and cultural context of its occurrence), and cohesion, the 
way the elements within a text bind it together as 'a unified whole'. The result the interaction of these two dimensions is a piece of language which is using linguistic resources in a meaningful way within a situational and cultural context (Eggins, 2004, p. 24).

This lexicogrammatical and semantic unification can be observed in the functions language performs in context. The ability to make meanings is the basis of language but it is not launched automatically. Only social interactions can articulate these meanings.

The metafunctions stand for the choices that lie behind the explicit purposes and articulations (Halliday \& Hasan, 1989; Martin, 2000; Halliday \& Matthiessen 2004). These choices are small details that make the whole mechanism work. Halliday $\&$ Matthiessen (2004) maintain that the term 'metafunction' derives from the view that function is an integral component within the overall theory.

Text as the complex semantic whole is what this thesis is concerned with. The three metafunctions are basics in construing the grammar of text. Each metafunctional dimension has it own hierarchy based on clause stratification. And every clause is attributed a semantico-structural rank. Following Halliday and Matthiessen's (2004) names and statuses, the organizational framework of metafunctions in the text is the following:

Table 1. Metafunctions in text (p. 61)

\begin{tabular}{|l|l|l|l|l|}
\hline \multicolumn{2}{|l|}{ Metafunction } & Definition & $\begin{array}{l}\text { Corresponding status } \\
\text { in clause }\end{array}$ & $\begin{array}{l}\text { Favoured type of } \\
\text { structure }\end{array}$ \\
\hline Ideational & experiential & $\begin{array}{l}\text { construing a model of } \\
\text { experience }\end{array}$ & clause as representation & $\begin{array}{l}\text { segmental (based on } \\
\text { constituency) }\end{array}$ \\
\cline { 2 - 5 } & logical & $\begin{array}{l}\text { construing logical } \\
\text { relations }\end{array}$ & $\begin{array}{l}\text {--- } \\
\text { (embodied in clause } \\
\text { complex) }\end{array}$ & iterative \\
\hline Interpersonal & $\begin{array}{l}\text { enacting social } \\
\text { relationships }\end{array}$ & clause as exchange & prosodic \\
\hline Textual & creating relevance to & clause as message & culminative \\
\hline
\end{tabular}


context

This study is an attempt to research the micro-levels of clauses that form the discursive features of academic discourse and more specific applied linguistic features in research article conclusions. I aim to answer the research question that was referred to earlier:

$\rightarrow$ What elements of the SFL metafunctional model are prominent in the AL article conclusions?

The SFL approach gives an opportunity to analyze the micro-levels that together create a text as an entity where meanings are born out of conceptual and interactive collaboration. This fact finds its proof in the three metafunctions that create (Halliday \& Matthiessen, 1999, 2004) concepts, interaction and texture of discourse. In this paper, the text analysis goes through the following lexicogrammatical layers (Table 2) that trigger the recipient interpretations, through the semantics of the given data and context.

Table 2. Lexicogrammar rank-function matrix for analysis

\begin{tabular}{|c|c|c|c|c|}
\hline \multicolumn{2}{|c|}{ Metafunction } & Lexicogrammar & Rank & Class \\
\hline \multirow{3}{*}{ Ideational } & Experiential & Transitivity & clause & \\
\hline & & $\begin{array}{l}\text { Process, Participant, Circumstance } \\
\text { Type }\end{array}$ & group / phrase & $\begin{array}{l}\text { Verbal } \\
\text { Nominal } \\
\text { Adverbial } \\
\text { Prepositional } \\
\text { phrase }\end{array}$ \\
\hline & Logical & Taxis and Logico-Semantic Type & clause & \\
\hline \multirow{4}{*}{\multicolumn{2}{|c|}{ Interpersonal }} & Mood & clause & \\
\hline & & MOOD and RESIDUE & clause / group & \\
\hline & & Polarity/Modality & group & Verbal \\
\hline & & Attitude and Connotation & group/word & $\begin{array}{l}\text { Verbal groups / } \\
\text { Word units }\end{array}$ \\
\hline \multicolumn{2}{|l|}{ Textual } & $\begin{array}{l}\text { Rhetorical Organization } \\
\text { (Nominalization and Lexical }\end{array}$ & group / word & $\begin{array}{l}\text { Nominal groups } \\
\text { Word units }\end{array}$ \\
\hline
\end{tabular}




\begin{tabular}{|l|l|l|l|}
\hline & Density, Cohesion, Reference) & & \\
\cline { 2 - 4 } & Theme & clause & \\
\hline
\end{tabular}

These constituent descriptors (Halliday \& Matthiessen, 2004) are important as separate meaningful micro-engines. However, they should be explained as independent items and then contribute to the overall interpretation. This dual-aspect of one analytical move is important to consider.

Although there are clearly these three motifs [metafunctions] running side by side in every clause, a clause is still one clause - it is not three. It is a familiar problem for functional grammarians that everything has to be described before everything else; there is no natural progression from one feature in language to another (Halliday \& Matthiessen, 2004, p. 62).

\subsection{Ideational Metafunction Elements}

The Ideational Metafunction answers the following questions:

- Who are the primary and secondary participants?

-What processes are these participants involved in?

-What do the circumstances focus on?

The ideational meanings reflect human experiences, namely "it is our interpretation of all that goes on around us, and also inside ourselves" (Halliday \& Matthiessen, 1999, p. 511). The process types project experiential implications, whereas the way they are connected between each other in a clause structure shows the meaningful logic. Together these factors create the logico-experiential relationships in the discourse, construing our experiential world (Halliday \& Matthiessen, 1999).

Since I discussed the importance of decoding the meanings within each of the three SFL metafunctions, I need to explain the specific components that form a systemic model 
of understanding the depths of the discourse. In this section, I describe the constructs of the SFL method that serves as the dominant focus for my research.

\subsubsection{Transitivity (experiential dimension)}

The discourse exists due to the events that happen and thus move the narrative forward. The sequence of happenings creates the context in the discourse. The reader receives the answer to a simple but cornerstone question "What is going on?"

This flow of events is chunked into quanta of change by the grammar of the clause: each quantum of change is modeled as a figure of happening, doing, sensing, saying, being, or having. All figures consist of a process unfolding through time and of participants being directly involved in this process in some way; and in addition there may be circumstances of time, space, cause, manner... (Halliday \& Matthiessen, 2004, p. 170).

Thus Halliday and Matthiessen (1999), Halliday \& Matthiessen (2004), Eggins (2004) describe the processes as constructs of the transitivity system and circumstances as necessary extensions in contexts. The verb is the semantic and syntactic centre of the clause. The text is a gathering of clauses and represents the logical flow of events through the concrete forms of process types. This complex network of processes is called the transitivity system to construe the world of experience into a manageable set (Halliday, 1973; Halliday \& Matthiessen, 1999, 2004). Every verb creates its own experiential micro-space. 
Table 3. The grammar of experience: processes in English

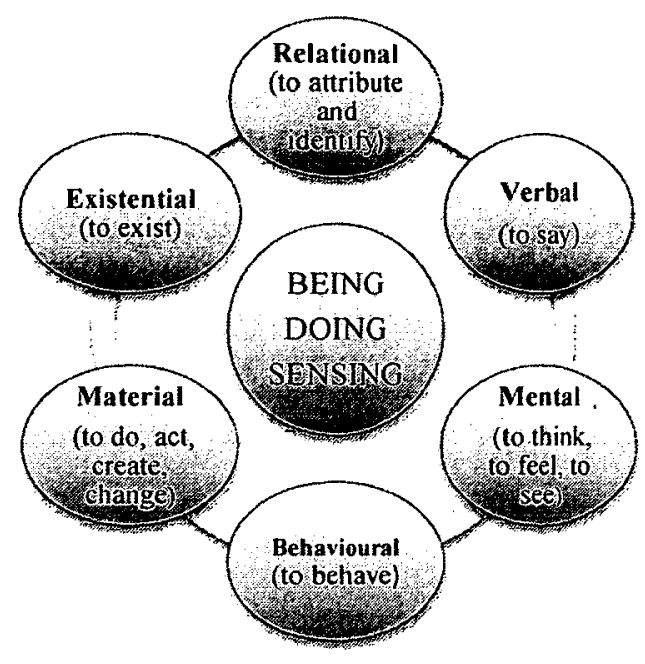

Functional grammarians see that as the intertwinement of outer and inner experiences (Halliday \& Matthiessen, 2004). Something that happens out there becomes my experience through language, i.e. these experiences become parts of my consciousness. The external world actions are presented in functional grammar with 6 process types. They are mental, material, relational, verbal, behavioural and existential processes. Mental processes represent humans' (Sensers') thinking and feeling and are extended by phenomena (Phenomenon), imaginary results of reflections and reactions. According to Halliday \& Matthiessen (2004) and Eggins (2004), three classes of mental reactions are distinguished:

- $\quad$ Cognition (verbs of thinking, knowing, and understanding)

- $\quad$ Affection (verbs of liking, fearing, etc.)

- $\quad$ Perception (verbs of seeing, hearing, etc.)

Material processes denote concrete acts of 'doing' so that the action is tangible. This verbal class means "some entity does something, undertakes some action" (Eggins, 
2004, p. 215). The doer is Actor and the discourse often involves Goals (participant), Ranges (related participant), and Beneficiaries (recipient). Behavioural processes are found not so often because they embody ambiguous semantic implications. Such verbs as 'sigh', 'cry', or 'sneeze' are located between material and mental spheres because they are a semantic mixture of mental and physical processes. The verbal process type is quite evident. The Sayer expresses himself through directly through speech (say, speak, exclaim, etc.) and through ideas (conclude, show, acknowledge, etc.). The relative 'that'clause can help to identify this type in the discourse. The existential type is easy to detect through the wide-spread use of the structure 'there is'. The participant 'Existent' follows the verb. The circumstance of location 'there' sheds its concrete locational meaning in the structure 'there is / there are'. It becomes an entity with a unified grammar and semantics. Other examples of this class are verbs 'exist', 'arise', and 'occur'.

Another aspect of 'being' is opened up in the relational processes. On the one hand, there is the attributive type (Carrier + Verb + Attribute). The Carrier is usually expressed by a noun and connected with its characteristics (Attribute) with the verb 'be' or its equivalent ('to turn, stay, grow, seem, look, taste, feel' + epithet) to mean that something 'belongs to the class of $\mathrm{X}$ '. This structure is not reversible, unlike the other relational type. Identifying processes are to define. The meaning of an identifying structure is that ' $X$ serves to define the identity of $Y$ ' (Eggins, 2004). The Token is being defined by the Value. As Halliday \& Matthiessen (2004) explains, semantically the Token designates 'a sign, name, form, hold, or occupant' of a Value, which gives 'the meaning, referent, function, status, or role' of the Token. In this case, the noun or nominal group classifies the noun or nominal group ('Manners make the man' / 'Her smile expressed pleasure' / 
'His behaviour exemplified the typical criminal'). Additional relational subtypes are possessives and causatives. The idea of ownership ('She has a car') and causativity in a identifying sense ('They made Simon the barman for the night' / Donating blood results in weakness') and in an attributive sense ('The experience of Geneva made Diana become a blood donor').

There is no priority of one of the group over the other. The table that follows shows that they are equal in organizing not a hierarchy but a shared semiotic domain. This semiotic domain can be also seen as a system network that "construes a continuous semiotic space" (Halliday \& Matthiessen, 2004, p. 173).

Table 4. Transitivity as system network

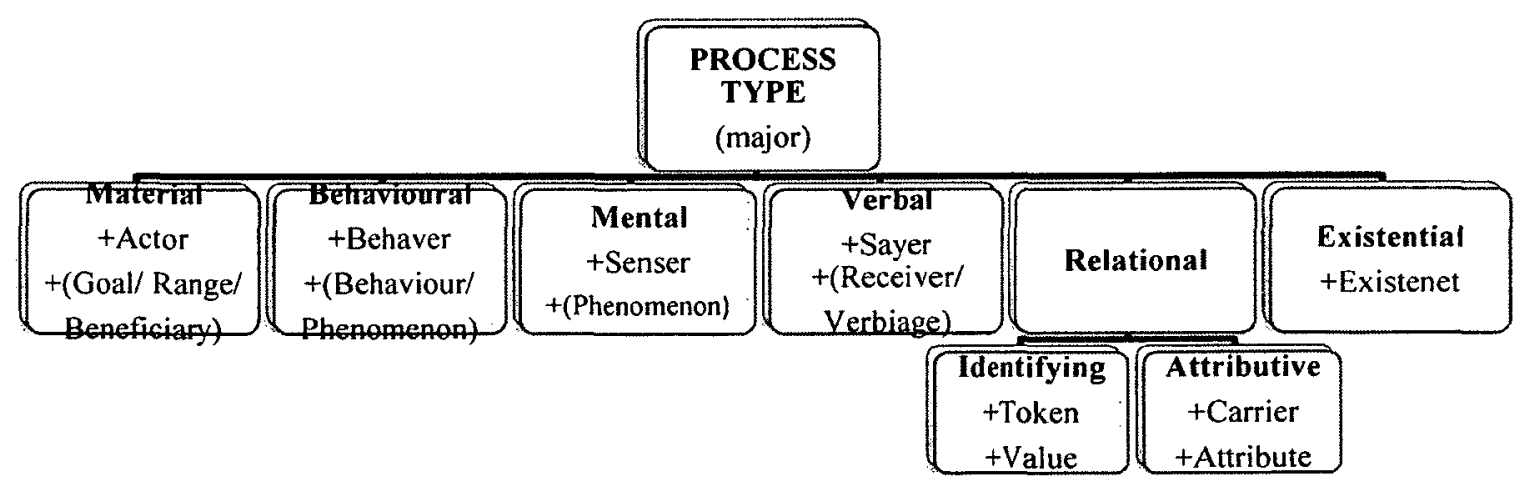

The analysis of the transitivity system in a discourse not only clarifies the relationships between the participant, actions, and circumstances. Moreover, it allows the discourse analyst to trace the factor of determination (why did the author choose the given process type?) and contextual influences (how did the discourse modify the processes?). 
The Transitivity patterns represent the encoding of experiential meanings: meanings about the world, about the experience, about how we perceive and experience what is going on. By examining the Transitivity patterns in text, we can explain how the field of the situation is being constructed, i.e. we can describe 'what is being talked about' and how shifts in the field are achieved (Eggins, 2004, p. 249).

Thus the transitivity system meanings let me approach the level of realization and choices in the discourse being observed. The participants and their foregrounded experiences construct the field of discourse.

\subsubsection{Taxis and Logico-semantic Clause Type (logical dimension)}

Relationships between clauses are the second component of the ideational metafunction. The clauses are tightly connected with each other. The factors of clause interdependency (taxis) and connections between the primary and secondary clause (logico-semantic types) are important features to consider in an SFL discourse analysis.

Table 5. Taxis and logico-semantic relationships between clauses

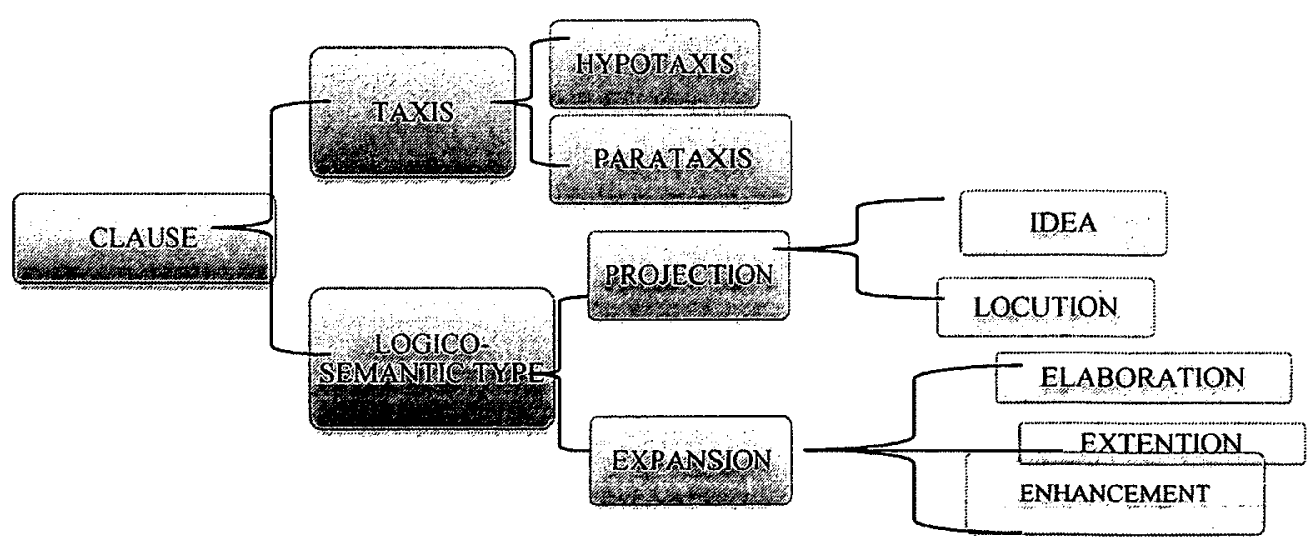

The status of a clause may vary in a clause complex. Sometimes they are equal.

Sometimes one clause acts as a complete statement modified by the adjacent clauses in a clause complex. The equal status of clauses is called parataxis. The unequal status is 
hypotaxis where the dominant clause is connected to its dependents. The paratactic and hypotactic relations reveal the sequence of clauses and meanings behind it. The primary clause initiates and the secondary continues in the paratactic environment with conjunctions 'and', 'but', 'neither-nor', 'either-or' and such punctuation marks as colon, semi-colon, or comma. In hypotaxis the secondary clause is dependent on the primary clause. In my Study I use numbers 1-2 and Greek letters to signify:

\begin{tabular}{|c|c|c|}
\hline & primary & secondary \\
\hline parataxis & 1 (initiating) & 2 (continuing) \\
\hline hypotaxis & $\alpha$ (dominant) & $\beta, \lambda$ (dependent) \\
\hline
\end{tabular}

It is not rare when both parataxis and hypotaxis develop complex relationships in one sentence. The more nesting (Halliday \& Matthiessen, 2004) the more implications appear while decoding the author's choices.

The other side of the same coin is the factor of logico-semantic type realizations between clauses. The two main directions are expansion and projection. Halliday \& Matthiessen (2004, p. 593) explain:

- Expansion: the secondary clause expands the primary clause, by elaborating it, extending it, or enhancing it

- Projection: the secondary clause is projected through the primary clause, which states it as a locution or an idea.

Looking at the clause types, I can see clearly how the text develops horizontally. Reporting or expanding, the writer / speaker 'weaves' the narrative tapestry and the recipient gets the logical and semiotic entity, instead of separate pieces-clauses. Halliday \& Matthiessen $(1999,2004)$ and Eggins (2004) describe these relations in detail: 
Table 6. Logico-semantic types (detailed)

\begin{tabular}{|l|l|r|l|}
\hline Logico-semantic Clause Type & Symbol & Description \\
\hline EXPANSION & $\begin{array}{l}\text { Elaboration } \\
\text { 'i.e./for } \\
\text { example/namely' }\end{array}$ & $\begin{array}{l}\text { Restating the primary clause (PC) in other } \\
\text { words, specifying in greater detail, commenting, } \\
\text { or exemplifying }\end{array}$ \\
\hline $\begin{array}{l}\text { Extension } \\
\text { 'and/or' }\end{array}$ & $\begin{array}{l}\text { Enhancement } \\
\text { 'so/yet/then' }\end{array}$ & x & $\begin{array}{l}\text { Adding some new element to the PC, giving an } \\
\text { exception to it, or offering an alternative }\end{array}$ \\
\hline PROJECTION & $\begin{array}{l}\text { Embellishing the PC, qualifying it with some } \\
\text { cocumstantial feature of time, place, cause, } \\
\text { condition, etc. }\end{array}$ \\
\hline 'says' & "s & $\begin{array}{l}\text { Projecting one clause through another, which } \\
\text { presents it as a locution, a construction of } \\
\text { wording }\end{array}$ \\
\cline { 2 - 4 } & $\begin{array}{l}\text { Idea } \\
\text { 'thinks' }\end{array}$ & $\begin{array}{l}\text { Projecting one clause through another, which } \\
\text { presents it as an idea, a construction of meaning }\end{array}$ \\
\hline
\end{tabular}

Also, it is important to mention the phenomenon of embedding. Embedded clauses are rank-shifted units. They lose their status of clause and become a part of the clause they are in. Usually clauses in simplexes tend to pack much information in a limited syntactic space. "While the principle behind taxis and complexing is expansion, the principle behind embedding is compression" (Eggins, 2004, p. 269).

Overall, taxis and logico-semantic relations help to understand a clause as an entity with explicit links between and with implied functions to perform in the discourse. Thus I can examine the field of discourse through its constituent clauses to grasp the dynamics of the text and its meanings. Clusters of clauses that are thoroughly connected into complexes connote written (prepared) discourse. In contrast, less complex and more spontaneous clauses are more typical for the spoken discourse.

The content must be expressed in a way which makes clear its relationship to prior text, and which signals to us which part of the text is more / less important to an understanding of the overall text. Clauses need to be structured in ways which enable interactants to interpret the speaker's priorities and direction (Eggins, 2004, p. 295). 


\subsection{Interpersonal Metafunction Elements}

The categories in this section of analysis reveal the information to answer the questions:

- Who is doing the writing/ talking?

- Whom is the author writing / talking to?

- How is the dialogue being maintained in the discourse?

As an SFL analyst, I evaluate the degrees of reciprocity and interactive efficiency in a socio-cultural ambiance of the given discourse.

\subsubsection{MOOD and RESIDUE}

Through the creation of certain grammatical elements in the utterance, the speaker or writer becomes involved in the exchange of propositions. The clause contains two parts, the MOOD and RESUDUE. The MOOD component includes the Subject, finite and Polarity, for example:

\begin{tabular}{|l|l|l|l|}
\hline Students & are & taking & an examination. \\
\hline Subject & Finite / Positive Polarity (implied) & Predicator & Complement \\
\hline \multicolumn{2}{|c|}{ MOOD } & & RESIDUE \\
\hline
\end{tabular}

No clause exists without MOOD. The MOOD element as an entity contains three constituents:

1. an expression of polarity: either Yes (positive polarity) or No (negative polarity)

2. a nominal-type element, the Subject

3. a verbal-type element, the Finite (Eggins, 2004, p.150). 
This component carries the essential information about the exchange process.

Sometimes the Subject and / or the Finite (as constituents of MOOD) can be omitted but they are programmed as ellipsis in an English construction that makes the border between the clauses evident. Let us take a look at an example:

1) He is reading a book (in this case one clause can identified with one MOOD and one RESIDUE):

1) $\mathrm{He}($ Subject) $+\underline{\text { is (Finite) }}+\underline{\text { reading (Preqicator) }}+\underline{\text { a book (Compliment) }} \rightarrow 1$ clause

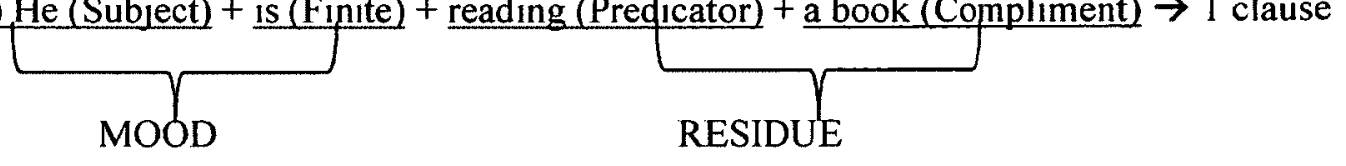

2) He is reading a book and eating some ice-cream (there are two clauses with two MOOD patterns and two RESIDUE patterns)

2) Clause 1:

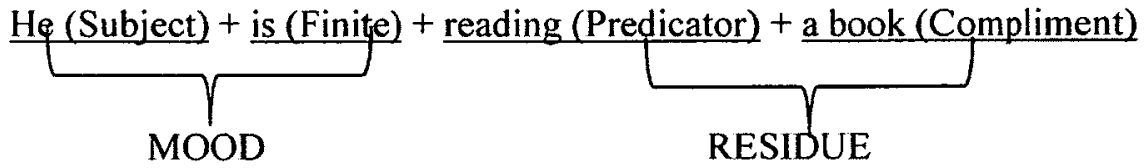

Clause 2:

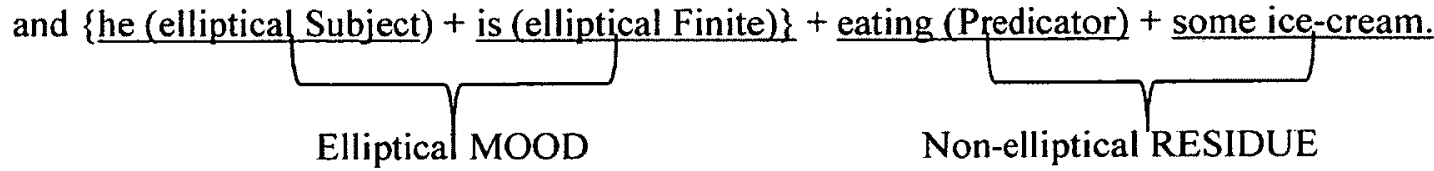

How do the MOOD constituents function in language utterances? The Subject is a nominal-type element. Following Halliday \& Matthiessen (2004) and Eggins (2004), the subject "realizes the thing by reference to which the proposition can be affirmed or denied" (p. 117 and p. 151 respectively). The Subject designates someone or something, 
being held responsible - responsible for the functioning of the clause as an interactive event (Halliday \& Matthiessen 1999, 2004; Eggins 2004). It is not difficult to detect the Subject element. It is the replacement for the pronoun in the tag clause of a tag question ('tag test').

Your friend can come, can't he? [Your friend (he) is the Subject]

The Finite element is expressed by a verbal group. In terms of the clause the Finite makes "the proposition definite, to anchor the preposition in a way that we can argue about it" (Halliday \& Matthiessen, 2004, p. 115; Eggins, 2004, p. 152). The tag test will identify it easily:

a) You are going with us, aren't you? ['Are' is the Finite]

b) You finished the assignment yesterday, didn't you? ['Did' indicates that the Finite is hidden in the 'finished']

\begin{tabular}{|l|l|l|l|l|l|l|}
\hline You & \multicolumn{2}{|l|}{ finished } & $\begin{array}{l}\text { the } \\
\text { assignment }\end{array}$ & yesterday, & didn't & you? \\
\hline Subject & Finite & Predicator & Complement & $\begin{array}{l}\text { Adjunct: } \\
\text { time }\end{array}$ & Finite & Subject \\
\hline \multicolumn{2}{|c|}{ MOOD } & \multicolumn{2}{|c|}{ RESIDUE } & \multicolumn{2}{|c|}{ MOOD } \\
\hline
\end{tabular}

The example B shows that the Finite can be packed with the Predicator in one graphical unit. This fusion is quite typical for contemporary English. Unlike the earlier periods of the English language, modern English makes frequent use of auxiliaries, which encapsulate the Finite, and are used in composite tense forms (Progressive, Perfect, Progressive Perfect forms), in negative and interrogative sentences.

In language, there are two types of the Finite: 
1. Temporal Finite Verbal Operators refer the proposition to time. These operators are used in either present, or past, or future tense forms.

2. Finite Modal Operators refer to modality, not time.

The Polarity element can be positive or negative. Obviously, it is seen only in the negative form with the particle 'not'. It looks like a supplement to the first two semantically foregrounded Subject and Finite. However, the evident preferences in choosing this or that polarity can add additional implications to consider in the analysis of a concrete discourse.

Finally, the RESIDUE components complete the picture of the clause seen through the interpersonal metafunction lens. The three components that should be remembered are the Predicator, Complement, and Adjunct. The Predicator "fills the role of specifying the actual event, action or process being discussed" (Eggins, 2004, p. 155). It completes tenses, grammar aspects, and voice forms. The Complement is an element that elaborates and brings clarity to clause MOODs though it is not mandatory. The Adjunct is a secondary element too. It adds more information to the MOOD in terms of circumstances. They can be expressed by nominal, adverbial, and prepositional groups. There are name the following classes of Adjuncts. The circumstances can be different (time, place, cause, manner, matter, agent, etc.):

- I saw him yesterday (TIME).

- He did that for fun (CAUSE).

- The lecturer talked about the mass media (MATTER).

- He was greeted by his friends (AGENT).

- He talks fast (MANNER).

The next point on the Adjunct list is the class of modal Adjuncts which express the category of judgment that is especially interactive in maintaining a dialogue in the 
discourse. In general, modals "can do this either by impacting directly on the MOOD element (by adding some qualification to the Subject / Finite), or indirectly, by merely adding an expression of attitude or making an attempt to direct the interaction itself" (Eggins, 2004, p. 160). The modal Adjuncts are divided into Mood Adjuncts, Polarity Adjuncts, Comment Adjuncts, and Vocative Adjuncts. Also, there is a separate class of textual Adjuncts, namely conjunctive adjuncts to provide clauses with cohesion and continuity adjuncts to introduce a signal response. What is interesting is that not all the Adjuncts belong to the RESIDUE. The interpersonal tissue of dialogue is rather subtle. Some adjuncts are constructs of the essential MOOD part. Some adjuncts belong to neither MOOD, nor RESIDUE.

Table 7. Types of Adjuncts

\begin{tabular}{|l|l|l|l|l|l|}
\hline Type & Sub-type & Meaning & Class of Item & $\begin{array}{l}\text { Location in } \\
\text { Analysis }\end{array}$ & Examples \\
\hline Ideational & circumstantial & $\begin{array}{l}\text { time, location, } \\
\text { manner, etc. }\end{array}$ & $\begin{array}{l}\text { prepositional } \\
\text { adverb }\end{array}$ & in RESIDUE & $\begin{array}{l}\text { now, at } \\
\text { school, } \\
\text { abruptly }\end{array}$ \\
\hline Interpersonal & mood & $\begin{array}{l}\text { probability, } \\
\text { usuality }\end{array}$ & adverb & in MOOD & $\begin{array}{l}\text { probably, } \\
\text { usually, } \\
\text { sometimes }\end{array}$ \\
\cline { 2 - 6 } & $\begin{array}{l}\text { polarity } \\
\text { comment }\end{array}$ & $\begin{array}{l}\text { positive or } \\
\text { negative }\end{array}$ & $\begin{array}{l}\text { yes/no } \\
\text { (elliptical) }\end{array}$ & in MOOD & -Yes. \\
\cline { 2 - 6 } & vocative & $\begin{array}{l}\text { nominating } \\
\text { next speaker }\end{array}$ & name & $\begin{array}{l}\text { not in } \\
\text { MOOD or } \\
\text { RESIDUE }\end{array}$ & John,... \\
\hline Textual & conjunctive & $\begin{array}{l}\text { logical linking } \\
\text { of messages }\end{array}$ & $\begin{array}{l}\text { cohesive } \\
\text { conjunction }\end{array}$ & $\begin{array}{l}\text { not in } \\
\text { MOOD or } \\
\text { RESIDUE }\end{array}$ & $\begin{array}{l}\text { thus, } \\
\text { however, } \\
\text { in conclusion }\end{array}$ \\
\cline { 2 - 6 } & continuity & $\begin{array}{l}\text { message } \\
\text { coming }\end{array}$ & $\begin{array}{l}\text { minor clauses } / \\
\text { adverbs } \\
\text { (yeh/nah) }\end{array}$ & $\begin{array}{l}\text { not in } \\
\text { MOOD or } \\
\text { RESIDUE }\end{array}$ & well, oh, yea \\
\hline
\end{tabular}

The Adjuncts are not compulsory but the clause loses the richness of the meaning without them. Eggins (2004) accurately describes their function as 'querying' (p. 160). 
Though they are not essential as Subjects, they complement the MOOD element. The RESIDUE, in general, and the adjuncts, in particular, reasonably question the other meaning-carriers in the clause. As it can be seen in Table 7, the classification of adjuncts reflects the tripartite SFL model.

\subsubsection{Mood}

The SFL approach distinguishes the indicative Mood (including the declarative and interrogative types) and imperative Mood. This element should not be confused with the MOOD element. At the same time they are connected as constructs of the one and the same Finite classification, belonging to the various delicacies, i.e. SFL branching:

Table 8. Mood

\begin{tabular}{|l|l|l|l|l|}
\hline Status & MOOD Type & Indicative Type & Interrogative Type \\
\hline Clause
\end{tabular}

The essence of the distinctions nests in the understanding of clause as exchange. On

the one hand, it can be the exchange of information. On the other hand, it can be the exchange of goods and services. The declaratives are offering information / goods / services. The typical declarative structure:

\begin{tabular}{|l|l|l|l|}
\hline She & read & an article & yesterday. \\
\hline Subject & Finite: Predicator & Complement & Adjunct: time \\
\hline
\end{tabular}

The Subject goes first and the Finite follows it. The Predicator, Complement, and Adjuncts are optional and usually placed in the RESIDUE pattern. The interrogative 
Mood is divided into two groups, polar interrogatives (yes / no questions) and WHinterrogatives (when, what, why, etc.). The structure has an inversion inside (with an exception of the question to Subjects with 'who' and 'what').

\begin{tabular}{|l|l|l|l|l|}
\hline Did & she & read & an article & yesterday? \\
\hline Finite & Subject & Predicator & Complement & Adjunct: time \\
\hline
\end{tabular}

The analysis of Mood is often 'swallowed' by the analysis of the MOOD element. It is an incentive to get acquainted with the concrete Finite and to start analyzing it in greater detail.

\subsubsection{Modality}

The modality is another essential element of the interpersonal aspects of text. The modality enriches 'yes / no'- categorization with many intermediate shades to have a productive dialogue. Halliday \& Matthiessen (2004) describe two variations of modality, modalization (propositions) and that is of modulation (proposals). Modalization means the distance between the positive and negative poles and its asserting / denying nature (Halliday \& Matthiessen, 2004). It encompasses degrees of probability and usuality. These degrees are articulated with the help of a modal verb (Modal Finite Operators mentioned above) or a modal adjunct. Modulation measures the distance between the Yes-No poles through "prescribing and proscribing" (Halliday \& Matthiessen, 2004, p. 147). It depends on the speech function, i.e. command or offer. Command ignites various degrees of obligation ('be allowed to'. 'be supposed to', 'be required to'). Offers represent degrees of inclination ('be willing to', 'be anxious to', 'be determined to'). The 
Value and Polarity categories will complete the paradigm of modality. Probabilities can range from 'high' (certain) to 'low' (possible).

Table 9. Modality as system

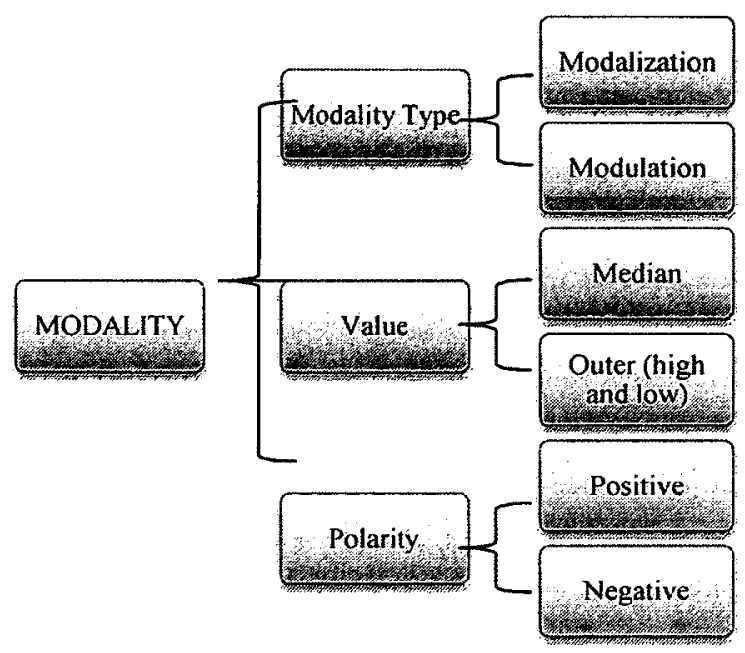

If modalization and modulation are realized efficiently in the discourse, the author can send them as signals to interact with the reader. As a whole, discourse is a cooperative phenomenon of initiating and responding.

\subsubsection{Attitudinal Items}

The category of attitudinal words is a little fuzzy. There are no restrictions on their grammar class or graphical image. The focus is on the connotation inside an item. The attitudes are quite explicit in colloquial speech:

It was a really cute little town. / We had such an awful day.

When attitudes are analyzed in a written text, the connotations are implied. The lexical environment helps to spot the positivity and negativity in words and phrases. The attitude is a very subtle matter and although my connotation decoding may seem 
subjective. I will provide evidence of positive and negative hints not in an isolated item but in a context.

It is by looking at how people use these systems of Mood and Modality in the clause they exchange with each other that we can see speakers making meanings about such interpersonal dimensions as: the power or solidarity of their relationship; the extent of their intimacy; their level of familiarity with each other; and their attitudes and judgments (Eggins, 2004, p. 184).

Evidently, the familiarity and intimacy seem to be quite far from the academic written text that is the scope of attention for my research. However, I would not agree that they are out of sight when the RA author creates his text. His attitudes and judgment get mingled with his interactive intentions of being closer and understandable to his reader. So he needs to think carefully about MOOD, Mood, Modality, Polarity, etc. to make his voice 'sound' loudly in the discourse.

\subsection{Textual Metafunction Elements}

In my analysis of the RA conclusion, the Textual Metafunction answers the question:

-What determines that this text is perceived as a unified and cohesive and coherent whole?

Nominalization, lexical density, Theme patterns, and cohesion are the three categories for the SFL analysis in my research that answer the above question. The texts express ideas and attitudes but cannot exist without explicit textual relations. The narrative is a flow of language items, united in meaning-making sequences and orders, which can be found by analyzing the textual meanings. The 'enabling' mission of this metafunction (Halliday \& Matthiessen, 2004; Eggins, 2004) is the last in the process of 
discourse construction. With it, I trace the stages of packing information into visual structural items with accordance with the discourse objectives and contexts.

\subsubsection{Nominalization}

This category is a 'stop' sign for analysts to dig deeper in the text. One and the same meaning can be articulated differently. Eggins (2004) asks to compare two sentences:

A) I handed (V) my essay in late because my kids got sick (V-Adj).

B) The reason $(\mathrm{N})$ for the late'submission $(\mathrm{N})$.of my essay was the illness of my children (Noun- preposition-Noun).

These sentences belong to different fields. The example $\mathrm{A}$ is more colloquial and accentuates the verbs. The example B makes the nominal groups more distinct. And that feature is not a mere coincidence. The author makes an intentional choice in favour of verb or noun domineering. In the example B there is only one verb and it is static ('to be'). "By turning what were verbs into nouns, sentence $[\mathrm{B}]$ is now able to express the logical relation between the two events although through a noun 'reason' which now becomes the point of the departure for the message [instead of the personal pronoun 'I']" (Eggins, 2004, p. 94). The Subjects 'I' and 'kids' are replaced by the abstract noun 'reason'. The two clauses become one. Processes are realized by actors in the structure.

Nominalization is a characteristic of written language. Eggins (2004) draws the line between the spoken and written discourses (p. 95):

\begin{tabular}{|l|l|}
\hline \multicolumn{1}{|c|}{ written language } & \multicolumn{1}{c|}{ spoken discourse } \\
\hline ideas, reasons linked by & human actors \\
relational processes & action processes \\
in condensed, dense sentence & dynamically related clauses \\
\hline
\end{tabular}


Academic written discourse is heavily nominalized (Halliday \& Matthiessen 2004;

Eggins, 2004). The abstract processes reign in the academic world and applied linguistics is not an exception.

Nominalization allows us to get away from the dynamic and usually real-world sequencing that goes with speaking, where we relate sequences of actions in which we featured as actors. By nominalizing actions and logical relations, we can organize our text not in terms of ourselves, but in terms of ideas, reasons, causes, etc. (Eggins, 2004, p. 95).

\subsubsection{Lexical Density}

The understanding of this category depends on the context. I will modify the initial way of calculating lexical density in the discourse. Eggins (2004) discusses the lexical density of a text with no specifications. Thus the content carrying items are considered all the meaningful parts of speech (verbs, noun, adjectives, adverbs, etc.). Prepositions, particles, articles, conjunctions, and auxiliaries are called non-content items. I will modify the approach to the lexical density in terms of an academic text with a narrow specification in analyzing the applied linguistic samples. So I consider AL terms as content-carrying items and non-terms as lexical units to support the specific-natured context. I will use calculations (quantitative research patterns) to conduct qualitative research point of view.

Table 10. Lexical density in a specific-natured discourse

\begin{tabular}{|l|l|}
\hline Lexical Density & AL Lexical Density \\
\hline Number of content-carrying items in text & No. specific content-carrying items (terminology) \\
Number of lexical items in text & Number of words in text \\
Total specific lexical density & Specific Lexical Density \\
\hline
\end{tabular}


The lexical density 'walks hand in hand' with nominalization. They complement each other in terms of discourse rhetorical organization. "Nominalization allows us to pack in more lexical content per sentence. Rhetorical organization of the kind made possible by nominalization becomes an option because written text is rehearsed, polished, redrafted" (Eggins, 2004, p. 96). Highly nominalized texts are more lexically dense (Halliday \& Matthiessen, 2004; Eggins, 2004). I will calculate the concentrations of terms in RA conclusions in applied linguistics to see the percentage of the terminological density in the AL conclusions. Taking into consideration these numbers, I can estimate the influence of the mode of a situation and textual metafunction implications on the discourse to justify their significance in language.

\subsubsection{Theme}

Theme is an important category to analyze the meanings of the textual metafunction. The factor of primary and secondary positioning is crucial in ThemeRheme patterns. Simultaneously, the word order becomes a material for SFL analysts that signals about cohesive interrelations in the clause and between clauses. When a clause is complete, it consists of two main constituents, the Theme and Rheme.

The Theme is described in SFL as the starting point that introduces what clause is going to be about (Halliday \& Matthiessen, 1999, 2004; Eggins, 2004). That is the given information for the readers because these items of this information have been already mentioned. In English where word order is a particular meaningful category the Theme has a double value. The Theme element becomes the key with which the rest of the clause can be unlocked. The rest of the clause is called the Rheme. 
There are also single and multiple (complex) Themes in the clauses of the four conclusions. In my data the Theme can be categorized, as follows:

Table 11. Theme in clause (Eggins, 2004, p. 299):

\begin{tabular}{|l|l|l|} 
THEME in CLAUSE & $\begin{array}{l}\text { single (topical Theme) } \\
\text { attitudinal (interpersonal Theme } \\
\wedge \text { topical Theme) } \\
\text { conjunctive textual Theme } \\
\text { topical Theme) } \\
\text { both (textual Theme } \\
\text { interpersonal Theme } \\
\text { Theme) topical }\end{array}$ \\
\hline
\end{tabular}

No clause can exist without a topical Theme. Eggins (2004) defines it as "the first constituent to which we can attach a transitivity role, such as Actor, Behaver, Senser or Circumstance" or action itself (p. 303). The other two types are optional. But with their presence the clause expands the Theme pattern. The interpersonal Theme is a Moodrelated (not Transitivity-related) item. These items can be Modal Adjuncts: Mood, Vocatives, Polarity or Comment. Textual Themes do not express any attitudes or experiences but they "are doing important cohesive work in relating the clause to its context" (Eggins, 2004, p. 305). This role is usually assigned to Continuity Adjuncts (oh, well, yeah, no) or Conjunctive Adjuncts (and, but, however, therefore, etc.).

I go to work by bicycle. (Topical)

Maybe you are right. (Interpersonal ^ Topical)

But in Australia the immigration policies are different. (Textual ${ }^{\wedge}$ Topical)

Theme choices are very important in interpreting the textual meanings. "Thematic choices realize meanings about the organization of the communicative event (how the 
text bangs together), and the experiential and interpersonal distance involved (how the text relates to its context)" (Eggins, 2004, p. 320). The Theme unites many layers and draws attention to the priority positions in the clause. Moreover the implications of Theme go beyond the clause (Martin 1987, 2000) in providing an opportunity to discover the typical organizing priorities and rhythms of sending portions of information. Thus the organization of the micro-level structure (Theme and Rheme in a clause) tells me about the way the author approaches to his text as an utterance.

To complete the description of the textual metafunction, it is necessary to look at cohesion categories for analysis. Cohesion refers to the internal organization of items, the way they are related and tied together as bits of discourse (Halliday\& Hasan, 1976; Eggins, 2004). These semantic ties, their reference and interdependence, can be traced in the text to understand what the actual textual tissue is made of and how the process of creation can be unfolded (Halliday \& Matthiessen, 2004; Halliday \& Hasan, 1976; Martin, 1987; Eggins, 2004). To be precise, my analysis identifies reference chains in the AL discourse to show how attentive the author is in making his discourse cohesive.

Therefore, the textual strand of meaning, while not adding a new reality altering interpersonal dimensions of the clause, is concerned with the potential the clause offers for its constituents to be organized differently, to achieve different purposes (Eggins, 2004, p. 298). Examining the nominal groups, sequence of terms, Themes, cohesion (including reference) I will be able to prove how order creates meanings in English academic texts. 


\subsection{Context and Data}

The context of research article writing draws a lot of attention in modern social sciences and humanities. Nowadays researchers all over the world publish their articles to establish their position and reputation in the academia. The Anglophone supremacy in academic writing has been commented on by Swales (2004):

While there is no doubt that English has become the worlds predominant language of research and scholarship, the extent of that predominance may have been exaggerated (Swales, 2004, p. 33).

However, the genre of a research article, no matter what language is chosen by the author, is of the utmost importance in all the scientific and scholastic branches. I scrutinize four branches of applied linguistics to showcase how the discourse is being construed step by step (or metafunction by metafunction). This analysis and its mapping stages can help researchers to build their conclusions efficiently and the RA readers to follow the content and structure elements to participate in an indirect dialogue. In fact, a research article conclusion is a short but multi-tier interaction as any other academic or non-academic part of the text.

Applied linguistics is chosen from both my own position in it as an active researcher (internal understanding of research reporting processes) and as a frequent reader of academic journal articles (external reviewer of other researchers' papers). This perspective helps me to identify choices in conclusions.

The data for the analysis include four conclusions from various $\mathrm{AL}$ journals to represent a scholastic variety within the field of one study. It will be analyzed qualitatively with quantitative elements to prove the findings. The selection criteria of the 
analytical material are of objective and subjective nature. There are three formal criteria of opting for the conclusions to analyze:

1. The chronological criterion: the $\mathrm{AL}$ articles written within the past two decades (the 90s and 2000s) to reflect the tendencies of AL discourse development at the border between two centuries.

2. The length: there were chosen two long (2 paragraphs, 9-11 sentences) and two short (1 paragraph, 5-6 sentences) conclusions to understand whether the number of sentences limit the meanings and implications.

3. The specific nature of discourse: the conclusions were selected as representatives of various AL branches (Academic Writing, ESP, CDA, and Language Acquisition) to see the ways applied linguists from different research domains realize their meanings in terms of the structure and semantics of the clause. 


\section{Chapter Four - SFL Analysis}

\section{TEXT I}

Author: Ken Hyland

Title: "Hedging in Research Articles"

Journal: Applied Linguistics

Year: 1996

\begin{tabular}{|c|c|c|}
\hline Sentence & Clause & TEXT 1 \\
\hline \multirow[t]{2}{*}{1} & 1 & I have argued \\
\hline & 2 & $\begin{array}{l}\text { that hedges in scientific texts are the result of informational, rhetorical, and } \\
\text { personal choices which cannot be fully understood in isolation from social } \\
\text { and institutional contexts. }\end{array}$ \\
\hline \multirow[t]{2}{*}{2} & 3 & Linguistic analyses alone cannot provide a rationale for such choices \\
\hline & 4 & $\begin{array}{l}\text { and the framework proposed here seeks to reflect this interpretive } \\
\text { environment. }\end{array}$ \\
\hline \multirow[t]{2}{*}{3} & 5 & $\begin{array}{l}\text { Research articles clearly reveal the relationship between a discourse } \\
\text { community, standards of knowledge, and textual representations, }\end{array}$ \\
\hline & 6 & and it is these in combination which motivate the use of hedges. \\
\hline \multirow[t]{2}{*}{4} & 7 & Hedges are abundant in science \\
\hline & 8 & and play a critical role in academic writing more generally \\
\hline \multirow[t]{2}{*}{5} & 9 & $\begin{array}{l}\text { They constitute an essential element of argumentation in presenting new } \\
\text { claims for ratification, }\end{array}$ \\
\hline & 10 & $\begin{array}{l}\text { and are among the primary features which shape the research article as the } \\
\text { principle vehicle for new knowledge. }\end{array}$ \\
\hline \multirow[t]{2}{*}{6} & 11 & $\begin{array}{l}\text { An understanding of their use therefore has important implications for a } \\
\text { number of areas }\end{array}$ \\
\hline & 12 & $\begin{array}{l}\text { and can contribute to the growing literature on the rhetoric of science, } \\
\text { revealing important insights into how science establishes its claim to } \\
\text { knowledge and how scientists carry out their work. }\end{array}$ \\
\hline \multirow[t]{5}{*}{7} & 13 & $\begin{array}{l}\text { Information about hedging can also advance our understanding of the } \\
\text { practice of evidential reasoning }\end{array}$ \\
\hline & 14 & and has practical consequences in ESP \\
\hline & 15 & where textbooks often emphasize the impersonality of scientific discourse \\
\hline & 16 & and either ignore hedges \\
\hline & 17 & or advise students to avoid them completely (Hyland, 1994). \\
\hline 8 & 18 & $\begin{array}{l}\text { Most importantly, however, the analysis demonstrates the dynamic and } \\
\text { interactive nature of scientific writing. }\end{array}$ \\
\hline 9 & 19 & $\begin{array}{l}\text { It contributes to a growing sociological and linguistic interest in } \\
\text { professional writing by providing a discourse analytic understanding of one } \\
\text { means by which scientific discourse is both socially situated and structured } \\
\text { to accomplish rhetorical objectives. }\end{array}$ \\
\hline
\end{tabular}




\subsection{Ideational Metafunction Analysis}

The systemic functional linguistic tri-metafunctional modal is used to analyze how language performs its functions in a particular RA framework. The primary research article is written for a specific purpose, i.e. to report the research results and to make appropriate conclusions out of these findings. The RA author considers "the choices when they write to exchange meanings with readers" (Young \& Fitzgerald, 2006, p. 16). If the RA writer takes into account the participants, processes, circumstances, attitudes, cohesions, and Themes, his thoughts will be expressed in the most precise and effective way. The systemic functional approach provides me with a set of parameters and questions that will triggers to my analytical interpretations of the author's intentions.

At the clause level, the verb is the best way to start analysis because it contains the gist of participants and events, radiating it to circumstantial exposure. Selecting a process type and configurations of participants is to represent experience in a particular way (Eggins, 2004, p. 253). Carrying out a transitivity analysis (Eggins, 2004) I will try to point out the dominant process types in order to get closer to the message that is being communicated by the writer-researcher.

In this conclusion the following groups of processes can be distinguished (see Appendix 2, p. 182):

\begin{tabular}{|ll|ll|}
\hline Material & 0 & Relational: identifying & $2(11 \%)$ \\
\hline Mental & $10(52 \%)$ & Existential & 0 \\
\cline { 3 - 4 } & & Behavioural & 0 \\
\hline Verbal & $2(11 \%)$ & Possessive & $2(11 \%)$ \\
\hline
\end{tabular}


Relational: attributive $3(15 \%)$

Total

19

It is obvious that the dominant process type is mental. Relational processes follow. Verbal processes are not many but they are significant. It is interesting to note that the mental processes are so influential that they include some verbs that could be mental and material in different contexts:

Provide a rationale

Play a critical role

Contribute to the growing literature

Advance our understanding

Demonstrate the dynamic nature

For example,

Most importantly, however, the analysis demonstrates the dynamic and interactive nature of scientific writing (clause 17 , sentence 8)

\begin{tabular}{|l|l|l|l|l|}
\hline $\begin{array}{l}\text { Most } \\
\text { importantly }\end{array}$ & however & the analysis & demonstrates & $\begin{array}{l}\text { the dynamic and } \\
\text { interactive nature of } \\
\text { scientific writing }\end{array}$ \\
\hline & & Actor & $\begin{array}{l}\text { Process: mental- } \\
\text { material }\end{array}$ & Goal \\
\hline
\end{tabular}

The verb 'to demonstrate' can be material under certain circumstances. In the context of this AL conclusion, it becomes a mental process. Out of 19 clauses, there are 2 clause simplexes, 7 sentences are paratactic, and six embedded clauses. Hyland's conclusion balances between independent parallel clauses ( 7 cases of parataxis) and hypotaxis (projection of an idea, expansions in enhancement). 


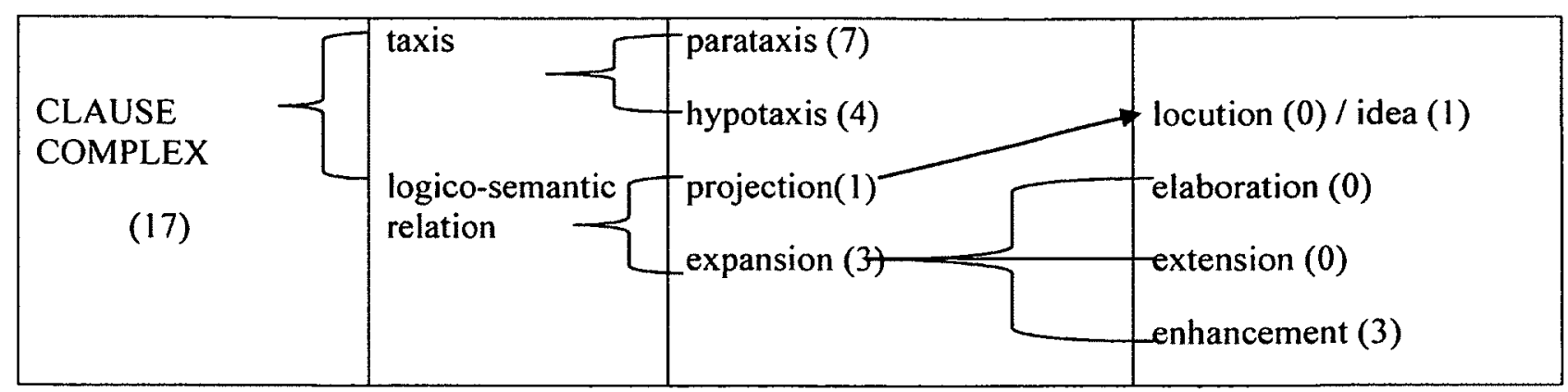

The following study of sub-components of experiential and logical connections within micro-structures of Hyland's RA conclusion can be regarded as discourse-specific. The discourse uses mental processes, clause complexes, and parataxis to highlight the problem of hedges as the central topic of this academic discussion.

\subsection{Interpersonal Metafunction Analysis}

The interpersonal stratum reveals the essence of the dialogue. Interpersonality is explicit in a spoken dialogue when the utterance receives an immediate answer. However, it is more implicit in a written form. Hyland's text is a multi-layered entity with an implied interaction in it which comes out of his being particularly reader-conscious text as we will see in the interpersonal analysis. The author invites his readers to embrace this indirect communication. This text reflects Bakhtin's theory of multi-voicedness or heteroglossia (Bakhtin 1981, p. 414).

"They [voices in discourse] penetrate one another and overlap one another from various dialogical angles. As a result of this meeting, new aspects and new functions of the word are revealed and come to the fore" (Bakhtin, 1973, p. 227).

Bakhtin considers that the combination of two energies in an academic text is a specific type of balancing. Following this concept, I approach the word as a semiotic message to start or continue a dialogue in the discourse. The synergetic potential of the 
word is similar to opening the door into academic discourse, that is a particular sociosemiotic universe with its own implications and between-lines. That means that the discourse, including the discourse of applied linguistics, is based on a dialogue. The interpersonal implications help the text to distribute social roles to language users, i.e. participants of this written interaction. The purpose of the upcoming linguistic observation is to reveal the dialogue in Hyland's research article conclusion. It is the conclusion section where the article writer has to send the final message and to make his reader-colleague react, that is agree, disagree, challenge, assert, contradict, offer, refuse, etc. (Halliday \& Matthiessen, 1999, 2004; Eggins, 2004). Dialogizing though text may seem to be obvious. But it is not enough to understand that text tries to speak to us and awaits readers' reactions. There is more to it than that.

Systemic functionalists distinguish such interaction constructs as speech role, in terms of commodity exchange, speech functions (Halliday \& Matthiessen, 2004; Eggins, 2004).

Table 12. Speech functions

\begin{tabular}{|l|l|l|l|}
\hline SPEECH ROLE & \multicolumn{2}{|l|}{ COMMODITY EXCHAGED } & $\begin{array}{l}\text { SPEECH } \\
\text { FUNCTIONS }\end{array}$ \\
\hline & Information & Goods and services & $\begin{array}{l}\text { Initiating or } \\
\text { Responding }\end{array}$ \\
\hline Giving & Statement & Offer & \\
\hline Demanding & Question & Command & \\
\hline
\end{tabular}

Having an individual voice in a dialogue, dialogue participants give information or demand it (speech roles). Doing this they indicate that they are dealing with a certain nature of information they are exchanging. The information can be information distilled 
or goods and services. "Cross-classifying these two dimensions of 'speech roles' and 'commodity', we can come up with the four 'basic moves' we can make to get a dialogue going" (Eggins, 2004, p. 145). Thus there appear notions of statement, question, offer, and command.

\begin{tabular}{|l|l|l|}
\hline Speech functions & Typical mood of clauses & Ken Hyland's text \\
\hline Statement & declarative Mood & $\begin{array}{l}\text { 5 statements and 4 mixed } \\
\text { (statement and } \\
\text { acknowledgement hybrids *) }\end{array}$ \\
\hline Question & interrogative Mood & 0 \\
\hline Question & imperative Mood & 0 \\
\hline Offer & modulated interrogative Mood & 0 \\
\hline Answer & elliptical declarative Mood & 0 \\
\hline Acknowledgement & elliptical declarative Mood & 4 mixed ( explained above) * \\
\hline Accept & minor clause & 0 \\
\hline Compliance & minor clause & 0 \\
\hline
\end{tabular}

*a sentence with a mix of statement and acknowledgement

The excerpt consists of 9 sentences, only one of which is a simplex. All these syntactic units are declarative. The intention of concluding foretells the high rates of declarative Mood. The interrogatives must be totally justified or avoided. Imperative Mood implies command that can be dissonant with the tone of concluding. So the number 9 for declaratives in form ( $100 \%)$ in Hyland's conclusion is explicable. The author's dedication to stating gives his text the air convincing confidence. An interesting transformation of statement can be found in sentences 4-7. I would call this phenomenon a statement-acknowledgement hybrid. This hybrid mixes the author`s confidence with some article Thematic foci to create a solid piece of mental conclusion with instructional implications. Hyland as an educator interweaves new information while stating his point of view. That makes his Conclusion section sound mentoring but not imposing. 
In sentences 4-7 the Subjects create an axis to combine non-elliptical declarative Mood (statement) and elliptical declarative Mood (acknowledgement):

Note: S stands for the Subject; [S] stands for the elliptical Subject

Sentence 4: The subjects are 'hedges' and elliptical 'hedges' (S+ are abundant and [S] play),

Hedges are abundant in science and play a critical role in academic writing more generally.

Sentence 5: We have the Subject-reference 'they' with one elliptical 'they' and

'which' as Subject-connector* (S+ constitute and [S] are among, $\mathrm{S}\left({ }^{*}\right.$ which $)+$ shape),

They constitute an essential element of argumentation in presenting new claims for ratification, and are among the primary features which shape the research article as the principle vehicle for new knowledge.

Sentence 6: "An understanding' is used in 1 non-elliptical and 1 elliptical structure.

Sentence 6: An understanding of their use therefore has important implications for a number of areas and \{an understanding\} can contribute to the growing literature on the rhetoric of science, revealing important insights into how science establishes its claim to knowledge and how scientists carry out their work.

Sentence 7: The Subject 'information' is used as non-ellipsis and ellipsis. It starts the sentence but it is implicit in the next clause. Importantly, the subject connects the previous author's Subjects through the noun 'understanding' as an Object ('understanding' is the Subject in sentence 6) and 'hedging' (Subject in sentence 4), specifying the type of information. Thus in sentence 7 , there are two pairs of parallel clauses with two elliptical structures (Subject-[elliptical S] where Subject- either [elliptical Subject], or [elliptical Subject]). Also two hybrid sets of stating and acknowledging are present, namely $\mathrm{S}+$ can advance and $[\mathrm{S}]+$ has consequences where [S] emphasize and either [S] + ignore, or [S]advise, 
Sentence 7: Information about hedging can also advance our understanding of the practice of evidential reasoning and has practical consequences in ESP where textbooks often emphasize the impersonality of scientific discourse and either ignore hedges or advise students to avoid them completely.

Thus, the statement is continuously developing, using a combination of speech roles, declarative statement and declarative acknowledgement in one sentence with 5 clauses.

Table 12. Mood in Text 1

\begin{tabular}{|l|l|l|}
\hline Sentence & Speech Role & Speech Function \\
\hline 1 & declarative Mood & statement \\
\hline 2 & declarative Mood & statement \\
\hline 3 & declarative Mood & statement \\
\hline 4 & declarative Mood + ellipsis (hedges) & $\begin{array}{l}\text { statement and } \\
\text { acknowledgement }\end{array}$ \\
\hline 5 & declarative Mood + ellipsis (they) & $\begin{array}{l}\text { statement and } \\
\text { acknowledgement }\end{array}$ \\
\hline 6 & $\begin{array}{l}\text { declarative Mood + ellipsis (understanding) + non-ellipsis } \\
\text { (science v scientists) }\end{array}$ & $\begin{array}{l}\text { statement and } \\
\text { acknowledgement }\end{array}$ \\
\hline 7 & $\begin{array}{l}\text { declarative Mood + ellipsis (information [about hedging]) } \\
\text { (textbooks) }\end{array}$ & $\begin{array}{l}\text { statement and } \\
\text { acknowledgement }\end{array}$ \\
\hline 8 & declarative Mood & statement \\
\hline 9 & declarative Mood & statement \\
\hline
\end{tabular}

Instead of repetition, Hyland chooses the tactics of elliptical declaratives that shift attention to the verbs and give more space to communicative meaning elaborations. It occurs in the middle of the conclusion. This duality of speech functions in sentences 4-7 is a great contributor to the whole design of Hyland's conclusion. He announces the main ideas of this article reminding his preceding research by referring his sentence 7 to his own source dated back in 1994. That is an excellent example of the marked voice as Eggins (2004) calls a phenomenon of declaratives with implications. Declaratives in 
Hyland's conclusion serve as explicit grammar models to generate meanings beyond the well-formed structures.

To continue to analyze the micro-structures of Hyland's conclusion, it is important to interpret the MOOD/RESIDUE element, one of the essentials in the interpersonal metafunction. Eggins (2004) explains that "to discover which parts of the clause constitute the MOOD element, we ask which part of the clause cannot disappear when the responding speaker takes up his/her position' (p. 150). According to systemic functional theory of language, the MOOD contains the Subject, Finite, and Polarity as we have seen. The RESIDUE constituents are Predicator, Complement, and Adjuncts.

Also, it is important to return to the point I started with - the dialogue in Hyland's conclusion. The function of the analyzed excerpt is to finalize. That intention predicts the choice of mood, the structure of MOOD and RESIDUE, the balance of positive and negative polarities, modalities, and modulations. He gives his statements and supports them, initiating the process of exchange. And this process is well balanced and properly organized. Out of 21 Finites:

\begin{tabular}{|l|l|}
\hline & Finites \\
\hline Polarity & 18 positives and 1 negative \\
\hline Temporal Finite Verbal Operators & 17 temporal finite operators \\
\hline Finite Modal Operators & 2 finite modal operators \\
\hline
\end{tabular}

Explicit subjects: 13 / Elliptical Subjects: 6

Finite + Predicator (as one fused unit): 9

Finites without Predicators: 4

Finite and Predicator as separate units: 6 
The author states and acknowledges, building up his final argumentation summary. The temporal operators outnumber the modal ones that showcase the writer's confidence. In sentence 2 I find two modal verbs 'can' with a negative particle 'not' to express the inability of the isolated contexts to provide us with the comprehensive view on hedges. In sentences 6 and 7, there appear modal verbs again but in their positive forms ('understanding can contribute and can advance'). This positive modality directs the reader's attention to the author's message about the important role of hedging in academic writing.

Sentence 6: An understanding of their [hedges] ... can contribute to the growing literature on the rhetoric of science, revealing important insights ... Information about hedging can also advance our understanding of the practice of evidential reasoning...

The RESIDUE element seems to be not overloaded which adds more points to the comprehensibility of the conclusion section. There are 6 Predicators that are separate units and 9 forms that represent a fusion of the Finite and Predicators. In 19 clauses, there are 18 Compliments (see Appendix 2, p. 180). This number is quite high (15 clauses have compliments out of 19). The structure 'Subject + Verb + Object' is widening the message of the unit. With the help of compliments Hyland 'knits' his discourse together. Ideas are more significant than actions in the conclusion. Verbs are used to make a conclusion and to make a personal statement supported with scientific evidence.

Most circumstantial adjuncts in this text are phrasal unit with a preposition and a noun. In addition, many adjuncts (as well as complements) are loaded with embedded clauses. This way of articulating location, time, manner, etc. are characteristics of academic, not colloquial, discourse. Conjunctive adjuncts help textual cohesion relations to sound rhetoric and logical. The academic dialogue is not explicit, so I expected not to 
find any vocative adjuncts that usually reflect an immediate response. But the dialogic intentions are of great importance in academic discourse though they are not always that evident.

The readers' views are politely and collaboratively taken into account; but collaboration is a two-way process, and the readers are therefore encouraged to take part in the interaction and to collaborate back, by accepting, even if only provisionally, the roles, stances and arguments that are attributed to them. ...In academic written text, interactional resources are less salient, but they still play an essential role (Thompson, 2001, p. 62).

The communicative implications should be understood widely. The interpersonal metafunction is multi-layered and includes not only grammar forms but socio-sematic contexts. It is a complex network of various types of interrelations, i. e. the writer-the reader, the text- the context, the form -the meaning, etc. There are several levels (Halliday \& Matthiessen, 2004), notably social-contextual, semantic, and grammatical, that are to be considered in the interpersonal dimension as we have seen.

Ken Hyland's conclusion manages to instruct and to create reciprocity simultaneously. The RA author succeeds in both directions. Being straightforward and precise, he claims the importance of hedging and he uses hedging himself. There is the introductory clause 'I have argued', 1 mood adjunct 'often', 3 conjunctive adjuncts ('therefore', 'also' and 'however') that have the implications of hedging in themselves. However, his mentoring is inexplicit and thus may be more efficient. The readers are professional applied linguists and need a specific approach. Imperatives and interrogatives will hardly be tolerated. Hyland uses hedges and shows how effective they are in his own context. In addition, the author balances between complexity of academic discourse and clarity of conclusion. His structures are uniform in terms of the 
complements and adjuncts (they are present almost in every clause but not piled on each other). In this conclusion the speech roles in a dialogue are distributed. Hyland creates this dialogue and orchestrates it perfectly. The readers receive the information, categorize it and follow the author's 'first violin'.

\subsection{Textual Metafunction Analysis}

The participants in an academic writing discourse create a linear dimension of textual configurations to negotiate (Eggins, 2004) situational meanings. This metafunction is characterized by Halliday $(1999,2004)$ as the 'enabling' one. As Eggins (2004) states, "this is the level of organization of the clause which enables the clause to be packaged in ways which make it effective given its purpose and its context" (p. 298). Thus the textual metafunction supports the ideational and interpersonal ones, helping the Receiver to recognize cohesive links in the right order to get at the semantic whole.

Ken Hyland's text is an example of written, formal, AL-natured discourse of conclusions in the journal article. Obviously the conclusion is not supposed to share some new information with the reader. However, each clause starts with Theme (given) and Rheme (new), which structures the information in all the 9 sentences in Ken Hyland's RA conclusion.

Following Halliday \& Matthiessen (1999, 2004), Eggins (2004), Theme is the element which serves as the starting point for the message. That correlates with the criterion 'the given information'. Considering the way the given information is introduced in Hyland's conclusive sentences, I will talk about topical, interpersonal, and textual (structural as a subtype) types of THEME. It is important to mention that the 
thematic classification reflects an overall tri-functional system in text-linguistic analysis. The topical Theme corresponds with the Ideational metafunction. As Eggins (2004) states, it "is a constituent to which we can attach a transitivity role, such as Actor, Behaver, Senser or Circumstance" (p. 302). That is the projection of the experiential aspect in the text. Every sentence must have the topical Theme because it provides the syntactic structure with the meaning. The interpersonal Theme is obviously linked to the interpersonal level. The textual Themes serve as links between clauses and statements in the text.

10 out of 19 clauses have multiple Themes (the multiple type 'Textual + Topical' Theme pattern dominates). All the Theme types are involved in the process of concluding. Hedging as an interpersonal aspect expresses the author's opinion ('most importantly'). Textual Themes ('and', 'or', 'however', etc.) function as logical connectors, contributing to the conclusion's clarity and cohesion. Topical Themes are compulsory.

Topical Themes can be divided into several groups in the given excerpt: topical Themes, structural-topical Themes, notably 'that' in relative clauses and 'which / who' as Subjects - connectors as the "link [that] is created through the use of the relative pronoun and should be analyzed a conflation (fusing) of topical meaning" (Eggins, 2004, p. 315 316), elliptical topical Themes, and topical Themes with the preceding structural connector:

\begin{tabular}{|l|l|l|}
\hline Type & N & Hyland's Conclusion (Text 1) \\
\hline Topical Themes & 11 & $\begin{array}{l}\text { / / linguistic analysis / the framework / research articles / it / hedges / } \\
\text { they / an understanding of their use / information about hedging / the } \\
\text { analysis / it }\end{array}$ \\
\hline
\end{tabular}




\begin{tabular}{|l|l|l|}
\hline $\begin{array}{l}\text { Structural-Topical } \\
\text { (TH-Theme) }\end{array}$ & 1 & that hedges \\
$\begin{array}{l}\text { Structural-Topical } \\
\text { (WH-Theme) }\end{array}$ & 1 & where \\
\hline $\begin{array}{l}\text { Elliptical Topical } \\
\text { Themes }\end{array}$ & 6 & $\begin{array}{l}\{\text { \{hedges / they / an understanding of their use / information about } \\
\text { hedging / textbooks / textbooks }\end{array}$ \\
\hline
\end{tabular}

Topical Themes (19) bear the meanings and are absolutely obligatory for a clause structure in a sentence. Almost half of the non-elliptical topical Themes (6) have their 'twins' as ellipses:

Clauses 10 and 11: they [hedges] - \{they\}

Clauses 13 and 14: an understanding of their use - \{an understanding of their use \}

Clauses 17 and 18: information about hedging - \{information about hedging\}

Clauses 19,20 and 21: where [meaning textbooks] - \{textbooks\} - \{textbooks\}

The discourse has meaningful cycles that function as compasses for the reader's perception. The Themes are often repeated in one sentence. That is how the given information is being widened and elaborated gradually. The diversity within one topical group is an interesting fact to notice. The author has one topical dominant 'hedging'. It is supported by the reference (pronoun 'they'), structural replacements ('which'), and miscellaneous AL accompaniment elements ('linguistic analysis' of hedging, 'framework' of using hedges, 'understanding of their use', etc.). All the topical elements work for one function to make the element 'hedging' textually prominent.

Looking at the general picture of the Theme component in the discourse shows the following result. 
Table 14. Theme in Text 1

\begin{tabular}{|c|c|c|c|c|}
\hline Sentence/ & \multicolumn{2}{|c|}{ THEMES: Textual } & \multirow{2}{*}{$\begin{array}{l}\text { Interpe } \\
\text { rsonal }\end{array}$} & \multirow{2}{*}{$\begin{array}{c}\text { Topical } \\
\mathbf{A}\end{array}$} \\
\hline $1 / 1$ & $I$ & & & \\
\hline $1 / 2$ & that hedges & & & $\mathbf{\Delta}$ (structural-topical) \\
\hline II $/ 3$ & Linguistic analysis & & & $\Delta$ \\
\hline II $/ 4$ & and the framework & $\Delta$ & & $\Delta$ \\
\hline III $/ 5$ & research articles & & & $\Delta$ \\
\hline III $/ 6$ & and it & $\Delta$ & & $\Delta$ \\
\hline IV / 7 & hedges & & & $\Delta$ \\
\hline IV / 8 & and (hedges) & $\mathbf{A}$ & & $(\mathbf{\Delta})$ \\
\hline $\mathrm{V} / 9$ & they & & & $\Delta$ \\
\hline$V / 10$ & and (they) & $\Delta$ & & $(\mathbf{\Delta})$ \\
\hline $\mathrm{VI} / 11$ & an understanding of their use & & & $\Delta$ \\
\hline $\mathrm{VI} / 12$ & and (understanding) & $\mathbf{\Delta}$ & & $(\mathbf{A})$ \\
\hline $\mathrm{VII} / 13$ & information about hedging & & & $\Delta$ \\
\hline $\mathrm{VII} / 14$ & and (information) & $\Delta$ & & $(\Delta)$ \\
\hline VII / 15 & where & & & $\Delta$ (structural-topical) \\
\hline VII / 16 & and (textbooks) & $\mathbf{A}$ & & $(\mathbf{\Delta})$ \\
\hline VII / 17 & or (textbooks) & $\Delta$ & & $(\mathbf{A})$ \\
\hline VIII / 18 & $\begin{array}{l}\text { most importantly, however, } \\
\text { the analysis }\end{array}$ & $\overline{\mathbf{A}}$ & $\mathbf{A}$ & $\boldsymbol{A}$ \\
\hline $\mathrm{IX} / 19$ & it & & & $\Delta$ \\
\hline & Total: & 10 & 1 & 19 \\
\hline
\end{tabular}

So Interpersonal Themes are used moderately. But I would not say that this category is insignificant in Hyland's discourse. There are some shades of interpersonality in the first clause 'I have argued' (as a modified hedging 'I argue'), in the textual transition 'however' (connecting clauses and initiating an argument)._In other words, interpersonal Themes are not many but interpersonal motifs are hidden in the texture of the text. Textual Themes are to maintain the cohesion between clauses and concepts. I think their use is an obvious signal of a cohesive conclusion. However, Hyland widens the boarders of conclusions, saying 'we have stated this but we should keep in mind some additional factors'. And I cannot help mentioning an astonishing number of the coordinating conjunction 'and' in Hyland's context. I interpret that fact as a sign of the 
utter balance in communicating the author's message. The distance between the writer and the reader is neither long, nor short. Using various types of topical Themes and exploiting textual Themes, the author contributes to the interactive nature of his text. $\mathrm{He}$ establishes a medium spatial distance in which the roles are assigned.

Lexical density is another criterion that is used to evaluate the efficiency of the textual organization. I will discuss the density of the specific lexical items, AL terms. To be fair, the author does not inundate his RA with AL terminology but he persistently accentuates the main idea of his article - 'hedging'. The text has 3 words 'hedges', 1 'hedging', and two pronouns 'they', non-elliptical and elliptical ones, to substitute 'hedges'. That is 6 direct and indirect references to the key notion of Hyland's research. Other specific field vocabulary units can be positioned between the applied linguistic and general academic discourses. That creates an effect of comprehensibility.

Table 15. Specific lexical density in Text 1

\begin{tabular}{|l|l|}
\hline & Text 1 \\
\hline $\begin{array}{l}\text { No. of specific content- carrying lexical } \\
\text { item in text }\end{array}$ & 91 \\
\hline No. of lexical items in text & 259 \\
\hline Total Specific Lexical Density & $35 \%$ \\
\hline
\end{tabular}

Applied linguistics is presented by such lexical entities as 'linguistics analysis', 'social context', 'textual representations', 'impersonality of scientific discourse', 'dynamic and interactive nature of scientific writing', 'socially situated and structured'. However, they are balanced with general linguistic or widely academic terms:

Informational, rhetorical, and personal choices / provide a rationale for choices / community/ knowledge / argumentation / primary features / evidential reasoning / 
practical consequences / growing sociological and linguistic interest / analytic understanding / rhetorical objectives

The examples given above are terms that are used in many fields in the academic discourse. They cannot be labeled as applied linguistics terminology. However, they are part of the language of academia and will be counted as specific content items with consideration of their broader scientific usage. For example,

Personal choices (term in psychology, psychiatry, etc.) - personal choices in $\mathrm{AL}$ (meaning choices in articulation made by the language user to perform a certain function in speech)

Community (sociological term 'a group of individuals') - community in AL (meaning a collective of language users)

Evidential reasoning (a philosophical term 'thinking with logics and evidence) - evidential reasoning in AL (meaning 'interpreting the items with evidence from language practices)

The tendency to broaden the AL terminology dimension can also be detected in metaphors rooted in politics (ratification) and mechanics (principle vehicle for new knowledge). The author uses academic verbs ('propose, seek, provide, motivate, play a critical role, constitute, contribute, establish, carry out, advance, emphasize, accomplish') to link huge groups of nominalizations. Nominalization is the dominant trait in Hyland's conclusion. Nominalized units are obvious signals of elaborately organized academic textual environment. The preposition 'in' is as active as the preposition 'of'. The prepositions 'for', 'on', 'into', and 'to' are important cohesive elements as well.

\begin{tabular}{|l|l|}
\hline In-Phrases & Of-Phrases \\
\hline in isolation from context & $\begin{array}{l}\text { element of argumentation } \\
\text { understanding of use } \\
\text { interest in writing }\end{array}$ \\
$\begin{array}{l}\text { understanding of practice of reasoning } \\
\text { understanding of means }\end{array}$ \\
\hline
\end{tabular}


For instance, there is a perfectly organized 2-level nominalized group 'an element of argumentation in presenting new claims for ratification' in sentence 5. Despite its complex structure, the phrase is absolutely congruent. Hyland alludes to his reader, establishing the academic status of his discourse through a collection of Themes, bundles of nominalizations and $35 \%$ terminology concentration.

The use of pronominal references is limited. The pronoun 'they' (one explicit case, one elliptical 'they', and one 'them') channels 'hedges'. The possessive adjectives are more frequent (their, its, our). But the determiner 'which' is significant throughout the text (sentences 3, 5, and 9). Hyland's preference of 'which' is his choice of compact forms for several functions. Unlike pronouns, the determiner 'which' contains both elements, that is of categorization (similar to articles) and that is of referring (similar to pronouns). The complex 'which' works very productively in the textual tissues of Hyland's text. It determines the connections between the previous and current ideas in context and cements the clause structure as the Subject or Circumstance (by which). This AL conclusion is cohesive for several reasons, not least of which is the fact that the nouns are easy to trace, being presented explicitly as subjects, objects and circumstantial nominalized clusters. The final sentence starts with the pronoun 'it'. The anaphoric reference of this pronoun belongs to the previous noun 'analysis' but can be also associated with 'the nature of scientific discourse' and includes a particle of the conclusive impersonality.

To summarize, there are cohesive relations in forms of vocabulary nominalized chains, elliptical structures, and anaphoric reference. Multiple Themes units, consisting of Topical, Interpersonal and Textual Theme items, supplement Hyland's "discussion very 
helpfully as the connection between parts of a message" (Young \& Fitzgerald, 2006, p. 115). A reasonable number of pronominal and possessive substitutes showcase the author's willingness to be completely clear in his conclusion. 


\section{Chapter Five - Text 2}

\section{TEXT 2}

Authors: Desmond Allison, Linda Cooley, Jo Lewkowicz, and David Nunan

Title: "The development of a dissertation writing support program for ESL graduate research students"

Journal: English for Specific Purposes

Year: 1998

\begin{tabular}{|c|c|c|}
\hline Sentence & Clause & TEXT 2 \\
\hline 1 & 1 & $\begin{array}{l}\text { Research amongst supervisors and graduate students at UHK, the numbers } \\
\text { of students registering for the writing program that was induced, students' } \\
\text { positive reactions to the program and the growing number of graduate } \\
\text { students attending the English Centre's one-to-one Writing Support Service } \\
\text { have combined to show that there is clearly a need for a writing program to } \\
\text { become a regular feature of graduate life at the university. }\end{array}$ \\
\hline 2 & 2 & $\begin{array}{l}\text { In this paper, we have described the development of a program to help } \\
\text { NNS research students develop skills in planning, drafting, and revising } \\
\text { their theses. }\end{array}$ \\
\hline 3 & 3 & $\begin{array}{l}\text { The program evolved from a grounded investigation into the problems } \\
\text { encountered by students in their struggle to produce a thesis in a language } \\
\text { other than their own. }\end{array}$ \\
\hline 4 & 4 & $\begin{array}{l}\text { Data for this investigation came from interviews with supervisors, } \\
\text { students' questionnaires and an analysis of student writing. }\end{array}$ \\
\hline 5 & 5 & $\begin{array}{l}\text { The initial study, as indicated above, revealed shortcomings in four main } \\
\text { areas which can be summarized as follows: } \\
\text { 1. A failure to organize and structure the thesis in a way which made } \\
\text { the objectives, purpose and outcomes of the research transparent to } \\
\text { the reader, and a failure to create "a research space"; } \\
\text { 2. A failure to substantiate arguments with evidence from the } \\
\text { literature and a tendency to make claims for own research findings } \\
\text { which were too strong or overgeneralized; } \\
\text { 3. An inability to organize information at the level of the paragraph, } \\
\text { to show relationships and to develop texts in functionally } \\
\text { appropriate ways; } \\
\text { 4. 'local' problems to do with editing, spelling, grammar and } \\
\text { bibliographical referencing. }\end{array}$ \\
\hline \multirow[t]{2}{*}{6} & 6 & While, at first sight, local errors were the most evident, \\
\hline & 7 & $\begin{array}{l}\text { by far the greatest number of communication problems occurred at the } \\
\text { macro-level of audience, purpose and overall structuring. }\end{array}$ \\
\hline 7 & 8 & $\begin{array}{l}\text { Hence the diagnostic framework and the resultant writing program were } \\
\text { designed to focus primarily on these macro-level problems. }\end{array}$ \\
\hline \multirow[t]{2}{*}{8} & 9 & $\begin{array}{l}\text { A limitation of the work that has been reported here is its situation-specific } \\
\text { nature - }\end{array}$ \\
\hline & 10 & although this is in some ways a strength. \\
\hline
\end{tabular}




\begin{tabular}{|l|l|l|}
\hline 9 & 11 & While we have expressed a degree of confidence \\
\hline & 12 & $\begin{array}{l}\text { that the approach we have described will be applicable in work with NNS } \\
\text { research students in other situations, }\end{array}$ \\
\hline & 13 & $\begin{array}{l}\text { we are sure } \\
\text { that adaptations will prove to be necessary. }\end{array}$ \\
\hline 10 & 15 & $\begin{array}{l}\text { Indeed, some changes have already been implemented in subsequent } \\
\text { workshops at UHK }\end{array}$ \\
\hline 11 & 16 & $\begin{array}{l}\text { and research is continuing into ways in which students can be assisted } \\
\text { further with the challenging task of writing a dissertation in a second or } \\
\text { foreign language. }\end{array}$ \\
\hline & 17 & $\begin{array}{l}\text { Yet we believe } \\
\text { that the focus on extended texts and the macro-level of writing as } \\
\text { emphasized in this paper are essential }\end{array}$ \\
\hline & 18 & $\begin{array}{l}\text { if students are to go beyond improving their writing at the sentence level } \\
\text { and actually enhance the quality of their dissertation writing. }\end{array}$ \\
\hline
\end{tabular}

\subsection{Ideational Metafunction}

The micro-structures that are the scope of the attention in my analysis are an important architectural brick in the research article (RA) genre. These structures realize a human being's semantic choices. At the micro-level, the human language abilities are evident if the appropriate strategies, as is evident through SFL tri-functional model. Here, I will also analyze the forms and types of processes (Transitivity), lexical domains, and clause design looking at the article ideationally. Thus I can describe how Allison and his co-authors place the results of their language experiment into logico-experiential dimension of the RA conclusion.

Desmond Allison's article is different from Ken Hyland's. Allison wrote the article in collaboration with 3 co-authors Linda Cooley, Jo Lewkowicz, and David Nunan. Unlike Hyland's theoretical topic about academic hedging, Allison's article describes the results of a real-life linguistic experiment. Allison and his co-authors participate in discussions on improvement in dissertation writing. The message is sent to those who are 
educating and to those who are being educated. The sentences are structured with 6 simplexes and 5 complexes. All the eleven sentences are declarative. There are no interrogatives or direct commands. The first sentence is rather long, though it is a clause simplex. It encompasses 3 Sensers attached to the mental process 'combine':

Sentence 1: Research amongst supervisors and graduate students at UHK, the numbers of students [[registering for the writing program [[that was induced]] / ]], students' positive reactions to the program and the growing number of graduate students [[attending the English Centre's one-to-one Writing Support Service]] have combined to show [[that there is clearly a need for a writing program to become a regular feature of graduate life at the university]].

\begin{tabular}{|l|l|l|}
\hline $\begin{array}{l}\text { Research' amongst supervisors and graduate students at UHK, the } \\
\text { numbers of students }{ }^{2} \text { [[registering for the writing program [[that was } \\
\text { induced]] / ]], students' positive reactions to the program and the } \\
\text { growing number of graduate students [[attending the English Centre's } \\
\text { one-to-one Writing Support Service]] }\end{array}$ & $\begin{array}{l}\text { have } \\
\text { combined }\end{array}$ & $\begin{array}{l}\text { to show } \\
\text { [[that there is } \\
\text { clearly a } \\
\text { need...]] }\end{array}$ \\
\hline Sensers 1, 2,3 & $\begin{array}{l}\text { Process: } \\
\text { mental }\end{array}$ & $\begin{array}{l}\text { Phenomenon: } \\
\text { fact }\end{array}$ \\
\hline
\end{tabular}

Also, it is extended with 4 embedded clauses ( 2 participle phrases and 2 rankshifting units), and 5 attributes (graduate, writing, positive, growing, one-to-one). After that, there are 4 simplexes. Sentence 5 (a simplex with 4 embedded clauses and a list) is the 'equator' of the text. Moreover, it attracts the reader's attention because of its unconventional format. It contains a list with numerated pitfalls in dissertation writing. The structure is overloaded intentionally, to my mind. Allison and co-authors establish a straightforward relationship with their reader. The beginnings of sentences 1-4 are preparing for perceiving list of 'dangers' (in sentence 5) to deal with in the dissertation process, notably such lexical items as 'research / students / reactions / students attending 
UHK Writing Support Service / in this paper, we / the program / data'. The authors start with the project results and reveal the initial failures that were struggled against afterwards. It is a psychological method that reminds me of a doctor's appointment. First, the doctor starts an appointment with positive results of treatment and returns a bit later to the disease symptoms that are nearly gone now. The fifth sentence describes these 'symptoms' of an unsuccessful graduate paper. The climax in sentence 5 is followed by a clause simplex in sentence 7 . The last four sentences represent hypotactic complexes.

Verbs are of a great importance in these circumstances. They are guiding the reader through the WSS project ups and downs. A verb is one of the most efficient ways to transmit an instruction. However, this instruction can be expressed explicitly and implicitly. Instruction is not always an imperative. The intention of motivating lies behind any verbal form in an instructional text.

The process types are diffused in Allison and his co-authors' conclusion as follows (see Appendix 2, p. 194):
1) Mental - 10
2) Material - 0
3) Verbal processes -2
4) Relational attributive processes -4
5) Relational identifying processes -3
6) Relational circumstantial process - 1
7) Existential - 0

The highest number refers to mental processes (10) and it is similar to Hyland's conclusion. That is an effective way to conclude the intellectual work and cognitive results in the AL discourse. The number of verbal processes is 4 because the authors are reporting the experiment results in the article and its conclusion. Attributions are as often as verbalizations in the transitivity of this conclusion (sentences 2 and 9). The Attributes 
are represented by the following characteristics 'too strong or overgeneralized', 'the most evident', 'sure', 'essential'. Interestingly, attributive relations are established in the second half of the conclusion (sentences 6,9, and 11). The identifying processes are not numerous (2):

Sentence 8: A limitation of the work [[that has been reported here]] is its situation-specific nature - although this is in some ways a strength.

The verb 'continue' is used in an unusual Present Progressive form to underline the potential longevity of the program:

Sentence 10: Indeed, some changes have already been implemented in subsequent workshops at UHK and research is continuing into ways in which students can be assisted further with the challenging task of writing a dissertation in a second or foreign language.

This is a subtype of the relationals that is called the relational circumstantial process. "Circumstantial relational processes encode meanings about circumstantial dimensions: location, manner, cause, etc." (Eggins, 2004, p 245). In this case the time is the focus. The research is presented as an important activity with long-term perspectives, with its present and future.

In addition to verbs in finite clauses, Allison's conclusion is dotted with 16 infinitives. Some of them are located in the embedded clauses while the rest acts as circumstances. Their number is so considerable for an eleven-sentence conclusion section that it cannot be unnoticed:

Sentence 1: Research amongst supervisors and graduate students at UHK, the numbers of students registering for the writing program [[that was induced]], students' positive reactions to the program and the growing number of graduate students [[attending the English Centre's one-to-one Writing Support Service]] have combined to show [[that there is clearly a need for a writing program to become a regular feature of graduate life at the university]]. 
Sentence 3: The program evolved from a grounded investigation into the problems [[encountered by students in their struggle to produce a thesis in a language other than their own]].

Sentence 5: a failure to organize / failure to create "a research space" / failure to substantiate arguments / tendency to make claims/ inability to organize / to show relationships / to develop texts / problems to do with editing

Sentence7: Hence the diagnostic framework and the resultant writing program were designed to focus primarily on these macro-level problems.

Sentence 9: ... we are sure that adaptations will prove to be necessary

As the reader can see, the first three infinitives are to create settings and motives for the experiment described in the RA. Sentence 5 has a concentration of infinitives and the final statements provide us with opening perspectives. The choice of nominal groups (in majority, except 'designed to focus', 'prove to be necessary') with infinitive extensions is a conscious choice of describing the stepping stones in the Writing Support Service project.

/Concept appears/: a need for a writing program to become a regular feature of graduate life

/Concrete objectives/: to help NNS research students to develop skills in planning, drafting, and revising their theses

/Challenge appears/: struggle to produce a thesis

/Reasons for being challenging/: failure to organize, failure to create a research space, failure to substantiate arguments, tendency to make claims, inability to organize information, to show relationships, and to develop texts, problems to do with editing, spelling, grammar, and referencing

/Measures are taken/: diagnostic framework and resultant writing program were designed to focus on macro-level problems

/Program improvement is needed/: adaptations will prove to be necessary

/Perspective development/: students are to go beyond improving their writing at the sentence level 
The infinitives imply regulations in a very gentle way helping the reader follow the steps of the conclusion and understand the problems in thesis writing. The authors make infinitive forms function efficiently in place of commands. They become supporters of the process-carrying cores in most clauses. Their type, if identified, will be mental as well.

To conclude the Ideational metafunction analysis in my second analytical sample, I will mention the factor of clause structure and its logico-semantic type. I will identify taxis as logical connections and logico-semantics relationships between clauses that assist the conclusion clause constructs to project and to expand each other. Interpreting the amount and structures of clause simplexes and complexes, I will be able to de-code the whole message of the Ideational metafunction in the genre of the RA conclusion as "the logical system of the clause complex complement transitivity choices, allowing us to compose complex clusters of experiential representations" (Eggins, 2004, p. 254).

In the conclusion of the RA written by Allison and his co-authors, I have detected 5 clause complexes and 6 clause simplexes (see Appendix 2, p. 188).

Table 16. Taxis and Logico-semantic relationships between clauses in Text 2

\begin{tabular}{|l|l|l|l|}
\hline $\begin{array}{l}\text { Clause Complexes } \\
\text { Clause Simplexes }\end{array}$ & 6 & $\begin{array}{l}\text { Parataxis } \\
\text { Hypotaxis }\end{array}$ & 2 \\
\hline & & & \\
\hline $\begin{array}{l}\text { Projection (total) } \\
\text { locution } \\
\text { idea }\end{array}$ & $(3)$ & $\begin{array}{l}\text { Expansion (total) } \\
\text { elaboration } \\
\text { extension } \\
\text { enhancement (temporal, concession, } \\
\text { condition x 2) }\end{array}$ & 5 \\
& 2 & & \\
& & & \\
\hline
\end{tabular}


In contrast, here I can see a clause simplex cluster in the opening statements (Sentences $1-5$ ). The last clause simplex can be found in sentence 7. In the first half of the conclusion simplexes prepare the reader to receive the list of the project problematic targets. And afterwards the simplex in sentence 7 contracts the information articulated above.

The simplicity of sentence clause structures (though enriched with a significant number of embedded clauses an) is 55 per cent of the total clause system (6 out of 11). That is how the authors keep the balance because the rest of the clauses comprise multistory structures (sentences $6,8,9,10$, and 11 ). There is clearly an advantage of hypotaxis, namely 8 hypotactic sentences versus 2 paratactic ones. Allison and his coauthors' conclusion is quite complex in its simplex structures (embedded clauses, loaded Phenomena). Interestingly, the last two sentences are paratactic. They finalize the conclusion, setting up egalitarian relations between 'changes' (that 'have been implemented') and 'research' (that 'is continuing') in sentence 10. Sentence 11 is a bit intricate. There is 1 parataxis ('students are to go beyond the improving and enhance) and 2 hypotaxis ('we believe that the focuses / the focuses are essential if students are to go beyond the improving and (if students\} enhance')

\begin{tabular}{|l|l|l|}
\hline $\begin{array}{l}\text { Yet we } \\
\text { believe }\end{array}$ & $\begin{array}{l}\text { that the focuses on extended texts and } \\
\text { the macro-level of writing [[as } \\
\text { emphasized in this paper]] are essential }\end{array}$ & $\begin{array}{l}\text { if students are to go beyond improving their } \\
\text { writing at the sentence level }\end{array}$ \\
$\begin{array}{l}\text { \{if students }\} \\
\text { actually enhance the quality of their dissertation } \\
\text { writing. }\end{array}$ \\
\hline
\end{tabular}


The clause relations are linear as it can be seen in the table above (main clause ${ }^{\wedge}$ projection of idea ^ enhancement of condition AND enhancement of condition). Considering the paratactic and hypotactic relations, it is easier to perceive multi-tier clauses, often used in the AL discourse.

The phenomenon of rank-shifting deserves particular attention in this conclusion. There are embedded participle phrases as well as rank-shifting clauses. Embedded clauses help the writer "to pack more meaning into units, usually by packing a whole clause into a unit of a lower rank" (Eggins, 2004, p. 269). According to Eggins (2004), embedded clauses are better-thought patterns that are static, compressed and attributed to "formal, careful written text". It is undeniable that the complexity of the clause sparks readers' interpretations. In the given conclusion, complex clauses interact with embedded clauses, complimenting each other to create a complex discursive environment. Whereas Halliday characterizes clause complexes as "the dynamic potential of the system - the ability to choreograph very long and intricate patterns of semantic movement" (Halliday, 1985, p. 224), I feel the authors' capability of 'choreographing' and 'orchestrating' the meanings and their realizations in the text of RA conclusion by mixing complex and embedded clauses. What is also important, embedding becomes a technique to get closer and more comprehensible to the reader, by compressing processes and participants into more compact structural units but not losing their conceptual value.

Finally, the logico-semantic relationships, those in projections and those in expansions, are important clues to meanings in this AL conclusion. There are 3 projections, 1 locution and 2 idea expressions. As for expansions, 5 of them, 1 extension and 4 enhancements are identified. The authors express their confidence and certitude 
('we have expressed a degree of confidence / we are sure' in sentence 9) and offer a solution ('we believe' in sentence 11).

The combination of extension and enhancement in the expanding clauses is curious. One extension is introduced with the conjunction 'while', describing the meaning of addition. Other expansions are enhancing the clauses. Such types of enhancement as temporal ('while'), concessive ('although'), conditional ('if') widen the general picture, giving the necessary circumstances to the project results being described in the conclusion. Interestingly, there are two different meanings of the conjunction 'while' in one text. The authors add in the context 'while local errors were the most evident' (similar cases are mentioned by Eggins (2004, p. 283) and describe the time frame in 'while we have expressed a degree of confidence'. The first case is static and broadens the horizons of the situation not sure I agree. The second case is dynamic, for the academic entity 'we' express their confidence (answering the question 'when?').

To sum up the ideational metafunction of this conclusion, the authors combine various logico-experiential means in a clever manner to make difficulties more understandable. This manner is 'prescribed' by the context of the research article. The Writing Support Service project is to face major problems in academic writing and to assist graduate students whose native language is not English in integrating in the English-speaking academic community. The authors negotiate between various options of expressing the experiential and logical meanings to help the reader get the gist of the project as well as its pre- and post-contexts. The authors do not 'rest on laurels', praising the project. They centralize the challenges and accentuate NNS students' needs. The ideational model is two-fold. Firstly, the reader is led through the mental processes, 
showing their cognitive process preference, to share the research problem with specialists and to find the way out together. The authors' mastery and professionalism allows them to balance between complexity and simplicity implying several meanings beyond formal academic structures.

\subsection{Interpersonal Metafunction}

The authors have created an AL article conclusion that combines complex ideational meanings and structures but, at the same time, it is perceived with an evident simplicity. This effect is achieved through well-thought out realizations and evident consideration of the audience factor. The latter means the excellent performance of the interpersonal metafunction in this RA conclusion which showcases the most interesting language observations of the 'authors-readers' relationship is the scope of attention of this chapter.

The verb and verbal forms create the 'spine' of the text. In the previous chapter I interpreted verbs as conveyors of experiential and logico-semantic meanings. This chapter continues to accentuate the role of verbs as Finites to highlight their ability to build the relationship channel between the authors and their audience. The Finites are centrifugal forces that contribute to the interactional aspect of the discourse of this $\mathrm{AL}$ conclusion. To illustrate the Interpersonal metafunction in the text, I will analyze the Mood, Finites (MOOD) and modalities. This analysis will explain how the authors and their audiences are involved in the applied linguistic discourse.

The interpersonal metafunction analysis as seen through Systemic Functional Linguistics helps to undercover the process of creating the relationship between the 
Sender and the Recipient that actually ensures the existence of the text as a part of the discourse. The indicators of contact, involvement, and power are linguistic fundamentals to consider when writing in the academic discourse.

Through engaging in sustained dialogue ... we can establish and develop the social roles we are playing with other people. Establishing social identities ... is not done by holding up a sign with a role label on it. Instead, it is done through talk (Eggins, 2004, p. 144).

Evidently, the notion of 'talk' stands for a phenomenon that is much wider than oral communication. Language users create dialogues throughout their life, realizing themselves as active community members. The analysis of the micro-structures at the level of clauses in this chapter demonstrates how the dialogue is put into action in the RA conclusion in the applied linguistic field. Again, the term 'speech roles' is to be perceived at its broadest. When I analyze the Interpersonal metafunction realization in the RA conclusion, I pay attention to the speech roles attributed to the participants of this written interaction. The distance between the carriers of these roles and the degree of their reciprocity are the factor that the RA writer should be aware of if he intends to communicate his research results and discuss them with the academic community.

With a reference to the Speech Roles and Commodities in Interaction table from Eggins' book An Introduction to Systemic Functional Linguistics (2004) based on SFL language theory, I understand the given conclusion as an act of taking on certain speech roles and exchanging certain goods-services (p. 146):

Table 17. Speech roles and commodity exchanged

\begin{tabular}{|c|l|l|}
\hline \multicolumn{3}{|c|}{ Commodity Exchanged } \\
\hline Speech Role & Information & Goods and Services \\
\hline Giving & Statement & Offer \\
\hline
\end{tabular}




\begin{tabular}{|l|l|l} 
Demanding & Question & Command
\end{tabular}

Every step within this table is an expected move in speaking or writing. These moves construct human interaction and every single utterance, in particular.

Figure 4. Clause as interaction (pyramid)

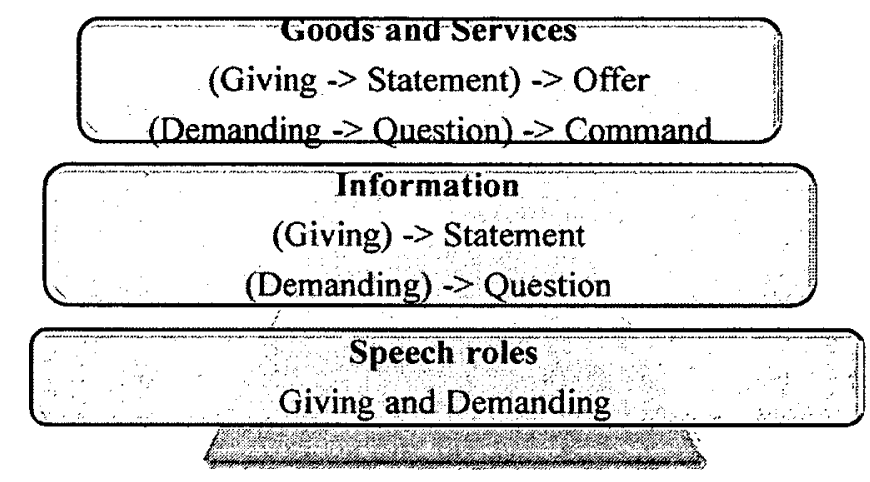

In my attempt to apply this theory in the analysis, I perceive every clause as an interaction with the stage of the above interpersonal pyramid (Figure 6). A language user realizes his meanings by choosing. He starts with very broad categories 'Am I giving or demanding?' (the lowest level of the pyramid) and narrows them down with appropriate specifications, namely sharing or asking for specific information (the second level of the pyramid). And, finally, the language user is ready to exchange goods and commodities (the top level of the pyramid). The genre of an RA conclusion can be seen through this interpersonal pyramid too. At first, the authors choose the direction of giving (the lowest / broadest level of options). Conclusions cannot demand. It is time and place to summarize. Then evident are the authors' willingness to give the compact, but comprehensive gist of what has been read, takes on concrete forms of statements (the intermediate level of the pyramid) and not a question is used. Finally there are the subtexts of these statements that offer (the top level) me, as the RA reader, the synopsis of the experimental writing 
program and its results. Here is a modified linear pattern of interpersonal moves that can be an action plan for conclusion writing. As a result, commands are hardly acceptable and should be replaced with recommendations.

Table 18. Commodity exchanged in RA conclusions

\begin{tabular}{|l|l|l|l|l|l|}
\hline \multicolumn{6}{|c|}{ Commodity Exchanged in RA Conclusions } \\
\hline Speech Role & & Information & & Goods and Services & \\
\hline GIVING & $\mathrm{V}$ & STATEMENT & $\mathrm{V}$ & OFFER & V \\
\hline Demanding & $\mathrm{X}$ & Question & $\mathrm{X}$ & Command & $\mathrm{X}$ \\
\hline
\end{tabular}

To support my theoretical observations, I need to find significant constructs of the interpersonal metafunction to show how it works in the realities of the applied linguistic discourse. I will start with the Mood types. All eleven sentences are declarative. The authors do not question their readers but affirm. Next, I should mention the MOOD versus RESIDUE factor as one of fundamentals of the Interpersonal metafunction in this text. As syștemic functionalists claim,

To discover which part(s) of the clause constitute the MOOD element, we ask which part of the clause cannot disappear when the responding speaker takes up his / her position. The essential part of the clause contains the nub of the argument (Eggins, 2004, p. 149).

Clearly, every clause in the conclusion of Allison and his co-authors' article has a Subject. 20 Subject patterns are found in this conclusion. Let us look at them more closely:

Subject-Nouns and Noun phrases: $16 \quad(80 \%)$

Subject-Pronouns ('we'): 3 (15\%)

TH/Subjects ('this'): $1 \quad(5 \%)$ 
Most of Subjects are expressed with nouns $(80 \%)$. The range of these nouns embraces the clue concepts of the RA article. Among them there are participants of the academic discourse and the writing program, in particular, and key academic terms. Such Subjects as 'research (2), program (2), data, study, errors, framework, limitation, approach, adaptations, changes, students $(2+1$ ellipsis $)$, focus' place the readers into the context of the applied linguistic discourse. What is more, three Subject-elements 'research', 'program', and 'students' are slightly foregrounded. These three ideas are very important for the authors. They develop relations between themselves ("students get the program via research') and measure the distance between the counterparts in the RA discourse. Other Subject groups are significantly smaller in numbers. One can detect 3 pronouns and, interestingly, all of them the first person plural 'we'. It is an inclusive academic type of 'we' ("we have described, we have expressed, we are sure and we believe'). This pronoun unites researchers, the writing program developers, and professors. 'We' does not duplicate any of the Subject-nouns, but is paralleled with the Subject 'students'. The authors say what has been done in 'we have described / expressed' (the Present Perfect accentuates the accomplishments between the past and present). And the final sentences sound assertive, containing 'we are sure' and 'we believe'. These subjects dialogize with 'students' ('students are to go beyond improving / students enhance the quality') within the borders of this RA article. The readers are involved indirectly. They look on the inner article interaction between applied linguists and students and make their conclusion, planning the future teaching or research activities.

The TH-Subject plays the roles of descriptor: 


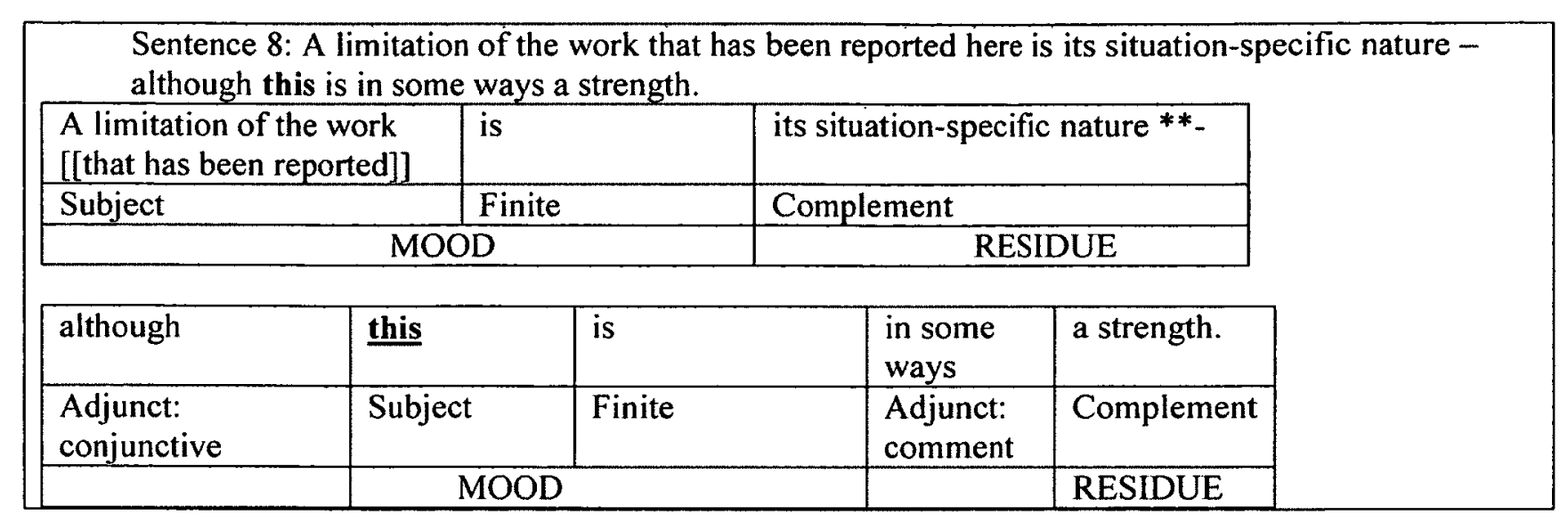

'This' is a mix of relative pronoun (reference to situation -specific nature), demonstrative pronoun (attention to the limitations), and determiner (substitute for the definite article). The concessive subordinate with the Subject 'this' is definitely distinctive ('although this is in some ways a strength'). It is separated from the other clauses with a dash (signal of longer pause when reading or pronouncing to express importance or dissimilarity). 'In some ways' is situated between the Subject and the verb 'to be', on the one hand, and the nominal part of the complex predicative 'a strength'. For me, the form 'in some ways' is less popular though it is an absolute equivalent of the more widely used expression 'in a way':

in a way (or in some ways or in one way): to a certain extent, but not altogether or completely (used to reduce the effect of a statement)

Retrieved from http://oxforddictionaries.com (Oxford Dictionaries Online)

I see this replacement as a hint to two facets of this expression. The adverbial meaning of 'sometimes but not always' and 'somehow' (meaning 'somehow the program's/student's circumstances can turn it into an advantage'). As far as I am concerned, the authors say that their research tackles only the problems of non-native 
speakers' dissertation writing. However, this narrow specification points out a limited number of problems to encourage me to think wider, i.e. students and their problems in academic writing. In addition, the word 'strength', usually uncountable, is also used in its specific countable meaning of 'advantage, strong point' (the indefinite article + noun). The effect has been achieved. The ambiguity of the Subject makes the reader analyze the content. The power construct stands out with its implications in the text because the authors influence the perception process by choosing unusual forms and foregrounded meanings.

The second element of the MOOD is the Finite. There are 20 Finite Verbal Operators in this conclusion. The verbal pattern may combine the Finite and Predicator units, for example, 'the program evolved'. Some Finite structures consist of two or more elements where the first one represents the verbal axis and the rest acts as the semanticogrammatical supplement (e.g. 'we have described' where 'have' is the proposition basis and 'described' is the meaning of the action and participle II for the Present Perfect). Also, there is a special class of Finites without Predicators ('to be' as a state and 'to have" as a possession). The balance between the Finite as a separate unit and the finite combined with the Predicator in this conclusion is 11 and 8 respectively.

\section{Finite Structures}

Separated Finites: $10 \quad(50 \%)$

Fused Finites: 5 (25\%)

Finites without Predicators: 5 (25\%)

Finite Types

Temporal Finite Verbal Operators: 18 (90\%)

Finite Modal Operators: $2(10 \%)$ 
Table 19. Finites in Text 2

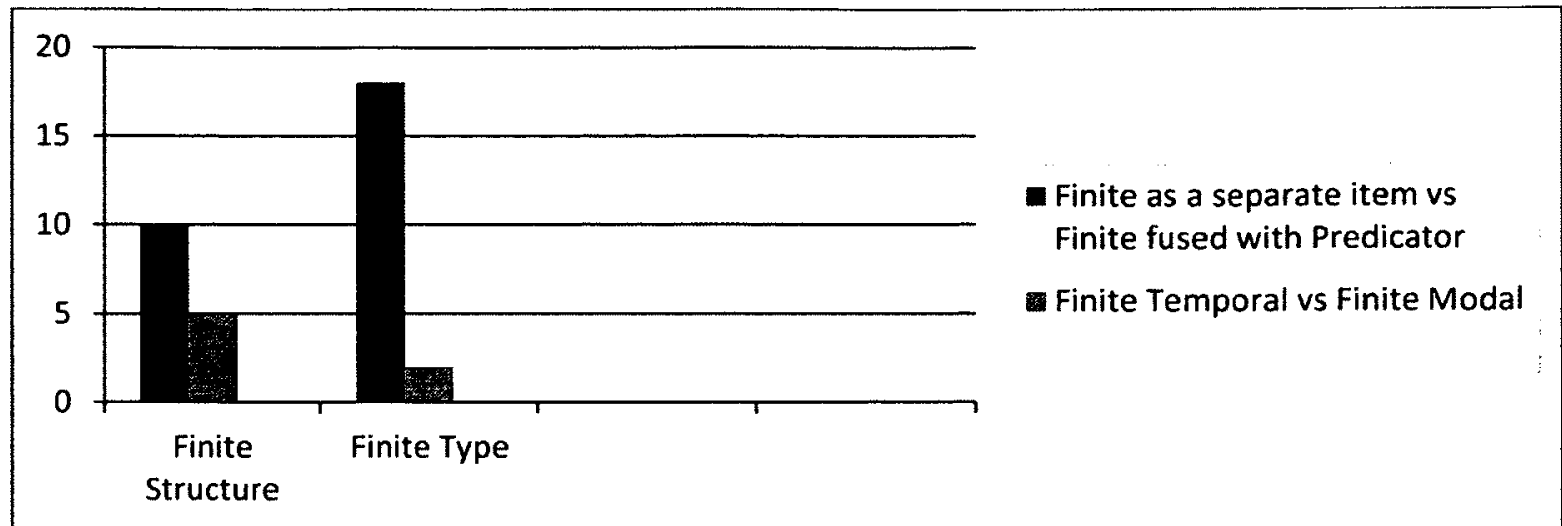

The authors use various types Finites. The proportion between temporal Finites

(18) and modal (2) Finites is not big but not surprising at all. On the contrary, it is logical.

Modality is used very moderately ( 1 non-elliptical and 1 elliptical obligation in sentence

11):

Sentence 11: Yet we believe that the focus on extended texts and the macro-level of writing as emphasized in this paper are essential if students are to go beyond improving their writing at the sentence level and actually \{are to\} enhance the quality of their dissertation writing.

The verb 'are to' is a modulation in this context (obligation) to mitigate the negative concentration of hinders that are discussed as major problems of dissertation writing. Modals make the propositions more tentative in the text. If the author overuses modals in his or her conclusion, the interpersonal message may seem far from certain at the moment when he had better be firm and consistent.

I am about to summarize Mood, MOOD and RESIDUE patterns, and Modality within clauses construct the relationship between the author and the reader.

It is by looking at how people use these systems of Mood and Modality in the clauses they exchange with each other that we can see speakers making meanings about such interpersonal dimensions as: the power or solidarity of their relationship; the extent of their intimacy, their level of familiarity with each other; and their attitudes and judgments (Eggins, 2004, p. 184). 
Applied linguists cannot help considering the interpersonal metafunction as a medium to assist in comprehensibility and recognition. Allison and co-authors' conclusion carries an extremely difficult mission. The research on writing problems is turned by them into positive, professional, and positive conversation between program researchers and potential program users (applied linguists, educators, and students).

\subsection{Textual Metafunction}

The textual strand of this RA conclusion highlights the organization text as realization of the authors' communication message. The textual metafunction reflects the process of producing meanings in the texture of the text.

What is the language doing here in this conclusion? It communicates the results of the UHK dissertation writing program in a formal written manner. In the previous chapters I demonstrated the logico-experiential meanings and interactional implications with which the authors articulate the final stage of their RA dialogue with their reader. This section is focused on the role of cohesion in making this discourse meaningful.

I will examine the Theme component, nominalizations and specific lexical density in the given $\mathrm{AL}$ article conclusion. The textual metafunction realizations are evidence of how every single clause and its constituents form a meaning via their organization and sequence. The textual dimension analysis provides the researcher with transparent implications triggered by the order and organization features. Eggins (2004) summarizes the significance of the textual metafunction, as it was discussed earlier,

This is the level of organization of the clause which enables the clause to be packaged in ways which make it effective given its purpose and its context. ... Thus, the textual strand of meaning, while not adding a new reality nor altering 
interpersonal dimensions of the clause, is concerned with the potential the clause offers for its constituents to be organized differently, to achieve different purposes (Eggins, 2004, p. 298).

The chains of nominal groups, specific terminological choices and Theme patterns are organized in this conclusion in a special way to create a productive finalizing statement for the research article in applied linguistics.

The textual metafunction feature of nominal groups in this text reflects the overall tendency of combining content-loaded items into compressed syntactic units. Each author carries out variations of this requirement in accordance with his/their article concept and design. For example, Allison and his co-authors talk about challenges in dissertation writing. Their conclusion as well as their article shows how it is possible to be prepared for miscellaneous 'bumps' on this road. They describe it through the lens of the UHK support writing program but the message is wider than that. The framework of the academic research article provides certain rules and moves that can be implemented differently but are recognized as uniformly related to acceptable practices in applied linguistics. Nominalization is one these academic practices. In addition, the specific content component (terminology) will be distinguished as prominence in this conclusion.. I mean that in applied linguistic conclusions I observe numerous chains of nominal terminological groups. First, I will talk about the nominalization (including gerund forms used as nouns) at the level of the textual metafunction. Here are the nominalizations from this conclusion:

The writing program (3) Students' positive reactions The development of a program Students in their struggle Data for this investigation An analysis of student writing
Problems to do with editing, spelling, and referencing Communication problems The macro-level of overall structuring Express a degree of confidence The challenging task of writing 


\begin{tabular}{|l|l|}
\hline $\begin{array}{l}\text { Arguments with evidence } \\
\text { Make claims for own research findings }\end{array}$ & $\begin{array}{l}\text { The macro-level of writing } \\
\text { To go beyond improving their writing } \\
\text { The quality of writing }\end{array}$ \\
\hline
\end{tabular}

The phenomenon of nominalization does not contradict the leading verbal axis in

the text. On the contrary, the abundance of nominalized groups foregrounds the actions (mostly mental and verbal in the AL discourse). I identify 16 nominal groups. The most popular prepositions that cement the nominal groups from within are collected in the table below. It is easy to notice that the prepositions 'of' is the most widely used:

Prepositions in nominalizations: of (7), for (2), with (2), beyond (1), in (1)

Nominalization is a characteristic of the academic discourse (Eggins, 2004). It combines the action implied in the nominal form. Another nominal phenomenon to be prominent in academic texts is terminology. Here are the groups that contain terms in this conclusion:

Research/ supervisors/graduate students/ English Centre's one-to-one Writing Support Service/ NNS research students/ skills in planning, drafting, and revising their theses/ grounded investigation/ dissertation writing/ a research space/ editing, spelling, grammar and bibliographical referencing/ local errors/ communication problems/ diagnostic framework/ macro-level problems/ situation-specific nature/ sentence level/ this paper/ etc.

I observe two groups of terms. The first group represents terminological tags for the participant of the AL discourse. The second group denotes the research targets, objectives, methods, etc.

\begin{tabular}{|l|l|}
\hline Participant in AL Discourse & AL Content \\
\hline -supervisors (2) & -writing program (4)/English Centre's one-to-one \\
-(graduate / NNS research) students (8) & Writing Support Service (1) \\
-UHK/ university (3) & -this paper(2)/ research (5) \\
-reader (1) and audience (1) & -thesis (2)/ dissertation (2)/ writing (6)/ macro level \\
& $(2) /$ skills (1)/ language (2)/ texts (2) \\
& -investigation (2)/ interviews (1)/ questionnaires (1) \\
& -problems(3) and equivalents (shortcomings (1)/ \\
& errors (1)/ failure (2)/inability (1) \\
\hline
\end{tabular}


Together these terms create a complex network of the AL conclusion, emphasizing the value of the article context. Content-carrying items can be summarized in one table, as in Eggins' (2010) table Contrasting lexical density (p. 97):

Table 20. Specific lexical density in Text 2

\begin{tabular}{|l|l|}
\hline Number of content carrying lexical items & 136 \\
\hline Number of lexical items in text & 435 \\
\hline Total lexical density & $32 \%$ \\
\hline
\end{tabular}

Thirty two per cent (136 words) are loaded with the writing support project and AL discourse information. The $\mathrm{AL}$ interactants and $\mathrm{AL}$ phenomena mentioned above are spirally repeated in the conclusion (the text is presented as a spiral):

Table 21. Specific lexical density zones in text 2

Zone I: Starting point: research and program and its associations (study, investigation, interviews, questionnaires, service, efc.)

Zone II: Sentences 5 and 6: probłems (shortcoming, error, failure, inability)

Zone III: Finalizing: program results ard prospects

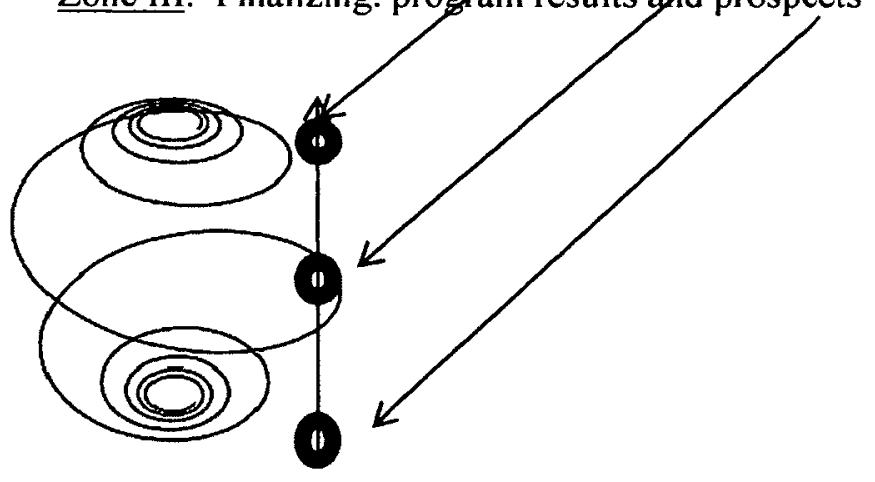


The authors are circulating in the selected pool of the $\mathrm{AL}$ terms as signal words that connect the research experiences and create a discursive environment. The largest concentration of terms can be observed in the middle of the conclusion (sentences 5 and 6 in zone II). This feature of textual design and terms integrated is a prominent feature in the discourse of the given $\mathrm{AL}$ article conclusion.

Finally, the textual strand analysis will not be complete without looking at the Theme patterns of this conclusion. This type of semantic negotiation becomes one of the most important 'puzzle' pieces in the overall textual organization, resulting in the conclusion section of the research article as a final product.

In describing the structural configurations by which the clause is organized as a message, we will recognize that one major system is involved, that of Theme, with a configuration of the clause into the two functional components of a Theme (point of departure for the message) and a Rheme (new information about the point of departure) (Eggins, 2004, p. 296).

The three-functional semantic structure of language finds its place in the Theme classification. Systemic functionalists distinguish three types of the Theme-element, notably

The sentence order produces meanings itself and the authors have an opportunity to pinpoint the main informational accents in the complex network of clause Themes. Every clause has a topical Theme. Among 20 topical Themes, all the key concepts of this research article (e.g. 'research', 'this paper', 'program', 'data', 'study', 'diagnostic framework', 'changes', 'students', etc.) are found. 
Table 22. Theme in Text 2

\begin{tabular}{|c|c|c|c|c|}
\hline \multirow{2}{*}{$\begin{array}{l}\text { Sentence/ } \\
\text { Clause } \\
\mathrm{I} / 1\end{array}$} & \multicolumn{2}{|l|}{ THEMES: Textual } & \multirow[t]{2}{*}{ Interpersonal } & \multirow{2}{*}{ Topical } \\
\hline & $\begin{array}{l}\text { Research + the numbers of } \\
\text { students + students' positive } \\
\text { reactions }\end{array}$ & & & \\
\hline II / 2 & In this paper & & & $\mathbf{A}$ \\
\hline III / 3 & the program & & & $\Delta$ \\
\hline IV / 4 & data for this investigation & & & $\Delta$ \\
\hline $\mathrm{V} / 5$ & the initial study & & & $\Delta$ \\
\hline $\mathrm{VI} / 6$ & while, at first sight, local errors & $\Delta$ & $\Delta$ & $\Delta$ \\
\hline & $\begin{array}{l}\text { by far the greatest number of } \\
\text { communication problems }\end{array}$ & $\mathbf{A}$ & & $\Delta$ \\
\hline VII $/ 7$ & hence the dialogic framework & $\Delta$ & & $\Delta$ \\
\hline VIII / 8 & a limitation of the work & & & $\Delta$ \\
\hline $\mathrm{VIII} / 9$ & although this & $\Delta$ & & $\mathbf{A}$ \\
\hline $\mathrm{IX} / 10$ & while we & $\Delta$ & & $\Delta$ \\
\hline IX $/ 11$ & that the approach & $\Delta$ & & $\Delta$ \\
\hline $\mathrm{IX} / 12$ & we & & & $\Delta$ \\
\hline $\mathrm{IX} / 13$ & that adaptions & $\Delta$ & & $\Delta$ \\
\hline $\mathrm{X} / 14$ & indeed, some changes & & $\Delta$ & $\Delta$ \\
\hline $\mathrm{X} / 15$ & and research & $\Delta$ & & $\Delta$ \\
\hline $\mathrm{XI} / 17$ & Yet we & $\Delta$ & & $\Delta$ \\
\hline $\mathrm{XI} / 18$ & that the focus & $\Delta$ & & $\Delta$ \\
\hline $\mathrm{Xl} / 19$ & if students & $\Delta$ & & $\Delta$ \\
\hline $\mathrm{XI} / 20$ & and (students) & $\Delta$ & & $(\mathbf{A})$ \\
\hline & Total: & 11 & 2 & 20 \\
\hline
\end{tabular}

Interestingly, some topicals are not only 'noun + preposition', but also 'preposition + noun'. A bright example of the latter is the nominal group 'in this paper'. This prepositional phrase ('in this paper') adds more significance by being placed at the very beginning of the second sentence, playing the role of the Topical Theme and that is the way of emphasizing the reading context is a complement to the extremely extended topical Theme of the first sentence in this conclusion.

Topical Theme in Sentence 1: 


\begin{tabular}{|l|l|}
\hline $\begin{array}{l}\text { students at UHK, the numbers of students } \\
\text { [[registering for the writing program [[that } \\
\text { was induced]] / ]], students' positive } \\
\text { reactions to the program and the growing } \\
\text { number of graduate students [[attending the } \\
\text { English Centre's one-to-one Writing } \\
\text { Support Service]] }\end{array}$ & $\begin{array}{l}\text { clearly a need for a writing program to } \\
\text { become a regular feature of graduate life at } \\
\text { the university]]. }\end{array}$ \\
\hline \multicolumn{1}{|c|}{ TOPICAL THEME } & RHEME \\
\hline
\end{tabular}

Topical Theme in sentence 2:

\begin{tabular}{|c|l|}
\hline In this paper, & $\begin{array}{l}\text { we have described the development of a program to help } \\
\text { NNS research students develop skills in planning, drafting, } \\
\text { and revising their theses. }\end{array}$ \\
\hline TOPICAL THEME & RHEME \\
\hline
\end{tabular}

The topical Theme is a conglomeration of 'research', 'students' and 'reactions' are Given in the first sentence. The Given Information (Theme) in sentence 2 is 'in this paper'. Together they give the gist of this AL article. Thus topical Themes develop the texture of this conclusion, giving the key postulates in portions of topical Themes.

Research + the numbers of students + students' positive reactions $--->$ in this paper $--->$ the program ---> data for this investigation ---> the initial study ---> local errors ---> the dialogical framework and the resultant writing program ---> a limitation of the work ---> approach ---> adaptions ---> changes --.> research ---> the focus on extended texts and the macro-level writing ---> students

The method of combining Themes is used again by the authors in 12 multiple Themes. Most of them are a combination of textual and topical Themes. One example contains a tripartite Theme ('while, at first sight, local errors' in clause 6) and one case combines an interpersonal and topical Themes ('indeed, some changes' in clause 15).

Interpersonal Themes are not numerous, 'at first sight' and 'indeed'. Here, the authors set up a goal to foreground the mission of the program, not the interactive aspect 
of this research article discourse. The article does not intend to spark debate. It is more concerned with finding solutions to existing problems. As for textual Themes, I see 12 of them. Conjunctions 'while' (2), 'that' (2), 'although', 'and' in addition to the adverbs 'hence' and 'yet', configure the textual structure of this conclusion.

Expanding the concept of Thematic multiplicity from Eggins' (2004) explains:

While it is possible for a clause to realize only one Thematic element (in which case it must be a topical Theme), it is far more common for clauses to contain a sequence of Themes, with often several textual and/or interpersonal (p. 307).

Allison and his collaborators use all the three types of Themes in their conclusion. Possibly, through the Theme patterns the authors' hint how to structure an academic text. The research tackles the obstacles in dissertation writing as a hurdle to surmount in a wider range of academic writing discourse. The authors show in their article and particularly in their article conclusion how to organize the content and structure in an academic message.. Firstly, one should the present all the necessary information and conceptual items (sentences 1-4). Then, one is likely to sum them up in a problemsolution environment (sentences 5 and 6). Ultimately, one can describe the up-to-date results, prospects, limitations, convictions and even hopes (sentences 7-11). The final part needs interpersonal Themes to establish a closer contact with the reader and textual Theme to be ideally structured to prevent incoherence and misunderstanding.

I should say that I cannot completely agree with Eggins (2004) who writes that "the textual metafunction is in a sense parasitic upon both the ideational and interpersonal strands of meanings" (p. 320). It is undeniable that this metafunction cannot exist without ideational meanings and interactive stances. However, the other two will not be able to articulate without the compositional component at all. The 'enabling' potentials (Halliday 
\& Matthiessen 2004, Eggins 2004) of the textual metafunction are of a great importance in discourse realizations.

Therefore, the context of this research article fosters the outstanding position of the textual metafunction, the one to be responsible for the structuring. This conclusion becomes a mini-class in how to report research outcomes in writing. The contents and communication importance is taken for granted. However, the order and organization are to be highlighted as stepping stones to get through the rough river of dissertation writing. 


\section{Chapter Six - Text 3}

\section{TEXT 3}

Author: Lilie Chouliaraki

Title: "Ordinary Witnessing in Post-television news: Towards a New Moral Imagination"

Journal: Critical Discourse Analysis

Year: 2010

\begin{tabular}{|l|l|l|}
\hline Sentence & Clause & \\
\hline 1 & 1 & In this paper, I explored the nature of witnessing in post-television news. \\
\hline 2 & 2 & $\begin{array}{l}\text { Taking my point of departure on an analysis of the emergent narratives of } \\
\text { convergent journalism, }\end{array}$ \\
\hline & 3 & $\begin{array}{l}\text { I showed how the multi-modality of convergence has affected the narrativity } \\
\text { of the news along three key textual dimensions: the cohesive, clause and } \\
\text { process structure of the news. }\end{array}$ \\
\hline 3 & 4 & $\begin{array}{l}\text { Insofar as such structural changes result in replacing the logic of news as } \\
\text { story-telling with a logic of news as techno-textual interactivity. }\end{array}$ \\
\hline 4 & 5 & $\begin{array}{l}\text { I argued } \\
\text { post-television witnessing can be seen as becoming increasingly } \\
\text { technologized. }\end{array}$ \\
\hline 5 & 6 & $\begin{array}{l}\text { This technologisation of witnessing has enabled the emergence of ordinary } \\
\text { witnessing and the manifestation of a caring ethos towards vulnerable others }\end{array}$ \\
\hline 6 & 7 & $\begin{array}{l}\text { Yet it has simultaneously given rise to ambivalent forms of collective agency, } \\
\text { which potentially produce post-humanitarian news publics - }\end{array}$ \\
\hline & 9 & publics that are driven by a communitarian moral imagination \\
\hline
\end{tabular}

\subsection{Ideational Metafunction}

In this section, I aim to inspect the ideational metafunction dimension of the conclusion retrieved from Chouliaraki's AL article, analyzing its Transitivity and logicosemantic relationships between the clauses to answer the question, "What is the author's language about?" as I have examined in two earlier texts. 
Lilie Chouliaraki's article is titled Ordinary witnessing in post-television news:

towards a new moral imagination. Her conclusion is an example of brevity. It consists of 6 sentences. The sentences are not overloaded in structure. The conclusion highlights the main points of the article in a very concise manner. Every conclusion should be perceived contextually. However, I interpret the size of this conclusion is in a sense the author's statement. Chouliaraki chooses to compress the article information in this case. Let us categorize the processes in this conclusion:

Table 23. Processes in Text 3

\begin{tabular}{|c|c|c|c|c|}
\hline & Participant & Process & Type & Participant \\
\hline 1 & I (Senser) & explored & MENTAL & $\begin{array}{l}\text { the nature of witnessing } \\
\text { (Phenomenon) }\end{array}$ \\
\hline 2 & I (Senser) & showed & MENTAL & $\begin{array}{l}\text { [[how the multimodality of } \\
\text { convergence has affected ..]] } \\
\text { (embedded clause as Phenomenon: } \\
\text { fact) }\end{array}$ \\
\hline 3 & + Tempered clause & \multicolumn{3}{|c|}{$\begin{array}{l}\text { Taking my point of departure on an analysis of the emergent narratives } \\
\text { of convergent journalism (MENTAL) }\end{array}$} \\
\hline 4 & $\begin{array}{l}\text { such cultural changes } \\
\text { (Token) }\end{array}$ & result in & $\begin{array}{l}\text { RELATIONAL: } \\
\text { identifying }\end{array}$ & $\begin{array}{l}\text { replacing the logic of news } \\
\text { (Value) }\end{array}$ \\
\hline 5 & I (Sayer) & argued & VERBAL & \\
\hline 6 & $\begin{array}{l}\text { post-television } \\
\text { witnessing } \\
\text { (Phenomenon) }\end{array}$ & can be seen & MENTAL & \\
\hline 7 & $\begin{array}{l}\text { this technologisation } \\
\text { of witnessing } \\
\text { (Token) }\end{array}$ & has enabled & $\begin{array}{l}\text { RELATIONAL: } \\
\text { identifying }\end{array}$ & $\begin{array}{l}\text { the emergence of ordinary } \\
\text { witnessing and the manifestation of } \\
\text { a caring ethos (Value) }\end{array}$ \\
\hline 8 & it (Token) & has given & $\begin{array}{l}\text { RELATIONAL: } \\
\text { identifying }\end{array}$ & $\begin{array}{l}\text { rise to ambivalent forms of } \\
\text { collective agency (Value) }\end{array}$ \\
\hline 9 & which (Senser) & produce & MENTAL & $\begin{array}{l}\text { post-humanitarian news publics } \\
\text { (Phenomenon) }\end{array}$ \\
\hline 10 & $\begin{array}{l}\text { publics that } \\
\text { (Phenomenon) }\end{array}$ & are driven & MENTAL & by imagination (Senser) \\
\hline 11 & $\begin{array}{l}\text { \{publics that } \\
\text { (elliptical Token) }\end{array}$ & are based & $\begin{array}{l}\text { RELATIONAL: } \\
\text { identifying }\end{array}$ & on forms (Value) \\
\hline
\end{tabular}


I can identify 11 clauses with one participle phrase as a tempered clause that has a process as well. Among 11 processes, there are 6 mental processes, 4 relational identifying ones, and 1 verbal process. There are no relational attributives or material processes. The text has a variety of Sensers ('I, which [forms of collective agency], imagination') and Tokens ('cultural changes, it [this technologisation of witnessing], publics that'). Phenomena vary in structures. In clause 2 the Phenomenon of fact is represented by a long embedded clause "how the multi-modality of convergence has affected the narrativity of the news along three key textual dimensions; the cohesive, clause and process structure of the news'. Other participants that play the role phenomena are 'the nature of witnessing', post-television witnessing, as becoming increasingly technologized, post-humanitarian news publics, publics that'). Values ('posthumanitarian news publics, the emergence and manifestations, rise to ambivalent forms of collective agency, on instantaneous, albeit discontinuous, forms of technological activism') are parts of such process as 'result in', 'enable', 'give (rise), 'be based'.

It is obvious that the sphere of mental activities dominates in the AL discourse. These processes express the cognitive activities that are scopes of attention in applied linguistics. Identifying processes are to support mental ones in defining the key cognitive notions of this $\mathrm{AL}$ discourse. The author packs article-related information in a relatively small box of a 6-sentence conclusive paragraph. The clause core (Senser + Phenomenon/ Token + Value / Sayer + Verbal) is extended not only by other participants that are located after the verb and have a secondary (optional) nature but by circumstances. Here, circumstances are not numerous but variable: 
$>\quad$ Role (2): as story-telling / as techno-textual interactivity

$>\quad$ Manner (3): simultaneously / potentially / by a communitarian moral imagination

$>\quad$ Matter (1): on instantaneous, albeit discontinuous, forms of technological activism

$>\quad$ Accompaniment (1) : with a logic

All the clauses, except the last two ones, are similarly structured (Participant Process - Participant). Circumstances are used moderately. But one pattern of this conclusion is prominent because of the effect of a duplicated item. There is an excessive element in the sixth sentence ('publics that' in clauses 10 and 11). The reader is presented with two Subjects instead of one and they mean one and the same notion (publics that). This repetition can be interpreted as the author's signal to the reader who has already tuned to the same discourse wave. The term is one of the keys to open this terminologically dense and compressed conclusion and this key word is structurally and semantically prominent enough to be memorable.

The relationships between clauses are as various as in the longer conclusions analyzed previously. In the Appendix, I decode these relations and counted them:

\begin{tabular}{|l|l|}
\hline Clause Simplexes - 3 & Parataxis -1 \\
\hline Clause Complexes - 3 & Hypotaxis -4 \\
\hline
\end{tabular}

In hypotaxis, 1 projection of idea and 2 elaborations (one exposition and one hypotactic elaboration in the form of a non-defining relative clause) can be seen. There is also one enhancement in a tempered clause (sentence 2). Thus, in a short conclusion, there are two main directions of hypotactic development. 
Sentence 4: Projection of an Idea "where one clause anchors the complex by telling us or thought something, which is then linked to a quoting or reporting of what someone said or thought" (Eggins, 2004, p. 271):

\begin{tabular}{|c|}
\hline$\alpha \quad$ I argued, \\
\hline ' $\beta$ post-television witnessing can be seen as \\
becoming increasingly technologized.
\end{tabular}

Sentence 6: Yet it has simultaneously given rise to ambivalent forms of collective agency, which potentially produce post-humanitarian news publics - publics that are driven by a communitarian moral imagination and are based on instantaneous, albeit discontinuous, forms of technological activism.

\begin{tabular}{|c|}
\hline$\alpha$ Yet it has simultaneously given rise to \\
ambivalent forms of collective agency, \\
$=\beta$ which potentially produce post-humanitarian \\
news publics - \\
\hline$=\lambda 1$ publics that are driven by a communitarian \\
moral imagination \\
albeit discontinuous, forms of technological activism. \\
\hline
\end{tabular}

Commentary: Elaboration via Exposition to reinforce the message and Hypotactic Elaboration where "a non-defining relative clause adds a further characterization for something that is taken to be already fully specific" (Eggins, 2004, p. 281).

The 'which' clause in the last sixth sentence is an interesting feature of this

discourse. It is not an embedded clause. It is a non- defining clause that offers additional information to describe 'ambivalent forms of collective agency' and can be omitted, if necessary.

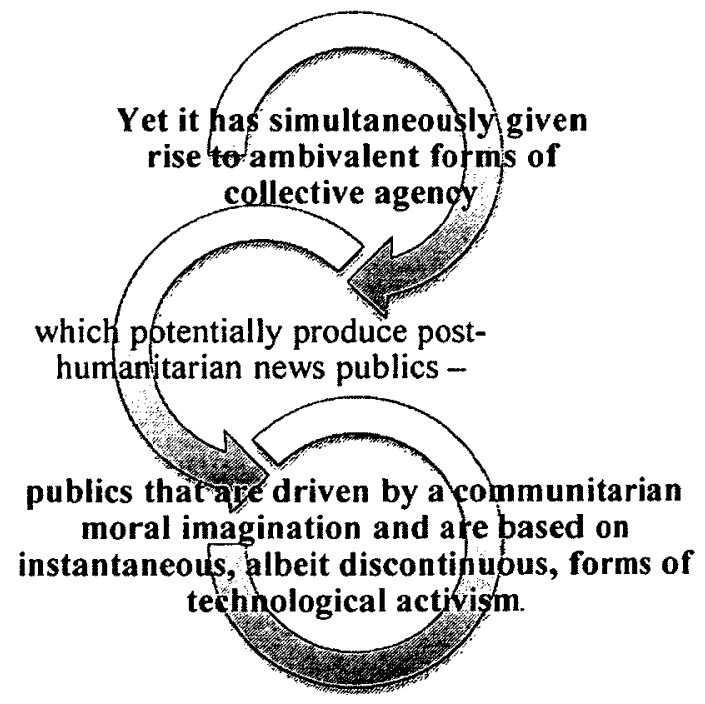


The problem of juxtaposed taxis and embedding are discussed by Eggins as the contrasting pair the non-defining clause versus defining relative clause:

The non-defining relative clause is an expanding clause complex, but the defining relative clause is an embedded structure in the nominal group. In writing, the nondefining relative clause is marked off by punctuation (paired commas if it's inserted into the alpha clause or a dash if it's appended at the end). Defining relative clause are not separated by punctuation from the nominal group they modify (Eggins, 2004, p. 282).

To conclude this section, I would say that this conclusion is prominent with its tendency to make big meanings compacted into 6 packed sentences. The concept of "packaging" the logical and experiential meanings in the ideational metafunction "through choices of transitivity and Clause complex, language user express experiential meanings about participants and processes, and link these logically into coherent, semantically sequenced packages" (Eggins, 2004, p. 295).Thus the discourse concepts becomes visible, tangible, and approachable.

\subsection{Interpersonal Metafunction Analysis}

The interpersonal Metafunction realizations showcase the author's awareness of the audience she is addressing her article message to. The consideration of the reader factor arises immediately with the first utterance because the dialogue in the article is inevitable. The mission of language is to articulate information to exchange. That is especially the case of a journal article. The author constructs a semantic system (article) with implications (realizations of 3 Metafunctions) to initiate a dialogue (Discourse) between its participants (the author and the readers).

The author initiates a formal academic discussion (journal article genre) with the focus on an applied linguistic problem. To investigate the researcher's relationships with 
the reader and the degrees of the reader's communication reaction and involvement into the discourse, such elements of the interpersonal metafunction as Mood, MOOD \& RESIDUE, Modality, and Attitudinal words will help me to decipher interactive subtexts, as I have carried out in the two former analyses.

The given conclusion consists of 6 declarative sentences. The declarative Mood pattern communicates the facts of stating and acknowledging in reporting the research finding in this AL conclusion. To continue with the interpersonal implications in the clause structure, I will enumerate the MOOD patterns encountered in this conclusion (the full analysis is in Appendix 2, p. 198):

Table 24. MOOD and RESIDUE in Text 3

\begin{tabular}{|c|c|c|c|c|}
\hline & \multirow[t]{2}{*}{ RESIDUE } & \multicolumn{2}{|c|}{ MOOD } & \multirow[t]{2}{*}{ RESIDUE } \\
\hline & & SUBJECT & FINITE & \\
\hline $1 / 1$ & In this paper & 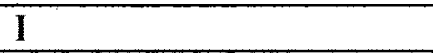 & \multicolumn{2}{|c|}{ explored. } \\
\hline II $/ 2$ & & I & \multicolumn{2}{|c|}{ showed. } \\
\hline II / (3) & \multicolumn{4}{|c|}{$\begin{array}{l}\text { Taking my point of departure on an analysis of the emergent narratives of convergent } \\
\text { journalism (tempered non-Finite clause) }\end{array}$} \\
\hline III / 4 & Insofar as & $\begin{array}{l}\text { such constructional } \\
\text { changes }\end{array}$ & \multicolumn{2}{|c|}{ result in $\ldots$} \\
\hline IV $/ 5$ & & $I$ & \multicolumn{2}{|c|}{ argued. } \\
\hline IV / 6 & & post-television witnessing & can be & seen ... \\
\hline $\mathrm{V} / 7$ & & $\begin{array}{l}\text { The technologisation of } \\
\text { witnessing }\end{array}$ & has & enabled ... \\
\hline $\mathrm{VI} / 8$ & Yet & it & has & $\begin{array}{l}\text { given rise } \ldots \\
\text { s. - }\end{array}$ \\
\hline VI/9 & & which & \multicolumn{2}{|c|}{ produce } \\
\hline $\mathrm{VI} / 10$ & & publics that & are & driven. \\
\hline VI/11 & & (that) & are & based .. \\
\hline
\end{tabular}

In the table above I identified the MOOD element in 11 clauses in this conclusion. It is noticeable that many clauses have the Subjects that represent a range of the article key notions ('constructional changes', 'post-television witnessing', and 'technologisation 
of witnessing'). The prominent MOOD position of the significant concepts accentuates the author's emphasis on the research topic. Finites of both types (Temporal Operators and Modal Operators) show how resourceful and versatile the researcher can be even in a one short paragraph of a conclusion. Finite Temporal operators contain such tense forms as 'explored', 'showed', 'has effected', etc. Modal Operators are presented by the modalization ('can be seen') to imply probability that enriches the text with debatable and open to further research hints.

Complement and adjuncts are secondary components that widen the discourse framework to the necessary extents. Though these constituents are not of primary order, this fact does not diminish their importance.

Table 25. Complements and adjuncts in Text 3

\begin{tabular}{|c|c|c|c|}
\hline Clause & Complements & Adjuncts & $\begin{array}{l}\text { Adjuncts: } \\
\text { MOOD or } \\
\text { RESIDUE }\end{array}$ \\
\hline 1 & $\begin{array}{l}\text { the nature of } \\
\text { witnessing }\end{array}$ & $\begin{array}{l}\text { In this paper (location)/ in post-television } \\
\text { news (location) }\end{array}$ & RESIDUE \\
\hline \multicolumn{4}{|c|}{ 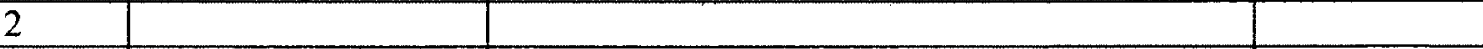 } \\
\hline 3 & $\begin{array}{l}\text { the narrativity of the } \\
\text { news }\end{array}$ & $\begin{array}{l}\text { along three key textual dimensions: the } \\
\text { cohesive, clause and process structure of the } \\
\text { news (location) }\end{array}$ & RESIDUE \\
\hline 4 & $\begin{array}{l}\text { replacing the logic } \\
\text { of news }\end{array}$ & $\begin{array}{l}\text { *Insofar as (conjunctive) } /{ }^{* *} \text { as story-telling } \\
\text { with a logic of news as techno-textual } \\
\text { interactivity.(role }{ }^{\wedge} \text { role) }\end{array}$ & $\begin{array}{l}* \text { not in MD } \\
\text { or RD / } \\
* * \text { RESIDUE }\end{array}$ \\
\hline \multicolumn{4}{|c|}{ 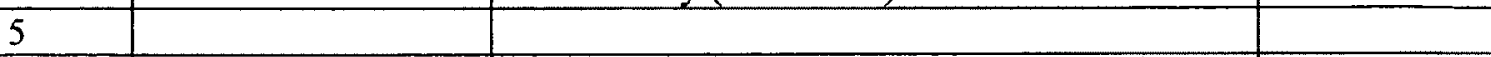 } \\
\hline 6 & & $\begin{array}{l}\text { as becoming increasingly technologized. } \\
\text { (role) }\end{array}$ & RESIDUE \\
\hline 7 & $\begin{array}{l}\text { the emergence of } \\
\text { ordinary witnessing } \\
\text { and the } \\
\text { manifestation of a } \\
\text { caring ethos }\end{array}$ & towards vulnerable others. (location) & RESIDUE \\
\hline 8 & & $\begin{array}{l}\text { *Yet (conjunctive) / simultaneously (time) / } \\
\text { ** to ambivalent forms of collective agency } \\
\text { (matter), }\end{array}$ & $\begin{array}{l}\text { *not in MD } \\
\text { or RD / } \\
\text { ** RESIDUE }\end{array}$ \\
\hline 9 & post-humanitarian & potentially (mood) & in MOOD \\
\hline
\end{tabular}




\begin{tabular}{|l|l|l|l|}
\hline & news publics - & & RESIDUE \\
\hline 10 & $\begin{array}{l}\text { by a communitarian moral imagination } \\
\text { (agent) }\end{array}$ & $\begin{array}{l}\text { *and (conjunctive)/ on instantaneous, albeit } \\
\text { discontinuous, forms of technological } \\
\text { activism. (matter) }\end{array}$ & $\begin{array}{l}\text { *not in MD }_{\text {or RD / }} \\
\text { RESIDUE }\end{array}$ \\
\hline 11 &
\end{tabular}

The complement is the secondary participant, it continues the Subject and Finite, making the mini-context complete. Adjuncts establish the situation of the clause. The preference towards adjuncts communicates the author's intention of giving the general research picture in one-paragraph conclusion. She starts with two adjuncts of location with terminological inclinations ('in this paper' and 'in post-television news'). After a tempered Finite clause with a participle, 1 adjunct of place is given to locate the research pre-suppositions ('along three key textual dimensions: the cohesive, clause and process structure of the news'). The chains of adjuncts of matter and role can be traced within clauses 3-11. They act as considerable supporters for terms in the Subjects. Finally, there are several adjuncts of another nature. Conjunctive adjuncts 'insofar' (clause 4) and 'yet' (clause 8) belong to neither MOOD, nor RESIDUE. But their exclusiveness specifies their interpersonal value. What is more, there is a Mood Adjunctive, the adverb 'potentially', to imply the author's attitude mixed with modal probability (potential hints about ability).

The text is not dotted with modals but there are particular cases:

Clause 6: post-television witnessing can be seen as becoming increasingly technologized (modalization) 
The dialogue is maintained in an objective and confident manner ( 1 modalization with the meaning of probability). Here, the idea of probability ('can') expresses the author's personal academic position and invites the reader to debate.

To conclude, Chouliriaki's conclusion is an example of how a compressed conclusion constructs a comprehensive dialogical space for its reader. The author manages to balance compactness and important information. The focus is on the terms (the Subjects and Adjuncts, especially). Attitudes are not foregrounded. And that feature can be seen as an attitude itself because she articulates her findings and interpret them in terms of the CDA theory.

\subsection{Textual Metafunction}

As we have seen previously, the textual metafunction projects the mode of discourse. The mode showcases how the language is constructing the discursive environment. The texture plays an important role in all texts. The RA article conclusion is a formal written discourse with no immediate interaction but with delayed experience reflections. Nominalization, lexical density, cohesion and Theme are characteristics of the RA situation being edified. Looking at them, I will be able to evaluate the degree of discourse complexity and efficiency of its organization. Textual meaning is embodied throughout the entire structure, since it determines the order in which the elements are arranged, as well as patterns of information structure in the clause" (Halliday, 2004, p. 328).

Nominalization as a trait of formal written discourse (Eggins, 2004) is a component of rhetorical organization of the text. This expressive method positions the reader among 
concepts, causes, outcomes, subjects. The hierarchy of ideas becomes much more transparent in nominalized segments. Nominalization makes the academic textual organization more dynamic and precise. Considering the size of this conclusion, this is also the way of packing the necessary information into compact nominal cells. The text is presented as a well-organized, "rehearsed, polished [and] redrafted" (Eggins, 2004, p. 96) pattern.

- the nature of witnessing

- my point of departure on an analysis of the emergent narratives

- replacing the logic of news as story-telling

- post-television witnessing

- this technologisation of witnessing

- the emergence of ordinary witnessing and the manifestation of a caring ethos

- a communitarian moral imagination

- based on forms of technological activism

It is noticeable that some nominal groups are combined with each other in long chains 'stapled' with one or more prepositions.

In fact, the nominalization process can be named as one of the main compositional elements of this text. The author constructs meaning based on nominal clusters that can occupy almost all space of the clause:

Taking my point of departure on an analysis of the emergent narratives of convergent journalism, I showed ...(clause 2)

$\checkmark$ how the multi-modality of convergence has affected the narrativity of the news along three key textual dimensions: the cohesive, clause and process structure of the news (clause 3)

$\checkmark$ Insofar as such structural changes result in replacing the logic of news as story-telling with a logic of news as techno-textual interactivity. (clause 4)

The narrative gains some intricacy. But the prepositions act as visual assistants to connectors the strings of the nouns many of which are important article concepts. The following prepositions are used in nominal chains: 


\begin{tabular}{|l|l|}
\hline $\begin{array}{l}\text { Of: } 12 \\
\text { On: } 1\end{array}$ & $\begin{array}{l}\text { Comment: There are 13 nominalizations with } \\
\text { prepositions (93\% of them are with the } \\
\text { preposition 'of') }\end{array}$ \\
\hline
\end{tabular}

The calculation demonstrates that 'of' outnumbers other prepositions significantly. Its grammatical meaning is much wider than the idea of possession (the modern from of Genitive case in the Old and Middle English). The preposition 'of' can imply location, relationship (origin, direction, source), agency, composition, classification, partitivity, characterization, etc. In this context, the reader receives a sequence of genetically related concepts from the article research field to re-build the same hierarchy in his own understanding of the topic being discussed. Definitely, the nominalization is a wellthought out method to support the high concentration of terms and research findings that are compressed into 6 sentences.

As I have already mentioned, many nominal groups contain RA specific contentcarrying items. Some terms are rooted specifically in applied linguistics (e.g. 'multimodality', 'key textual dimensions', 'cohesive and clause structure', 'techno-textual interactivity'). Alongside, I can find some lexical items that gain their terminological statuses only in the discursive settings of the RA topic:

\begin{tabular}{|l|l|}
\hline AL Terminology & $\begin{array}{l}\text { Neutral or Wide Terminological English } \\
\text { Vocabulary }\end{array}$ \\
\hline$\rightarrow$ the multi-modality of convergence & $\rightarrow$ convergence \\
$\rightarrow$ process structure of the news & $\rightarrow$ process / structure / news \\
$\rightarrow$ structural changes & $\rightarrow$ structural / changes \\
$\rightarrow$ the logic of news as story-telling & $\rightarrow$ logic / news / story-telling \\
$\rightarrow$ this technologisation of witnessing & $\rightarrow$ manifestation / ethos / vulnerable \\
$\rightarrow$ the manifestation of caring ethos & $\rightarrow$ news / publics \\
$\rightarrow$ towards vulnerable others & $\rightarrow$ communitarian / moral / imagination \\
$\rightarrow$ post-humanitarian news publics & \\
\hline
\end{tabular}


$\rightarrow$ instantaneous, albeit discontinuous, forms of technological activism

The text is dense in a terminological sense. Even neutral words do not belong to everyday activities any longer. The combinations are structured in a particular way and supported by ideational and interactive meanings. Words behave like human beings gathering into groups and pursuing one topical ideology.

Table 26. Specific lexical density in Text 3

\begin{tabular}{|l|l|}
\hline $\begin{array}{l}\text { Number of content-carrying lexical } \\
\text { items }\end{array}$ & 49 \\
\hline Number of lexical items in text & 147 \\
\hline Total lexical density & $33 \%$ \\
\hline
\end{tabular}

The percentage of specific subject lexical units is 33 per cent. If I compare this result with the other three samples numbers, the average density is about 30 percent. So the lexical density of Chouliaraki's conclusion is slightly higher but it fits in the range of the 30-35 percent. That fact explains the reader's impression that the text has a high terminological concentration. However, this intensification is not overwhelming. The terms are given in nominal clusters and supported with a sufficient number of verbs.

The cohesion relationships are clear and explicit. As Halliday \& Matthiessen (2004) and Eggins (2004) state, generic coherence identifies the genre while registerial coherence specifies the situation. As the genre of an academic text advises, this conclusion possesses a number of cohesive conjunctions (insofar, yet, that, and, albeit) and the author's hedges (I explored, I showed, taking my point, I argued). The contextual coherence highlights the AL context. After the reader identifies the genre path (RA 
conclusion), his perception needs more details that will help him to envision "the entire collection of clauses: the domain the text is focusing on (its field), what roles the writer or interactants are playing (its tenor), and how closely language is tied to the experience it's commenting on (its mode)" (Eggins, 2004, p. 29). In this context, there are two main threads of semantic reference. The first reference link has an implication of subjectivity ('in this paper $-I-I-I$ '). These cohesive constructs represent the research project and the researcher's identity. The other motif refers to the research material and findings (witnessing, dimensions, changes, technologisation, post-humanitarian news publics, collective agency, technological activism). Here is the shortened version of the Table "Reference Chains in Text 3":

*In this paper, ${ }^{*} \mathbf{I} \rightarrow$ the nature of witnessing $\rightarrow{ }^{*} I \rightarrow$ the multi-modality of convergence $\rightarrow$ the narrativity $\rightarrow$ three key textual dimensions $\rightarrow$ structural changes $\rightarrow$ logic of news as techno-textual interactivity $\rightarrow * I \rightarrow$ post-television witnessing $\rightarrow$ becoming technologized $\rightarrow$ This technologisation of witnessing $\rightarrow$ the emergence of witnessing and the manifestation of ethos $\rightarrow$ it $\rightarrow$ ambivalent forms of collective agency $\rightarrow$ which $\rightarrow$ post-humanitarian news publics $\rightarrow$ *publics that $\rightarrow$ a communitarian moral imagination $\rightarrow$ forms of technological activism

*Reference to the researcher and her work

** combined duplicated reference

The organization of the text with only 10 clauses focuses on lexical cohesion when the research findings are discussed in the evolution (nature of witnessing $->$ multimodality of convergence $\rightarrow$ narrativity $\rightarrow 3$ dimensions $\rightarrow$ changes $\rightarrow>>$ news as technotextual interactivity $->$ technologisation of witnessing $->$ manifestation of ethos $->$ ambivalence of collective agency -> post-humanitarian news publics forms of technoactivism). As I follow the steps of cohesive reference, I comprehend the gist of Chouliaraki's research project as a whole. Important research patterns can be recovered 
through prominent referential chains that represent the doer (the article author) and the $\mathrm{AL}$ activity (research on post-television witnessing).

Finally, Themes should be considered as an organizational intention of sending meaningful messages to the recipient. There are 11 topical and 2 textual Themes.

Table 27. Theme in Text 3

\begin{tabular}{|c|c|c|c|c|}
\hline $\begin{array}{l}\text { Sentence/ } \\
\text { Clause }\end{array}$ & \multicolumn{2}{|c|}{ THEMES: Textual } & Interpersonal & Topical \\
\hline I/1 & In this paper, & & & $\mathbf{\Delta}$ \\
\hline II $/(2)$ & \multicolumn{4}{|c|}{ Taking my point....(tempered clause)I } \\
\hline 3 & 1 & & & $\Delta$ \\
\hline III / 4 & $\begin{array}{l}\text { Insofar as such structural } \\
\text { changes }\end{array}$ & $\Delta$ & & $\boldsymbol{\Delta}$ \\
\hline IV/5 & I & & & $\boldsymbol{A}$ \\
\hline IV / 6 & post-television witnessing & & & $\Delta$ \\
\hline $\mathrm{V} / 7$ & $\begin{array}{l}\text { This technologisation of } \\
\text { witnessing }\end{array}$ & & & $\overline{\mathbf{\Delta}}$ \\
\hline $\mathrm{VI} / 8$ & Yet it & $\mathbf{\Delta}$ & & $\boldsymbol{\Delta}$ \\
\hline $\mathrm{VI} / 9$ & which & & & $\begin{array}{l}\Delta \text { (structural- } \\
\text { topical) }\end{array}$ \\
\hline $\mathrm{VI} / 10$ & publics that & & & $\Delta^{2}$ \\
\hline $\mathrm{VI} / 11$ & (publics that) & & & $\left(\Delta^{2}\right)$ \\
\hline & Total: & 2 & $\overline{0}$ & 11 \\
\hline
\end{tabular}

The first sentence has a circumstance as a Theme ('in this paper'). Eggins (2004) classifies this type as a highly marked Theme when "skillful writers and speakers choose marked Themes to add coherence and emphasis to their text" (p. 320). There are two first-person singular pronouns (the topical one in clause 2 and the interpersonal one in clause 5).The other Theme patterns contain conceptual foci of the given discourse ('in this paper - structural changes - post-television witnessing - technologisation of witnessing - publics'). Two pronouns, a substitute 'it' and a determiner 'which' can be found in clauses 8 and 9 . In the end, there appear interesting cases in the last two clauses (9 and 10). There is an unusual Theme 'publics that' where the items repeat each other. 
Here, the pronoun-determiner 'that' connects the clauses and plays the role of the Subjects before the verb 'are driven' and acts as the elliptical unit before the verb 'are based'. There is no need to use the word 'publics' since it has already had its substitute. The author deliberately bends the syntactic rule. This duplication makes the composition prominent and underlines the final statement in the given $\mathrm{AL}$ conclusion:

Yet it has simultaneously given rise to ambivalent forms of collective AGENCY, WHICH potentially produce post-humanitarian news PUBLICS -

PUBLICS THAT are driven by a communitarian moral imagination and YPUBLICS THAT $\}$ are based on instantaneous, albeit discontinuous, forms of technological activism.

Thus this compositional strategy helps the author to focus the reader's attention on her AL viewpoint. The term 'publics' finishes the terminological chain in this conclusion and opens a perspective for further research and discussion.

In this AL discourse, the author starts with her vision ('in this paper' and 'I') and continues with her article key concepts. Eventually, she makes the main ideas textually prominent with reference 'it' in clause 7 , determination 'which' in clause 8 , and duplication 'publics that' in clause 10. As for the interpersonal Theme element, one case is evident (the hedge 'I argued' in clause 5).

To sum up, Chouliaraki's article conclusion has the following characteristics: highly nominalized texture, 40 percent of terminological density, terminology as the prominent cohesive and Thematic element. The compact size of the conclusion in her research article does not restrict but rather gives value to the composition of this discourse. The reader receives the $\mathrm{AL}$ article conclusion framework that is a 
terminologized but not confusing in organizing structures and composing textual meanings. 


\section{Chapter Seven - Text 4}

\section{TEXT 4}

Authors: C. Kenner, Gunther Kress, H. Al-Khatib, R. Kam, \& K.-C. Tsai

Title: "Finding the Keys to Biliteracy: How Young Children Interpret Different Writing Systems"

Journal: Language and Education

Year: 2004

\begin{tabular}{|c|c|c|}
\hline Sentence & Clause & TEXT 4 \\
\hline 1 & 1 & $\begin{array}{l}\text { The children in the 'Signs of Difference' study were able to cope well with } \\
\text { learning different writing systems at the same time. }\end{array}$ \\
\hline \multirow[t]{2}{*}{2} & 2 & Rather than being 'confused' by simultaneous input, \\
\hline & 3 & the children were experiencing cognitive benefits. \\
\hline \multirow[t]{4}{*}{3} & 4 & They were able to look for \\
\hline & 5 & and comprehend the principles on which each system was based, \\
\hline & 6 & clarifying differences between systems \\
\hline & 7 & as their learning progressed over time. \\
\hline 4 & 8 & $\begin{array}{l}\text { The research underlines young children's ability to make well-founded } \\
\text { interpretations of the teaching available at school and at home in order to } \\
\text { understand graphic representations. }\end{array}$ \\
\hline \multirow[t]{4}{*}{5} & 9 & It suggests \\
\hline & 10 & $\begin{array}{l}\text { that children's awareness of the principles on which writing systems } \\
\text { operate is stimulated }\end{array}$ \\
\hline & 11 & and enhanced by biliterate experience, \\
\hline & 12 & $\begin{array}{l}\text { and that this experience should be available to both monolingual and } \\
\text { bilingual children as part of mainstream education. }\end{array}$ \\
\hline
\end{tabular}

\subsection{Ideational Metafunction}

The ideational metafunction is a complex network of logical and experiential language implications, described earlier. I will tackle two main phenomena in the ideational dimension, notably the transitivity system to reflect the experiences articulated via language and clause typology to pinpoint the logical intra-textual connections here.

C. Kenner, G. Kress, H. Al-Khatib, R. Kam, and K.-C. Tsai create a 5-sentence article conclusion which is created in a teletype fashion, with a minimum of connectors 
and transitions. The results are reported in a concise and precise manner. This conclusion is literally a string of concrete happenings, i.e. processes.

Sentences 1, 2: The main article idea (children were able to cope with writing systems and to experience cognitive benefits) and the main context are given (the 'Signs of Difference' study).

Sentence 3: Specifications about the main message are explained ('cognitive benefit' is defined as 'to comprehend' and 'to cope' which is uncovered as 'clarifying differences between systems).

Sentence 4: The usefulness of comprehension is interpreted as 'children's ability to grasp teaching and graphic representations at school.

Sentence 5: The co-authors make an overall summary with cycled repletion (e.g. "the principles on which each system was based and the principles on which writing systems operate') and conclude ('Children are able to cope with different systems that is why bilingual [study] experiences should be available to them').

These happenings help to observe how multifaceted this very short conclusion is.

Every stage consists of one (maximum two) not overly complex sentences. The authors chose the abbreviated structure to sum up their message (children are able/ are aware of) and their prospects (willingness to promote multi-system [bilingual] teaching/ learning at school). The compressed way of self-expression does not prevent the authors from being versatile. They do not use one and the same process type to write a conclusion. In contrast, they have a teletype 'process-by-process' manner.

There are 9 fully ranked clauses. In addition, there are 2 tempered clauses and 2 embedded clauses. The tempered clauses are expressed by the participle phrases and save their status but are completely dependent on the main clause. An embedded clause loses its status of a clause and develops another clause element. The process type classification is given in the Appendix, here is the calculated result:

\begin{tabular}{|l|l|}
\hline Process Type & Text 4 \\
\hline Material & 0 \\
\hline
\end{tabular}




\begin{tabular}{|l|l|}
\hline Mental & $10(84 \%)+1$ in a tempered clause \\
\hline Verbal & $1(8 \%)$ \\
\hline Relational: attributive & $1(8 \%)+1$ in a tempered clause \\
\hline Relational: identifying & 0 \\
\hline Existential & 0 \\
\hline Behavioural & 0 \\
\hline Possessive & 0 \\
\hline
\end{tabular}

The prevailing majority of the processes are of mental (cognitive) nature, namely:

\begin{tabular}{lll} 
Senser - & Mental Process - & \multicolumn{1}{c}{ Phenomenon } \\
The children & were able to cope & (with learning) \\
The children & were experiencing & (cognitive benefits) \\
They & were able to look for & \\
\{They & \{were able to comprehend & \\
The research & underlines & (children's ability)
\end{tabular}

\section{Phenomenon -}

The children's awareness is stimulated structures)
Mental Process (inversed in Passive Voice

\{The children's awareness $\quad\{$ is $\}$ enhanced

The domination of the mental processes can be seen even in non-finite infinitive patterns, for example, 'to make interpretations'. 'Make' in isolation implies a material process but it is extended by purely cognitive lexical component interpretations. As a result, the reader receives a metaphorical process 'to make interpretations' where his role of a doer intermingles with abstract cognitive capabilities. Likewise, 'cope with learning' is a concrete plan to excel ('cope') in studies but also successful entering ('learning') the abstract writing system. The AL discourse eliminates all the shades of the material characteristics and make these processes completely mental. 
Attributive and verbal processes are moderately used in this conclusion. The verbal process 'suggest' has a very important position. It is situated in the main clause of the final sentence of the conclusion. The rest that is said in the sentence is of an immense importance.

\begin{tabular}{|l|l|}
\hline $\begin{array}{l}\text { It [research] } \\
\text { suggests }\end{array}$ & $\begin{array}{l}\text { that children's awareness of the principles on which writing systems } \\
\text { operate is stimulated and enhanced by biliterate experience, and that } \\
\text { this experience should be available to both monolingual and bilingual } \\
\text { children as part of mainstream education. }\end{array}$ \\
\hline
\end{tabular}

The process is close to the mental sphere because it is a projection of an idea (cognitive matter), not a locution (projection of the said words).

As for the logical meanings, they can be analyzed through the clause simplexes and complexes. Two (40\%) sentences are simplexes and three $(60 \%)$ are complexes. Let us take a look at the final sentences as a clause complex.

\begin{tabular}{|l|l|l|l|}
\hline $\begin{array}{l}\text { Main } \\
\text { Clause }\end{array}$ & $\begin{array}{l}\text { Dependent Clause } \\
\text { (projection of idea') }\end{array}$ & $\begin{array}{l}\text { Dependent } \\
\text { Clause }^{2} \\
\text { (paralleled with } \\
\text { projection of } \\
\text { idea') }\end{array}$ & $\begin{array}{l}\text { Dependent Clause } \\
\text { (paralleled with } \\
\text { projections }^{\prime, 2} \text { ) }\end{array}$ \\
\hline It suggests & $\begin{array}{l}\text { that children's awareness of } \\
\text { the principles on which } \\
\text { writing systems operate is } \\
\text { stimulated } \\
\text { and enhanced by } \\
\text { biliterate } \\
\text { experience, }\end{array}$ & $\begin{array}{l}\text { and that this experience } \\
\text { should be available to } \\
\text { both monolingual and } \\
\text { bilingual children as part } \\
\text { of painstream education. }\end{array}$ \\
\hline
\end{tabular}

The given sentence includes paratactic and hypotactic relations. The main clause starts as a classic example of hypotaxis ('It suggests that'). Then the relationships get more intricate. There are two parallels and they intertwine with each other. The first 
dependent clause is connected with the second dependent clause (the children`s awareness is stimulated and enhanced) and, at the same time, it is logically connected with the third dependent clause:

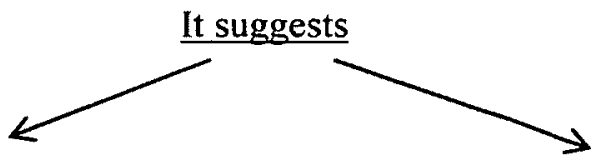

[that the children's awareness is stimulated and enhanced] and [that this experience should be available]

\begin{tabular}{|c|c|c|}
\hline Sentence 5 & & It suggests \\
\hline $\begin{array}{l}\text { clause } \\
\text { complex }\end{array}$ & $\mathrm{H}$ & $\begin{array}{c}1 \text { ' } \beta \quad 3 \text { that children's awareness of the principles [[on which } \\
\text { writing systems operate]] is stimulated }\end{array}$ \\
\hline & $\mathbf{P}$ & +4 and enhanced by biliterate experience, \\
\hline & $\begin{array}{l}\mathrm{P} / \\
\mathrm{H}\end{array}$ & $\begin{array}{l}+2 \lambda \text { and that this experience should be available to both } \\
\text { monolingual and bilingual children as part of mainstream education. }\end{array}$ \\
\hline
\end{tabular}

Within the borders of one sentence there are logical cycles as phenomenon of the ideational metafunction. In my opinion, the pattern 'it suggests' + dependent clauses $1,2,3$ shows a logico-semantic connection. The authors of this AL conclusion are very concise. They conclude their research findings, compressing meaningful items into 5 significant contexts-sentences.

\subsection{Interpersonal Metafunction}

The article topic and journal context dictate the implied nature of the dialogue between the authors and the readers who are, most likely, applied linguists and educators. The Mood, MOOD and RESIDUE patterns, Modality and polarity connotation are examined as interpersonal constructs of the given conclusion. 
In this chapter, the analysis of the interpersonal metafunction measures the distance between the dialogizing sides and their involvement in the discourse. The context of an AL article establishes certain roles, that of the knowledgeable author and that of the reader who is open to specific-subject knowledge. The powers in dialogue tend to be set up in this context from the start as an even balance. Therefore, the involvement should be high to provide a professionally convincing tone. The interpersonal metafunction realizations will show how this dialogue about language instruction is being developed and how the modality, mood and polarity elements are chosen to build relationships here.

This conclusion as well as the article is written co-operatively. It is the shortest conclusion out of four excerpts in this research. There are 5 declarative sentences. No interrogatives and imperatives are detected.

Table 28. Mood in Text 4

\begin{tabular}{|l|l|l|}
\hline Sentence 1 & Declarative Mood & Statement \\
\hline Sentence 2 & Declarative Mood & Statement \\
\hline Sentence 3 & Declarative Mood & Statement and Acknowledgement \\
\hline Sentence 4 & Declarative Mood & Statement \\
\hline Sentence 5 & Declarative Mood & Statement and Statement \\
\hline
\end{tabular}

The MOOD pattern consists of the Subject, Predicator, and polarity. I de-compose every clause to point out the MOOD elements in 10 clauses with 2 tempered clauses (see MOOD \& RESIDUE analysis in Appendix). Let us start with the MOOD patterns.

Table 29. MOOD and RESIDUE in Text 4

\begin{tabular}{|l|l|l|l|}
\hline $\begin{array}{l}\text { Sentence/ } \\
\text { Clause }\end{array}$ & \multicolumn{2}{|c|}{ MOOD: SUBJECT and FINITE } & RESIDUE \\
\hline $\mathrm{I} / \mathrm{l}$ & $\begin{array}{l}\text { The children in the 'Signs } \\
\text { of Difference' study }\end{array}$ & were able & to cope \\
\hline
\end{tabular}




\begin{tabular}{|c|c|c|c|}
\hline II $/(2)$ & \multicolumn{3}{|c|}{ Rather than being 'confused' by simultaneous input (tempered clause) } \\
\hline $11 / 3$ & the children & were & experiencing \\
\hline III/4 & they & were able & to look for \\
\hline III $/ 5$ & $\{$ they & $\{$ were able $\}$ & $\begin{array}{l}\{\text { to }\} \\
\text { comprehend }\end{array}$ \\
\hline III / (6) & \multicolumn{3}{|c|}{ clarifying differences between systems } \\
\hline $111 / 7$ & their learning & \multicolumn{2}{|l|}{ progressed } \\
\hline IV /8 & the research & \multicolumn{2}{|l|}{ underlines } \\
\hline $\mathrm{V} / 9$ & it & \multicolumn{2}{|l|}{ suggests } \\
\hline $\mathrm{V} / 10$ & $\begin{array}{l}\text { children's awareness of } \\
\text { the principles [[on which } \\
\text { writing systems operate]] }\end{array}$ & is & stimulated \\
\hline $\mathrm{V} / 11$ & \{children's awareness\} & $\{$ is $\}$ & enhanced \\
\hline $\mathrm{V} / 12$ & this experience & should & be available \\
\hline
\end{tabular}

It is remarkable that all the Subjects are key concepts and the pronouns that replace them. There are no such Subjects as academic 'we' or impersonal 'it'. These Subjects are structured to encompass the synopsis of the article and to build a discussion around them. Among the article notions that are chosen to be the part of the MOOD, the unit 'children' seems to be prominent. The Subject in the first sentence combines two important key notions 'the children' and 'the "Signs of Difference" study". Thus the authors pinpoint their article's scope. The Subject 'children' is foregrounded in the second (as a noun with the definite article)) and third (a pronoun-substitute 'they') sentences. Also, there is 'the children's ability' and 'experience' as Subjects of subordinate clauses in the fifth sentence. I assume, the Subject patterns send direct signals to the reader that this research aims at the children's benefit and progress. It addresses the linguists and educators as the topic is being analyzed for children.

\begin{tabular}{|l|}
\hline Subjects in TEXT 4 \\
\hline The children in the 'Signs of Difference' study \\
\hline the children \\
\hline they \\
\hline they \\
\hline their learning \\
\hline
\end{tabular}




\begin{tabular}{|l|}
\hline the research \\
\hline it \\
\hline children's awareness of the principles [[on which writing \\
systems operate]] \\
\hline \{children's awareness \\
\hline this experience \\
\hline
\end{tabular}

I can see how the notion 'children' is being consistently repeated. This prominence can be interpreted as an interpersonal signal to attract the reader's attention to the significant interactant of the AL language acquisition discourse.

The Subjects are supported by the Finite elements in the MOOD, the core that gives life to the unit as a whole. Out of 12 Finites, 3 Finites combine the Finite and the Predicator in themselves ('progressed', 'underlines' and 'suggests'). Most of Finites (7) are complex, having separate elements for the Finite and the Predicator. 6 Finites are temporal operators and 4 Finites are modal.

Table 30. Finites in Text 4

\begin{tabular}{|c|c|c|}
\hline were & able to cope & Modal Finite: modulation \\
\hline were & experiencing & Temporal Finite: Past Progressive \\
\hline were & able to look for & Modal Finite: modulation \\
\hline$\{$ were $\}$ & \{able to comprehend & Elliptical Modal Finite: modulation \\
\hline progressed & & Temporal Finite: Past Simple \\
\hline underlines & & Temporal Finite: Present Simple \\
\hline suggests & & Temporal Finite: Present Simple \\
\hline is & stimulated & $\begin{array}{l}\text { Temporal Finite: Present Simple } \\
\text { Passive }\end{array}$ \\
\hline$\{$ is $\}$ & enhanced & $\begin{array}{l}\text { Temporal Finite: Present Simple } \\
\text { Passive }\end{array}$ \\
\hline should & be available & Modal Finite: modulation \\
\hline
\end{tabular}

All the modal operators are modulations ( 2 forms of inclination and 1 form of obligation). The temporal operators vary, namely they are expressed with two tense aspects, Progressive and Simple. In addition, Present and Past interact. Both the Active 
and Passive voice help to accomplish the mission of the Finites in this conclusion. In the process of summarizing, the RESIDUE pattern Complements and Adjuncts, are helpers in supporting a dialogue between the author and the reader in the clause. 4 complements and 14 circumstantial adjuncts provide communication channels with necessary details and accents (see the MOOD and RESIDUE analysis in Appendix 2, p. 204). Six out of 14 adjuncts ( 3 conjuncts 'and', 'that' (2), and 'as) are conjunctive they make the dialogue of the AL discourse smooth and cohesive but belong to neither MOOD, nor RESIDUE. The classification of complements and adjuncts (only those in RESIDUE) in Finite clauses in this conclusion is the following:

Table 31. Complements and Adjuncts in Text4

\begin{tabular}{|l|l|l|}
\hline Complements & Adjuncts & Location \\
\hline & $\begin{array}{l}\text { well (Manner)/with learning different } \\
\text { writing systems (Matter) / at the same time. } \\
\text { (Time) }\end{array}$ & RESIDUE \\
\hline cognitive benefits. & & RESIDUE \\
\hline $\begin{array}{l}\text { the principles [[on which each } \\
\text { system based]] }\end{array}$ & & RESIDUE \\
\hline $\begin{array}{l}\text { young children's ability to } \\
\text { make... available / well- } \\
\text { founded interpretations }\end{array}$ & $\begin{array}{l}\text { at school (Location) and at home (Location) / } \\
\text { in order to understand graphic } \\
\text { representations.(Purpose) }\end{array}$ & RESIDUE \\
\hline $\begin{array}{l}\text { to both monolingual and } \\
\text { bilingual children }\end{array}$ & by biliterate experience (Agent) & RESIDUE \\
\hline
\end{tabular}

Considering the classification Summary of types of Adjuncts (Eggins, 2004, p. 165), I sum up:

The total number of Adjuncts: 14

Circumstantial (Location (1), Time (2), Matter (1), Manner (1), Purpose (1), Agent (1), and Role (1)) 
Interpersonal (mood, polarity, comment, vocative): 0

Textual (conjunctive, continuity): and (3), that (2), as (1)

Even though complements and adjuncts are non-essential parts of the clause, they contribute to the process of assertion of speech roles in this academic written interaction. Within the limits of quite short 5-sentence conclusion, the reader is supplied with the essential information from the MOOD part and various details about location, time, purpose, agency, manner, matter, and role in the RESIDUE part. If the reader has access only to conclusion, he will still be able to make initial evaluations of the article.

Modality is another factor that expresses interpersonal meanings. As I have mentioned above, there are three modals in the text and all of them are modulations. The modal structure 'be able to' refer to the children's abilities. The modal 'should' is a recommendation (mitigated obligation) implanted in the $\mathrm{AL}$ conclusion.

It is noticeable that the Polarity component is $100 \%$ positive in this discourse (absence of negative Finite forms). The Polarity positivity is supported by positive connotations:

- to cope well

- experiencing cognitive benefits

- $\underline{\text { able }}$ to comprehend

- clarifying differences

- their learning progressed over time

- young children's ability

- to make well-founded interpretations

- awareness is stimulated and enhanced

- available to monolingual and bilingual children

The positive connotation accentuates the tact of the interaction in this AL discourse. Some collocations can tend into the negative direction in some other contexts but in this interpersonal environment they transform this negative tendency:

\begin{tabular}{|l|l|}
\hline Ambiguous Connotations & Commentary \\
\hline Rather than being 'confused' & $\begin{array}{l}\text { The structure 'rather than' modifies the perception } \\
\text { of the negative attribute 'confused' }\end{array}$ \\
\hline
\end{tabular}




\begin{tabular}{|l|l|}
\hline $\begin{array}{l}\text { clarifying differences between systems as their } \\
\text { learning progressed over time }\end{array}$ & $\begin{array}{l}\text { 'Differences' are surrounded by evidently positive } \\
\text { 'clarifying' and 'progressed' }\end{array}$ \\
\hline $\begin{array}{l}\text { this experience should be available to both } \\
\text { monolingual and bilingual children as part of } \\
\text { mainstream education. }\end{array}$ & $\begin{array}{l}\text { 'Mainstream' is equivalent to available and } \\
\text { accessible. Mainstream education with a biliteracy } \\
\text { component is preferable and experience-enriching. }\end{array}$ \\
\hline
\end{tabular}

To sum up, this dialogue is an interaction with not two but three interactants. Considering the context of Language Acquisition as an $\mathrm{AL}$ branch dominant in this conclusion, Not only the the authors (AL researchers) and readers (AL educators) are invited into this discourse but the most important participant, the child, domineers in the MOOD pattern (as shown in Figure)

Figure 5. Dialogue of three participants in the discourse of Text 4

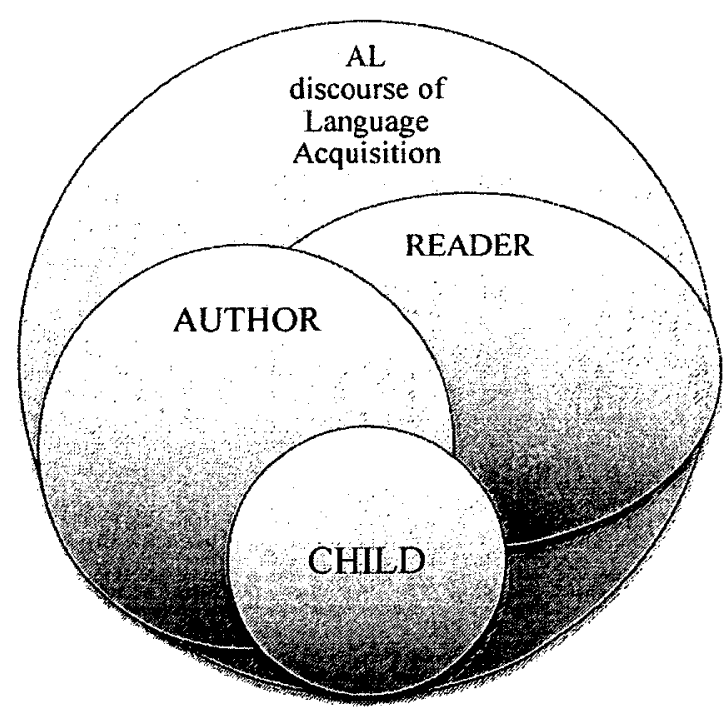

The children are the Subjects of the educational branch of applied linguistics. The Interpersonal metafunction in this conclusion shows a dialogue of the three sides that are trying to benefit from knowledge. 


\subsection{Textual Metafunction}

The meanings of the textual metafunction represent the compositional factor in the discourse production. The reader has 5 complex but not 'wordy' sentences. The discourse is written and formal. I will examine first the phenomenon of nominalization.

Although heavily nominalized language can sound pretentious and may make the meaning obscure, the real motivation for this grammatical process is a functional one: by nominalizing we are able to do things with the text that we cannot do it in unnominalized text. Nominalization has two main textual advantages: rhetorical organization and increased lexical density (Eggins, 2004, p. 95).

I strongly support Suzanne Eggins who defends the nominalization as a dynamic element that achieves logic and consciousness. The nominal chains play a crucial role in organizing academic journal discourse, in general, and applied linguistics discourse (as in the text being analyzed), in particular. "By nominalizing actions and logical relations, we can organize our text not in terms of ourselves, but in terms of ideas, reasons, causes, etc." (Eggins, 2004, p. 95). The given conclusion has only 10 clauses. But it still contains a large number of nominalizations.

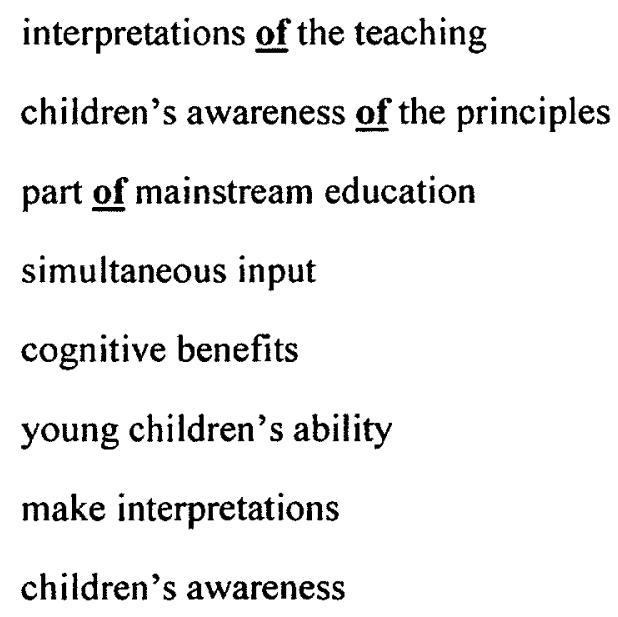

The nominal groups contain lexical chains of terms that are characteristics of the specific field of applied linguistics. The nouns 'awareness, 'education', or 'input' become 
AL terms with the help of the discourse they are placed in and are connected with the preposition 'of' (3). The specific lexical density becomes a feature which highlights the authors' choices for loading the compositional framework with AL content. The discourse contains many terms:

The Applied Linguistics content-carriers:

- children(4) + monolingual and bilingual children

- signs

- difference (2)

- learning (2)

- writing systems (2)

- system (2)

- simultaneous input

- cognitive benefits

- research / study

- ability / awareness (2)

- biliterate experience (2)

- interpretations / representations

- teaching / education

Table 32. Specific lexical density in Text 4

\begin{tabular}{|l|l|}
\hline number of content carrying lexical items & 122 \\
\hline number of lexical items in text & 37 \\
\hline total lexical density & $30 \%$ \\
\hline
\end{tabular}

Yet, Kenner and co-authors' conclusion is not too highly nominalized. It possesses a sufficient amount of content-carriers to construct a brief and formal academic summary. As a result, every third word ( 30 per cent of the total number of words) contains an important semantic message to the specialist. This lexical medium density makes the conclusion meaningful but easy to perceive.

The cohesive factor is worth mentioning as well. The five sentences are thoroughlyelaborated because they are linked to each other in a simplified way. There are few transitions. The linkage is being developed at the micro-level of clause, within the 
terminological nominal groups. There are three main cohesive prospects that are described as parallels throughout the conclusion. I have labeled them 'reference groups' that refer to research participants, research presuppositions and research results. These three groups have implied perceptive 'hooks' in every clause. At the end of the conclusion the reader starts to perceive them as three cohesion paths that meet in the final statement and sum up the entire utterance. The nominal and pronominal items as the reference chains:

\begin{tabular}{|c|c|c|}
\hline$\rightarrow$ Research Participant & $\rightarrow$ Research Presuppositions & $\rightarrow$ Research Result \\
\hline $\begin{array}{l}\text { The children in the 'Signs of } \\
\text { Difference' } \rightarrow \text { the children } \\
\rightarrow \text { They } \rightarrow \text { their (learning) } \rightarrow \\
\text { young children's ability } \rightarrow \\
\text { children's awareness } \rightarrow \\
\text { monolingual and bilingual } \\
\text { children }\end{array}$ & $\begin{array}{l}\text { Learning systems } \rightarrow \text { input } \rightarrow \\
\text { cognitive benefits } \rightarrow \text { the } \\
\text { principles } \rightarrow \text { system } \rightarrow \\
\text { differences between systems } \rightarrow \\
\text { interpretations } \rightarrow \text { graphic } \\
\text { representations } \rightarrow \text { principles } \\
\rightarrow \text { systems }\end{array}$ & $\begin{array}{l}\text { (Their) learning } \rightarrow \text { the research } \\
\rightarrow \text { it } \rightarrow \text { biliterate experience } \rightarrow \\
\text { this experience } \rightarrow \text { mainstream } \\
\text { education }\end{array}$ \\
\hline
\end{tabular}

The cohesion factor is one of the main contributors to forming the text as semantic unit. In this case, it is not conjunctive cohesion that is chosen to make the text look whole. It is lexical cohesion where elements perform multiple functions, being contentcarriers and cohesion constructs at the same time. Eggins (2004) call them "lexical strings that add texture to text" (p. 44).

Eventually, discussing the textual tissues of the text body, I need to mention Theme-patterns. In this conclusion, 12 topical Themes in 12 clauses $(2$ clauses are tempered). Also, there are 6 textual Themes. No interpersonal Themes can be observed. 
Table 33. Theme in Text 4

\begin{tabular}{|c|c|c|c|c|}
\hline $\begin{array}{l}\text { Sentence/ } \\
\text { Clause }\end{array}$ & THEMES: Textual & & Interpersonal & Topical \\
\hline $\mathrm{I} / \mathrm{I}$ & $\begin{array}{l}\text { The children in the 'Signs of } \\
\text { Difference' }\end{array}$ & & & $\Delta$ \\
\hline II $/(2)$ & $\begin{array}{l}\text { ((Rather than being } \\
\text { confused by simultaneous } \\
\text { input)), }\end{array}$ & \multicolumn{3}{|c|}{ tempered clause } \\
\hline II $/ 3$ & the children & & & \\
\hline III / 4 & They & & & $\Delta$ \\
\hline III / 5 & and (they) & $\Delta$ & & $(\mathbf{A})$ \\
\hline III / (6) & $\begin{array}{l}\text { ((clarifying differences } \\
\text { between systems)) }\end{array}$ & \multicolumn{3}{|c|}{ tempered clause } \\
\hline III/ 7 & as their learning & $\Delta$ & & $\Delta$ \\
\hline IV / 8 & The research & & & $\Delta$ \\
\hline $\mathrm{V} / 9$ & It & & & $\Delta$ \\
\hline $\mathrm{V} / 10$ & $\begin{array}{l}\text { that the children's } \\
\text { awareness of the principles } \\
\text { [[on which the writing } \\
\text { systems operate]] }\end{array}$ & $\Delta$ & & $\Delta$ \\
\hline $\mathrm{V} / 11$ & $\begin{array}{l}\text { and (the children's } \\
\text { awareness) }\end{array}$ & $\Delta$ & & ( $\mathbf{\Delta})$ \\
\hline $\mathrm{V} / 12$ & and that this experience & $\Delta \mathbf{A}$ & & $\Delta$ \\
\hline & Total: & 6 & 0 & 12 \\
\hline
\end{tabular}

Topical Themes are of two types, 7 non-elliptical and 2 elliptical ('they' and 'children's awareness'), ones. Among 7 non-ellipticals, two are extended with embedded clauses. Let us look at one example to see how this extended topical Theme functions in the discourse (clause 8):

Sentence 5: It suggests that children's awareness of the principles [lon which writing systems operate]] is stimulated and enhanced by biliterate experience, and that this experience should be available to both monolingual and bilingual children as part of mainstream education.

The rank-shifting clause serves as a characteristic of the topical Theme 'children's awareness of the principles'. Due to a long nominal group with a connector-preposition and reference linkage "principles on which", the construction cannot change the sequence of its items. Thus the embedded clause becomes the dependent part of the single but 
composite topical Theme and occupies the position between the main part of the topical and the Rheme 'is stimulated'.

Clause 8

\begin{tabular}{|l|l|l|l|}
\hline that & $\begin{array}{l}\text { children's awareness of the principles [[on } \\
\text { which writing systems operate]] }\end{array}$ & is & stimulated \\
\hline $\begin{array}{l}\text { Textual } \\
\text { Theme }\end{array}$ & $\begin{array}{l}\text { Topical Theme: nominal chain + embedded } \\
\text { clause }\end{array}$ & Rheme & \\
\hline
\end{tabular}

These slight non-conformist 'bumps' help to make the textual level more natural (resemblance to spoken academic discourse extended topical Themes. The textual Themes are presented by 'and' (3), 'that' (2), and 'as'. Interestingly, there are no interpersonal Themes in this conclusion. That means the discourse has no Mood Adjuncts, i.e. Mood, Vocative, Polarity or Comment Adjuncts. The attention is shifted from the author's stance onto the topical Themes, comprised of article key notions and their characteristics.

The essential contribution made by textual meaning is to actualize a range of different textual structures which operate at all levels of the text, and whose function is to enable the ideational and interpersonal meanings we have chosen to make to be realized in a cohesive text (Eggins, 2004, p. 326).

Kenner, G. Kress, H. Al-Khatib, R. Kam, \& K.-C. Tsai create a short but inclusive conclusion with fully realized metafunctions. They initiate an AL discussion with an educational scope, teaching teachers how to teach. They choose the text structures carefully, triggering a complex dialogue and transmitting the results of their biliteracy experience project "Signs of Difference". In writing their conclusion, the authors are clear, concise and proficient as educators in applied linguistics should be. 


\section{Chapter Eight - Discussion}

Four conclusions from research articles in applied linguistics have been analyzed by me. After interpreting ideational, interpersonal an textual meanings in these texts, I am ready to summarize my findings and make conclusions for many writers involved in the genre of RA conclusion-writing in the AL discourse.

\begin{tabular}{|l|l|l|l|l|l|}
\hline Text & & Journal & AL Branch & $\begin{array}{l}\text { No. } \\
\text { sentences }\end{array}$ & $\begin{array}{l}\text { No. } \\
\text { clauses }\end{array}$ \\
\hline $\begin{array}{l}\text { K. Hyland } \\
\text { Writing without conviction? } \\
\text { Hedging in science research } \\
\text { articles. }\end{array}$ & 1996 & Applied Linguistics & $\begin{array}{l}\text { Academic } \\
\text { Writing }\end{array}$ & 9 & 19 \\
\hline $\begin{array}{l}\text { D. Allison, L. Cooley, J. } \\
\text { Lewkowicz, \& D. Nunan } \\
\text { Dissertation writing in } \\
\text { action: The development of } a \\
\text { dissertation writing support } \\
\text { program for ESL graduate } \\
\text { research students. }\end{array}$ & 1998 & $\begin{array}{l}\text { English for Specific } \\
\text { Purposes }\end{array}$ & ESP & 11 & 20 \\
\hline $\begin{array}{l}\text { L. Chouliaraki } \\
\text { Ordinary witnessing in post- } \\
\text { television news: } \text { towards a } \\
\text { new moral imagination. }\end{array}$ & 2010 & $\begin{array}{l}\text { Critical Discourse } \\
\text { Analysis }\end{array}$ & CDA & 6 & 11 \\
\hline $\begin{array}{l}\text { C. Kenner, G. Kress, H. Al- } \\
\text { Khatib, R. Kam, \& K.-C. } \\
\text { Tsai } \\
\text { Finding the keys to biliteracy: } \\
\text { How young children interpret } \\
\text { different writing systems. }\end{array}$ & 2004 & $\begin{array}{l}\text { Language and } \\
\text { Education }\end{array}$ & $\begin{array}{l}\text { Language } \\
\text { Acquisition }\end{array}$ & 5 & 12 \\
\hline
\end{tabular}

I would like to talk about two analytical angles of academic writing. The first angle is a wide genre analysis of academic article writing. Organizing and balancing introduction and conclusion with results and discussion / conclusion (the model IMRD) and the specific nature of the discourse regulations that are noticeable in the article as a whole and then each section. The second angle is approaching the discourse meanings through micro-structural items, for example, clauses. 
My thesis opted for the second type of analyzing the discourse patterns. The examination of clauses as meaningful semantico-structural elements has revealed how logical-experiential, interpersonal, and textual meanings create a specific discourse of applied linguistics within the framework of a research article conclusion. The four sample conclusions were taken from four different AL journals. Their authors discuss diverse topics in the domains of Academic Writing, English as a Second Language, Critical Discourse Analysis, and Language Learning. These topics accentuate numerous aspects of language and its practices as the foci of applied linguistics. Analyzing the three metafunctions in each conclusion, I examined the meanings and implications that lie behind the words. The SFL tripartite model proves that the discourse is a complex network of realizations.

This chapter summarizes the findings from 12 analyses of SFL metafunctions conclusions. The aim of the summaries is to find common features in the RA conclusions in order to map the micro-level stages in AL conclusion writing.

To make it shorter, I will refer to the samples for analysis as Text $1,2,3$, and 4. They will coordinate with the authors and AL branches as in the table on page 138.

The Transitivity System (Ideational Metafunction)

The processes, as we have seen, play a significant role in the clause. The events (either dynamic or static) wrap the syntactic unit. This rule cannot be bent in the English grammar that obeys the principle, "There is no clause without a verb". Having the same number of processes and clauses, I have identified the types of the processes: 
Table 34. Processes in $4 \mathrm{AL}$ article conclusions (overview)

\begin{tabular}{|c|c|c|c|c|}
\hline Process Type & Text 1 & Text 2 & Text 3 & Text 4 \\
\hline Material & 0 & 0 & 0 & 0 \\
\hline Mental & $7(37 \%)$ & $10(50 \%)$ & $6 \quad(55 \%)$ & $10(82 \%)$ \\
\hline Verbal & $2(11 \%)$ & $2(10 \%)$ & $1(9 \%)$ & $1 \quad(9 \%)$ \\
\hline Relational: attributive & $5(26 \%)$ & $4(20 \%)$ & 0 & $(9 \%)$ \\
\hline Relational: identifying & $3(15 \%)$ & $3(15 \%)$ & $4 \quad(36 \%)$ & 0 \\
\hline Relational circumstantial & 0 & $1 \quad(5 \%)$ & 0 & 0 \\
\hline Existential & 0 & 0 & 0 & 0 \\
\hline Behavioural & 0 & 0 & 0 & 0 \\
\hline Possessive & $2(11 \%)$ & 0 & 0 & 0 \\
\hline Total & 19 & 20 & 11 & 12 \\
\hline
\end{tabular}

As is evident, the mental process prevails. In one case, there is a group of verbs where material processes are metaphorically used to represent the mental sphere under the influence of the discourse. The study of Applied Linguistics deals with cognitive domains, linguistic systems, and language users. Text 1 has groups of typical mental ('understand', 'motivate', 'emphasize', 'ignore') and verbal ('argue', 'advise') processes. But there appears an interesting phenomenon of type-shifting in the text of the conclusion. Three verbs (provide, play, and demonstrate) lose their material meanings and begin to act like mental processes, for example:

\footnotetext{
$\rightarrow \quad$ Analysis cannot provide a rationale

$\rightarrow \quad$ Hedges play a crucial role

$\rightarrow \quad$ The analysis demonstrates the dynamic and interactive nature of scientific writing
}

Participants (research articles, linguistic analysis, hedges, science, scientists, knowledge, rationale, etc.) and Circumstances ('in isolation from contexts', 'in academic writing', 'for ratification', 'in ESP', 'in professional writing', etc.) belong strictly to the area of AL study. The AL terminology monopolizes the discourse space of the RA 
conclusion in Text 1 . In a sense, the verbs have no choice but accommodate to the specific environment requirements.

Text 2 has also the metaphorically mental processes ('combine, evolve, come from interviews, go beyond improving and enhance quality'). In other contexts these processes could easily be material. But this is not the case of the AL discourse. Text 2 is about dissertation writing problems among L2 graduates. The situation is cognitive (mental) and the processes describe what happens in the cognitive sphere of writing. Also, a significant number of verbal and relational processes can be observed. The given context needs describing ('report, express, and describe twice') and characterizing ('be overgeneralized, too strong, applicable, sure, and essential'). Though the process group number seem quite balanced in Text 2 , the mental, verbal and attributive processes tend to unite to create an specific AL linguistic discourse.

Text 3 contains 11 clauses. The information is compressed and the material processes convert into metaphorical mental processes, losing almost all the link with the material world. They are completely cognitive by nature,

E.g. I explored the nature of witnessing

The multimodality has affected the narrativity of news

Ambivalent forms of collective agency produce post-humanitarian news publics

These verbs can be material in some other contexts but this AL discourse is too compact and concentrated for any material implications. The Participants ('multimodality of convergence, cultural changes, the emergence and manifestations, post-humanitarian 
news publics') lock the verbs in between and make them mental. Circumstances support the mental sphere of the discourse, describing the AL ambience:

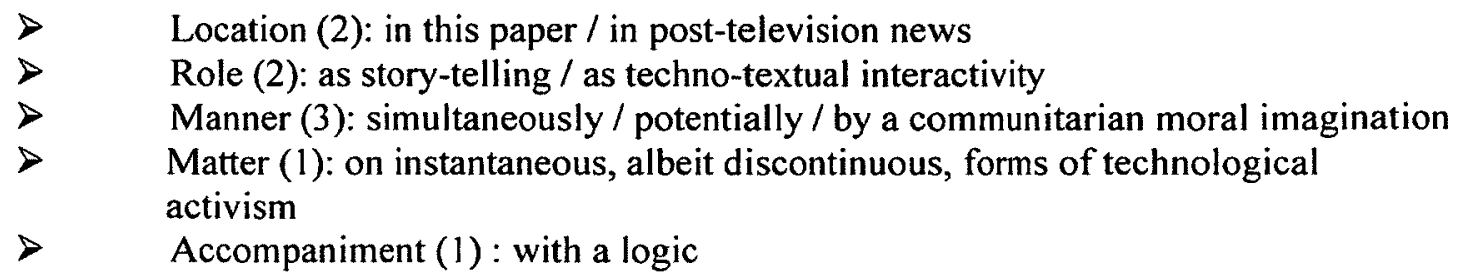

The general picture of processes arises with a dominance of mental and relational processes. The author creates an imaginary analytico-cognitive field and fills it with her assumptions, explorations, and demonstrations that sound well-thought out, objective, and grounded.

Text 4 with its 10 clauses is a one-paragraph compact conclusion. The situation is similar to the third case. 8 mental processes, mixed with 1 verbal and 1 attributive. Such verbs as 'to cope', 'to look for', 'to underline', or 'to enhance' again lose their material aspects completely and irrevocably in the compressed and highly terminologized $\mathrm{AL}$ discourse of the fourth conclusion. As a result, the discourse denies any material meanings in the surroundings of the following participants and circumstances:

Participants:

- children

- simultaneous input

- cognitive benefits

- research

- young children's ability

- interpretations of teaching

- children's awareness

- experience
Circumstances:

- over time

- at school and at home

- by biliterate experience

- to monolingual and bilingual children

- as part of mainstream education

The dominant class is a group of mental processes. This largest group comprises not only classical cognitive processes ('understand', 'see', 'comprehend', etc.) but a vast group of verbs that perceived as cognitive processes through the lens of the applied 
linguistic discourse. The smaller the discourse, the more 'absorbing' this cognitive tendency is. Verbal and relational processes share the second place after the mental type. They present the RA author a rich arsenal of verbs that can communicate their ideas to the reader, revealing details and depths through the relationships 'Sayer-Verbiage', 'Carrier-Attribute' or 'Token-Value'.

\section{Taxis and Logico-semantic Clause Type}

The logical meanings are expressed through clause taxis and choices of logicosemantic types. The correlation of clause simplexes and complexes is not homogeneous in the four conclusions analyzed. The overall results can be seen in the following table:

Table 35. Clause simplexes and complexes (overview)

\begin{tabular}{|l|l|l|l|l|}
\hline & Text 1 & Text 2 & Text 3 & Text 4 \\
\hline Clause Simplexes & 2 & 6 & 3 & 2 \\
\hline Clause Complexes & 17 & 5 & 3 & 3 \\
\hline No. clauses/ sentences & $19 / 9$ & $20 / 11$ & $11 / 6$ & $12 / 5$ \\
\hline
\end{tabular}

Text 1 is exceptional with its huge gap between the simple and complex clauses. Text 2 gives a slight preference to simplexes (though loaded with embedded clauses and expanded circumstances). Texts 3 and 4 use almost the same number of simplexes and complexes. The discourse will not necessarily be more difficult with more complexes. Certainly, simplexes will not make the discourse shallow and non-informative. Though simplexes are graphically shorter, they are as elaborate in meaning-making as complexes. They tend to compress the information but to carry the same amount of terminological content and research result report. However, the size of the conclusion may influence the author's preferences. As the table above shows, the first two long conclusions have gaps 
between clause structures. The author has time and space for branching within a clause.

On the other hand, Texts 3 and 4 are short. They need balance when their clauses are structured. Thus they can be perceived quickly but efficiently.

In terms of taxis and clause types, here are the results from my four analyses:

Table 36. Taxis and Logico-semantic types of relationships between clauses (overview)

\begin{tabular}{|l|l|l|l|l|l|}
\hline \multicolumn{2}{|c|}{} & Text 1 & Text 2 & Text 3 & Text 4 \\
\hline Taxis & Parataxis & 7 & 2 & 1 & 3 \\
& Hypotaxis & 4 & 8 & 4 & 5 \\
\hline $\begin{array}{l}\text { Logico-semantic } \\
\text { Type }\end{array}$ & $\begin{array}{l}\text { projection: } \\
- \text { idea }\end{array}$ & 1 & 2 & 1 & 2 \\
& - locution & 0 & 1 & 0 & 0 \\
& & & & & \\
& expansion: & & & & \\
& $-\quad$ elaboration & 0 & 0 & 2 & 0 \\
& - extension & 0 & 1 & 0 & 0 \\
& - enhancement & 5 & 4 & 1 & 3 \\
\hline
\end{tabular}

Each discourse has its unique clause structural balance. Considering a limited number of samples, I will make a micro-generalization, talking about these four cases. Interestingly, some commonalities to use in the mapping of an AL conclusion can be observed. Paratactic and hypotactic relationships complement each other in the discourse. The frequent logico-semantic types of connecting clauses are expansion enhancements, and projections of ideas.

Regarding the authors' choices of logico-semantic clause types, projection claims the tendency of reporting ideas, not speech. Text 2 is the only discourse with one locution (reported speech). RA conclusions are intended to summarize the author's findings and ideas about these findings. Direct or indirect speech is not a feature of this section. To make a conclusion means to interpret and offer an efficient solution to the topic-problem. 
As for expansion, the authors may be a bit more inclined to elaborations and enhancements. There is an obvious preference of enhancements in Texts 1 and 2. Elaborations are used twice in Texts 2 and 4. One thing is definitely noticeable, extension is used once (in Text 2). Extension repeats the information from the primary clause, going into detail and exemplification. This way of expanding seems to be less popular because the details are congruent for the research descriptions and result discussions whereas the conclusion is focused on findings, their limitations and perspectives (no need in more details). Enhancements are used in two longest excerpts when the authors have opportunity to inform about time, place, cause, condition, etc. Elaborations are sometimes necessary to specify the context of the main clause. The author can use different clause types to develop logics between clauses but he is not obliged to. Text 4 has only two idea projections and two participle phrases as tempered clauses. They are linked not only by primary-secondary clause relations but by terms, repeated references and topical Themes (as the interpersonal metafunction analysis shows below).

Mood

Having a choice between the declarative, interrogative, or imperative clauses in the language system, the authors of AL the four conclusions opt for the declarative Mood in their discourses. They use the declarative Mood in 100 per cent of the sentences.

\begin{tabular}{|l|l|l|l|l|}
\hline & Text 1 & Text 2 & Text 3 & Text 4 \\
\hline Declarative Mood & $9(100 \%)$ & $11(100 \%)$ & $6(100 \%)$ & $5(100 \%)$ \\
\hline
\end{tabular}

Their unanimous decision is very prominent and needs interpreting. Questions are likely to be asked in the introduction. This way the author shares his incentives and 
motives of staring the research. He identifies the gap and tries to construe the article to bridge over scientific problems not been solved yet. Questions are usually used to introduce ideas in the academic discourse (Hyland, 2002). Imperatives are commands that are too direct. The declarative statement and acknowledgement seem to the most congruent structures to make conclusions in the AL discourse.

The analysis of the Mood becomes the first step to perceive the discourse of an $\mathrm{AL}$ article as a multi-voiced (Bakhtin, 1981) dialogic structure where the researchers and their addressees are recognized as identities in the AL discourse. Looking closer at some concrete examples from my analysis, it is evident there is one common principle "no interrogatives in AL conclusions". Text 1 contains 5 statements and 4 acknowledgements. I created a table to show the author's interpersonal messages in each of 9 sentences.

\begin{tabular}{|l|l|l|}
\hline Sentence & Speech Role & Speech Function \\
\hline 1 & declarative Mood & statement \\
\hline 2 & declarative Mood & statement \\
\hline 3 & declarative Mood & statement \\
\hline 4 & declarative Mood + ellipsis (hedges) & $\begin{array}{l}\text { statement and } \\
\text { acknowledgement }\end{array}$ \\
\hline 5 & declarative Mood + ellipsis (they) & $\begin{array}{l}\text { statement and } \\
\text { acknowledgement }\end{array}$ \\
\hline 6 & $\begin{array}{l}\text { declarative Mood + ellipsis (understanding) + non-ellipsis } \\
\text { (science v scientists) }\end{array}$ & $\begin{array}{l}\text { statement and } \\
\text { acknowledgement }\end{array}$ \\
\hline 7 & declarative Mood + ellipsis (information [about hedging]) \\
(textbooks) & $\begin{array}{l}\text { statement and } \\
\text { acknowledgement }\end{array}$ \\
\hline 8 & declarative Mood & statement \\
\hline 9 & declarative Mood & statement \\
\hline
\end{tabular}

The table above shows that the author of Text 1 thoroughly groups the acknowledgements in the middle of the conclusion, sentences $4-7$. He uses statements in 
the opening and closing sentences and inserts acknowledgement-ellipses in between to help the reader to follow his dialogical moves.

In Text 2, I offer the following table to reflect the Mood in the discourse. It can be used as a prompt when writing an AL conclusion:

\begin{tabular}{|l|l|l|l|l|l|}
\hline \multicolumn{7}{|c|}{ Commodity Exchanged in an RA Conclusion } \\
\hline Speech Role & & Information & & Goods and Services & \\
\hline GIYTNG & $\mathrm{X}$ & STATEMENT & $\mathrm{X}$ & OFFER & $\mathrm{X}$ \\
\hline Demanding & $\mathrm{X}$ & Question & $\mathrm{X}$ & Command & $\mathrm{X}$ \\
\hline
\end{tabular}

The conclusion is open to the speech role of giving, stating information (including acknowledgement) and offering goods and services. Conversely, demanding, i.e. questions and commands do not seem the wide-spread way to make an efficient conclusion.

\section{MOOD \& RESIDUE}

My analyses also focus on the MOOD element that contains the Subject, Finite, and Polarity. This is the core from which the dialogical initiative starts its way to the reader. The rest of the clause is the RESIDUE element that includes Complements and Adjuncts.

Keeping in mind the fact that the number of Subjects equals to the number of clauses and that the Subjects usually initiate English structures and contributes most significantly to the clause meaning alongside with the Finite, I analyzed the Subjects in each clause to see the authors' choices. 
Table 37. Subjects (overview)

\begin{tabular}{|c|c|c|c|c|}
\hline & Text 1 & Text 2 & Text 3 & Text 4 \\
\hline SUBJECTS & $\begin{array}{l}\text { I - hedges - which } \\
\text { (choices) - analyses - } \\
\text { framework - articles } \\
\text { - which } \\
\text { (combination) - } \\
\text { hedges - they } \\
\text { (hedges) - which } \\
\text { (features) - } \\
\text { understanding - } \\
\text { science - scientists - } \\
\text { information - } \\
\text { textbooks - analysis - } \\
\text { it (nature of scientific } \\
\text { writing) - scientific } \\
\text { discourse }\end{array}$ & $\begin{array}{l}\text { Research - } \\
\text { program - we - } \\
\text { program - data - } \\
\text { study - which } \\
\text { (shortcomings) - } \\
\text { which (way) - } \\
\text { which (findings) - } \\
\text { errors - } \\
\text { framework - } \\
\text { limitation - that } \\
\text { (nature) - we - } \\
\text { approach - we - } \\
\text { we - adaptations }\end{array}$ & $\begin{array}{l}\text { I-I - } \\
\text { multimodality - } \\
\text { changes - I - } \\
\text { technologisation } \\
\text { - it - which } \\
\text { (forms) - publics }\end{array}$ & $\begin{array}{l}\text { Children - } \\
\text { children - they - } \\
\text { system - } \\
\text { research - } \\
\text { awareness - } \\
\text { experience }\end{array}$ \\
\hline
\end{tabular}

There is a tendency to have a term as the Subject, not the researcher in these discourses. To begin to interpret this fact, I need to walk in the RA article author's shoes. Being an applied linguist, the author understands that he is making meanings and how he is making these meanings.

Two types of Finites can be found, the Temporal Finite Operators and Modal Operators. Most of Finites belong to the first group. Modal verbs are not frequent in the four analyzed discourses. It is interesting that the longest conclusion (Text 1) and the shortest conclusion (Text 4 ) have the same number of modal Finites. That may signify that the proportions of temporal and modal Finites depend on the author's personal choice to express attitude and judgment. In the first example the proportion is 18 to 3 , whereas in the fourth example it is 8 to 4 . But one commonality still can be found. Modal Finites do not outnumber their Temporal counterparts. 
The Finite structure varies. Complex tense forms, Passive Voice, and Modal forms are composite in English and are represented by the Finite and Predicator as two separate units (in the affirmative sentence), for instance:

Text 2: The research is continuing (Present Progressive auxiliary verb 'is' and Predicator 'continuing')

Text2: The program was designed (Pas Simple Passive Finite 'was' and Predicator 'designed')

Text 4: Experience should be available to children (Modal Finite "should" and Predicative 'be available')

Composite forms are wide spread as well as simple forms because English is an analytical language in which grammar forms are modified not with morphemes but with auxiliaries in most cases. Some Finites are fused with the Predicator:

Text 2: Data for the investigation came from interviews.

Text 3: I explored the nature of witnessing.

Also, there is a special group of Finites without Predicators ('to be' and 'to have' in their direct meanings):

$\rightarrow \quad$ Hedges are abundant.

$\rightarrow \quad$ Information has practical consequences. Compare with the pattern 'Finite and Predicator' pattern in 'It has given rise to ambivalent forms of collective agency'.

The Finite of various structures and semantics forms the AL discourse of the given conclusions:

Table 38. Finite types and structures (overview)

\begin{tabular}{|l|l|l|l|l|l|}
\hline & Text 1 & Text 2 & Text 3 & Text 4 \\
\hline $\begin{array}{l}\text { Temporal Finite } \\
\text { Operators }\end{array}$ & $16(84 \%)$ & $18(90 \%)$ & $10(91 \%)$ & $8 \quad(67 \%)$ \\
\hline Modal Finite Operators & $3(16 \%)$ & $2 \quad(10 \%)$ & $1 \quad(9 \%)$ & $4 \quad(33 \%)$ \\
\hline
\end{tabular}




\begin{tabular}{|c|c|c|c|c|}
\hline Finite + Predicator & $6 \quad(32 \%)$ & $10(50 \%)$ & $5(45 \%)$ & $5(42 \%)$ \\
\hline $\begin{array}{l}\text { Finite and Predicator } \\
\text { fused }\end{array}$ & $\begin{array}{ll}9 & (47 \%)\end{array}$ & $\begin{array}{ll}5 & (25 \%)\end{array}$ & $5(45 \%)$ & $7(58 \%)$ \\
\hline $\begin{array}{l}\text { Finites without } \\
\text { Predicators }\end{array}$ & $4 \quad(21 \%)$ & $5 \quad(25 \%)$ & $1(10 \%)$ & 0 \\
\hline No. clauses & 19 & 20 & 11 & 12 \\
\hline
\end{tabular}

The difference in Finite structure is quite balanced, except in Text 1 . There is an approximate parity between the two most popular structures of Finites (the fused type and the 'Finite and Predicator' type). To my mind, this fact merely reflects the English grammar in which simple and composite Tense forms are exploited in a balanced way. Evidently, the applied linguistic discourse uses all the forms from the arsenal of English language.

The results from the table confirm the key role of the Finites that refer the discourse participant either to time frames, or attitudinal frames. The temporal frames are met more often because the discursive dialogue needs to be placed in real time and space. Modal shades are additional features that cannot be ignored in the natural flow of the discoursedialogue. The complexity of form allows for the expression of grammatical particularities, Tense aspects (Progressive, Perfect, etc.), Tense perspectives (Future tenses), Voices (Passive Voice), Modality (the author's attitude and stance). The choice of form can foreground that the reader sees unconventional context. For example, in Text 2 , the authors want to underscore their research as a perspective:

Text 2, sentence 10: Indeed, some changes have already been implemented in subsequent workshops at UHK and research is continuing into ways in which students can be assisted further with the challenging task of writing a dissertation in a second or foreign language. 
The verb 'to continue' contains the idea of duration. But the verb is used in the Present Progressive tense form (not typical for the verb 'to continue'). The Finite 'is' and the predicator 'continuing repeat each other to double the perceptive effect and to emphasize the continuous nature of the authors' project.

To complete the MOOD discussion, the Polarity needs to be mentioned. There are two poles in language, the positive and the negative one. The analysis demonstrates the following:

Table 39. Polarity (overview)

\begin{tabular}{|l|l|l|l|l|}
\hline Polarity & Text 1 & Text 2 & Text 3 & Text 4 \\
\hline Positive Finites & 19 & 20 & 11 & 12 \\
Negative Finites & 1 & 0 & 0 & 0 \\
\hline
\end{tabular}

The reality projected though the discourse is described in universal terms " $\mathrm{X}$ is $\mathrm{Y}$ " or "X is not Y" so that the objects are related objectively. But one thing to notice, the negative forms are used very little. Also, I need to mention the RESDIUE component, comprising Compliments and Adjuncts.

Table 40. Complements and adjuncts (overview)

\begin{tabular}{|l|l|l|l|l|}
\hline & Text 1 & Text 2 & Text 3 & Text 4 \\
\hline $\begin{array}{l}\text { Complements } \\
\text { (in RESDUE) }\end{array}$ & 18 & 7 & 7 & 4 \\
\hline Adjuncts (in & & & & \\
RESIDUE): & & & & \\
location & 6 & 7 & 3 & 1 \\
time & - & 1 & 1 & 2 \\
matter & - & - & - & 1 \\
role & - & - & 3 & 1 \\
manner & 1 & 2 & - & 1 \\
agent & - & 1 & 1 & 1 \\
\hline
\end{tabular}




\begin{tabular}{|l|l|l|l|l|}
\hline purpose & 1 & 2 & - & 1 \\
\hline $\begin{array}{l}\text { Mood Adjuncts } \\
\text { (in MOOD) }\end{array}$ & 1 & 1 & 1 & 0 \\
\hline $\begin{array}{l}\text { Conjunctive } \\
\text { Adjuncts (not } \\
\text { in MD or RD) }\end{array}$ & 2 & 10 & 3 & 6 \\
$\begin{array}{l}\text { Comment } \\
\text { Adjuncts (not } \\
\text { in MD or RD) }\end{array}$ & 2 & 2 & 0 & 0 \\
\hline
\end{tabular}

Text 1 has a type of pattern that is repeated many times 'Subject + Finite + Complement + Adjunct of location'. This consistency makes the dialogical environment cycled and structurally predictable. To my mind, that technique is congruent for long conclusions. The diversity of structures should not be overwhelming if the author wants to pack a lot of information in the discourse that aims to finalize the research descriptions and results.

\begin{tabular}{|l|l|l|l|l|}
\hline \multicolumn{2}{|c|}{ MOOD } & \multicolumn{2}{c|}{ RESIDUE } \\
\hline Subject & Finite & Predicator & Complement & Adjunct of Location \\
\hline Hedges & are & abundant & in science \\
\hline $\begin{array}{l}\text { (Information } \\
\text { about hedges) }\end{array}$ & \multicolumn{2}{|c|}{ has } & practical consequences & in ESP \\
\hline It & \multicolumn{2}{|c|}{ contributes } & $\begin{array}{l}\text { to a growing sociological } \\
\text { and linguistic interest }\end{array}$ & in professional writing \\
\hline
\end{tabular}

In Text 2 the author's preferences in the MOOD and RESIDUE structuring are evident as well. Complements and Adjuncts of locations are the most frequent RESIDUE elements. Besides, there is a significant number of conjunctive and comment Adjuncts. The first group is not a rare element at all because that is a way to coordinate the primary and secondary clauses. The popularity of comment adjuncts seems to me a characteristic 
of this concrete discourse. The article has 4 authors. That is the way they express their collective attitude:

Indeed, some changes have already been implemented

While, at first sight, local errors were the most evident

(Students) actually enhance the quality of their dissertation writing.

Modality

The AL discourse shows that the modalization and modulation are present in the four AL conclusions:

Table 41. Modality (overview)

\begin{tabular}{|c|c|c|c|c|}
\hline & Text 1 & Text 2 & Text 3 & Text 4 \\
\hline $\begin{array}{c}\text { Modalization: } \\
-\quad \text { probability } \\
-\quad \text { usuality }\end{array}$ & $\begin{array}{l}1 \\
\bullet\end{array}$ & $\mathbf{0}$ & $\begin{array}{l}1 \\
-\end{array}$ & 0 \\
\hline $\begin{aligned} \text { Modulation: } \\
-\quad \text { inclination } \\
-\quad \text { obligation } \\
\end{aligned}$ & 2 & 2 & 0 & $\begin{array}{l}4 \\
-00 \\
- \\
\end{array}$ \\
\hline
\end{tabular}

Modality constructs the AL discourse as a dialogue because the reader can get the article author's viewpoint via the lexico-grammatical form.

\begin{tabular}{|l|l|}
\hline Modality Example & Implied Attitude \\
\hline $\begin{array}{l}\text { Choices cannot be understood fully in isolation } \\
\text { (modalization in Text 1) }\end{array}$ & $\begin{array}{l}\text { The author shows his attitude to problem- } \\
\text { solving. }\end{array}$ \\
$\begin{array}{l}\text { The children in the 'Signs of Difference' study } \\
\text { were able to cope well with learning different }\end{array}$ & $\begin{array}{l}\text { The author sees the children's inclination to } \\
\text { diversity in learning language systems }\end{array}$ \\
$\begin{array}{l}\text { writing systems at the same time (modulation } \\
\text { in Text } 4 \text { ) }\end{array}$ & $\begin{array}{l}\text { The authors give their recommendation to } \\
\text { monolingual and bilingual children }\end{array}$ \\
\hline
\end{tabular}


(modulation in Text 4)

topical program.

The conclusions need modality if it is used reasonably. Probability and usuality in modalization with inclination and obligation in modulation can enrich the Tenor of the AL discourse with uniqueness of the RA author's language identity and expertise. The modality level is median in the interpersonal metafunction of these four AL discourses. The modal verb 'can' that means modalization with the meaning of median-high probability in this context is used only once in Text 3 (see Table 38). There are no examples of 'may' or 'must'. The former sounds weak and the latter could be oppressive. The case of modulation (especially the meaning of inclination) is the most prominent element of the four analyzed discourses. Overall, modality is an indicator of the golden mean in the discourse of an AL conclusion. If it is used consciously, it will help the voices sound strong and effective in the conclusive discourse of an AL article.

\section{Nominalization (Textual Metafunction)}

Nominalizations are one of the main characteristics of the academic discourse, in general, and of the AL discourse, in particular. Above, I described the processes as engines in the clause to move the narrative forward. Nominal groups are very popular in forming the textual dimension of the discourse. The 'thingness' (Halliday \& Matthiessen 2004) of the academic discourse reflects the academic realm of phenomena, empirical and practical. This discourse is created to describe these phenomena many of which are the central terms of the particular study. Nominalization penetrates all the parts of the clause, not limiting itself with participants and circumstances. The verbs undergo metamorphoses as well: 
Text 1: Hedges in scientific texts are results of choices / it is these in combination which motivate the use of hedges / they constitute an essential element of argumentation / an understanding of their use / science establishes its claim to knowledge / hedging can also advance our understanding of the practice of evidential reasoning

Text 2: We have described the development of a program / Data for this investigation came from interviews with supervisors and analysis of student writing / to substantiate arguments with evidence from the literature and a tendency to make claims for own research findings

Text 3: This technologisation of witnessing has enabled the emergence of ordinary witnessing and the manifestation of a caring ethos/ it has simultaneously given rise to ambivalent forms / publics are based on instantaneous, albeit discontinuous, forms of technological activism

Text 4: The children were experiencing cognitive benefits / young children's ability to make well-founded interpretations of the teaching / to understand graphic representations / the children's awareness of the principles / enhanced by biliterate experience

The information is communicated through nouns that, in their turns, combine into nominal chains. The prepositions that connect the links of these chains can be diverse.

But there is a preposition that participates in nominalized groups more often than others. In nominal chains, the prepositions 'of' takes the first places in all the four conclusions. The table below shows a considerable numbers in my analyses:

\begin{tabular}{|l|l|l|l|l|}
\hline & Text 1 & Text 2 & Text 3 & Text 4 \\
\hline of & 7 & 7 & 8 & 3 \\
\hline
\end{tabular}

Three out of four conclusions (Texts 1,2, and 3) foreground the role of the preposition 'of'. Two out of four conclusions (Text 1 and 2) often use the 'in'-groups. 'Of' traces the origins and genealogy of the RA terminology. Other prepositions (at, on, between, among, etc.) add more detail to the leading classification (of) and locational (in) tendencies in the highly-nominalized discourse of the AL conclusions in my research. 
Specific Lexical Density (Textual Metafunction)

The SFL category of lexical density undergoes a slight change under the influence of the specific discursive nature that is examined in this paper. Eggins (2004) calculates the lexical density rate, comparing the numbers of content-carrying lexical items (nouns, verbs, adjectives, adverbs, etc.) and number of lexical items (all the words in text). Thus the researcher can see the correlation between items, carrying meanings, and items, performing only structure / grammar functions. Considering the applied linguistic nature of my material, I calculated the number of specific content-carries in four $\mathrm{AL}$ conclusions. In fact, I tried to identify the concentration of terminological items in a specific-natured discourse. Obviously, the duality of some items has a disputable nature. In my research, I concentrate on the quantities of terms to understand how many terms are presented by the author in his article conclusion.

Table 42. Specific lexical density (overview)

\begin{tabular}{|l|l|l|l|l|}
\hline & Text 1 & Text 2 & Text 3 & Text 4 \\
\hline $\begin{array}{l}\text { No. of specific content- } \\
\text { carrying lexical item in text }\end{array}$ & 91 & 136 & 49 & 37 \\
\hline No. of lexical items in text & 259 & 435 & 147 & 122 \\
\hline $\begin{array}{l}\text { Total Specific Lexical } \\
\text { Density }\end{array}$ & $35 \%$ & $32 \%$ & $33 \%$ & $30 \%$ \\
\hline
\end{tabular}

Following the numbers from the table above, I can claim the authors' tendency of having AL terms as $30-35$ percent of the conclusion lexicon. To be fair, such a balanced result seems quite predictable to me. It proves the importance of the discourse influence on every single item in it. This finding is not a directive. However, it seems that this range (approximately $1 / 3$ ) reflects the reasonable loading of terminological contentcarriers in the AL conclusion discourse. 
Theme

The Theme element is the key to opening the clause composition and its implications. The author choses the order of his ideas in the clause and this order can be a meaningful implication itself. The input of information creates the 'rhythm' of the narrative and helps the reader to foresee the next informational portion and adjust his perception to it. In the four analyzed clauses The following Theme types are identified in the four AL article conclusions:

Table 43. Theme in $4 \mathrm{AL}$ article conclusions (overview)

\begin{tabular}{|l|l|l|l|l|}
\hline THEME & Text 1 & Text 2 & Text 3 & Text 4 \\
\hline Topical & 19 & 20 & 11 & 12 \\
\hline Interpersonal & 1 & 2 & 0 & 0 \\
\hline Textual & 10 & 11 & 2 & 6 \\
\hline
\end{tabular}

Every clause has a topical Theme. Other groups are optional. While interpersonal Themes make the author's attitudes more evident, the textual Themes (conjunctions and transitions) are builders of the texture. The number of interpersonal Themes is very small. These words and phrases are used in a very moderate way. The conclusion is the final stage of the RA dialogue. Often, the author prefers to concentrate on the research findings and the problem-solving tactics instead of expressing his personal attitude and judgment. Therefore, interpersonal Theme patterns are rare ('I argued', 'indeed', 'most importantly'). It is more space-conscious to foreground the research ideas, not the personality of the researcher. At the same time, the numbers of the textual Themes are significant. They are used as links to keep the textual flowing logic, cohesive, and natural. 
The Theme patterns can be single and multiple. The correlation between them may vary in an AL conclusion but in a balanced way:

Table 44. Single and multiple Themes (overview)

\begin{tabular}{|l|ll|ll|l|l|l|}
\hline THEME & \multicolumn{2}{|l|}{ Text 1 } & \multicolumn{2}{|l|}{ Text 2 } & Text 3 & \multicolumn{2}{l|}{ Text 4 } \\
\hline $\begin{array}{l}\text { Single Themes } \\
\text { Multiple } \\
\text { Themes }\end{array}$ & 9 & $(47 \%)$ & 9 & $(45 \%)$ & 9 & 6 & $(50 \%)$ \\
& 10 & $(53 \%)$ & 11 & $(55 \%)$ & $(82 \%)$ & 6 & $(50 \%)$ \\
& & & & $(18 \%)$ & \\
\hline No. of clauses & 19 & 20 & & 11 & 12 \\
\hline
\end{tabular}

The diversity can be connected with compactness of space for packing the main research ideas in $\mathrm{AL}$ conclusions. The author is not limited with the conclusion size. $\mathrm{He}$ creates a mini discourse in the article to be comprehensible, convincing, and consistent in its articulation. So he chooses either to start a clause with the concept, or whether he needs extra thematic elements before sharing the principal block of information. If the author has only topical Themes, the text will lose its structural (textual Themes) and attitudinal (interpersonal Themes) bridges.

\section{Reference chains}

It is difficult to calculate the items in the referential chains even in one discourse. The references are constituents of one structural and semantic network that leads the reader through the discourse, marking the evolvement of the topic and its components in the text. As a result, the reference chains are contributors to it as a cohesive whole. It is important to see how the ideas are connected with each other because the reader's brain will feel the disorganization at the subconscious level. Here is a bright example of developing reference relationships: 
Text 4

\begin{tabular}{|c|c|c|}
\hline$\rightarrow$ Research Participant & $\begin{array}{l}\rightarrow \text { Research } \\
\text { Presuppositions }\end{array}$ & $\rightarrow$ Research Result \\
\hline $\begin{array}{l}\text { The children in the 'Signs of } \\
\text { Difference' } \rightarrow \text { the children } \\
\rightarrow \text { They } \rightarrow \text { their (learning) } \rightarrow \\
\text { young children's ability } \rightarrow \\
\text { children's awareness } \rightarrow \\
\text { monolingual and bilingual } \\
\text { children }\end{array}$ & $\begin{array}{l}\text { Learning systems } \rightarrow \text { input } \rightarrow \\
\text { cognitive benefits } \rightarrow \text { the } \\
\text { principles } \rightarrow \text { system } \rightarrow \\
\text { differences between systems } \\
\rightarrow \text { interpretations } \rightarrow \text { graphic } \\
\text { representations } \rightarrow \text { principles } \\
\rightarrow \text { systems }\end{array}$ & $\begin{array}{l}\text { (Their) learning } \rightarrow \text { the } \\
\text { research } \rightarrow \text { It } \rightarrow \text { biliterate } \\
\text { experience } \rightarrow \text { this experience } \\
\rightarrow \text { mainstream education }\end{array}$ \\
\hline
\end{tabular}

Every nominal cohesive chain and pronominal replacement is an in-discourse code to the recipient who has to store the previous patterns in his memory and to pull out the exact block to combine with the given reference. In the given conclusions, up to three various referential threads sometimes intertwine in these four discourses and sometimes occur as parallels. Nevertheless, all of them are carefully woven into the fabric of the textual metafunction to demonstrate the author's confident consistency in the discourse, made meaningful by him.

\section{Mapping a Conclusion}

Linguistic analysis cannot provide academic writers with a uniform instruction how to write a perfect RA conclusion. But the SFL model can show how the three metafunctions and their meanings are realized into the ideational, interpersonal, and textual dimensions of the AL discourse. The SFL analysis discovers some important semantico-syntactic moves in the process of producing these meanings. The SFL observations can be helpful in choosing the word or structuring the clause to perform efficient functions in AL conclusions, foregrounding the specific nature of the discourse. 
I strongly support Eggins' (2004) evaluation of the SFL model "as a functional-semantic resource: language is modeled as networks of interconnected linguistic systems from which we choose in order to make the meanings we need to make to achieve our communicative purposes" (p. 327). Through the SFL analytical magnifying glass, the applied linguist is able to see the ways to create a discourse packed with the meanings, necessary for the AL context and AL socializing.

In conclusion, I will summarize the common features of the four $\mathrm{AL}$ article conclusions. These factors are the findings from the four AL conclusion analyses. I cannot generalize after scrutinizing only four patterns. However, it is possible to find some commonalities to mention.

1. Transitivity: Verbal groups that represent mental processes are the dominant that outnumbers other types. Moreover, other group items are influenced and modified by the mental processes. The material processes can no longer exist in their specific meaning. The AL discourse, including AL participants and circumstances create the conditions for the material-to-mental metaphorical transformation. The groups of relational and verbal processes are also prominent in the $\mathrm{AL}$ conclusions. They assist in performing the functions of defining the relations between the research concepts (relational identifying processes) along with characterizing them (relational attributive processes) and reporting them to reader (verbal processes).

2. Logico-semantic Types of Relationships between Clauses: Clause simplexes and clause complexes as well as parataxis and hypotaxis influence the discursive choices equally. As the analyses show, the complexes and hypotaxis can slightly 
outnumber their counterparts. The balancing between the choices in the process of combining clauses as constituents in a sentence create diversified meanings within the framework of an AL conclusion. The type of Projection is used quite often. But the idea projection is preferred over the locution projection. Expansions may vary, though the elaborations and enhancements are more popular in the given four discourses analyzed.

3. Mood: The declarative Mood is omnipresent and has no alternative in the given four $\mathrm{AL}$ conclusions. With the declarative statements and acknowledgements, $\mathrm{AL}$ conclusions answer the question that the authors asked in their articles. Consequently, no questions or imperatives are detected in these four $\mathrm{AL}$ conclusions.

4. MOOD \&RESIDUE Patterns: Both elements are elaborate and contain many components. The Subject seem to be an important article concept. Finites are of various kinds and structures. Temporal Finite Operators are exploited in the AL conclusions more often than Modal Finite Operators. The positive polarity in the MOOD element outnumbers negative Finites significantly. The RESIDUE component, containing Compliments and various types of Adjuncts, enriches the core MOOD element in the clause.The authors may repeat one and the same RESIDUE structure several times, for example 'Subject + Finite + Predicator + Complement'. Nonetheless, the Adjuncts in the RESIDUE are wide-spread as well. Considerable numbers of Complements and Adjuncts are used in the RA conclusions in order to provide all the necessary details about AL concepts being discussed in the discourse. 
5. Modality: Modal verbs are used moderately. But at the same time they are indispensable when the author needs to express the implications of probability or usuality in modalizations and inclination or obligation in modulations.

6. Nominalization: The RA conclusions in AL are highly nominalized. Nominal groups play a crucial role in creating an academic written discourse of the AL conclusion. The preposition 'of' is most likely to cement the nominal groups in the discourse.

7. Specific Content-carrying Lexical Density: The specific content-carrying items represent 30-35 percent of the total number of lexical items in the four analyzed $\mathrm{AL}$ conclusions. The terms may be marked as $\mathrm{AL}$ specifications or generally academic terms. The discourse that is moderately dense in terms of terminology $(30-35 \%)$ is reasonably complicated but is perhaps perceived in a more efficient way.

8. Theme: The Theme element can be single or multiple, with no evident preferences in the AL article conclusion. The topical Theme is mandatory and functions as the key to the proper understanding of the discourse texture. The second most used Theme component is the textual type. This type builds cohesive connections between the clauses and their Themes, in particular. The interpersonal Theme is the least used. The Theme component can be multiple but the AL conclusion Themes do not have tendencies to be loaded with all the three Thematic types in one pattern. The Theme represents the Given Information in the discourse. It should be prominent (but not overloaded) for the readers. 
The AL conclusion, of course, consists of the author's choices. The text itself is the visual image of these choices realized through language. Thus language utterances become social practices with which the AL researcher positions himself in academia. It is always very important to keep in mind that the discourse is a social activity. It helps to understand the effect of a word that becomes a social event and, as a result, a message to society. The AL conclusion is a message itself. Its constructs have semantic implications, their order is meaningful, and their appearance or absence performs certain functions. The SFL analyses of four AL article conclusions demonstrates that the AL writer seems to be careful in making his choices in order to produce efficient realizations and to make his discourse function a valuable message to the reader. 


\section{Chapter Nine - Conclusion}

\subsection{Research Question Revisited}

In order to answer the research question articulated at the beginning of this thesis "What elements of three SFL metafunctions are prominent in the framework of applied linguistic article conclusions?", I analyzed four $\mathrm{AL}$ article conclusions and presented my findings in this thesis. Using the SFL three-metafunction model it was revealed that:

1. Verbal groups that represent mental processes are clearly prominent in the discourse of these four AL conclusions. They play the leading role in the transitivity system of the conclusions. In terms of the logico-semantic clause types, it was also discovered that the projection of ideas and expansionenhancement were prominent. There are no obvious preferences in choosing between paratactic and hypotactic relationships between clauses in the sentences of these AL conclusions.

2. Within the plane of the interpersonal metafunction, the fact of the declarative Mood prominence was identified. Positive polarity outnumbered negative polarity significantly. Modal Finite operators were used moderately in the discourse of the analyzed conclusions.

3. Within the textual metafunction framework, such compositional phenomena as nominalization, specific lexical density, and Theme prominence were detected and discussed in this paper. The texture of the text is expressed through considerable numbers of nominalized groups. Approximately 30-35 percent of all lexical items are AL content-carrying items so that the discourse is quite dense 
with AL-related terms. Finally, the Theme pattern acts as a capsule to incorporate the keys to decode the article, containing article terms, findings, outcomes alongside the researchers' identities, their attitudes and stances.

\subsection{Implications and Perspectives of Discourse Analysis}

The systemic functional approach to the AL discourse and the three metafunctions, in particular, became a set of problem-solving techniques that discovered the wealth of meanings in the texts of $\mathrm{AL}$ article conclusions. The lens of the SFL three-metafunction model provided the evidence of language as a complex network of interrelated meanings. I have shown how the AL article authors are able to present the discourse events and concepts with the ideational metafunction meanings, how they are leading in the process of the discourse interaction, expressing their attitudes and stances through the interpersonal metafunction, and how they account for the composition of their message to make the necessary to create not only many meanings but to also suggest implications. The analysis of prominent metafunctional elements, determined by the AL language user's choices, produced 4 specific-natured contexts that acted as a social happening in the AL community.

It is, however, necessary to discuss the limitations and perspectives of this type of analysis in order to understand how to bridge the gap between the analyses of visible linguistic structures and invisible socio-cultural processes in the discourse. This thesis examined the micro-level of clauses and their constituents in the discourse of AL article conclusions. Its main purpose was to demonstrate how lexical and grammatical categories, once placed in the context, initiated correlations and relationships, meaningful not only for certain clause patterns, but for the situation of the AL research article at its 
conclusive stage. While investigating the SFL prominent elements, I realized that further analytical work was necessary. The specific-natured discourse develops particular settings for meanings. Understanding the implications of the collaboration between language and situation will uncover the effectual ways of producing and receiving the discourse messages. In my opinion, the SFL methodology can be enriched with CDA to address social problems in discourse, such as balancing equity and power. Thus it will be possible to make a shift from the tangible language structures to introspection of intangible relations of the discourse elements. Seeing the prominent structures may be the clue to start examining the ideological component, equality, collision of voices or even clash of powers in the discourse. Thus the discourse material could be evaluated on global scales to measure its historical and socio-cultural prominence. After answering the questions 'How is this discourse written and what elements makes it specific and efficient?', I need to ask myself, "What is the objective of this pattern?" . In this paper, I have described how some language choices appear more often in the four $\mathrm{AL}$ conclusions. CDA can dig deeper and help to uncover the types of prominent meanings in the AL discourse, evoke and develop. It is very important not to stop at the descriptive level, if there is a desire to grasp the depth of meaning-making processes in language and its situational discourses.

SFL provides you with the methodological tool to answer questions that provide a description of discourse. You can take the descriptions supplied by SFL and answer CDA questions that provide an explanation and interpretation of a discourse in terms of the relationships between language, power, and ideology (Young \& Fitzgerald, 2006, p. 23). 
This gap between micro-meanings of small items and patterns and macro-levels of social significance are bridgeable through careful de-composing, examining and recomposing of discourse constructs.

My thesis has undertaken the analysis of clauses and their constituents to show that semantics starts its way of being realized at the initial level of choosing the form and the word for the context of a certain discourse. The further investigation may reveal the intentions and opinions that take an active part in determining the discourse construction and content. As intentions and attitudes are subjective and subtle matters, SFL will foreground the prominent structures to support or disclaim the interpretations.

In tandem SFL and CDA can potentially unveil the profound semiotic processes that tie the concepts together not only on the surface of lexico-grammar, but at the stage of sending and receiving power-loaded messages from the core of the discourse as a social phenomenon. It is evident that the analysis of structures should lead to a critical dialogue around the discourse meaning-making implications. This way, the phenomenon will be scrutinized effectively to use the findings and understandings in various spheres of language use.

The thesis findings may be of value for participants of the language teachinglearning process. The analysis of the discourse and discussion of its results are indispensable sociolinguistic practices that, potentially, can be an attempt to bridge the theories of language with the theories of EAP and L2 learning.

The SFL-based approach provides methods and procedures to examine the discourse features through the analyses of the ideational, interpersonal and textual 
meanings. According to Richards \& Rogers' (2001) classification, the SFL tradition is a functional view of language.

This theory emphasizes the semantic and communicative dimension rather than mere the grammatical characteristics of language, and leads to a specification and organization of language teaching content by categories of meaning and function rather than by elements of structure and grammar (Richards \& Rogers, 2001, p. 17).

This functional linguistic framework may be material for helping to design syllabi

(Richards \& Rogers give an example of Wilkins' Notional Syllabuses). As other SFL analyses, this research tries to serve as a comprehensive and "useful way of distinguishing the relationship between the underlying theoretical principles and the practices derived from them" (Richards \& Rogers, 2001, p. 16). Thus the SFL findings and their CDA interpretations may be considered materials for pedagogical theories to contribute to this linguistic stance and observations into ESL, ESP and EAP learning procedures. The process of convergence is clearly not one-dimensional but rather gradual and needs time and research effort. The set of SFL analytical description creates a method that, in its turn, forms an approach.

An approach is a set of correlative assumptions dealing with the nature of language teaching and learning. It is axiomatic and describes the nature of the subject matter to be taught (Anthony, 1963 cited in Richards \& Rogers, 2001, p. 15).

Choosing an approach, the researcher seeks an insight that situates his or her linguistic assumptions and convictions. At the level of the method, it is necessary to be aware of the concrete theory that can supply the analysts with particular skills and itineraries in order not to be lost in multiple layers of the discourse analyzed. My research tries to contribute to the systemic functional approach to $\mathrm{AL}$ article conclusions as one of many possible methods to detect meanings that perform certain functions in the representational (ideational metafunction), interactive (interpersonal metafunction) and 
compositional (textual metafunction) dimensions. As a particle of the whole, my SFL analytical method flows into the greater systemic functional approach to language. This approach may seem not applicable straight away into the classroom because of its specific knowledge and understanding. But it can help language learning specialists to turn it into real-life teaching methods. In other words, following Richards \& Rogers' classification, condition-oriented SFL theory needs to reach the final and most favourable point, notably the systemic realization in process-oriented theories built on learning processes. Apparently, these two scientific stops can be connected by pedagogical theories as a medium between theoretical perception and practical applications. To find these pedagogical theories is also a perspective for further research on discourse studies. They could bond together these two dimensions to help teachers who might "develop their own teaching procedures, informed by a particular view of language and a particular theory of learning" (Richards \& Rogers, 2001, p. 19).

It is understandable that an approach does not shape a procedure. There is something in between which language researchers should be aware of while thinking about their theories' applications. Systemic functional linguistics cannot make everyone perceive language as a paradigmatic set of choices, realizations, and functions. The link between theory and practice in the educational domain is neither direct, nor simple. But the concepts, the design, and concrete analytical evidence can make these two sides connectable. 


\section{References}

Allison, D., Cooley, L., Lewkowicz, J., \& Nunan, D. (1998). Dissertation writing in action: The development of a dissertation writing support program for ESL graduate research students. English for Specific Purposes, 17(2), 199-217.

Atkinson, D. (2003). L2 writing in the post-process era: Introduction. Journal of Second Language Writing, 12, 3-15.

Bakhtin, M. (1973). Types of prose word. The word in Dostoevsky. In M. Bakhtin, Problems of Dostoevsky's poetic (pp. 150-169). Ann Arbor, Michigan: Ardis.

Bakhtin, M. (1981). The dialogic imagination. Austin, TX: University of Texas press.

Berry, M. (1975). Introductions to systemic linguistics 1. London: Batsford.

Bernstein, B. (1995). Code theory and its positioning: A case study in misrecognition. British Journal of Sociology of Education, 16 (1), 3-19.

Bernstein, B. (1996). Pedagogy, symbolic control, and identity. London, Washington D.C: Taylor and Francis.

Bunton, D. (2005). The structure of PhD conclusion chapters. Journal of English for Academic Purposes, 4, 207-224.

Butt, D., Fahey, R., Feez, S., Spinks, S., \& Yallop, C. (2003). Using functional grammar: An explorer's guide. Sydney: Macquarie University (National Centre for English Language Teaching and Research). 
Chanock, K. (1999). Using systemic functional linguistics in university teaching: A postgraduate class on making writing more 'readable'. Monash University Linguistic Papers, 2(1), 61-67.

Chouliaraki, L. (1996). Regulative processes in a progressivist classroom: 'good habits' as a 'disciplinary technology. Language and Education, 10 (23), 103-118.

Chouliaraki, L. (1998). Regulation in progressivist pedagogic discourse: Individualized teacher-pupil talk. Discourse and Society, 9(1), 5-32.

Chouliaraki, L. (2010). Ordinary witnessing in post-television news: towards a new moral imagination. Critical Discourse Studies, 7 (4), 305-319.

Christie, F. (2004). Authority and its role in the pedagogic relationship of schooling. In L. Young \& C. Harris (Eds.), Systemic functional linguistics and critical discourse analysis: Studies in social change (pp. 173-201). London, New York: Continuum.

Fawcett, R.P, van der Mije, A., \& van Wissen, C. (1988). Towards a systemic flowchart model for discourse structure. In R.P. Fawcett \& D. Young (Eds.), New developments in systemic linguistic, volume 2: Theory and application (pp. 116-140). London, New York: Pinter Publishers.

Foucault, M. (1970). The archaeology of knowledge. Social Science information, 9, $175-185$.

Gregory, M. (1987). The meaning of features in systemic linguistics. In M.A.K. Halliday \& R.P. Fawcett (Eds.), New developments in systemic 
linguistic, volume 2: Theory and description (pp. 94-106). London, New York: Pinter Publishers.

Halliday, M.A.K. (1973). Explorations in the functions of language. London: Edward Arnold.

Halliday, M.A.K. (1997). Linguistics as metaphor. In A.-M. Simon-Vandenbergen, K. Davids, \& I.D. Noé (Eds.), Reconnecting Language: Morphology and syntax in functional perspectives (pp.3-27). Benjamins: Amsterdam.

Halliday, M.A.K. \& Matthiessen, C. M.I.M. (2004). An introduction to functional grammar. Arnold: London.

Halliday, M.A.K. \& Hasan, R. (1976). Cohesion in English. London: Longman.

Halliday, M.A.K. \& Hasan, R. (1989). Language, context, and text: Aspects of language in a social-semiotic perspective. Oxford: Oxford University Press.

Halliday, M.A.K. \& Matthiessen, C. M.I.M. (1999). Construing experience through meaning: A language-based approach to cognition. Continuum: London, New York.

Halliday, M.A.K. \& Fawcett, R.P. (Eds). (1987). New developments in Systemic Linguistics. London: Pinter.

Hyland, K. (1996). Writing without conviction? Hedging in science research articles. Applied Linguistics, 17 (4), 433-454.

Hyland, K. (2002). What do you mean? Questions in academic writing. Text, 22 (4), 529-557. 
Hyland, K. (2002). Teaching and researching: Writing. Harlow, England: Pearson Education.

Hyland, K. (2004). Disciplinary interactions: Metadiscourse in L2 postgraduate writing. Journal of Second Language Writing, 13, 133-151.

Hyland, K. (2005). Stance and engagement: A model of interaction in academic discourse. Discourse Studies, 7 (2), 173-192.

Hyland, K. (2007). Applying a gloss: Exemplifying and reformulating in academic discourse. Applied Linguistics, 18 (2), 266-285.

Hyland, K. (2008). Disciplinary voices: Interaction in research writing. English Text Construction, 1 (1), 5-22.

Hyland, K. (2008). As can be seen: Lexical bundles and disciplinary variations. English for Specific Purposes, 27, 4-21.

Inghillieri, M. (1989). Learning to mean as a symbolic and social process: The story of ESL writers. Discourse Processes, 12, 391-411.

Iwamoto, N. (1995). The analysis of wartime reporting: Patterns of transitivity. Edinburgh Working Papers in Applied Linguistics, 6, 58-68.

Iwamoto, N. (1996). Constructing reality through metaphorizing processes in wartime reporting. Edinburgh Working Papers in Applied Linguistics, 7, 56-71.

James, C. \& Garrett, P. (Eds.). (1991). Language awareness in the classroom. London: Longman.

James, C. (1993). What is applied linguistics? International Journal of Applied Linguistics, 3(1), 17-32. 
Jin, K. (2008). Lexical cohesion patterns in NS and NNS dissertation abstracts in Applied Linguistics: A comparative study. Linguistics Journal 3(3), 132-144.

Johnson, F. L. (1979). Communicative competence and the Bernstein perspective. Communication Quarterly. 27, (4), 12-19.

Kellner, D. (2002). New life conditions, subjectivities and literacies: Some comments on the Lukes' reconstructive project. Journal of Early Childhood Literacy, 2(1), 105-112.

Kenner, C., Kress, G., Al-Khatib, H., Kam, R., \& Tsai, K.-C. (2004). Finding the keys to biliteracy: How young children interpret different writing systems. Critical Language and Education, 18 (2), 124-144.

Kilpert, D. (2003). Getting the full picture: A reflection on the work of M.A.K. Halliday. Language Sciences, 25, p. 159-209.

Lemke, J. (1995). Textual politics: Discourse and social dynamics. London: Taylor and Francis.

Lewin, B., Fine, J., \& Young, L. (2001). Expository Discourse: A genre-based approach to social science research texts. Continuum: London, New York.

Lillis, T. \& Curry, M.J. (2010). Academic writing in a global context: The politics and practices of publishing in English. London, New York: Routledge.

Matthiessen, C. M.I.M. \& Bateman, J. A. (1991). Text generation and Systemic Functional Linguistics: Experiences from English and Japanese. Pinter Publishers: London. 
Martin, J.R. (1987). The meaning of features in systemic linguistics. In M.A.K. Halliday \& R.P. Fawcett (Eds.), New developments in systemic linguistic, volume 2: Theory and description (pp. 14-40). London, New York: Pinter Publishers.

Martin, J. R. (1992). English text system and structure. Amsterdam: Benjamins. Martin, J. R. (1993). Life as a noun: Arresting the universe in science and humanities. In M.A.K. Halliday \& J.R. Martin (Eds.), Writing science: Literacy and discourse power (pp. 221-267). Pittsburgh: University of Pittsburgh Press.

Martin, J.R. (2000). Close reading: Functional linguistics as a tool for critical discourse analysis. In L. Unsworth (Ed.), Researching language in school and communities. Functional linguistic prospective (pp. 75-304). London: Cassell.

Martin J. R. (2003). Introduction. Text, 23(2), 171-181.

Murray, R. \& Moore, S. (2006). The handbook of academic writing: A fresh approach. Maidenhead, England, New York: McGraw Hill: Open University Press.

Nunan, D. (1995). Systemic-functional linguistics and education of secondlanguage teachers: A case study. Georgetown University Round Table on Languages and Linguistics, 1, 439-452.

Pennycook, A. (2001). Critical applied linguistics: A critical introduction. Mahwah, NJ: Lawrence Erlbaum Associates. 
Richards, J. \& Rogers, T. (2001). Approaches and methods in language teaching: A description and analysis. Cambridge: Cambridge University Press.

Rudestam, K.E. \& Newton, R.R. (2001). Surviving your dissertation: $A$ comprehensive guide to content and process. Thousand Oaks, London, New Delhi: Sage Publications.

Samraj, B. (2002). Introductions in research articles: Variations across disciplines. English for Specific Purposes, 21, 1-17.

Sheldon, E. (2011). Rhetorical differences in RA introductions written by English L1 and L2 and Castilian Spanish L1 writers. Journal of English for Academic Purposes 10, 238-251.

Swales, J. (1998). Textography: Toward a contextualization of written academic discourse. Research on Language and Social Interaction, 31 (1), 109121.

Swales, J. (1998). Other floors, other voices: A textography of a small university building. London, Mahwah, NJ: Lawrence Erlbaum.

Swales, J. \& Feak C.B. (2000). English in today's research world: A writing guide. Ann Arbor: The University of Michigan Press.

Swales, J. \& Najjar, H. (1987).The writing of research articles introductions. Written Communication, 4, 175-191.

Suau-Jimenez, F. (2005). The difficult balance between author's and academic community's power over research articles in applied linguistics. LSP and Professional Communication, 5(2), 59-72. 
Thompson, G. (2001). Interaction in academic writing: Learning to argue with the reader. Applied Linguistics, 22(1), 58-78.

Ventola, E. (1988). Text analysis in operation: A multilevel approach. In P. Fawcett \& D. Young (Eds.), New developments in systemic linguistic, volume 2: Theory and application (pp. 52-75). London, New York: Pinter Publishers.

Ventola, E. (1992). Writing scientific English: Overcoming intercultural problems. International Journal of Applied Linguistics, 2(2), 191-220.

Ventola, E. (1997). Modality: Probability - an exploration into its role in academic writing. In A. Duszak (Ed.), Trend in linguistics: Studies and monographs 104. Culture and styles of academic discourse (pp. 157181). Berlin, New York: Mouton de Gruyter.

Widdowson, H. G. (1984). Explorations in linguistics: No. 2. Oxford: Oxford University Press.

Yang, R. \& Allison, D. (2003). Research articles in applied linguistics: Moving from results to conclusions. English for Specific Purposes, 22(3), 365385.

Yang, R. \& Allison, D. (2004). Research articles in applied linguistics: Structures from a functional prospective. English for Specific Purposes, 23(4), 264-279.

Young, L. \& Fitzgerald, B. (2006). The power of language: How discourse influences society. Equinox: London, Oakville. 


\section{APPENDIX 1 - Applied linguistic article conclusions for analysis (full text)}

\section{TEXT 1}

\section{K. Hyland (1996)}

"Writing without conviction? Hedging in science research articles" Applied Linguistics, 17(4), 433-454.

I have argued that hedges in scientific texts are the result of informational, rhetorical, and personal choices which cannot be fully understood in isolation from social and institutional contexts. Linguistic analyses alone cannot provide a rationale for such choices and the framework proposed here seeks to reflect this interpretive environment. Research articles clearly reveal the relationship between a discourse community, standards of knowledge, and textual representations, and it is these in combination which motivate the use of hedges.

Hedges are abundant in science and play a critical role in academic writing more generally. They constitute an essential element of argumentation in presenting new claims for ratification, and are among the primary features which shape the research article as the principle vehicle for new knowledge. An understanding of their use therefore has important implications for a number of areas and can contribute to the growing literature on the rhetoric of science, revealing important insights into how science establishes its claim to knowledge and how scientists carry out their work. Information about hedging can also advance our understanding of the practice of evidential reasoning and has practical consequences in ESP where textbooks often emphasize the impersonality of scientific discourse and either ignore hedges or advise students to avoid them completely (Hyland, 1994). Most importantly, however, the analysis demonstrates the dynamic and interactive nature of scientific writing. It contributes to a growing sociological and linguistic interest in professional writing by providing a discourse analytic understanding of one means by which scientific discourse is both socially situated and structured to accomplish rhetorical objectives. 


\section{TEXT 2}

\section{Allison, L. Cooley, J. Lewkowicz, \& D. Nunan (1998)}

\section{"Dissertation writing in action: The development of a dissertation writing support program for ESL graduate research students"}

English for Specific Purposes, 17(2), 199-217.

Research amongst supervisors and graduate students at UHK, the numbers of students registering for the writing program that was induced, students' positive reactions to the program and the growing number of graduate students attending the English Centre's one-to-one Writing Support Service have combined to show that there is clearly a need for a writing program to become a regular feature of graduate life at the university. In this paper, we have described the development of a program to help NNS research students develop skills in planning, drafting, and revising their theses. The program evolved from a grounded investigation into the problems encountered by students in their struggle to produce a thesis in a language other than their own. Data for this investigation came from interviews with supervisors, students' questionnaires and an analysis of student writing. The initial study, as indicated above, revealed shortcomings in four main areas which can be summarized as follows:

5. A failure to organize and structure the thesis in a way which made the objectives, purpose and outcomes of the research transparent to the reader, and a failure to create "a research space";

6. A failure to substantiate arguments with evidence from the literature and a tendency to make claims for own research findings which were too strong or overgeneralized;

7. An inability to organize information at the level of the paragraph, to show relationships and to develop texts in functionally appropriate ways;

8. 'local' problems to do with editing, spelling, grammar and bibliographical referencing.

While, at first sight, local errors were the most evident, by far the greatest number of communication problems occurred at the macro-level of audience, purpose and overall structuring. Hence the diagnostic framework and the resultant writing program were designed to focus primarily on these macro-level problems. A limitation of the work that has been reported here is its situation-specific nature - although this is in some ways a 
strength. While we have expressed a degree of confidence that the approach we have described will be applicable in work with NNS research students in other situations, we are sure that adaptations will prove to be necessary. Indeed, some changes have already been implemented in subsequent workshops at UHK and research is continuing into ways in which students can be assisted further with the challenging task of writing a dissertation in a second or foreign language. Yet we believe that the focus on extended texts and the macro-level of writing as emphasized in this paper are essential if students are to go beyond improving their writing at the sentence level and actually enhance the quality of their dissertation writing.

\section{TEXT 3}

\section{Chouliaraki (2010)}

\section{“Ordinary witnessing in post-television news: towards a new moral imagination"}

Critical Discourse Studies, 7 (4), 305-319.

In this paper, I explored the nature of witnessing in post-television news. Taking my point of departure on an analysis of the emergent narratives of convergent journalism, I showed how the multi-modality of convergence has affected the narrativity of the news along three key textual dimensions: the cohesive, clause and process structure of the news. Insofar as such structural changes result in replacing the logic of news as storytelling with a logic of news as techno-textual interactivity. I argued, post-television witnessing can be seen as becoming increasingly technologized. This technologisation of witnessing has enabled the emergence of ordinary witnessing and the manifestation of a caring ethos towards vulnerable others. Yet it has simultaneously given rise to ambivalent forms of collective agency, which potentially produce post-humanitarian news publics publics that are driven by a communitarian moral imagination and are based on instantaneous, albeit discontinuous, forms of technological activism. 


\section{TEXT 4}

\section{Kenner, G. Kress, H. Al-Khatib, R. Kam, \& K.-C. Tsai (2004)}

"Finding the keys to biliteracy: How young children interpret different writing systems"

\section{Language and Education, 18 (2), 124-144.}

The children in the 'Signs of Difference' study were able to cope well with learning different writing systems at the same time. Rather than being 'confused' by simultaneous input, the children were experiencing cognitive benefits. They were able to look for and comprehend the principles on which each system was based, clarifying differences between systems as their learning progressed over time.

The research underlines young children's ability to make well-founded interpretations of the teaching available at school and at home in order to understand graphic representations. It suggests that children's awareness of the principles on which writing systems operate is stimulated and enhanced by biliterate experience, and that this experience should be available to both monolingual and bilingual children as part of mainstream education. 


\section{APPENDIX 2 - SFL Metafunctional Analysis}

TEXT 1: Ken Hyland in his article

"Hedging in Research Articles"

\begin{tabular}{|c|c|c|}
\hline Sentence & Clause & \\
\hline \multirow{2}{*}{1} & 1 & I have argued \\
\hline & 2 & $\begin{array}{l}\text { that hedges in scientific texts are the result of informational, rhetorical, and } \\
\text { personal choices which cannot be fully understood in isolation from social } \\
\text { and institutional contexts. }\end{array}$ \\
\hline \multirow{2}{*}{2} & 3 & Linguistic analyses alone cannot provide a rationale for such choices \\
\hline & 4 & $\begin{array}{l}\text { and the framework proposed here seeks to reflect this interpretive } \\
\text { environment. }\end{array}$ \\
\hline \multirow[t]{2}{*}{3} & 5 & $\begin{array}{l}\text { Research articles clearly reveal the relationship between a discourse } \\
\text { community, standards of knowledge, and textual representations, }\end{array}$ \\
\hline & 6 & and it is these in combination which motivate the use of hedges. \\
\hline \multirow[t]{2}{*}{4} & 7 & Hedges are abundant in science \\
\hline & 8 & and play a critical role in academic writing more generally \\
\hline \multirow[t]{2}{*}{5} & 9 & $\begin{array}{l}\text { They constitute an essential element of argumentation in presenting new } \\
\text { claims for ratification, }\end{array}$ \\
\hline & 10 & $\begin{array}{l}\text { and are among the primary features which shape the research article as the } \\
\text { principle vehicle for new knowledge. }\end{array}$ \\
\hline \multirow[t]{2}{*}{6} & 11 & $\begin{array}{l}\text { An understanding of their use therefore has important implications for a } \\
\text { number of areas }\end{array}$ \\
\hline & 12 & $\begin{array}{l}\text { and can contribute to the growing literature on the rhetoric of science, } \\
\text { revealing important insights into how science establishes its claim to } \\
\text { knowledge and how scientists carry out their work. }\end{array}$ \\
\hline \multirow[t]{5}{*}{7} & 13 & $\begin{array}{l}\text { Information about hedging can also advance our understanding of the } \\
\text { practice of evidential reasoning }\end{array}$ \\
\hline & 14 & and has practical consequences in ESP \\
\hline & 15 & where textbooks often emphasize the impersonality of scientific discourse \\
\hline & 16 & and either ignore hedges \\
\hline & 17 & or advise students to avoid them completely (Hyland, 1994). \\
\hline 8 & 18 & $\begin{array}{l}\text { Most importantly, however, the analysis demonstrates the dynamic and } \\
\text { interactive nature of scientific writing. }\end{array}$ \\
\hline 9 & 19 & $\begin{array}{l}\text { It contributes to a growing sociological and linguistic interest in } \\
\text { professional writing by providing a discourse analytic understanding of one } \\
\text { means by which scientific discourse is both socially situated and structured } \\
\text { to accomplish rhetorical objectives. }\end{array}$ \\
\hline
\end{tabular}

\subsection{Ideational Metafunction}

Process Analysis

1. I have argued that hedges in scientific texts are the result of informational, rhetorical, and personal choices which cannot be fully understood in isolation from social and institutional contexts. 


\begin{tabular}{|l|l|}
\hline I & Argued \\
\hline Sayer & Process: verbal \\
\hline
\end{tabular}

\begin{tabular}{|l|l|l|}
\hline $\begin{array}{l}\text { that hedges in scientific } \\
\text { texts }\end{array}$ & are & $\begin{array}{l}\text { The results of choices [[which } \\
\text { cannot be understood in isolation } \\
\text { from social and institutional } \\
\text { contexts]]. }\end{array}$ \\
\hline Token & $\begin{array}{l}\text { Process relational } \\
\text { (identifying) }\end{array}$ & Value \\
\hline
\end{tabular}

2. Linguistic analyses alone cannot provide a rationale for such choices and the framework proposed here seeks to reflect this interpretive environment.

\begin{tabular}{|l|l|l|}
\hline Linguistic analysis & cannot provide & $\begin{array}{l}\text { a rationale for } \\
\text { such choices }\end{array}$ \\
\hline Senser & Process: mental & Phenomenon \\
\hline
\end{tabular}

\begin{tabular}{|l|l|l|l|}
\hline and & $\begin{array}{l}\text { The framework } \\
\text { proposed here }\end{array}$ & seeks to reflect & $\begin{array}{l}\text { his interpretive } \\
\text { environment }\end{array}$ \\
\hline & Senser & Process: mental & Phenomenon \\
\hline
\end{tabular}

3. Research articles clearly reveal the relationship between a discourse community, standards of knowledge, and textual representations, and it is these in combination which motivate the use of hedges.

\begin{tabular}{|l|l|l|l|}
\hline $\begin{array}{l}\text { Research } \\
\text { articles }\end{array}$ & clearly & reveal & The relationship \\
\hline Senser & & Process: mental & Phenomenon \\
\hline
\end{tabular}

\begin{tabular}{|l|l|l|l|}
\hline and & it & is & $\begin{array}{l}\text { these in combination [[which } \\
\text { motivate the use of hedges]]. }\end{array}$ \\
\hline & Token & $\begin{array}{l}\text { Process: relational: } \\
\text { identifying }\end{array}$ & Value \\
\hline
\end{tabular}


4. Hedges are abundant in science and play a critical role in academic writing more generally.

\begin{tabular}{|l|l|l|}
\hline hedges & are & abundant \\
\hline Carrier & Process: relational: attributive & Attribute \\
\hline
\end{tabular}

\begin{tabular}{|l|l|l|l|l|}
\hline and & (hedges) & play & $\begin{array}{l}\text { a critical role in } \\
\text { academic writing }\end{array}$ & More generally \\
\hline & Token & $\begin{array}{l}\text { Process: } \\
\text { relational } \\
\text { identifying }\end{array}$ & Value & Circumstance \\
\hline
\end{tabular}

5. They constitute an essential element of argumentation in presenting new claims for ratification, and are among the primary features which shape the research article as the principle vehicle for new knowledge.

\begin{tabular}{|l|l|l|l|}
\hline They & constitute & $\begin{array}{l}\text { an essential element of } \\
\text { argumentation in presenting } \\
\text { new claims }\end{array}$ & for ratification \\
\hline Senser & Process: mental & Phenomenon & Circumstance \\
\hline
\end{tabular}

\begin{tabular}{|l|l|l|l|}
\hline and & (they) & are & $\begin{array}{l}\text { among the primary features } \\
{[[\text { which shape the research }} \\
\text { article }]] .\end{array}$ \\
\hline & Carrier & $\begin{array}{l}\text { Process: relational } \\
\text { (attributive) }\end{array}$ & Attribute \\
\hline
\end{tabular}

6. An understanding of their use therefore has important implications for a number of areas, and can contribute to the growing literature on the rhetoric of science, revealing important insights into how science establishes its claim to knowledge and how scientists carry out their work.

\begin{tabular}{|l|l|l|l|}
\hline $\begin{array}{l}\text { An understanding } \\
\text { of their use }\end{array}$ & therefore & $\begin{array}{l}\text { has } \\
\text { important } \\
\text { number of areas }\end{array}$ \\
\hline Carrier/Possessor & & $\begin{array}{l}\text { Process: relational attributive } \\
\text { (possessive) }\end{array}$ & Attribute/possessed \\
\hline
\end{tabular}




\begin{tabular}{|l|l|l|}
\hline (An understanding) & can contribute & $\begin{array}{l}\text { to the growing literature [[revealing } \\
\text { important insights into [[how science } \\
\text { establishes its claim to knowledge }]] \text { and } \\
{[[\text { how scientists carry out their work] }] /]}\end{array}$ \\
\hline Senser & Process: mental & Phenomenon \\
\hline
\end{tabular}

7. Information about hedging can also advance our understanding of the practice of evidential reasoning and has practical consequences in ESP where textbooks often emphasize the impersonality of scientific discourse and either ignore hedges or advise students to avoid them completely (Hyland, 1994).

\begin{tabular}{|l|l|l|}
\hline Information about hedging & can advance & $\begin{array}{l}\text { our } \\
\text { understanding }\end{array}$ \\
\hline Senser & Process: mental & Phenomenon \\
\hline
\end{tabular}

\begin{tabular}{|l|l|l|l|l|}
\hline and & (information) & has & practical consequences & in ESP \\
\hline & $\begin{array}{l}\text { Carrier/ } \\
\text { Possessor }\end{array}$ & $\begin{array}{l}\text { Process: } \\
\text { relational: } \\
\text { attributive } \\
\text { (possession) }\end{array}$ & Attribute/possessed & Circumstance \\
\hline
\end{tabular}

\begin{tabular}{|l|l|l|l|}
\hline where & textbooks & emphasize & $\begin{array}{l}\text { the impersonality } \\
\text { of scientific } \\
\text { discourse }\end{array}$ \\
\hline & Senser & Process: mental & Phenomenon \\
\hline
\end{tabular}

\begin{tabular}{|l|l|l|l|}
\hline and & (textbooks) & either ignore & hedges \\
\hline & Senser & Process: mental & Phenomenon \\
\hline
\end{tabular}

\begin{tabular}{|l|l|l|l|l|}
\hline or & (textbooks) & advise & students & to avoid them completely \\
\hline & Sayer & $\begin{array}{l}\text { Process: } \\
\text { verbal }\end{array}$ & Receiver & Verbiage \\
\hline
\end{tabular}


8. Most importantly, however, the analysis demonstrates the dynamic and interactive nature of scientific writing.

\begin{tabular}{|l|l|l|l|l|}
\hline $\begin{array}{l}\text { Most } \\
\text { importantly }\end{array}$ & however & the analysis & demonstrates & $\begin{array}{l}\text { the dynamic and } \\
\text { interactive nature of } \\
\text { scientific writing }\end{array}$ \\
\hline & & Senser & Process: mental & Phenomenon \\
\hline
\end{tabular}

9. It contributes to a growing sociological and linguistic interest in professional writing by providing a discourse analytic understanding of one means by which scientific discourse is both socially situated and structured to accomplish rhetorical objectives.

\begin{tabular}{|l|l|l|l|l|}
\hline it & $\begin{array}{l}\text { contribute } \\
\text { s }\end{array}$ & $\begin{array}{l}\text { to a growing } \\
\text { sociological } \\
\text { and linguistic } \\
\text { interest }\end{array}$ & $\begin{array}{l}\text { in professional } \\
\text { writing }\end{array}$ & $\begin{array}{l}\text { by providing a discourse } \\
\text { analytic understanding of one } \\
\text { means [[by which scientific } \\
\text { discourse is both socially } \\
\text { situated and structured to } \\
\text { accomplish rhetorical } \\
\text { objectives]]. }\end{array}$ \\
\hline Senser & $\begin{array}{l}\text { Process: } \\
\text { mental }\end{array}$ & Phenomenon & Circumstance & Circumstance \\
\hline
\end{tabular}

\section{Logico-Semantic Types of Clauses}

$1,+2$ parataxis and $3,+4 / \alpha, \beta, \lambda$ hypotaxis / ' projected idea, = elaboration, $\mathrm{x}$ enhancement

Paragraph I

$\alpha \quad$ (1i) I have argued

' $\beta$ (1ii ) that hedges in scientific texts are the result of informational, rhetorical, and personal choices [ [which cannot be fully understood in isolation from social and institutional contexts]].

1 (2i) Linguistic analyses alone cannot provide a rationale for such choices

+2 (2ii) and the framework proposed here seeks to reflect this interpretive environment.

1 (3i) Research articles clearly reveal the relationship between a discourse community, standards of knowledge, and textual representations,

+2 (3ii) and it is these in combination [[which motivate the use of hedges]].

\section{Paragraph II}

1 (4i) Hedges are abundant in science 
+2 (4ii ) and (hedges) play a critical role in academic writing more generally.

1 (5i) They constitute an essential element of argumentation in presenting new claims for ratification,

+2 (5ii) and are among the primary features [[which shape the research article as the principle vehicle for new knowledge]].

I (6i) An understanding of their use therefore has important implications for a number of areas,

+2 (6ii) and can contribute to the growing literature on the rhetoric of science, [[revealing important insights into [[how science establishes its claim to knowledge]] and [[how scientists carry out their work]]/]].

1 (7i ) Information about hedging can also advance our understanding of the practice of evidential reasoning

+2 (7ii) and has practical consequences in ESP

$x \beta^{1}$ (7iii) 3 where textbooks often emphasize the impersonality of scientific discourse

$x \beta^{2} \quad$ (7iv) +4 and either ignore hedges

$x \beta^{3} \quad(7 v)$ or advise students to avoid them completely (Hyland, 1994).

(8i) Most importantly, however, the analysis demonstrates the dynamic and interactive nature of scientific writing. -Clause Simplex-

(9i) It contributes to a growing sociological and linguistic interest in professional writing by providing a discourse analytic understanding of one means [[by which scientific discourse is both socially situated and structured to accomplish rhetorical objectives]]. Clause Simplex-

\subsection{Interpersonal Metafunction}

\section{MOOD and RESIDUE}

1. I have argued that hedges in scientific texts are the result of informational, rhetorical, and personal choices which cannot be fully understood in isolation from social and institutional contexts.

\begin{tabular}{|l|l|l|}
\hline I & have & argued \\
\hline Subject & Finite & Predicator \\
\hline \multicolumn{2}{|c|}{ MOOD } & RESIDUE \\
\hline
\end{tabular}

\begin{tabular}{|l|l|l|}
\hline $\begin{array}{l}\text { hedges in scientific } \\
\text { texts }\end{array}$ & are & $\begin{array}{l}\text { the result of informational, rhetorical, and personal } \\
\text { choices [[which cannot be fully understood in isolation } \\
\text { from social and institutional contexts]]. }\end{array}$ \\
\hline
\end{tabular}




\begin{tabular}{|c|l|l|}
\hline Subject & Finite & Compliment \\
\hline MOOD & RESIDUE \\
\hline
\end{tabular}

2. Linguistic analyses alone cannot provide a rationale for such choices and the framework proposed here seeks to reflect this interpretive environment.

\begin{tabular}{|l|l|l|l|}
\hline $\begin{array}{l}\text { Linguistic } \\
\text { analyses } \\
\text { alone }\end{array}$ & cannot & provide & $\begin{array}{l}\text { a rationale for such } \\
\text { choices }\end{array}$ \\
\hline Subject & Finite: modal: neg & Predicator & Complement \\
\hline \multicolumn{2}{|c|}{ MOOD } & RESIDUE \\
\hline
\end{tabular}

\begin{tabular}{|l|l|l|}
\hline $\begin{array}{l}\text { the } \\
\text { framework } \\
\text { proposed } \\
\text { here }\end{array}$ & seeks & $\begin{array}{l}\text { to reflect this } \\
\text { interpretive } \\
\text { environment. }\end{array}$ \\
\hline Subject & Finite: Predicator & Complement \\
\hline \multicolumn{2}{|c|}{ MOOD } & \multicolumn{2}{|c|}{ RESIDUE } \\
\hline
\end{tabular}

3. Research articles clearly reveal the relationship between a discourse community, standards of knowledge, and textual representations, and it is these in combination which motivate the use of hedges.

\begin{tabular}{|l|l|l|}
\hline $\begin{array}{c}\text { Research } \\
\text { articles } \\
\text { [clearly] }\end{array}$ & reveal & $\begin{array}{l}\text { the relationship between a discourse community, } \\
\text { standards of knowledge, and textual representations }\end{array}$ \\
\hline Subject & $\begin{array}{l}\text { Finite: } \\
\text { Predicator }\end{array}$ & Complement + Complement + Complement \\
\hline MOOD & RESIDUE \\
\hline
\end{tabular}

\begin{tabular}{|l|l|l|l|}
\hline it & is & these & $\begin{array}{l}\text { in combination } \\
{[[\text { which motivate }} \\
\text { the use of } \\
\text { hedges }]] .\end{array}$ \\
\hline Subject & Finite: & Compliment & Adjunct \\
\hline
\end{tabular}




\begin{tabular}{|l|l|}
\hline MOOD & RESIDUE \\
\hline
\end{tabular}

4. Hedges are abundant in science and play a critical role in academic writing more generally.

\begin{tabular}{|c|l|l|l|}
\hline Hedges & are & abundant & in science \\
\hline Subject & Finite & Complement: Attributive & Adjunct \\
\hline \multicolumn{2}{|c|}{ MOOD } & RESIDUE & \\
\hline
\end{tabular}

\begin{tabular}{|l|l|l|l|}
\hline \{hedges & play & a critical role & $\begin{array}{l}\text { in academic writing more } \\
\text { generally. }\end{array}$ \\
\hline $\begin{array}{l}\text { elliptical } \\
\text { Subject }\end{array}$ & Finite: Predicator & Complement & Adjunct \\
\hline \multicolumn{2}{|c|}{ MOOD } & RESIDUE & \\
\hline
\end{tabular}

5. They constitute an essential element of argumentation in presenting new claims for ratification, and are among the primary features which shape the research article as the principle vehicle for new knowledge.

\begin{tabular}{|c|l|l|l|}
\hline They & constitute & $\begin{array}{l}\text { an essential element } \\
\text { of argumentation }\end{array}$ & $\begin{array}{l}\text { in presenting new claims for } \\
\text { ratification }\end{array}$ \\
\hline Subject & Finite: Predicator & Compliment & Adjunct \\
\hline MOOD & \multicolumn{2}{|c|}{ RESIDUE } \\
\hline
\end{tabular}

\begin{tabular}{|l|l|l|}
\hline they\} & are & $\begin{array}{l}\text { among the primary features [[ which shape the } \\
\text { research article as the principle vehicle for new } \\
\text { knowledge]]. }\end{array}$ \\
\hline $\begin{array}{l}\text { elliptical } \\
\text { Subject }\end{array}$ & Finite & Adjunct \\
\hline \multicolumn{2}{|c|}{ MOOD } & RESIDUE \\
\hline
\end{tabular}

6. An understanding of their use therefore has important implications for a number of areas, and can contribute to the growing literature on the rhetoric of science, revealing important insights into how science establishes its claim to knowledge and how scientists carry out their work.

\begin{tabular}{|l|l|l|l|}
\hline An & therefore & has & important implications for a \\
\hline
\end{tabular}




\begin{tabular}{|c|l|l|l|}
\hline $\begin{array}{l}\text { understanding } \\
\text { of their use }\end{array}$ & & number of areas \\
\hline Subject & $\begin{array}{l}\text { Adjunct: } \\
\text { comment }\end{array}$ & Finite & Compliment \\
\hline MOOD & & MOOD & RESIDUE \\
\hline
\end{tabular}

\begin{tabular}{|l|l|l|l|}
\hline \{understanding\} & can & contribute & $\begin{array}{l}\text { to the growing literature on the } \\
\text { rhetoric of science, [[revealing } \\
\text { important insights into [[how } \\
\text { science establishes its claim to } \\
\text { knowledge]] and [[how scientists } \\
\text { carry out their work]]/]]. }\end{array}$ \\
\hline $\begin{array}{l}\text { elliptical } \\
\text { Subject }\end{array}$ & Finite: modal & Predicator & Compliment \\
\hline MOOD & \multicolumn{2}{|c|}{ RESIDUE } \\
\hline
\end{tabular}

7. Information about hedging can also advance our understanding of the practice of evidential reasoning and has practical consequences in ESP where textbooks often emphasize the impersonality of scientific discourse and either ignore hedges or advise students to avoid them completely (Hyland, 1994).

\begin{tabular}{|l|l|l|l|l|}
\hline $\begin{array}{l}\text { Information } \\
\text { about } \\
\text { hedging }\end{array}$ & can & also & advance & $\begin{array}{l}\text { our understanding of } \\
\text { the practice of } \\
\text { evidential reasoning }\end{array}$ \\
\hline Subject & Finite: modal & $\begin{array}{l}\text { Adjunct: } \\
\text { conjunctive }\end{array}$ & Predicator & Compliment \\
\hline \multicolumn{2}{|c|}{ MOOD } & & \multicolumn{2}{|c|}{ RESIDUE } \\
\hline
\end{tabular}

\begin{tabular}{|c|c|c|c|}
\hline \{information $\}$ & has & $\begin{array}{l}\text { practical } \\
\text { consequences }\end{array}$ & in ESP \\
\hline $\begin{array}{l}\text { elliptical } \\
\text { Subject }\end{array}$ & Finite & Compliment & Adjunct \\
\hline \multicolumn{4}{|c|}{ RESIDUE } \\
\hline
\end{tabular}

\begin{tabular}{|l|l|l|l|l|}
\hline where & textbooks & often & emphasize & $\begin{array}{l}\text { the } \\
\text { impersonality } \\
\text { of scientific }\end{array}$ \\
\hline
\end{tabular}




\begin{tabular}{|l|l|l|l|l|}
\hline & & & & discourse \\
\hline $\begin{array}{l}\text { Adjunct: } \\
\text { conjunctive }\end{array}$ & Subject & Adjunct: mood & Finite: Predicator & Compliment \\
\hline- & \multicolumn{2}{|c|}{ MOOD } & \multicolumn{2}{|c|}{ RESIDUE } \\
\hline
\end{tabular}

\begin{tabular}{|l|l|l|}
\hline \{textbooks\} & ignore & hedges \\
\hline $\begin{array}{l}\text { elliptical } \\
\text { Subject }\end{array}$ & Finite: Predicator & Compliment \\
\hline \multicolumn{2}{|c|}{ MOOD } & \multicolumn{2}{|c|}{ RESIDUE } \\
\hline
\end{tabular}

\begin{tabular}{|l|l|l|l|}
\hline$\{$ textbooks $\}$ & advise & students & to avoid them completely. \\
\hline $\begin{array}{l}\text { elliptical } \\
\text { Subject }\end{array}$ & Finite: Predicator & Compliment & Adjunct \\
\hline \multicolumn{2}{|c|}{ MOOD } & RESIDUE \\
\hline
\end{tabular}

8. Most importantly, however, the analysis demonstrates the dynamic and interactive nature of scientific writing.

\begin{tabular}{|l|l|l|l|l|}
\hline $\begin{array}{l}\text { Most } \\
\text { importantly }\end{array}$ & however & the analysis & demonstrates & $\begin{array}{l}\text { the dynamic and } \\
\text { interactive } \\
\text { nature of } \\
\text { scientific } \\
\text { writing. }\end{array}$ \\
\hline $\begin{array}{l}\text { Adjunct: } \\
\text { comment }\end{array}$ & $\begin{array}{l}\text { Adjunct: } \\
\text { conjunctive }\end{array}$ & Subject & Finite: Predicator & Compliment \\
\hline & - & MOOD & \multicolumn{2}{|c|}{ RESIDUE } \\
\hline
\end{tabular}

9. It contributes to a growing sociological and linguistic interest in professional writing by providing a discourse analytic understanding of one means by which scientific discourse is both socially situated and structured to accomplish rhetorical objectives.

\begin{tabular}{|l|l|l|l|}
\hline It & contributes & $\begin{array}{l}\text { to a growing } \\
\text { sociological and } \\
\text { linguistic interest } \\
\text { in professional } \\
\text { writing }\end{array}$ & $\begin{array}{l}\text { by providing a discourse } \\
\text { analytic understanding of one } \\
\text { means [[by which scientific } \\
\text { discourse is both socially } \\
\text { situated and structured to } \\
\text { accomplish rhetorical }\end{array}$ \\
\hline
\end{tabular}




\begin{tabular}{|l|l|l|l|l|}
\hline & & & objectives]]. \\
\hline Subject & \multicolumn{2}{|l|}{ Finite: Predicator } & Compliment & Adjunct \\
\hline \multicolumn{2}{|l|}{ MOOD } & \multicolumn{2}{|c|}{ RESIDUE } \\
\hline
\end{tabular}

\subsection{Textual Metafunction}

Theme

\begin{tabular}{|c|c|c|c|c|}
\hline Sentence/ & THEMES: Textual & & Interpersonal & Topical \\
\hline $1 / 1$ & I & & & $\Delta$ \\
\hline $1 / 2$ & that hedges & $\Delta$ & & $\begin{array}{l}\Delta \text { (structural- } \\
\text { topical) }\end{array}$ \\
\hline II $/ 3$ & Linguistic analysis & & & $\Delta$ \\
\hline II $/ 4$ & and the framework & $\Delta$ & & $\Delta$ \\
\hline III $/ 5$ & research articles & & & $\Delta$ \\
\hline $1 \mathrm{II} / 6$ & and it & $\Delta$ & & $\Delta$ \\
\hline IV / 7 & hedges & & & $\boldsymbol{\Delta}$ \\
\hline IV /8 & and (hedges) & $\Delta$ & & $(\mathbf{\Delta})$ \\
\hline $\mathrm{V} / 9$ & they & & & $\Delta$ \\
\hline $\mathrm{V} / 10$ & and (they) & $\Delta$ & & $(\mathbf{\Delta})$ \\
\hline $\mathrm{VI} / 11$ & $\begin{array}{l}\text { an understanding of their } \\
\text { use }\end{array}$ & & & $\Delta$ \\
\hline $\mathrm{VI} / 12$ & and (understanding) & $\Delta$ & & $(\mathbf{A})$ \\
\hline VII $/ 13$ & information about hedging & & & $\boldsymbol{\Delta}$ \\
\hline VII / 14 & and (information) & $\Delta$ & & $(\mathbf{A})$ \\
\hline $\mathrm{VII} / 15$ & where & & & $\begin{array}{l}\Delta \text { (structural- } \\
\text { topical) }\end{array}$ \\
\hline VII / 16 & and (textbooks) & $\Delta$ & & $(\Delta)$ \\
\hline $\mathrm{VII} / 17$ & or (textbooks) & $\Delta$ & & $(\Delta)$ \\
\hline $\mathrm{VIII} / 18$ & $\begin{array}{l}\text { most importantly, however, } \\
\text { the analysis }\end{array}$ & $\mathbf{A}$ & $\Delta$ & $\boldsymbol{\Delta}$ \\
\hline IX/19 & it & & & $\Delta$ \\
\hline & Total: & 10 & 1 & 19 \\
\hline
\end{tabular}

\section{Cohesion}

1. I $\rightarrow$ hedges $\rightarrow$ in texts $\rightarrow$ results of choices $\rightarrow$ which $\rightarrow$ in isolation from contexts

2. Linguistic analysis $\rightarrow$ a rationale for such choices $\rightarrow$ (and) the framework $\rightarrow$ this environment

3. Research articles $\rightarrow$ the relationships between a community, standards of knowledge, and representations, (and) it $\rightarrow$ in combination $\rightarrow$ which $\rightarrow$ the use of hedges

4. Hedges $\rightarrow$ in science (and) [hedges] $\rightarrow$ a role $\rightarrow$ in writing 
5. They $\rightarrow$ an element of argumentation $\rightarrow$ in claims for ratification, (and) [they] $\rightarrow$ among features $\rightarrow$ which $\rightarrow$ the research article $\rightarrow$ as the vehicle for knowledge

6. An understanding of their use $\rightarrow$ implications for a number of areas, (and) [understanding] $\rightarrow$ to the growing literature $\rightarrow$ on the rhetoric of science $\rightarrow$ insights $\rightarrow$ (into how) science $\rightarrow$ its claim to knowledge (and how) scientists $\rightarrow$ their work

7. Information about hedging $\rightarrow$ our understanding of the practice of reasoning (and) [information] $\rightarrow$ consequences (where) textbooks $\rightarrow$ the impersonality of discourse (and) [textbooks] $\rightarrow$ either hedges, $\rightarrow$ or [textbooks] $\rightarrow$ students $\rightarrow$ them

8. The analysis $\rightarrow$ the nature of writing

9. It $\rightarrow$ to a growing interest in writing $\rightarrow$ by a(n) understanding of means $\rightarrow$ by which $\rightarrow$ discourse $\rightarrow$ both (socially situated and structured) $\rightarrow$ objectives

TEXT 2. Desmond Allison, Linda Cooley, Jo Lewcowicz, \& David Nunan

"Dissertation Writing in Action: The Development of a Dissertation Writing Support Program for ESL Graduate Research Students"

\begin{tabular}{|l|l|l|}
\hline Sentence & Clause & TEXT 2 \\
\hline 1 & 1 & $\begin{array}{l}\text { Research amongst supervisors and graduate students at UHK, the } \\
\text { numbers of students registering for the writing program that was } \\
\text { induced, students' positive reactions to the program and the growing } \\
\text { number of graduate students attending the English Centre's one-to- } \\
\text { one Writing Support Service have combined to show that there is } \\
\text { clearly a need for a writing program to become a regular feature of } \\
\text { graduate life at the university. }\end{array}$ \\
\hline 3 & 2 & $\begin{array}{l}\text { In this paper, we have described the development of a program to } \\
\text { help NNS research students develop skills in planning, drafting, and } \\
\text { revising their theses. }\end{array}$ \\
\hline 4 & $\begin{array}{l}\text { The program evolved from a grounded investigation into the } \\
\text { problems encountered by students in their struggle to produce a } \\
\text { thesis in a language other than their own. }\end{array}$ \\
\hline 5 & $\begin{array}{l}\text { Data for this investigation came from interviews with supervisors, } \\
\text { students' questionnaires and an analysis of student writing. }\end{array}$ \\
\hline 5 & $\begin{array}{l}\text { The initial study, as indicated above, revealed shortcomings in four } \\
\text { main areas which can be summarized as follows: } \\
\text { 9. A failure to organize and structure the thesis in a way which } \\
\text { made the objectives, purpose and outcomes of the research } \\
\text { transparent to the reader, and a failure to create "a research } \\
\text { space"; } \\
\text { A failure to substantiate arguments with evidence from the } \\
\text { literature and a tendency to make claims for own research } \\
\text { findings which were too strong or overgeneralized; } \\
\text { 11. An inability to organize information at the level of the } \\
\text { paragraph, to show relationships and to develop texts in } \\
\text { functionally appropriate ways; } \\
\text { 12. 'local' problems to do with editing, spelling, grammar and }\end{array}$ \\
\hline
\end{tabular}




\begin{tabular}{|c|c|c|}
\hline & & bibliographical referencing. \\
\hline \multirow[t]{2}{*}{6} & 6 & While, at first sight, local errors were the most evident, \\
\hline & 7 & $\begin{array}{l}\text { by far the greatest number of communication problems occurred at } \\
\text { the macro-level of audience, purpose and overall structuring. }\end{array}$ \\
\hline 7 & 8 & $\begin{array}{l}\text { Hence the diagnostic framework and the resultant writing program } \\
\text { were designed to focus primarily on these macro-level problems. }\end{array}$ \\
\hline \multirow[t]{2}{*}{8} & 9 & $\begin{array}{l}\text { A limitation of the work that has been reported here is its situation- } \\
\text { specific nature - }\end{array}$ \\
\hline & 10 & although this is in some ways a strength. \\
\hline \multirow[t]{4}{*}{9} & 11 & While we have expressed a degree of confidence \\
\hline & 12 & $\begin{array}{l}\text { that the approach we have described will be applicable in work with } \\
\text { NNS research students in other situations, }\end{array}$ \\
\hline & 13 & we are sure \\
\hline & 14 & that adaptations will prove to be necessary. \\
\hline \multirow[t]{2}{*}{10} & 15 & $\begin{array}{l}\text { Indeed, some changes have already been implemented in subsequent } \\
\text { workshops at UHK }\end{array}$ \\
\hline & 16 & $\begin{array}{l}\text { and research is continuing into ways in which students can be } \\
\text { assisted further with the challenging task of writing a dissertation in } \\
\text { a second or foreign language. }\end{array}$ \\
\hline \multirow[t]{4}{*}{11} & 17 & Yet we believe \\
\hline & 18 & $\begin{array}{l}\text { that the focus on extended texts and the macro-level of writing as } \\
\text { emphasized in this paper are essential }\end{array}$ \\
\hline & 19 & $\begin{array}{l}\text { if students are to go beyond improving their writing at the sentence } \\
\text { level }\end{array}$ \\
\hline & 20 & and actually enhance the quality of their dissertation writing. \\
\hline
\end{tabular}

\subsection{Ideational Metafunction}

\section{Process Analysis}

\begin{tabular}{|l|l|l|l|}
\hline $\begin{array}{l}\text { Sentence } \\
N\end{array}$ & Predicate & Type & Description \\
\hline 1 & have combined & mental & $\begin{array}{l}\text { Present Perfect; } \\
\text { Active }\end{array}$ \\
\hline 2 & have described & verbal & $\begin{array}{l}\text { Present Perfect; } \\
\text { Active }\end{array}$ \\
\hline 3 & evolved & mental & $\begin{array}{l}\text { Past Simple; } \\
\text { Active }\end{array}$ \\
\hline 4 & came (from interviews) & mental & $\begin{array}{l}\text { Past Simple; } \\
\text { Active }\end{array}$ \\
\hline 5 & revealed & mental & $\begin{array}{l}\text { Past Simple; } \\
\text { Active }\end{array}$ \\
\hline 6 & were (the most evident) & relational: attributive & $\begin{array}{l}\text { Past Simple; } \\
\text { Active }\end{array}$ \\
\hline & occurred & $\begin{array}{l}\text { relational: } \\
\text { identifying }\end{array}$ & $\begin{array}{l}\text { Past Simple } \\
\text { Active }\end{array}$ \\
\hline 7 & were designed & $\begin{array}{l}\text { Past Simple; } \\
\text { Passive }\end{array}$ \\
\hline
\end{tabular}




\begin{tabular}{|c|c|c|c|}
\hline 8 & $\begin{array}{l}\text { is (its nature) } \\
\text { is (a strength) }\end{array}$ & $\begin{array}{l}\text { relational: } \\
\text { identifying } \\
\text { relational: } \\
\text { identifying }\end{array}$ & $\begin{array}{l}\text { Present Simple; } \\
\text { Active } \\
\text { Present Simple; } \\
\text { Active }\end{array}$ \\
\hline 9 & $\begin{array}{l}\text { have expressed } \\
\text { will be applicable } \\
\text { are sure } \\
\text { will prove }\end{array}$ & $\begin{array}{l}\text { verbal } \\
\text { relational: attributive } \\
\text { relational: attributive } \\
\text { mental }\end{array}$ & $\begin{array}{l}\text { Present Perfect; } \\
\text { Active } \\
\text { Future Simple; } \\
\text { Active } \\
\text { Present Simple; } \\
\text { Active } \\
\text { Future Simple; } \\
\text { Active }\end{array}$ \\
\hline 10 & $\begin{array}{l}\text { have been implemented } \\
\text { is continuing }\end{array}$ & $\begin{array}{l}\text { mental } \\
\text { relational: } \\
\text { circumstantial }\end{array}$ & $\begin{array}{l}\text { Present Perfect; } \\
\text { Passive } \\
\text { Present } \\
\text { Progressive; } \\
\text { Active }\end{array}$ \\
\hline 11 & $\begin{array}{l}\text { believe } \\
\text { are (essential) } \\
\text { are to go beyond improving } \\
\text { enhance }\end{array}$ & $\begin{array}{l}\text { mental } \\
\text { relational: attributive } \\
\text { mental } \\
\text { mental }\end{array}$ & $\begin{array}{l}\text { Present Simple; } \\
\text { Active } \\
\text { Present Simple; } \\
\text { Active } \\
\\
\text { Modal; Active; } \\
\text { Present aspect } \\
\text { Present Simple; } \\
\text { Active }\end{array}$ \\
\hline
\end{tabular}

\section{Taxis and Logico-semantic Clause Type}

Projection : " locution; ' idea

Expansion: = elaboration; + extension; $\mathbf{x}$ enhancement

1

(i) Clause Simplex Research amongst supervisors and graduate students at UHK, the numbers of students [[registering for the writing program [[that was induced]] /]], students' positive reactions to the program and the growing number of graduate students [[attending the English Centre's one-to-one Writing Support Service]] have combined to show [[that there is clearly a need for a writing program to become a regular feature of graduate life at the university]]. 
(i) Clause Simplex In this paper, we have described the development of a program to help NNS research students develop skills in [[planning, drafting, and revising their theses]].

(i) Clause Simplex The program evolved from a grounded investigation into the problems [[encountered by students in their struggle to produce a thesis in a language other than their own]].

(i) Clause Simplex Data for this investigation came from interviews with supervisors, students' questionnaires and an analysis of student writing.

(i) Clause Simplex The initial study, [[as indicated above]], revealed shortcomings in four main areas [[which can be summarized as follows]]:

1) A failure to organize and structure the thesis in a way [[which made the objectives, purpose and outcomes of the research transparent to the reader]], and a failure to create "a research space";

2) A failure to substantiate arguments with evidence from the literature and a tendency to make claims for own research findings [[which were too strong or overgeneralized]];

3) An inability to organize information at the level of the paragraph, to show relationships and to develop texts in functionally appropriate ways;

4) 'local' problems to do with editing, spelling, grammar and bibliographical referencing.

6

(i) $+\beta$ While, at first sight, local errors were the most evident,

(ii) $\alpha$ by far the greatest number of communication problems occurred at the macrolevel of audience, purpose and overall structuring.

(i) Clause Simplex Hence the diagnostic framework and the resultant writing program were designed to focus primarily on these macro-level problems.

(i) $\quad \alpha$ A limitation of the work [[that has been reported here]] is its situation-specific nature -

(ii) $\quad x \beta$ although this is in some ways a strength.

9

(i) $\quad x \beta$ While we have expressed a degree of confidence

(ii) " $\lambda$ that the approach [[we have described]] will be applicable in work with NNS research students in other situations,

(iii) $\alpha$ we are sure

(iv) ' $\mu$ that adaptations will prove to be necessary. 
(i) +1 Indeed, some changes have already been implemented in subsequent workshops at UHK

(ii) +2 and research is continuing into ways [[in which students can be assisted further with the challenging task of writing a dissertation in a second or foreign language]].

11

(i) $\alpha$ Yet we believe

(ii) ' $\beta$ that the focus on extended texts and the macro-level of writing [[as emphasized in this paper]] are essential

(iii) $+1 \times \lambda$ if students are to go beyond improving their writing at the sentence level

(iv) $+2 \times \lambda$ and \{if students\} and actually enhance the quality of their dissertation writing. ‘

\begin{tabular}{|c|c|c|c|}
\hline $\begin{array}{l}\text { Clause Complexes } \\
\text { Clause Simplexes }\end{array}$ & $\begin{array}{l}6 \\
5\end{array}$ & $\begin{array}{l}\text { Parataxis } \\
\text { Hypotaxis }\end{array}$ & $\begin{array}{l}2 \\
8 \\
\end{array}$ \\
\hline $\begin{array}{c}\text { Projection: } \\
-\quad \text { locution } \\
-\quad \text { idea }\end{array}$ & $\begin{array}{l}3 \\
1 \\
2\end{array}$ & $\begin{aligned} & \text { Expansion: } \\
&-\quad \text { elaboration } \\
&-\quad \text { extension } \\
&-\quad \text { enhancement (temporal, } \\
& \text { concession, condition } \times 2 \text { ) }\end{aligned}$ & $\begin{array}{l}5 \\
0 \\
1 \\
4\end{array}$ \\
\hline
\end{tabular}

\subsection{Interpersonal Metafunction}

\section{MOOD and RESIDUE}

1. Research amongst supervisors and graduate students at UHK, the numbers of students [[registering for the writing program [[that was induced]]/]], students' positive reactions to the program and the growing number of graduate students [[attending the English Centre's one-to-one Writing Support Service]] have combined to show [[that there is clearly a need for a writing program to become a regular feature of graduate life at the university]].

\begin{tabular}{|l|l|l|l|l|}
\hline $\begin{array}{l}\text { Research / the } \\
\text { numbers of students / } \\
\text { positive reactions }\end{array}$ & have & combined & to show & {$[$ [that ... } \\
\hline Subject & Finite & Predicator & Adjunct & Complement \\
\hline MOOD & RESIDUE & & \\
\hline
\end{tabular}

2. In this paper, we have described the development of a program to help NNS research students develop skills in planning, drafting, and revising their theses. 


\begin{tabular}{|l|l|l|l|l|}
\hline $\begin{array}{l}\text { In this } \\
\text { paper, }\end{array}$ & we & have & described & $\begin{array}{l}\text { the development t of a program to help } \\
\text { NNS research students develop skills in } \\
\text { planning, drafting, and revising their } \\
\text { theses. }\end{array}$ \\
\hline Adjunct & Subject & Finite & Predicator & Complement \\
\hline & MOOD & RESIDUE \\
\hline
\end{tabular}

3. The program evolved from a grounded investigation into the problems encountered by students in their struggle to produce a thesis in a language other than their own.

\begin{tabular}{|l|l|l|}
\hline The program & evolved & $\begin{array}{l}\text { from a grounded investigation into the } \\
\text { problems [[encountered by students in their } \\
\text { struggle to produce a thesis in a language } \\
\text { other than their own]]. }\end{array}$ \\
\hline Subject & Finite: Predicator & Adjunct \\
\hline MOOD & RESIDUE \\
\hline
\end{tabular}

4. Data for this investigation came from interviews with supervisors, students' questionnaires and an analysis of student writing.

\begin{tabular}{|l|l|l|}
\hline $\begin{array}{l}\text { Data for this } \\
\text { investigation }\end{array}$ & came & $\begin{array}{l}\text { from interviews with supervisors, students' } \\
\text { questionnaires and an analysis of student writing. }\end{array}$ \\
\hline Subject & Finite: Predicator & Adjunct \\
\hline MOOD & RESIDUE \\
\hline
\end{tabular}

5. The initial study, as indicated above, revealed shortcomings in four main areas which can be summarized as follows:

13. A failure to organize and structure the thesis in a way which made the objectives, purpose and outcomes of the research transparent to the reader, and a failure to create "a research space";

14. A failure to substantiate arguments with evidence from the literature and a tendency to make claims for own research findings which were too strong or overgeneralized;

15. An inability to organize information at the level of the paragraph, to show relationships and to develop texts in functionally appropriate ways;

16. 'local' problems to do with editing, spelling, grammar and bibliographical referencing.

\begin{tabular}{|l|l|l|}
\hline $\begin{array}{l}\text { The initial } \\
\text { study ... }\end{array}$ & revealed & shortcomings [[which * \\
\hline Subject & Finite: Predicator & Complement \\
\hline MOOD & RESIDUE \\
\hline
\end{tabular}

Embedded Clause

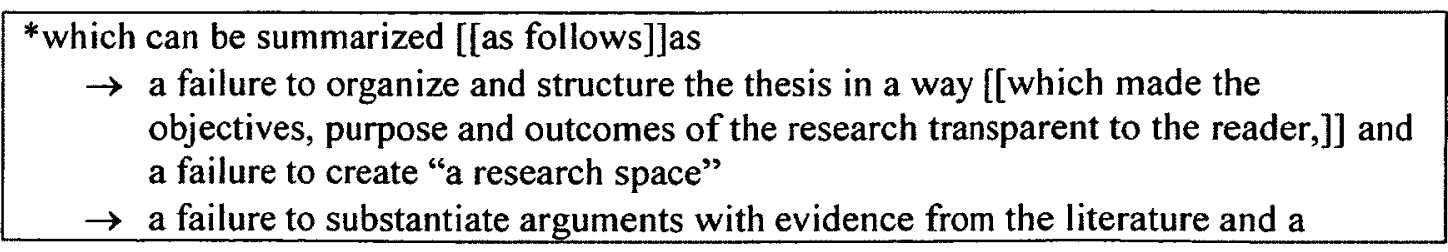



tendency to make claims for own research findings [[which were too strong or overgeneralized]]
$\rightarrow$ an inability to organize information at the level of the paragraph, to show relationships and to develop texts in functionally appropriate ways
$\rightarrow$ 'local' problems to do with editing, spelling, grammar and bibliographical referencing.

6. While, at first sight, local errors were the most evident, by far the greatest number of communication problems occurred at the macro-level of audience, purpose and overall structuring.

\begin{tabular}{|l|l|l|l|l|}
\hline While, & at first sight, & local errors & were & the most evident, \\
\hline $\begin{array}{l}\text { Adjunct: } \\
\text { conjunctive }\end{array}$ & $\begin{array}{l}\text { Adjunct: } \\
\text { comment }\end{array}$ & Subject & Finite & $\begin{array}{l}\text { Complement } \\
\text { (attributive) }\end{array}$ \\
\hline \multicolumn{2}{|c|}{ MOOD } & RESIDUE \\
\hline
\end{tabular}

\begin{tabular}{|l|l|l|l|}
\hline by far & $\begin{array}{l}\text { the greatest } \\
\text { number of } \\
\text { communicatio } \\
\text { n problems }\end{array}$ & occurred & $\begin{array}{l}\text { at the macro-level of audience, } \\
\text { purpose and overall structuring. }\end{array}$ \\
\hline $\begin{array}{l}\text { Adjunct: } \\
\text { time }\end{array}$ & Subject & Finite: Predicator & Adjunct \\
\hline RESIDUE & \multicolumn{2}{|c|}{ MOOD } & RESIDUE \\
\hline
\end{tabular}

7. Hence the diagnostic framework and the resultant writing program were designed to focus primarily on these macro-level problems.

\begin{tabular}{|l|l|l|l|l|}
\hline Hence & $\begin{array}{l}\text { the diagnostic } \\
\text { framework and the } \\
\text { resultant writing } \\
\text { program }\end{array}$ & were & designed & $\begin{array}{l}\text { to focus primarily on these } \\
\text { macro-level problems. }\end{array}$ \\
\hline $\begin{array}{l}\text { Adj: } \\
\text { conjunct }\end{array}$ & Subject & Finite & Predicator & Adjunct \\
\hline & MOOD & RESIDUE \\
\hline
\end{tabular}

8. A limitation of the work that has been reported here is its situation-specific nature although this is in some ways a strength.

\begin{tabular}{|l|l|l|}
\hline $\begin{array}{l}\text { A limitation of } \\
\text { the work [[that } \\
\text { has been reported } \\
\text { here]] }\end{array}$ & is & its situation-specific nature - \\
\hline Subject & Finite & Complement \\
\hline MOOD & RESIDUE \\
\hline
\end{tabular}




\begin{tabular}{|l|l|l|l|l|}
\hline although & this & is & in some ways & a strength \\
\hline Adjunct & TH/ Subject & Finite & Adjunct & Complement \\
\hline & MOOD & RESIDUE & \\
\hline
\end{tabular}

9. While we have expressed a degree of confidence that the approach we have described will be applicable in work with NNS research students in other situations, we are sure that adaptations will prove to be necessary.

\begin{tabular}{|l|l|l|l|l|}
\hline While & we & have & expressed & a degree of confidence \\
\hline Adjunct & Subject & Finite & Predicator & Complement \\
\hline & MOOD & RESIDUE \\
\hline
\end{tabular}

\begin{tabular}{|c|l|l|l|l|l|}
\hline that & $\begin{array}{l}\text { the approach } \\
\text { [[we have } \\
\text { described]] }\end{array}$ & will & $\begin{array}{l}\text { be } \\
\text { applicable }\end{array}$ & $\begin{array}{l}\text { in work with NNS } \\
\text { research students in } \\
\text { other situations, }\end{array}$ \\
\hline Adj. & Subject & Finite & Predicator & Adjunct \\
\hline & MOOD & & MOOD & RESIDUE \\
\hline
\end{tabular}

\begin{tabular}{|l|l|l|l|l|l|l|l|l|}
\hline we & are & sure & & that & $\begin{array}{l}\text { adaptati } \\
\text { ons }\end{array}$ & will & prove & $\begin{array}{l}\text { to be } \\
\text { necessary. }\end{array}$ \\
\hline $\begin{array}{l}\text { Sub } \\
\text { ject }\end{array}$ & Finite & $\begin{array}{l}\text { Comple } \\
\text { ment }\end{array}$ & $\begin{array}{l}\text { Adjunct: } \\
\text { conjunct } \\
\text { ive }\end{array}$ & Subject & Finite & Predicator & $\begin{array}{l}\text { Compleme } \\
\text { nt }\end{array}$ \\
\hline MOOD & RD & & \multicolumn{3}{|l|}{ MOOD } & RESIDUE \\
\hline
\end{tabular}

10. Indeed, some changes have already been implemented in subsequent workshops at UHK and research is continuing into ways in which students can be assisted further with the challenging task of writing a dissertation in a second or foreign language.

\begin{tabular}{|l|l|l|l|l|}
\hline Indeed, & $\begin{array}{l}\text { some } \\
\text { changes }\end{array}$ & have & $\begin{array}{l}\text { been } \\
\text { implemented }\end{array}$ & $\begin{array}{l}\text { in subsequent } \\
\text { workshops at UHK }\end{array}$ \\
\hline $\begin{array}{l}\text { Adjunct: } \\
\text { comment }\end{array}$ & Subject & Finite & Predicator & Adjunct \\
\hline & MOOD & RESIDUE \\
\hline
\end{tabular}

\begin{tabular}{|l|l|l|l|l|}
\hline and & research & is & continuing & $\begin{array}{l}\text { into ways [[in which students can be } \\
\text { assisted further with the challenging } \\
\text { task of writing a dissertation in a } \\
\text { second or foreign language]]. }\end{array}$ \\
\hline Adj. & Subject & Finite & Predicator & Adjunct \\
\hline & MOOD & RESIDUE & \\
\hline
\end{tabular}

11. Yet we believe that the focus on extended texts and the macro-level of writing as emphasized in this paper are essential if students are to go beyond improving their writing at the sentence level and actually enhance the quality of their dissertation writing. 


\begin{tabular}{|l|l|l|l|}
\hline Yet & we & \multicolumn{2}{|l|}{ believe } \\
\hline & Subject & Finite & Predicator \\
\hline & MOOD & RESIDUE \\
\hline
\end{tabular}

\begin{tabular}{|l|l|l|l|}
\hline that & $\begin{array}{l}\text { the focus on extended texts and } \\
\text { the macro-level of writing [[as } \\
\text { emphasized in this paper]] }\end{array}$ & are & essential \\
\hline Adjunct & Subject & Finite & $\begin{array}{l}\text { Complement } \\
\text { (attributive) }\end{array}$ \\
\hline & MOOD & RESIDUE \\
\hline
\end{tabular}

\begin{tabular}{|l|l|l|l|l|}
\hline if & students & are to & go & $\begin{array}{l}\text { beyond } \\
\text { improving their } \\
\text { writing at the } \\
\text { sentence level }\end{array}$ \\
\hline $\begin{array}{l}\text { Adj } \\
\text {. Subject }\end{array}$ & $\begin{array}{l}\text { Finite: } \\
\text { modal }\end{array}$ & Predicator & Adjunct \\
\hline & \multicolumn{2}{|l|}{ MOOD } & RESIDUE & \\
\hline
\end{tabular}

\begin{tabular}{|l|l|l|l|l|l|}
\hline and & $\{$ students $\}$ & actually & $\{$ are to & enhance & $\begin{array}{l}\text { the quality } \\
\text { of their } \\
\text { dissertatio } \\
\text { n writing. }\end{array}$ \\
\hline $\begin{array}{l}\text { Conjunctive } \\
\text { Adjunct }\end{array}$ & $\begin{array}{l}\text { elliptical } \\
\text { Subject }\end{array}$ & $\begin{array}{l}\text { Adjunct: } \\
\text { comment }\end{array}$ & $\begin{array}{l}\text { elliptical } \\
\text { Finite }\end{array}$ & Predicator & $\begin{array}{l}\text { Compleme } \\
\text { nt }\end{array}$ \\
\hline & MOOD & & MOOD & RESIDUE & \\
\hline
\end{tabular}

\subsection{Textual Metafunction}

Specific (terminological) lexical density

RESEARCH amongst SUPPERISORS and GRAPUATE STUPENTS at UHK, the numbers of STUDENTS registering for the WRITTNG PROGRAM that was induced, STUPENTS' positive REACTIONS to the PROGRAM and the growing number of GRADUATE STUDENTST, attending the ENGLISTH CENTRE'S ONE-TO-ONE WRITTNG SUPPORT SERVICE have combined to show that there is clearly a need for a WRITING PROGRAM to become a regular feature of GRADUATE LIFE at the UNIVERSITY. In THIS PAPER, we have described the DEYELOPMENT of a PROGRAM to help NNS RESEARCH STUDENTS develop SKIILLS in PLANNING, DRAFTING, and REVISING their THESES. The PROGRAM evolved from a GROUNDED INVESTIGATION into the PROBLEMS encountered by STUDENTS in their struggle to produce a THESIS in a LANGUAGE other than their own. DATA for this INVESTIGATION came from INTERVIEWS with SUPERVISORS, STUDENTS' QUESTIONNAIRES and an ANALYSIS of STUDENT WRITING. The initial STUDY, 
as indicated above, revealed SHORTCOMTNGS in four main AREAS which can be summarized as follows:

1. A FAILURE to organize and structure the THESIS in a way which made the OBJECTIVES, PURPOSE and OUTCOMES of the RESEARCH transparent to the READER, and a FAILURE to create "A RESEARCH SPACE";

2. A FAILURE to substantiate ARGUMENTS with EVIDENCE from the LITERATURE and a TENDENCY to make CLAIMS for own RESEARCH FINDINGS which were too strong or overgeneralized;

3. An INABILITY to organize INFORMATION at the LEVEL of the PARAGRAPH, to show RELATIONSWHIPS and to develop TEXTS in functionally appropriate ways;

4. 'LOCAL' PRQBLEMS to do with EDITNG, SPELLING, GRAMMAR and BIBLIOGRAPHICAL REFERENCING,

While, at first sight, LOCAL ERRORS were the most evident, by far the greatest number of COMMUNICATION PROBLEMS occurred at the MACRO-LEVEL OF AUDIENCE, PURPOSE and overall STRUCTURING. Hence the DIAGNOSTIC FRAMEWORK and the RESULTANT WRITING PROGRAM were designed to focus primarily on these MACRO-LEYEL PROBLEMS. A LIMITATION of the WORK that has been reported here is its SITUATION-SPECIFIC NATURE - although this is in some ways A STRENGTH. While we have expressed a DEGREE OF CONFIDENCE that the APPROACH we have described will be applicable in WORK with NNS RESEARCH STUDENTS in other situations, we are sure that ADAPTATIONS will prove to be necessary. Indeed, some changes have already been implemented in subsequent WORKSHOPS at UHK and RESEARCH is continuing into ways in which STUDENTS can be assisted further with the CHALLENGING TASK of writing a DISSERTATION in a SECOND OR FOREIGN LANGUAGE. Yet we believe that the FOCUS on EXTENDED TEXTS and the MACRO-LEVEL OF WRITING as emphasized in THIS PAPER are essential if STUDENTS are to go beyond IMPROVWNG their WRITING at the SENTENCE LEVEL and actually enhance the quality of their DISSERTATION WRITING

\section{Reference Chains}

Research $\rightarrow$ supervisors $\rightarrow$ graduate students $\rightarrow$ numbers of students $\rightarrow$ writing program

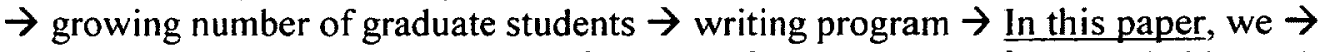
program $\rightarrow$ NNS research students $\rightarrow$ theses. $\rightarrow$ The program $\rightarrow$ grounded investigation $\rightarrow$ the problems $\rightarrow$ students $\rightarrow$ struggle to produce a thes is $\rightarrow$ Data for this investigation $\rightarrow$ interviews with supervisors, students' questionnaires and an analysis of student writing. The study $\rightarrow$ shortcomings:

1. A failure $\rightarrow$ thesis $\rightarrow$ reader $\rightarrow$ a failure $\rightarrow$ "a research space";

2. A failure $\rightarrow$ findings

3. An inability $\rightarrow$ information $\rightarrow$ texts

4. problems 
Errors $\rightarrow$ communication problems $\rightarrow$ macro-level of audience, purpose and overall structuring. $\rightarrow$ the diagnostic framework and the resultant writing program $\rightarrow$ macrolevel problems $\rightarrow$ work $\rightarrow$ work $\rightarrow$ NNS research students $\rightarrow$ UHK $\rightarrow$ research $\rightarrow$ students $\rightarrow$ challenging task of writing a dissertation $\rightarrow$ language $\rightarrow$ we $\rightarrow$ extended texts $\rightarrow$ macro-level of writing $\rightarrow$ in this paper $\rightarrow$ students $\rightarrow$ writing $\rightarrow$ sentence level $\rightarrow$ dissertation writing.

\section{Theme}

\begin{tabular}{|c|c|c|c|c|}
\hline \multirow{2}{*}{$\begin{array}{l}\text { Sentence/ } \\
\text { Clause } \\
\text { I / I }\end{array}$} & \multicolumn{2}{|l|}{ THEMES: Textual } & \multirow[t]{2}{*}{ Interpersonal } & \multirow{2}{*}{ Topical } \\
\hline & $\begin{array}{l}\text { Research + the numbers of } \\
\text { students + students' positive } \\
\text { reactions }\end{array}$ & & & \\
\hline II $/ 2$ & In this paper & & & $\Delta$ \\
\hline III / 3 & the program & & & $\Delta$ \\
\hline IV / 4 & data for this investigation & & & $\Delta$ \\
\hline $\mathrm{V} / 5$ & the initial study & & & $\Delta$ \\
\hline $\mathrm{VI} / 6$ & while, at first sight, local errors & $\Delta$ & $\Delta$ & $\Delta$ \\
\hline & $\begin{array}{l}\text { by far the greatest number of } \\
\text { communication problems }\end{array}$ & $\Delta$ & & $\boldsymbol{\Delta}$ \\
\hline $\mathrm{VII} / 7$ & hence the dialogic framework & $\Delta$ & & $\Delta$ \\
\hline VIII / 8 & a limitation of the work & & & $\mathbf{\Delta}$ \\
\hline VIII /9 & although this & $\Delta$ & & $\Delta$ \\
\hline $\mathrm{IX} / 10$ & while we & $\Delta$ & & $\Delta$ \\
\hline $\mathrm{IX} / 11$ & that the approach & $\Delta$ & & $\Delta$ \\
\hline $\mathrm{IX} / 12$ & we & & & $\Delta$ \\
\hline IX / 13 & that adaptions & $\Delta$ & & $\Delta$ \\
\hline $\mathrm{X} / 14$ & indeed, some changes & & $\Delta$ & $\Delta$ \\
\hline $\mathrm{X} / 15$ & and research & $\Delta$ & & $\Delta$ \\
\hline $\mathrm{XI} / 17$ & Yet we & $\mathbf{\Delta}$ & & $\Delta$ \\
\hline $\mathrm{XI} / 18$ & that the focus & $\Delta$ & & $\Delta$ \\
\hline $\mathrm{XI} / 19$ & if students & $\Delta$ & & $\Delta$ \\
\hline $\mathrm{XI} / 20$ & and (students) & $\Delta$ & & $(\mathbf{\Delta})$ \\
\hline & Total: & 11 & 2 & 20 \\
\hline
\end{tabular}

TEXT 3: Lilie Chouliaraki

\section{"Ordinary Witnessing in Post-television news: Towards a New Moral Imagination"}

\begin{tabular}{|l|l|l|}
\hline Sentence & Clause & TEXT 3 \\
\hline 1 & 1 & $\begin{array}{l}\text { In this paper, I explored the nature of witnessing in post-television } \\
\text { news. }\end{array}$ \\
\hline 2 & 2 & $\begin{array}{l}\text { Taking my point of departure on an analysis of the emergent } \\
\text { narratives of convergent journalism, }\end{array}$ \\
\hline
\end{tabular}




\begin{tabular}{|l|l|l|}
\hline & 3 & $\begin{array}{l}\text { I showed how the multi-modality of convergence has affected the } \\
\text { narrativity of the news along three key textual dimensions: the } \\
\text { cohesive, clause and process structure of the news. }\end{array}$ \\
\hline 3 & 4 & $\begin{array}{l}\text { Insofar as such structural changes result in replacing the logic of } \\
\text { news as story-telling with a logic of news as techno-textual } \\
\text { interactivity. }\end{array}$ \\
\hline 4 & 5 & I argued \\
\hline 5 & 6 & $\begin{array}{l}\text { post-television witnessing can be seen as becoming increasingly } \\
\text { technologized. }\end{array}$ \\
\hline & 7 & $\begin{array}{l}\text { This technologisation of witnessing has enabled the emergence of } \\
\text { ordinary witnessing and the manifestation of a caring ethos towards } \\
\text { vulnerable others }\end{array}$ \\
\hline 6 & 9 & $\begin{array}{l}\text { Yet it has simultaneously given rise to ambivalent forms of } \\
\text { collective agency, }\end{array}$ \\
\hline & 10 & $\begin{array}{l}\text { which potentially produce post-humanitarian news publics - } \\
\text { publics that are driven by a communitarian moral imagination }\end{array}$ \\
\hline & 11 & $\begin{array}{l}\text { and are based on instantaneous, albeit discontinuous, forms of } \\
\text { technological activism. }\end{array}$ \\
\hline
\end{tabular}

\subsection{Ideational Metafunction}

\section{Process Analysis}

1. In this paper, I explored the nature of witnessing in post-television news.

\begin{tabular}{|l|l|l|l|l|}
\hline In this paper, & I & explored & $\begin{array}{l}\text { the nature of } \\
\text { witnessing }\end{array}$ & $\begin{array}{l}\text { in post-television } \\
\text { news }\end{array}$ \\
\hline Circum: loc & Senser & Process: mental & Phenomenon & Circum: location \\
\hline
\end{tabular}

2. Taking my point of departure on an analysis of the emergent narratives of convergent journalism, I showed how the multi-modality of convergence has affected the narrativity of the news along three key textual dimensions; the cohesive, clause and process structure of the news.

\begin{tabular}{|l|l|l|l|}
\hline $\begin{array}{l}\text { *[Taking my } \\
\text { point of departure } \\
\text { on an analysis of } \\
\text { the emergent } \\
\text { narratives of } \\
\text { convergent } \\
\text { journalism] }\end{array}$ & $I$ & showed & $\begin{array}{l}\text { how the multi-modality of convergence } \\
\text { has affected the narrativity of the news } \\
\text { along three key textual dimensions; the } \\
\text { cohesive, clause and process structure of } \\
\text { the news }\end{array}$ \\
\hline & Senser & $\begin{array}{l}\text { Process: } \\
\text { mental }\end{array}$ & embedded clause as Phenomenon: fact \\
\hline
\end{tabular}

*Participle phrase as tempered clause

3. Insofar as such structural changes result in replacing the logic of news as story-telling with a logic of news as techno-textual interactivity.

\begin{tabular}{|l|l|l|l|l|l|l|}
\hline $\begin{array}{l}\text { Insofar } \\
\text { as }\end{array}$ & $\begin{array}{l}\text { such } \\
\text { structural }\end{array}$ & result in & $\begin{array}{l}\text { replacing } \\
\text { the logic }\end{array}$ & $\begin{array}{l}\text { as story- } \\
\text { telling }\end{array}$ & $\begin{array}{l}\text { with a } \\
\text { logic }\end{array}$ & $\begin{array}{l}\text { as } \\
\text { techno- }\end{array}$ \\
\hline
\end{tabular}




\begin{tabular}{|l|l|l|l|l|l|l|}
\hline & changes & of news & & & $\begin{array}{l}\text { textual } \\
\text { interacti } \\
\text { vity. }\end{array}$ \\
\hline & Token & $\begin{array}{l}\text { Process: } \\
\text { relational } \\
\text { identifying }\end{array}$ & Value & $\begin{array}{l}\text { Circum: } \\
\text { role }\end{array}$ & $\begin{array}{l}\text { Circum: } \\
\text { accompan } \\
\text { iment }\end{array}$ & $\begin{array}{l}\text { Circum: } \\
\text { role }\end{array}$ \\
\hline
\end{tabular}

4. I argued, post-television witnessing can be seen as becoming increasingly technologized.

\begin{tabular}{|l|l|l|l|l|}
\hline I & argued, & post-television witnessing & can be seen & $\begin{array}{l}\text { as becoming } \\
\text { increasingly } \\
\text { technologized }\end{array}$ \\
\hline Sayer & $\begin{array}{l}\text { Process: } \\
\text { verbal }\end{array}$ & Senser & $\begin{array}{l}\text { Process: } \\
\text { mental }\end{array}$ & Phenomenon: act \\
\hline
\end{tabular}

5. This technologisation of witnessing has enabled the emergence of ordinary witnessing and the manifestation of a caring ethos towards vulnerable others.

\begin{tabular}{|l|l|l|}
\hline $\begin{array}{l}\text { This technologisation of } \\
\text { witnessing }\end{array}$ & has enabled & $\begin{array}{l}\text { the emergence of ordinary witnessing } \\
\text { and the manifestation of a caring ethos } \\
\text { towards vulnerable others. }\end{array}$ \\
\hline Token & $\begin{array}{l}\text { Process: } \\
\text { relational } \\
\text { identifying }\end{array}$ & Value \\
\hline
\end{tabular}

6. Yet it has simultaneously given rise to ambivalent forms of collective agency, which potentially produce post-humanitarian news publics - publics that are driven by a communitarian moral imagination and are based on instantaneous, albeit discontinuous, forms of technological activism.

\begin{tabular}{|l|l|l|l|l|l|}
\hline Yet & it & has & simultaneously & given & $\begin{array}{l}\text { rise to ambivalent } \\
\text { forms of collective } \\
\text { agency, }\end{array}$ \\
\hline & Token & $\begin{array}{l}\text { Process: } \\
\text { material (part 1) }\end{array}$ & $\begin{array}{l}\text { Circum: } \\
\text { manner }\end{array}$ & $\begin{array}{l}\text { Process: } \\
\text { relational } \\
\text { identifying }\end{array}$ & Value \\
\hline
\end{tabular}

\begin{tabular}{|l|l|l|l|}
\hline which & potentially & produce & post-humanitarian news publics - \\
\hline Sensser & Circum: manner & Process: mental & Phenomenon \\
\hline
\end{tabular}

\begin{tabular}{|l|l|l|l|l|l|l|}
\hline $\begin{array}{l}\text { publics } \\
\text { that }\end{array}$ & are driven & $\begin{array}{l}\text { by a } \\
\text { communitari } \\
\text { an moral } \\
\text { imagination }\end{array}$ & and & (that) & are based & $\begin{array}{l}\text { on } \\
\text { instantaneous, } \\
\text { albeit } \\
\text { discontinuous, } \\
\text { forms of } \\
\text { technological }\end{array}$ \\
\hline
\end{tabular}




\begin{tabular}{|l|l|l|l|l|l|l|}
\hline & & & & & & activism. \\
\hline $\begin{array}{l}\text { Phenome } \\
\text { non }\end{array}$ & $\begin{array}{l}\text { Process: } \\
\text { mental }\end{array}$ & Senser & & $\begin{array}{l}\text { Elliptical } \\
\text { Value }\end{array}$ & $\begin{array}{l}\text { Process: } \\
\text { relational } \\
\text { identifying }\end{array}$ & Token \\
\hline
\end{tabular}

\section{Logico-semantic Types of Clauses}

\begin{tabular}{|c|c|c|c|c|}
\hline Sentence & Clause & & & \\
\hline I & 1 & simplex & & $\begin{array}{l}\text { In this paper, I explored the nature of witnessing in } \\
\text { post-television news. }\end{array}$ \\
\hline II & 2 & complex & $\mathrm{H}$ & $\begin{array}{l}x \beta \text { Taking my point of departure on an analysis } \\
\text { of the emergent narratives of convergent } \\
\text { journalism, (tempered clause) } \\
\alpha \text { I showed [[how the multi-modality of } \\
\text { convergence has affected the narrativity of the news } \\
\text { along three key textual dimensions; the cohesive, } \\
\text { clause and process structure of the news]]' }\end{array}$ \\
\hline III & 3 & simplex & & $\begin{array}{l}\text { Insofar as such structural changes result in } \\
\text { replacing the logic of news as story-telling with a } \\
\text { logic of news as techno-textual interactivity. }\end{array}$ \\
\hline \multirow[t]{2}{*}{ IV } & 4 & complex & $\mathrm{H}$ & $\alpha \quad$ I argued, \\
\hline & 5 & & & $\begin{array}{l}\text { ' } \beta \text { post-television witnessing can be seen as } \\
\text { becoming increasingly technologized. }\end{array}$ \\
\hline $\mathrm{V}$ & 6 & simplex & & $\begin{array}{l}\text { This technologisation of witnessing has enabled the } \\
\text { emergence of ordinary witnessing and the } \\
\text { manifestation of a caring ethos towards vulnerable } \\
\text { others. }\end{array}$ \\
\hline \multirow[t]{4}{*}{ VI } & 7 & complex & & $\begin{array}{l}\alpha \quad \text { Yet it has simultaneously given rise to } \\
\text { ambivalent forms of collective agency, }\end{array}$ \\
\hline & 8 & & $\mathrm{H}$ & $\begin{array}{l}=\beta \text { which potentially produce post-humanitarian } \\
\text { news publics - }\end{array}$ \\
\hline & 9 & & $\begin{array}{l}\mathrm{H} / \\
\mathrm{P}\end{array}$ & $\begin{array}{l}=\lambda 1 \text { publics that are driven by a communitarian } \\
\text { moral imagination }\end{array}$ \\
\hline & 10 & & & $\begin{array}{l}2 \text { and ((publics)) are based on instantaneous, } \\
\text { albeit discontinuous, forms of technological } \\
\text { activism. }\end{array}$ \\
\hline
\end{tabular}

\subsection{Interpersonal Metafunction}

\section{MOOD and RESIDUE}

1. In this paper, I explored the nature of witnessing in post-television news.

\begin{tabular}{|l|l|l|l|l|}
\hline In this paper & I & explored & $\begin{array}{l}\text { the nature of } \\
\text { witnessing }\end{array}$ & in post-television news \\
\hline Adjunct: location & Subject & $\begin{array}{l}\text { Finite: } \\
\text { Predicator }\end{array}$ & Complement & Adjunct: location \\
\hline RESIDUE & MOOD & RESIDUE & \\
\hline
\end{tabular}


2. Taking my point of departure on an analysis of the emergent narratives of convergent journalism, I showed how the multi-modality of convergence has affected the narrativity of the news along three key textual dimensions: the cohesive, clause and process structure of the news.

\begin{tabular}{|l|l|l|l|}
\hline $\begin{array}{l}\text { [ [Taking my point of departure } \\
\text { on an analysis of the emergent } \\
\text { narratives of convergent } \\
\text { journalism,]] }\end{array}$ & s & showed & $\begin{array}{l}{[\text { [how the multi- }} \\
\text { modality has } \\
\text { effected...] }]\end{array}$ \\
\hline Tempered clause & Subject & $\begin{array}{l}\text { Finite: } \\
\text { Predicator }\end{array}$ & Complement \\
\hline & MOOD & RESIDUE \\
\hline
\end{tabular}

3. Insofar as such structural changes result in replacing the logic of news as story-telling with a logic of news as techno-textual interactivity.

\begin{tabular}{|l|l|l|l|l|}
\hline Insofar as & $\begin{array}{l}\text { such } \\
\text { structural } \\
\text { changes }\end{array}$ & result in & $\begin{array}{l}\text { replacing the } \\
\text { logic of news }\end{array}$ & $\begin{array}{l}\text { as story-telling with a logic } \\
\text { of news as techno-textual } \\
\text { interactivity }\end{array}$ \\
\hline $\begin{array}{l}\text { Conjunctive } \\
\text { Adjunct }\end{array}$ & Subject & $\begin{array}{l}\text { Finite: } \\
\text { Predicator }\end{array}$ & Complement & Adjunct: role ${ }^{\wedge}$ role \\
\hline & MOOD & \multicolumn{3}{|c|}{ RESIDUE } \\
\hline
\end{tabular}

4. I argued, post-television witnessing can be seen as becoming increasingly technologized.

\begin{tabular}{|l|l|}
\hline I & \multicolumn{2}{|l|}{ argued } \\
\hline Subject & \multicolumn{2}{|l|}{ Finite: Predicator } \\
\hline MOOD & RESIDUE \\
\hline
\end{tabular}

\begin{tabular}{|l|l|l|l|}
\hline $\begin{array}{l}\text { post- } \\
\text { television }\end{array}$ & can & be seen & as becoming increasingly technologized \\
\hline Subject & $\begin{array}{l}\text { Finite: } \\
\text { modal }\end{array}$ & Predicator & Adjunct: role \\
\hline MOOD & RESIDUE \\
\hline
\end{tabular}

5. This technologisation of witnessing has enabled the emergence of ordinary witnessing and the manifestation of a caring ethos towards vulnerable others.

\begin{tabular}{|l|l|l|l|l|}
\hline $\begin{array}{l}\text { This } \\
\text { technologisation } \\
\text { of witnessing }\end{array}$ & has & enabled & $\begin{array}{l}\text { the emergence of ordinary } \\
\text { witnessing and the } \\
\text { manifestation of a caring } \\
\text { ethos }\end{array}$ & $\begin{array}{l}\text { towards } \\
\text { vulnerable } \\
\text { others. }\end{array}$ \\
\hline Subject & Finite & Predicator & Complement & $\begin{array}{l}\text { Adjunct: } \\
\text { location }\end{array}$ \\
\hline MOOD & RESIDUE \\
\hline
\end{tabular}


6. Yet it has simultaneously given rise to ambivalent forms of collective agency, which potentially produce post-humanitarian news publics - publics that are driven by a communitarian moral imagination and are based on instantaneous, albeit discontinuous, forms of technological activism.

\begin{tabular}{|l|l|l|l|l|l|}
\hline Yet & it & has & simultaneously & given rise & $\begin{array}{l}\text { to ambivalent } \\
\text { forms of collective } \\
\text { agency, }\end{array}$ \\
\hline $\begin{array}{l}\text { Conjunctive } \\
\text { Adjunct }\end{array}$ & Subject & Finite & Adjunct: time & Predicator & Compliment \\
\hline & MOOD & & RESIDUE \\
\hline
\end{tabular}

\begin{tabular}{|l|l|l|l|}
\hline which & potentially & produce & $\begin{array}{l}\text { post-humanitarian news } \\
\text { publics - }\end{array}$ \\
\hline Subject & Adjunct: mood & Finite: Predicator & Complement \\
\hline MOOD & RESIDUE \\
\hline
\end{tabular}

\begin{tabular}{|l|l|l|l|}
\hline publics that & are & driven & by a communitarian moral imagination \\
\hline Subject $\wedge$ Subject & Finite & Predicator & Adjunct: agent \\
\hline MOOD & RESIDUE \\
\hline
\end{tabular}

\begin{tabular}{|l|l|l|l|l|}
\hline and & \{publics & are & based & $\begin{array}{l}\text { on instantaneous, albeit } \\
\text { discontinuous, forms of } \\
\text { technological activism. }\end{array}$ \\
\hline $\begin{array}{l}\text { Conjunctive } \\
\text { Adjunct }\end{array}$ & $\begin{array}{l}\text { Elliptical } \\
\text { Subject }\end{array}$ & Finite & Predicator & Complement \\
\hline & MOOD & RESIDUE \\
\hline
\end{tabular}

\subsection{Textual Metafunction}

\section{Specific Lexical Density}

In this paper, I explored the nature of witnessing in post-television news. Taking my point of departure on an analysis of the emergent narratives of convergent journalism, I showed how the multi-modality of convergence has affected the narrativity of the news along three key textual dimensions: the cohesive, clause and process structure of the news. Insofar as such structural changes result in replacing the logic of news as story-telling with a logic of news as techno-textual interactivity. I argued, posttelevision witnessing can be seen as becoming increasingly technologised. This technologisation of witnessing has enabled the emergence of ordinary witnessing and the manifestation of a caring ethos towards vulnerable others. Yet it has simultaneously given rise to ambivalent forms of collective agency, which potentially produce post-humanitarian news publics - publics that are driven by a communitarian moral imagination and are based on instantaneous, albeit discontinuous, forms of technological activism. 
Theme

\begin{tabular}{|c|c|c|c|c|}
\hline Sentence/ & \multicolumn{2}{|c|}{ THEMES: Textual } & Interpersonal & Topical \\
\hline $1 / 1$ & In this paper, & & & $\Delta$ \\
\hline $\mathrm{II} /(2)$ & \multicolumn{4}{|c|}{ Taking my point....(tempered clause)I } \\
\hline 3 & I & & & $\boldsymbol{\Delta}$ \\
\hline $111 / 4$ & $\begin{array}{l}\text { Insofar as such structural } \\
\text { changes }\end{array}$ & $\Delta$ & & $\Delta$ \\
\hline IV/5 & I & & & $\Delta$ \\
\hline IV / 6 & post-television witnessing & & & $\Delta$ \\
\hline$V / 7$ & $\begin{array}{l}\text { This technologisation of } \\
\text { witnessing }\end{array}$ & & & $\mathbf{A}$ \\
\hline $\mathrm{VI} / 8$ & Yet it & $\Delta$ & & $\Delta$ \\
\hline $\mathrm{VI} / 9$ & which & & & $\begin{array}{l}4 \text { (structural- } \\
\text { topical) }\end{array}$ \\
\hline $\mathrm{VI} / 10$ & publics that & & & $\mathbf{\Delta}^{2}$ \\
\hline $\mathrm{VI} / 11$ & (publics that) & & & $\left(\Delta^{2}\right)$ \\
\hline & Total: & 2 & 0 & 11 \\
\hline
\end{tabular}

TEXT 4: C. Kenner, Gunther Kress, H. Al-Khatib, R. Kam, \& K.-C. Tsai

“Finding the Keys to Biliteracy: How Young Children Interpret Different Writing Systems"

\begin{tabular}{|l|l|l|}
\hline Sentence & Clause & TEXT 4 \\
\hline 1 & 1 & $\begin{array}{l}\text { The children in the 'Signs of Difference' study were able to cope } \\
\text { well with learning different writing systems at the same time. }\end{array}$ \\
\hline 2 & 2 & Rather than being 'confused' by simultaneous input, \\
\hline & 3 & the children were experiencing cognitive benefits. \\
\hline 3 & 4 & They were able to look for \\
\hline & 5 & and comprehend the principles on which each system was based, \\
\hline & 6 & clarifying differences between systems \\
\hline 4 & 7 & $\begin{array}{l}\text { as their learning progressed over time. } \\
\text { foundes research underlines young children's ability to make well- } \\
\text { home in order to understand graphic representations. }\end{array}$ \\
\hline 5 & 8 & $\begin{array}{l}\text { It suggests } \\
\text { that children's awareness of the principles on which writing systems } \\
\text { operate is stimulated }\end{array}$ \\
\hline & 10 & $\begin{array}{l}\text { and enhanced by biliterate experience, } \\
\text { and that this experience should be available to both monolingual and } \\
\text { bilingual children as part of mainstream education. }\end{array}$ \\
\hline
\end{tabular}




\subsection{Ideational Metafunction}

\section{Process Analysis}

1. The children in the 'Signs of Difference' study were able to cope well with learning different writing systems at the same time.

\begin{tabular}{|l|l|l|}
\hline $\begin{array}{l}\text { The children in the 'Signs of } \\
\text { Difference' study }\end{array}$ & were able to cope well & $\begin{array}{l}\text { with learning different } \\
\text { writing systems at the } \\
\text { same time. }\end{array}$ \\
\hline Senser & Process: mental & Phenomenon \\
\hline
\end{tabular}

2. Rather than being 'confused' by simultaneous input, the children were experiencing cognitive benefits.

\begin{tabular}{|l|l|l|l|}
\hline $\begin{array}{l}\text { ((Rather than being } \\
\text { 'confused' by simultaneous } \\
\text { input })),\end{array}$ & the children & were experiencing & cognitive benefits. \\
\hline tempered clause & Senser & Process: mental & Phenomenon \\
\hline
\end{tabular}

3. They were able to look for and comprehend the principles on which each system was based, clarifying differences between systems as their learning progressed over time.

\begin{tabular}{|l|l|l|l|l|l|}
\hline They & $\begin{array}{l}\text { were able to } \\
\text { look for }\end{array}$ & and & $\begin{array}{l}\text { \{were able to }\} \\
\text { comprehend }\end{array}$ & $\begin{array}{l}\text { the principles } \\
\text { [[on which } \\
\text { each system } \\
\text { based] }]\end{array}$ & $\begin{array}{l}\text { ((clarifying } \\
\text { differences } \\
\text { between systems } \\
\text { as their learning } \\
\text { progressed over } \\
\text { time)). }\end{array}$ \\
\hline Senser & $\begin{array}{l}\text { Process: } \\
\text { mental }\end{array}$ & & Process: mental & Phenomenon & $\begin{array}{l}\text { (tempered } \\
\text { clause) }\end{array}$ \\
\hline
\end{tabular}

\begin{tabular}{|l|l|l|l|}
\hline as & their learning & progressed & over time \\
\hline & Senser & Process: mental & $\begin{array}{l}\text { Circumstan } \\
\text { ce }\end{array}$ \\
\hline
\end{tabular}

4. The research underlines young children's ability to make well-founded interpretations of the teaching available at school and at home in order to understand graphic representations.

\begin{tabular}{|l|l|l|l|l|}
\hline $\begin{array}{l}\text { The } \\
\text { research }\end{array}$ & underlines & $\begin{array}{l}\text { young } \\
\text { children's } \\
\text { ability }\end{array}$ & $\begin{array}{l}\text { to make well-founded } \\
\text { interpretations of the } \\
\text { teaching available at } \\
\text { school and at home }\end{array}$ & $\begin{array}{l}\text { in order to } \\
\text { understand } \\
\text { graphic } \\
\text { representation } \\
\text { s. }\end{array}$ \\
\hline Senser & $\begin{array}{l}\text { Process: } \\
\text { mental }\end{array}$ & Phenomenon & Circum: purpose & \\
\hline
\end{tabular}


5. It suggests that the children's awareness of the principles on which writing systems operate is stimulated and enhanced by biliterate experience, and that this experience should be available to both monolingual and bilingual children as part of mainstream education.

\begin{tabular}{|l|l|}
\hline It & suggests \\
\hline Sayer & Process: verbal \\
\hline
\end{tabular}

\begin{tabular}{|l|l|l|}
\hline that & $\begin{array}{l}\text { children's awareness of the principles } \\
\text { [[on which writing systems operate]] }\end{array}$ & is stimulated \\
\hline & Phenomenon & Process: mental \\
\hline
\end{tabular}

\begin{tabular}{|l|l|l|l|}
\hline and & \{children's awareness $\}$ & $\{$ is $\}$ enhanced & $\begin{array}{l}\text { by biliterate } \\
\text { experience }\end{array}$ \\
\hline & Phenomenon & Process mental & Senser \\
\hline
\end{tabular}

\begin{tabular}{|l|l|l|l|l|l|l|}
\hline and & that & $\begin{array}{l}\text { this } \\
\text { experience }\end{array}$ & should be & available & $\begin{array}{l}\text { to both } \\
\text { monolingual and } \\
\text { bilingual children }\end{array}$ & $\begin{array}{l}\text { as part of } \\
\text { mainstream } \\
\text { education. }\end{array}$ \\
\hline & & Carrier & $\begin{array}{l}\text { Relational: } \\
\text { attributive }\end{array}$ & Attribute & Receiver $\left(^{*}\right)$ & $\begin{array}{l}\text { Circum: } \\
\text { role }\end{array}$ \\
\hline
\end{tabular}

\section{Logico-semantic Types of Clauses}

\begin{tabular}{|c|c|c|c|c|}
\hline Sentence & Clause & & & \\
\hline I & 1 & simplex & & $\begin{array}{l}\text { The children in the 'Signs of Difference' study were able } \\
\text { to cope well with learning different writing systems at the } \\
\text { same time. }\end{array}$ \\
\hline II & 2 & complex & $\mathrm{H}$ & $\begin{array}{l}x \beta \quad((\text { Rather than being 'confused' by simultaneous } \\
\text { input })) \\
\alpha \quad \text { the children were experiencing cognitive benefits. }\end{array}$ \\
\hline III & 4 & complex & $\mathbf{P}$ & \multirow[b]{2}{*}{ 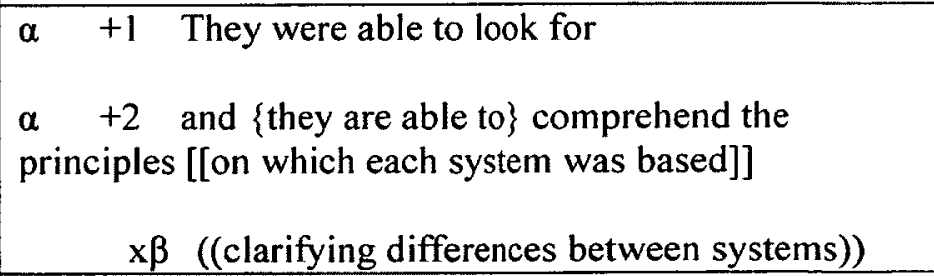 } \\
\hline & 6 & & & \\
\hline & 7 & & $\mathrm{H}$ & $\mathrm{x} \lambda$ as their learning progressed over time. \\
\hline IV & 8 & simplex & & $\begin{array}{l}\text { The research underlines young children's ability to make } \\
\text { well-founded interpretations of the teaching available at } \\
\text { school and at home in order to understand graphic } \\
\text { representations. }\end{array}$ \\
\hline $\mathrm{V}$ & 9 & complex & $\mathrm{H}$ & It suggests \\
\hline
\end{tabular}




\begin{tabular}{|l|l|l|l|l|}
\hline & 10 & & $\mathrm{H}$ & $\begin{array}{l}1 \text { ' } \beta \text { 3 that children's awareness of the principles } \\
\text { [Ion which writing systems operate]] is stimulated }\end{array}$ \\
\hline & 11 & & $\mathrm{P}$ & \multicolumn{1}{|c|}{+4 and enhanced by biliterate experience, } \\
\hline & 12 & & $\mathrm{P} / \mathrm{H}$ & $\begin{array}{l}+2 \text { ' } \lambda \text { and that this experience should be available to } \\
\text { both monolingual and bilingual children as part of } \\
\text { mainstream education. }\end{array}$ \\
\hline
\end{tabular}

\subsection{Interpersonal Metafunction}

\section{MOOD \& RESIDUE}

1. The children in the 'Signs of Difference' study were able to cope well with learning different writing systems at the same time.

\begin{tabular}{|l|l|l|l|l|l|}
\hline $\begin{array}{l}\text { The children in } \\
\text { the 'Signs of } \\
\text { Difference' study }\end{array}$ & $\begin{array}{l}\text { were } \\
\text { able }\end{array}$ & to cope & well & $\begin{array}{l}\text { with learning } \\
\text { different writing } \\
\text { systems }\end{array}$ & $\begin{array}{l}\text { at the same } \\
\text { time }\end{array}$ \\
\hline Subject & $\begin{array}{l}\text { Finite: } \\
\text { modal }\end{array}$ & Predicator & $\begin{array}{l}\text { Adjunct: } \\
\text { manner }\end{array}$ & Adjunct: matter & Adjunct: time \\
\hline MOOD & RESIDUE & \\
\hline
\end{tabular}

2. Rather than being 'confused' by simultaneous input, the children were experiencing cognitive benefits.

\begin{tabular}{|l|l|l|l|l|}
\hline $\begin{array}{l}\text { Rather than being } \\
\text { confused' by } \\
\text { simultaneous input, }\end{array}$ & the children & were & experiencing & $\begin{array}{l}\text { cognitive } \\
\text { benefits. }\end{array}$ \\
\hline Tempered clause & Subject & Finite & Predicator & Complement \\
\hline & MOOD & RESIDUE & \\
\hline
\end{tabular}

3. They were able to look for and comprehend the principles on which each system was based, clarifying differences between systems as their learning progressed over time.

\begin{tabular}{|l|l|l|}
\hline They & were able & to look for \\
\hline Subject & $\begin{array}{l}\text { Finite: } \\
\text { modal }\end{array}$ & Predicator \\
\hline MOOD & RESIDUE \\
\hline
\end{tabular}

\begin{tabular}{|l|l|l|l|l|l|}
\hline and & $\{$ they $\}$ & $\{$ were able $\}$ & $\begin{array}{l}\text { to } \\
\text { comprehend }\end{array}$ & $\begin{array}{l}\text { the principles } \\
{[\text { [on which }} \\
\text { each system } \\
\text { was based] }]\end{array}$ & $\begin{array}{l}\text { clarifying } \\
\text { differences } \\
\text { between } \\
\text { systems }\end{array}$ \\
\hline $\begin{array}{l}\text { Conjunctive } \\
\text { Adjunct }\end{array}$ & $\begin{array}{l}\text { elliptical } \\
\text { Subject }\end{array}$ & $\begin{array}{l}\text { elliptical } \\
\text { Finite: modal }\end{array}$ & Predicator & Complement & $\begin{array}{l}\text { Tempered } \\
\text { clause }\end{array}$ \\
\hline & MOOD & RESIDUE & \\
\hline
\end{tabular}




\begin{tabular}{|l|l|l|l|}
\hline as & their learning & progressed & over time. \\
\hline $\begin{array}{l}\text { Conjunctive } \\
\text { Adjunct }\end{array}$ & Subject & Finite: Predicator & Adjunct: time \\
\hline \multicolumn{3}{|l|}{} & RESIDUE \\
\hline
\end{tabular}

4. The research underlines young children's ability to make well-founded interpretations of the teaching available at school and at home in order to understand graphic representations.

\begin{tabular}{|l|l|l|l|l|}
\hline The research & underlines & $\begin{array}{l}\text { young children's ability to } \\
\text { make well-founded } \\
\text { interpretations of the } \\
\text { teaching available }\end{array}$ & $\begin{array}{l}\text { at school and at } \\
\text { home }\end{array}$ & $\begin{array}{l}\text { in order } \\
\text { to } \\
\text { understa } \\
\text { nd } \\
\text { graphic } \\
\text { represent } \\
\text { ations. }\end{array}$ \\
\hline Subject & $\begin{array}{l}\text { Finite: } \\
\text { Predicator }\end{array}$ & Complement & $\begin{array}{l}\text { Adjunct: } \\
\text { purpose }\end{array}$ \\
\hline MOOD & RESIDUE \\
\hline
\end{tabular}

5. It suggests that children's awareness of the principles on which writing systems operate is stimulated and enhanced by biliterate experience, and that this experience should be available to both monolingual and bilingual children as part of mainstream education.

\begin{tabular}{|l|l|}
\hline It & \multicolumn{2}{|l|}{ suggests } \\
\hline Subject & Finite: Predicator \\
\hline MOOD & RESIDUE \\
\hline
\end{tabular}

\begin{tabular}{|l|l|l|l|}
\hline that & $\begin{array}{l}\text { children's awareness of the } \\
\text { principles on which writing } \\
\text { systems operate }\end{array}$ & is & stimulated \\
\hline $\begin{array}{l}\text { Conjunctive } \\
\text { Adjunct }\end{array}$ & Subject & Finite & Predicator \\
\hline & MOOD & RESIDUE \\
\hline
\end{tabular}

\begin{tabular}{|l|l|l|l|l|}
\hline and & $\begin{array}{l}\text { \{the children's } \\
\text { awareness }\end{array}$ & is & enhanced & $\begin{array}{l}\text { by biliterate } \\
\text { experience }\end{array}$ \\
\hline $\begin{array}{l}\text { Conjunctive } \\
\text { Adjunct }\end{array}$ & elliptical Subject & Finite & Predicator & Adjunct: agent \\
\hline & MOOD & RESIDUE & \\
\hline
\end{tabular}

\begin{tabular}{|l|l|l|l|l|l|l|}
\hline and & that & $\begin{array}{l}\text { this } \\
\text { experience }\end{array}$ & should & $\begin{array}{l}\text { be } \\
\text { available }\end{array}$ & $\begin{array}{l}\text { to both } \\
\text { monoling } \\
\text { ual and } \\
\text { bilingual }\end{array}$ & $\begin{array}{l}\text { as part of } \\
\text { mainstrea } \\
\text { m } \\
\text { education }\end{array}$ \\
\hline
\end{tabular}




\begin{tabular}{|l|l|l|l|l|l|l|}
\hline $\begin{array}{l}\text { Conjunct- } \\
\text { ive } \\
\text { Adjunct }\end{array}$ & $\begin{array}{l}\text { Conjunct- } \\
\text { ive } \\
\text { Adjunct }\end{array}$ & Subject & $\begin{array}{l}\text { Finite: } \\
\text { modal }\end{array}$ & Predicator & $\begin{array}{l}\text { complem } \\
\text { ent }\end{array}$ & $\begin{array}{l}\text { Adjunct: } \\
\text { role }\end{array}$ \\
\hline & & MOOD & & RESIDUE & \\
\hline
\end{tabular}

\subsection{Textual Metafunction}

\section{THEME}

\begin{tabular}{|c|c|c|c|c|}
\hline $\begin{array}{l}\text { Sentence/ } \\
\text { Clause }\end{array}$ & THEMES: Textual & & Interpersonal & Topical \\
\hline $\mathrm{I} / \mathrm{I}$ & $\begin{array}{l}\text { The children in the 'Signs of } \\
\text { Difference' }\end{array}$ & & & $\boldsymbol{\Delta}$ \\
\hline II / (2) & $\begin{array}{l}\text { ((Rather than being } \\
\text { confused by simultaneous } \\
\text { input)), }\end{array}$ & \multicolumn{3}{|c|}{ tempered clause } \\
\hline II / 3 & the children & & & \\
\hline III / 4 & They & & & $\Delta$ \\
\hline III / 5 & and (they) & $\Delta$ & & $(\mathbf{\Delta})$ \\
\hline III /(6) & $\begin{array}{l}\text { ((clarifying differences } \\
\text { between systems)) }\end{array}$ & \multicolumn{3}{|c|}{ tempered clause } \\
\hline III $/ 7$ & as their learning & $\Delta$ & & $\Delta$ \\
\hline IV / 8 & The research & & & $\Delta$ \\
\hline $\mathrm{V} / 9$ & It & & & $\Delta$ \\
\hline $\mathrm{V} / 10$ & $\begin{array}{l}\text { that the children's } \\
\text { awareness of the principles } \\
\text { [[on which the writing } \\
\text { systems operate]] }\end{array}$ & $\bar{\Delta}$ & & $\Delta$ \\
\hline $\mathrm{V} / 11$ & $\begin{array}{l}\text { and (the children's } \\
\text { awareness) }\end{array}$ & $\mathbf{A}$ & & $(\mathbf{\Delta})$ \\
\hline $\mathrm{V} / 12$ & and that this experience & $\mathbf{A \Delta}$ & & $\Delta$ \\
\hline & Total: & 6 & 0 & 12 \\
\hline
\end{tabular}

\section{Reference Chains}

I The children in the 'Signs of Difference' $\rightarrow$ learning systems -- II -- input $\rightarrow$ the children $\rightarrow$ cognitive benefits -- III -- They $\rightarrow$ the principles $\rightarrow$ system $\rightarrow$ differences between systems -- IV -- The research $\rightarrow$ young children's ability $\rightarrow$ interpretations $\rightarrow$ graphic representations $--\mathrm{V}-\mathrm{It} \rightarrow$ children's awareness $\rightarrow$ principles $\rightarrow$ systems $\rightarrow$ biliterate experience $\rightarrow$ this experience $\rightarrow$ monolingual and bilingual children $\rightarrow$ mainstream education. 